\author{
UNIVERSIDADE DE SÃO PAULO \\ ESCOLA DE ENGENHARIA DE SÃO CARLOS \\ PROGRAMA DE MESTRADO EM ENGENHARIA DE PRODUÇÃO
}

YOVANA MARIA BARRERA SAAVEDRA

Práticas de Estratégias de Fim de Vida Focadas no Processo de Desenvolvimento de Produtos e suas Aplicações em Empresas que Realizam a Recuperação de Produtos Pós-Consumo 
YOVANA MARIA BARRERA SAAVEDRA

\section{Práticas de Estratégias de Fim de Vida Focadas no Processo de Desenvolvimento de Produtos e suas Aplicações em Empresas que Realizam a Recuperação de Produtos Pós-Consumo}

Dissertação apresentada à Escola de Engenharia de São Carlos da Universidade de São Paulo, como parte dos requisitos necessários à obtenção do título de mestre em Engenharia de Produção.

Área de concentração: "Processos e Gestão de Operações”

Orientador: Prof. Dr. Aldo Roberto Ometto

São Carlos 
AUTORIZO A REPRODUÇÃO E DIVULGAÇÃO TOTAL OU PARCIAL DESTE TRABALHO, POR QUALQUER MEIO CONVENCIONAL OU ELETRÔNICO, PARA FINS DE ESTUDO E PESQUISA, DESDE QUE CITADA A FONTE.

Ficha catalográfica preparada pela Seção de Tratamento da Informação do Serviço de Biblioteca - EESC/USP

\footnotetext{
Saavedra, Yovana Maria Barrera

Sp Práticas de estratégias de fim de vida focadas no processo de desenvolvimento de produtos e suas aplicações em empresas que realizam a recuperação de produtos pós-consumo / Yovana Maria Barrera Saavedra ; orientador Aldo Roberto Ometto. -- São Carlos, 2010.

Dissertação (Mestrado-Programa de Pós-Graduação em Engenharia de Produção e Área de Concentração em Processos e Gestão de Operações) -Escola de Engenharia de São Carlos da Universidade de São Paulo, 2010.
}

1. Sustentabilidade. 2. Remanufatura. 3. Estratégias de fim de vida.4. Práticas. 5. Práticas operacionais. 6. Desenvolvimento de produtos. I. Título. 
FOLHA DE JULGAMENTO

Candidato(a): Ingeniero YOVANA MARIA BARRERA SAAVEDRA.

Dissertação defendida e julgada em 21.09.2010 perante a Comissão Julgadora:
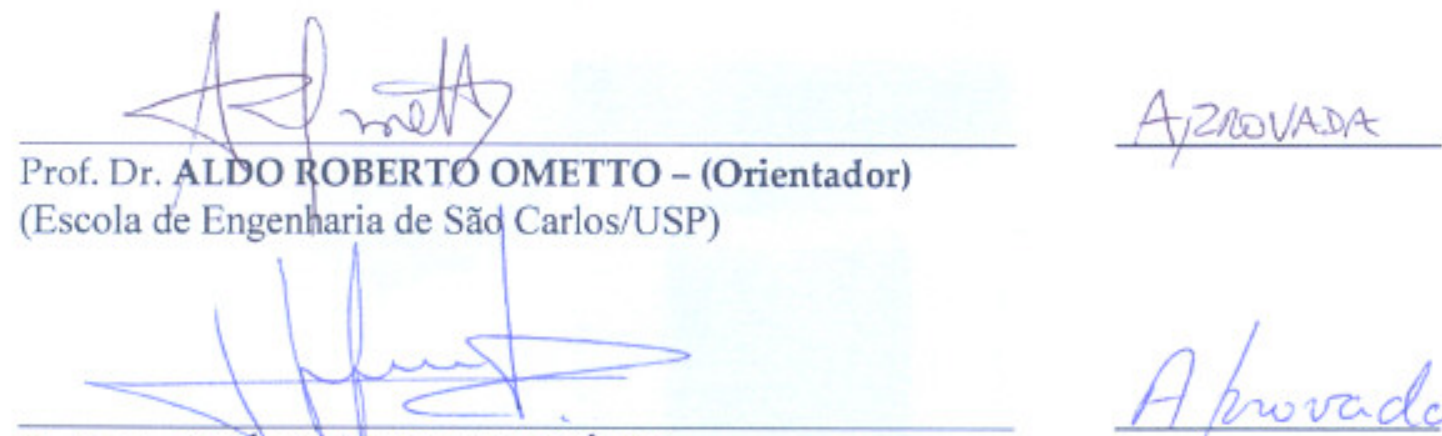

Prof. Dr. ALDO ROBERTO OMETTO - (Orientador)

Prof. Dr. JOSÊ DONATO AMBRÓSIO

(Universidade Federal de São Carlos/UFSCar)

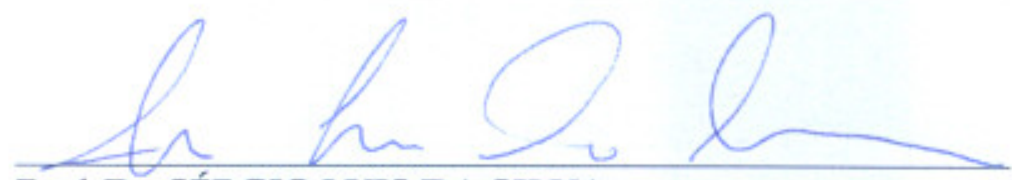

Prof. Dr. SÉRGIO LUIS DA SILVA

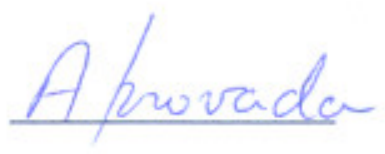

(Universidade Federal de São Carlos/UFSCar)
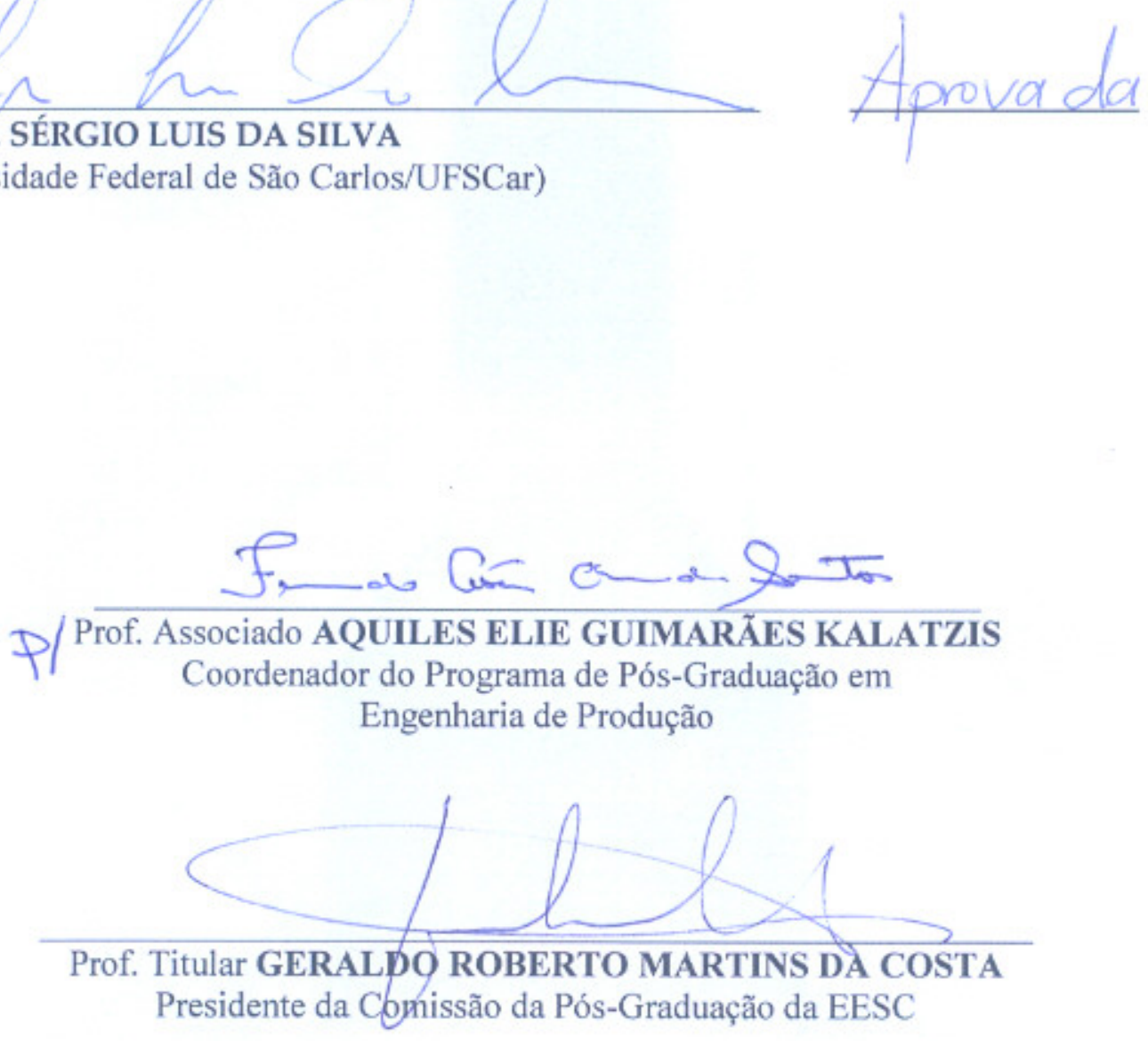


\section{DEDICATÓRIA}

A minha Mãezinha Betty Saavedra “in memoriam”, por ser a melhor mãe do mundo! Porque numa simples canção de ninar me ensinou a melodia da vida. e por me perdoar pela nossa distância física, nos seus últimos dias na terra. E ao meu pai, Ernesto Barrera, por estar sempre do meu lado, apoiando-me com grande amor, sacrifício e dedicação. 



\section{AGRADECIMENTOS}

Ao Deus pai, por permitir-me mais uma etapa neste caminho maravilhoso que é a vida. Por me levantar, me carregar e me dar às forças necessárias nesses momentos difíceis da minha existência. Por me deixar conhecer pessoas maravilhosas ao longo do meu caminho, que me permitiram entrar nas suas vidas e me fizeram, sem dúvida alguma, uma pessoa melhor, mais amiga, companheira, profissional e pesquisadora.

Ao meu orientador, Prof. Aldo Roberto Ometto, por abrir-me às portas do mundo da pesquisa, desde o intercâmbio da graduação. Pelas conversas sobre nossa vida pessoal e profissional, mas, especialmente, pela orientação dada, pelo grande apoio nos momentos de dificuldade, pela paciência, confiança e dedicação durante estes dois longos anos de mestrado.

Ao Prof. Henrique Rozenfeld, pelas orientações sugeridas para o desenvolvimento deste projeto. Especialmente, por me auxiliar nos momentos de dúvida e dificuldade, me fazendo entender que os problemas do mundo não são solucionados de uma vez, mas aos poucos, como para a construção de uma grande casa, colocando-se "tijolinho por tijolinho".

Ao Prof. Sergio Luis da Silva e o Prof. José Donato Ambrósio, pela suas oportunas e valiosas contribuições para o desenvolvimento e melhoramento deste projeto de mestrado.

Aos professores do Departamento de Engenharia de Produção da EESC/USP, pela oportunidade de assistir aulas e compartilhar conversas e momentos curtos, mas significativos para meu crescimento pessoal e profissional: Luiz C.R. Carpinetti, Marcel Andreotti, Edmundo Escrivão Filho, Fernando C. Almada, Daisy A.N. Rebelatto, José Dutra. Especialmente, ao Prof. Daniel Capaldo Amaral, por me incentivar por meio de suas aulas de Processo de Desenvolvimento de Produtos a encarar o desafio de integrar a área ambiental à área de produção. Pela paciência e ajuda nos momentos de angústia, relacionados a minha pesquisa. Agora posso concordar com a opinião do senhor “ os momentos que mais sofri, foram também os momentos que mais aprendi!”

Ao meu amigo Luis José Borrero, “Chamo”, pela amizade adquirida nestes últimos quatro anos. Por ser uma pessoa especial, meu irmão de coração. Pelas nossas conversas sobre nossos sonhos, tristezas, alegrias, desamores e amores. Por estar sempre pronto a me auxiliar. Desejo o melhor na sua vida profissional e nessa nova etapa da sua vida pessoal. 
A minha amiga desde os tempos da universidade, Pilar, ou "Pili", por ter paciência, paciência e mais paciência comigo no ano 2009. Ano complicado para nos duas! Por estar comigo nesse momento triste e difícil da minha vida. Sempre me apoiando e me incentivando para não desistir dos meus sonhos. Pelos momentos que tivemos de alegria e diversão. Pelas lágrimas que derramamos juntas, que fizeram com que fossemos hoje pessoas mais fortes. Para você desejo o melhor do mundo e, especialmente, muitas felicidades na sua vida pessoal e familiar.

Para "minhas colegas e amigas mais recentes, as meninas: Lillian "liloca”, Roberta "Rô", Sabrina “Sá”, Ana Paula “Ana”, Camila “florzinha” e Daniela "Dani”- semente do meu trabalho. Por me permitirem entrar nas suas vidas, por compartilharem seus sonhos pessoais, profissionais e familiares. Por estarem sempre prontas a me auxiliar, por corrigir o meu português, e por simplesmente serem elas!!

Aos meus colegas do Laboratório de Gestão de Operações, Grupo Engenharia do Ciclo de Vida e da Universidade Tecnológica de Berlin - TUB, por me aceitarem desde o primeiro momento de meu mestrado: André “baiano”, Catarina, Lie, Larissa, Daniel, Juliana, Fabio, Rafa, Olivia e Rafael, Henry e Semih. Por compartilharem comigo momentos de dúvida, dificuldade, alegria e tristeza, e estarem sempre prontos a me auxiliar.

Aos funcionários do Departamento de Engenharia de Produção: José Luis, Claudette, Sueli, Talita, Celso, Luiz Fernando e Daniel, pela ajuda e apoio durante a realização deste trabalho e aos funcionários da EESC-USP, pelo auxílio e apoio por meio de palavras ou, simplesmente, de um sorriso.

Aos funcionários da biblioteca da EESC-USP, pela ajuda e apoio durante a realização deste trabalho, especialmente a Elena e a Elenisse.

Ás pessoas das empresas, pelo apoio e constante colaboração na minha pesquisa de campo, Gabriel, Edmundo, Luiz Ponce, Airton R. Mattos, Luís Fernando, Luiz Antonio, Rodrigo, Ricardo, Lucas e Jefferson.

Á família Cardoza, Cisneros e Guedes de Oliveira, por me acolherem como mais um membro e pelos momentos maravilhosos que compartilhamos, e que serão lembrados por mim com 
grande carinho. Loly, Wendy, Claudia, Tio Lito, Alexandre e David Ariel. Especialmente ao Edwin Cardoza, pelo amor, paciência, companheirismo, lealdade, fidelidade, respeito, sinceridade e ajuda incondicional durante o tempo compartilhado. Para você desejo muito sucesso profissional, mas especialmente pessoal. Que encontre a felicidade que tanto procura e que a vida e o destino tragam o melhor para você.

A minha adorada família por me aceitar como sou! Com meus defeitos e minhas qualidades. Por me apoiar nas minhas tantas decisões e nas minhas loucuras. Sempre com grande amor, Liyin, Sandrita, Javi, Fresita, Lalis, Oscar, Nelly, William, Dianita, Paolita, Callila, Alex, Emer, Israel, Jairito, Belarmina e todos os demais. Especialmente aos meus pais, porque sem eles, este sonho nunca teria se realizado. A minha mãezinha Betty, que olha por mim do ceú, e ao meu pai Ernesto, por sempre, sempre estarem perto de mim, com grande amor e carinho. Amo vocês!

Ao Gordo “Topi”, por ser como meu segundo pai, por me apoiar e por escutar pacientemente minhas dúvidas pessoais e profisionais. Porque os laços familiares que se criam nos corações nunca se acabam, mesmo com as mudanças que a vida nos traz!

Aos meus amigos, colegas e parceiros de longas datas, e alguns mais recentes: Juanito, Maito, Kelly (por compartilharmos os sonhos de nossas vidas), Felipinho, Jairinho, Lucas, Gladys, Soledad, Edwin, Gabrielito, Bera, Passo, Guido, Andrés Q, Aléx, Richard, Adys, Marcos, Mauricio, Liana, Lina, Rafael, Gina, Rodrigo, Vanessa, Lucio, Amilcar, Giovanny, Carol, Marly, Eugenia, Andre, Sandra, Aymer, Abraham, Jorge e Gé (por aparecer no momento certo!). Obrigada pelo carinho, pelas palavras de apoio, pela amizade e pelos belos e grandes momentos compartilhados, dos quais nunca me esquecerei!

A toda a comunidade estrangeira de São Carlos, por ter a coragem de saírem dos seus países e explorar novos campos de conhecimento e novas oportunidades.

À embaixada do Brasil na Colômbia, pela concessão da bolsa, por meio do Conselho Nacional de Desenvolvimento Científico e Tecnológico-CNPq.

A todos que contribuíram de alguma forma para a realização deste trabalho. 



\section{RESUMO}

BARRERA SAAVEDRA, Y.M. (2010). Práticas de estratégias de fim de vida focadas no processo do desenvolvimento de produtos e suas aplicações em empresas que realizam a recuperação de produtos pós-consumo. 235p. Dissertação (Mestrado) - Escola de Engenharia de São Carlos, universidade de São Paulo, São Carlos, 2010.

A recuperação de produtos por meio das estratégias de fim de vida (EoL) é uma alternativa pró-ativa que visa diminuir os impactos ambientais e os resíduos decorrentes do descarte desses produtos. O objetivo deste trabalho é levantar as práticas ligadas às estratégias de fim de vida que podem auxiliar o processo de desenvolvimento de produtos (PDP) e verificar quais estão sendo aplicadas por algumas empresas que recuperam produtos na fase de pósconsumo. Para tanto, foi realizada uma revisão bibliográfica sistemática que identificou 87 práticas de estratégias de fim de vida e 64 práticas operacionais que podem ser usadas na integração da recuperação de produtos no PDP. De modo a verificar a aplicação das práticas operacionais, foram realizados quatro estudos de caso em empresas reconhecidas pela sua excelência em processos de remanufatura. Os resultados da pesquisa permitem verificar a baixa aplicação de práticas operacionais dentro dessas empresas no processo de desenvolvimento de produtos. Nos casos em que elas foram implantadas, observou-se que elas são uma mera conseqüência da melhoria continua dos processos. No entanto, as empresas já percebem a importância dessas práticas operacionais para a melhoria da gestão do ciclo de vida de seus produtos e das oportunidades relacionadas com os pilares da sustentabilidade (ambiental, econômico e social). Finalmente, conclui-se que há um paradoxo entre a teoria e a aplicação nas empresas com relação às práticas operacionais de fim de vida do produto, desde o PDP. Isto é ratificado pelo grande número de práticas existentes na literatura quando comparadas com a aplicação destas práticas operacionais nas empresas estudadas.

Palavras-chave: Sustentabilidade. Remanufatura. Estratégias de fim de vida. Práticas. Práticas operacionais. Desenvolvimento de produtos. 


\begin{abstract}
BARRERA SAAVEDRA, Y.M. (2010). Practices of end of life strategies with focus in the product development process and applications to companies that perform the recovery of post-consumer products. 235p. Dissertação (Mestrado) - Escola de Engenharia de São Carlos, universidade de São Paulo, São Carlos, 2010.
\end{abstract}

The recovery of products using end-of-life strategies (EoL) is a proactive alternative that aims to diminish environmental impacts and waste generated from the disposal of products. This research aims to compile practices based on the EoL strategy that are used by companies in the (PDP). Focus is given to companies that recover products after they have been disposed. To this end, a literature review was carried out, in which 87 EoL-like practices were identified. Additionally, this research identified 64 operational practices that integrate the PDP process with the recovery of products. Four case studies were conducted in companies renowned for their excellence in remanufacturing to assess the applicability of EoL-like practices. It was found a low degree of adoption of such practices in the companies researched, mainly in the PDP process. The practices implemented were a mere implication of the continuous improvement of processes. Nonetheless, it was observed that these companies realize the importance of EoL practices to improve the life-cycle management of their products, which may positively impact all facets of sustainability (environmental, economical and social). Finally, we conclude that there is a gap between theory and practice with respect to EoL practices used in the product development process, which is supported by the great variety of practices found in the literature as opposed to the use of operational practices in the companies studied.

Keywords: Sustainability. Remanufacturing. End of life. Práctices. Operational practices. Development process. 


\section{LISTA DE FIGURAS}

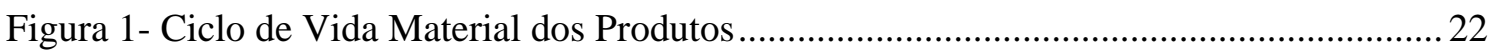

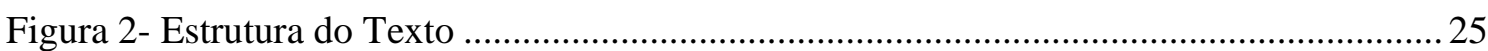

Figura 3 - Visão Geral do Modelo de Referência para o Processo de Desenvolvimento de

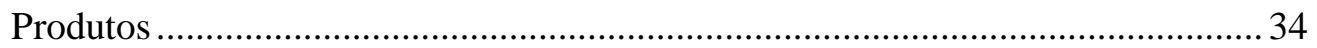

Fígura 4 - Ciclo de Vida do Produto e as Diferentes Formas de Recuperação ......................... 39

Figura 5 - Estratégias de Fim de Vida dos Produtos (EoL) .................................................... 41

Figura 6 - Etapas do Processo de Remanufatura ..................................................................... 43

Figura 7 - Visão Geral do Projeto de Pesquisa ......................................................................... 57

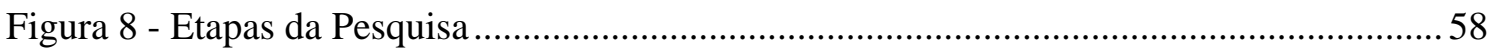

Figura 9 - Representação do Processo Sistemático ............................................................... 59

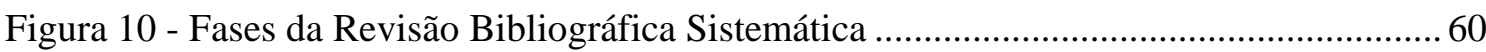

Figura 11 - Print Screen do Formulário de Cadastro das Técnicas, Métodos e Ferramentas no

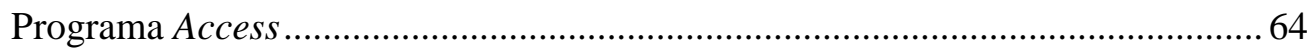

Figura 12 - Distribuição por Tipo de Estudo ............................................................................ 70

Figura 13 - Distribuição das Publicações por Ano ................................................................. 71

Figura 14 - Países com Maior Número de Publicações........................................................... 72

Figura 15- Países em Desenvolvimento em Pesquisas de EoL ............................................... 73

Figura 16 - Incidência de Práticas Identificadas na RS ............................................................ 75

Figura 17 - Classificação dos Procedimentos Técnicos Utilizados nas Práticas ....................... 76

Figura 18 - Classificação conforme a Consolidação da Prática ............................................. 77

Figura 19 - Classificação Conforme a Estratégia de Fim de Vida Aplicada ............................ 78

Figura 20 - Classificação da Área da Sustentabilidade Abordada pela Prática........................ 79

Figura 21 - Visão Geral da Aplicação das Práticas Operacionais na Empresa A..................... 87

Figura 22 - Visão Geral da Aplicação de Práticas na Empresa B............................................ 93

Figura 23 - Visão Geral da Aplicação das Práticas na Empresa C ........................................ 100

Figura 24 - Visão Geral da Aplicação das Práticas na Empresa D....................................... 105 


\section{LISTA DE QUADROS}

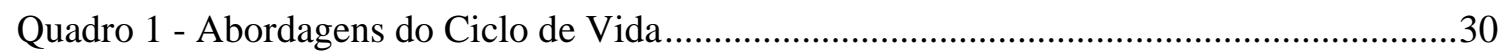

Quadro 2 - Comparação de Modelos de Referência para o PDP ............................................33

Quadro 3 - Produtos com Sucesso em Remanufatura Conforme sua Atividade......................42

Quadro 4 - Resumo das Estratégias de Fim de Vida (EoL) .................................................49

Quadro 5 - Benefícios Potenciais da EoL no Contexto da Sustentabilidade............................50

Quadro 6 - Strings de Pesquisa ......................................................................................62

Quadro 7 - Consolidação de Dados dos Estudos de Caso.......................................................68

Quadro 8 Práticas Operacionais Identificadas ...................................................................... 81

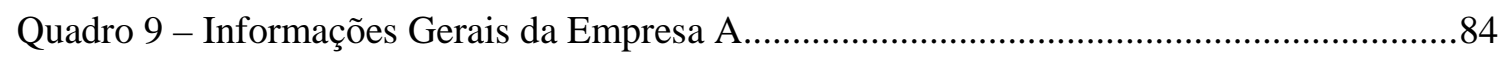

Quadro 10 -Relação das Práticas Operacionais Empresa A...................................................87

Quadro 11- Informações Gerais da Empresa B ...............................................................90

Quadro 12 - Relação das Práticas Operacionais Empresa B ................................................93

Quadro 13 - Informações Gerais da Empresa C................................................................96

Quadro 14 - Verificação das Práticas Operacionais Empresa C ............................................99

Quadro 15- Informações Gerais da Empresa D .................................................................102

Quadro 16- Verificação das Práticas Operacionais Empresa D...........................................105

Quadro 17 Comparação da aplicação das Práticas Operacionais das Empresas nas Atividades de Desmontagem e Remontagem..................................................................107

Quadro 18 - Comparação da Aplicação das Práticas Operacionais das Empresas na Atividade

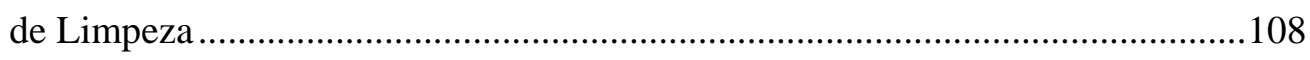

Quadro 19- Comparação da aplicação das Práticas Operacionais das Empresas na Atividade de Recuperação 110

Quadro 20- Comparação da aplicação das Práticas Operacionais das Empresas na Atividade de Impactos Ambientais.

Quadro 21 Relação entre as Questões da Pesquisa, os Objetivos e os Resultados do Trabalho113

Quadro 22-Leis/Políticas Relacionadass à Recuperação de Produtos ....................................132

Quadro 23 - Padronização dos Estudos Obtidos com a Revisão Sistemática ........................202

Quadro 24 - Resumo das Práticas das Estratégias de Fim de Vida de Produtos.....................217

Quadro 25 - Classificação das práticas das Estratégias de Fim de Vida de Produtos conforme

o Procedimento Técnico Utilizado para a Avaliação do Produto ..........................222

Quadro 26 - Classificação das Práticas das Estratégias de Fim de Vida de Produtos Conforme

o Nível de Consolidação da Prática e o Setor de Aplicação .228 
Quadro 27 - Classificação das Práticas Conforme a Estratégia de Fim de Vida do Produto . 230

Quadro 28 - Classificação das práticas Conforme a Área de Sustentabilidade Abordada na

Estratégia de Fim de Vida do Produto ...................................................................... 235 


\section{LISTA DE ABREVIATURAS E SIGLAS}

ABNT Associação Brasileira de Normas Técnicas

ACV Avaliação do Ciclo de Vida

CMMAD Comissão Mundial sobre Meio Ambiente e Desenvolvimento

CETESB Companhia Ambiental do estado de São Paulo

DECEX Departamento de Comercio Exterior

DFE Design for Environment

DS Desenvolvimento Sustentável

ECV Engenharia do Ciclo de Vida

EESC Escola de Engenharia de São Carlos

ELV Fim de vida dos veículos ou End-of-life vehicles

EoL Estratégias de Fim de Vida

EPR Extender Producer Responsability in Cleaner Production

GRI Global Reporting Iniciative

IBGE Instituto Brasileiro de Geografia e Estatística

IPP Política Integrada relativa aos produtos

ISO The International Organization for Standarization

LCE Life Cycle Engineering

LCM Life Cycle Managment ou Gestão do Ciclo de Vida

OECD Organization for Economic Cooperation and Development

OEM Original Equipment Manufacture

OMC Organização Mundial de Comercio

ONU Organização das Nações Unidas

PDP Processo de Desenvolvimento de produtos

PLM Product Life Cycle Management ou Gestão do ciclo de vida de produtos

PNSB Pesquisa Nacional de Saneamento Básico

PSS Product Service System ou Sistema produto-serviço

REP Responsabilidade Estendida do Produtor

RoHS Restriction of Hazardous Substances ou Restrição de substâncias perigosas

RS Revisão Sistemática

SGA Sistema de Gestão Ambiental

SPS Sistema produto-serviço

TR Relatório técnico 
UNEP United Nations Environment Programme

USP Universidade de São Paulo

WCED The World Comission on Environment and Development

WEEE Wastes from Electric and Electronic Equipment ou Resíduos de Equipamentos eletro-eletrônicos 


\section{SUMÁRIO}

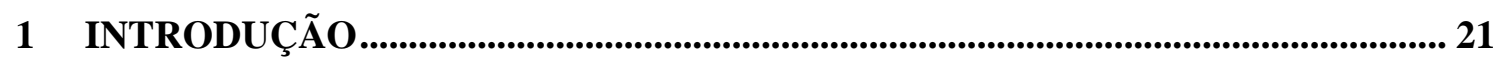

1.1 Contextualização e Justificativa da Pesquisa .......................................................21

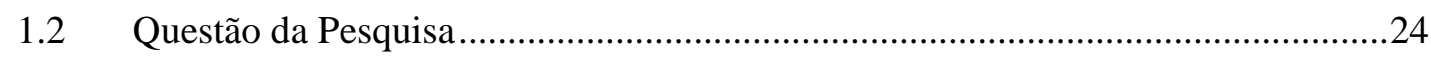

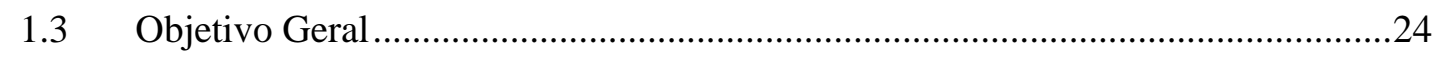

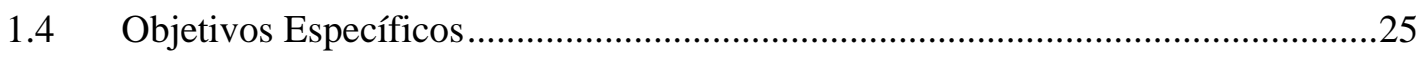

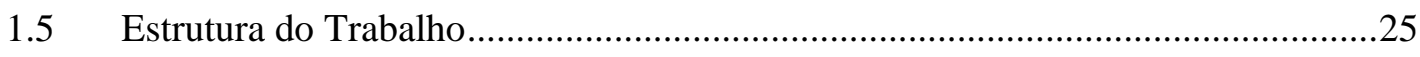

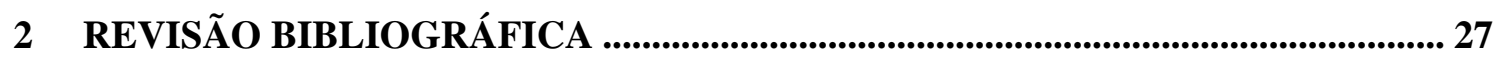

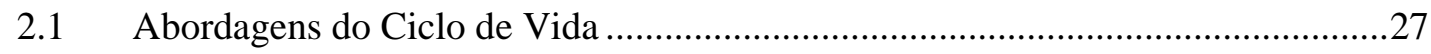

2.2 Processo de Desenvolvimento de Produtos (PDP) ...............................................31

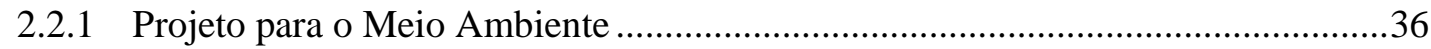

2.3 Recuperação de Produtos e as Estratégias de Fim de Vida de Produtos (EoL) .....38

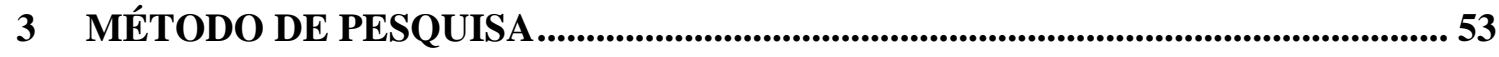

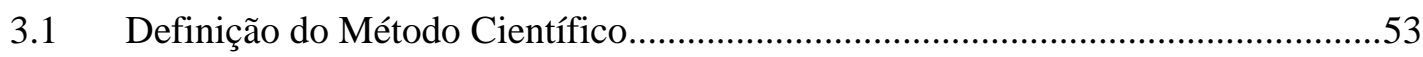

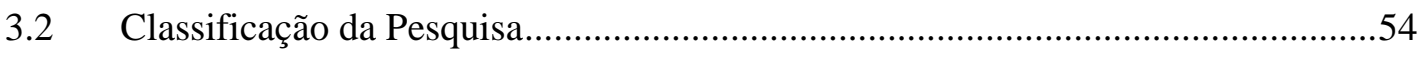

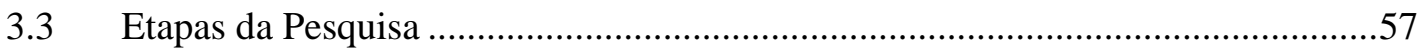

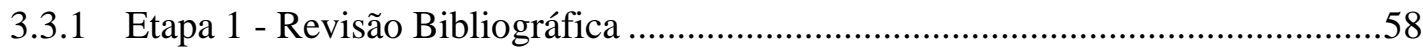

3.3.2 Etapa 2 - Revisão Bibliográfica Sistemática (RS) …..........................................59

3.3.3 Etapa 3 - Múltiplos estudos de caso ......................................................................66

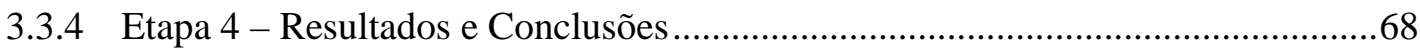

4 RESULTADOS DA REVISÃO BIBLIOGRÁFICA SISTEMÁTICA (RS)............. 69

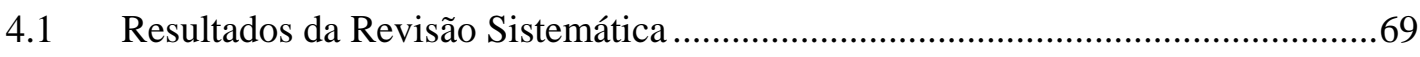

4.2 Resultados e análises das Práticas das Estratégias de Fim de Vida Identificadas na

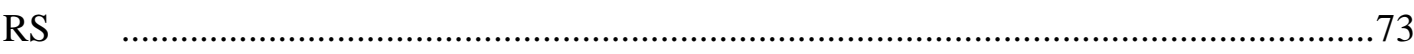

4.2.1 Critérios de classificação das técnicas, métodos e ferramentas das estratégias de

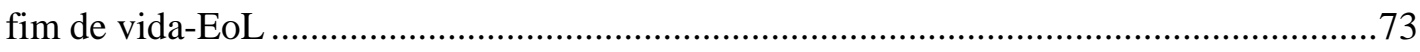

4.2.2 Análise das Práticas das Estratégias de Fim de Vida identificadas na RS.............74

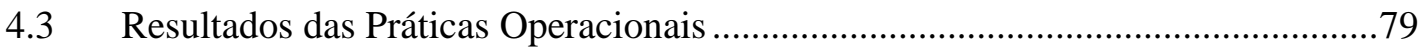

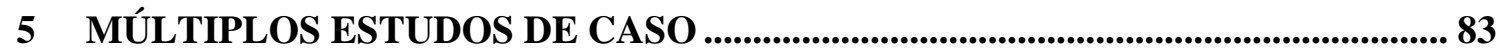

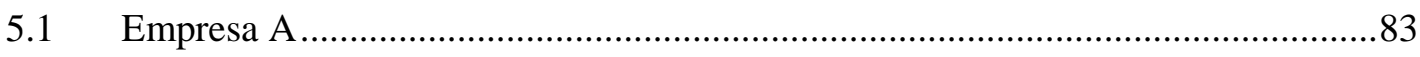

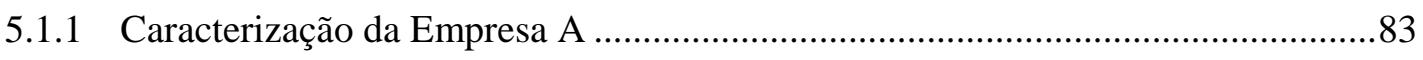

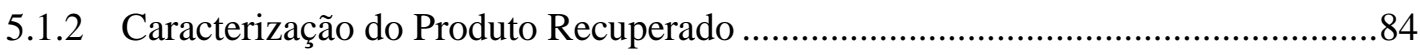




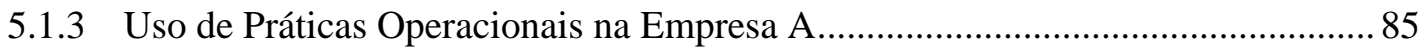

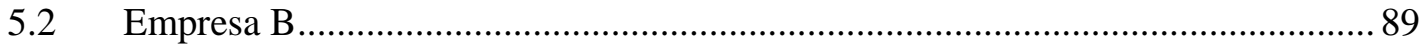

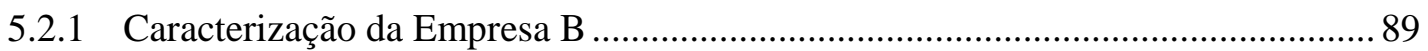

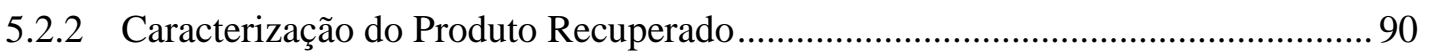

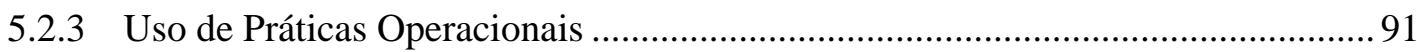

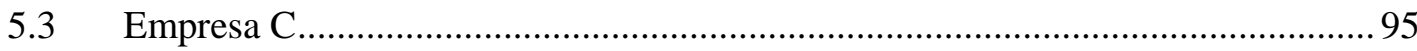

5.3.1 Caracterização da Empresa C ............................................................................... 95

5.3.2 Caracterização do Produto Recuperado..................................................................... 96

5.3.3 Uso de Práticas Operacionais ............................................................................... 97

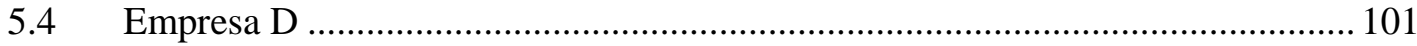

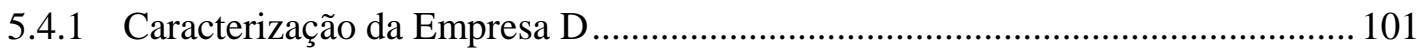

5.4.2 Caracterização do Produto Recuperado.............................................................. 102

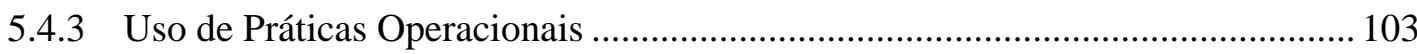

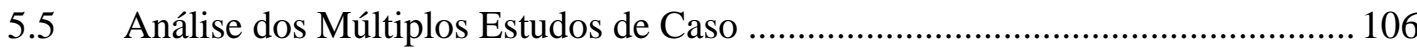

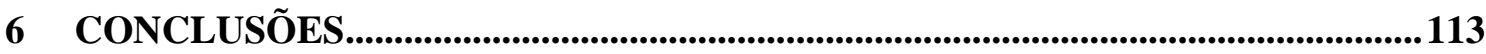

6.1 Contribuições Principais da Pesquisa ................................................................... 113

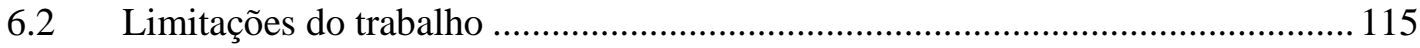

6.3 Considerações para futuros trabalhos ............................................................. 115

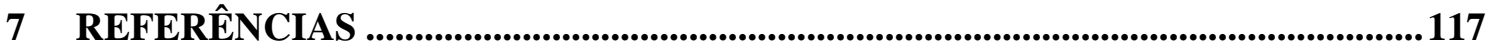

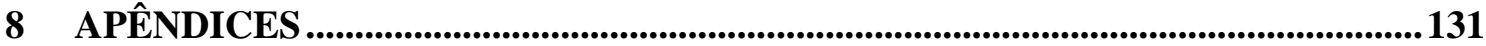

Apêndice A- Regulações e Políticas relacionadas à Recuperação de Produtos ............... 131

Apêndice B - Protocolo Carta de Apresentação ............................................................ 138

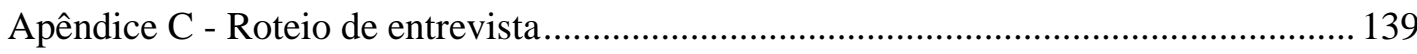

Apêndice D ～Base de Dados da Revisão Sistemática...................................................... 151

Apêndice E Padronização dos Estudos Obtidos com a Revisão Sistemática ............... 153

Apêndice F Resumos das Práticas das Estratégias de Fim de Vida ............................. 203

Apêndice G Classificação das Práticas Conforme o Procedimento Técnico Utilizado

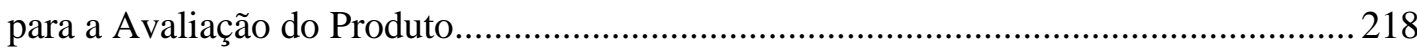

Apêndice H Classificação das Práticas das Estratégias de Fim de Vida de Produtos Conforme a Nível Consolidação da Prática e o Setor de Aplicação ................................. 223 Apêndice I Classificação das Práticas Conforme a Estratégia de Fim de Vida do Produto

Apêndice J Classificação das Práticas Conforme a Área de Sustentabilidade Abordada na Estratégia de Fim de Vida do Produto 



\section{INTRODUÇÃO}

Este capítulo inicial apresenta a contextualização e a justificativa que norteiam este trabalho. Além dessas informações, são proporcionadas as questões da pesquisa, os objetivos e a estrutura do texto adotada para apresentar os próximos capítulos.

\subsection{Contextualização e Justificativa da Pesquisa}

A Comissão Mundial sobre Meio Ambiente e Desenvolvimento (CMMAD) da Organização das Nações Unidas (ONU), também conhecida como Comissão de Brundtland, define o desenvolvimento sustentável como sendo o atendimento às necessidades presentes sem que estas comprometam a possibilidade das gerações futuras de satisfazerem as suas próprias necessidades (THE WORLD COMISSION ON ENVIRONMENT AND DEVELOPMENT - WCED, 1987).

A sustentabilidade é apresentada como um conceito sistêmico que visa o balanceamento entre os aspectos Ambientais, Econômicos e Sociais, elementos / dimensões integradas que também são conhecidas como Triple Botton Line (ELKINGTON, 2001; KATES; PARRIS; LEISEROWITZ, 2005).

Em 2008, a United Nations Environment Programme - UNEP (2008), acrescentou que o desenvolvimento sustentável pode ser promovido a partir de três estratégias:

i. Desmaterialização: enfoca a necessidade e a funcionalidade, ao invés do produto em si. O desenvolvimento sustentável se apresenta no acompanhamento do fluxo de materiais e de energia dos processos industriais e de consumo, bem como no aumento da produtividade do recurso.

ii. Gestão do ciclo de vida: é uma abordagem que integra ferramentas e conceitos de alternativas sustentáveis e repassa as informações relevantes às partes interessadas. A proposta engloba a avaliação do produto em todas as fases do ciclo de vida, (Figura 1) e o principal objetivo é fortalecer o processo de tomada de decisão relacionado com o desenvolvimento de produtos e serviços com menos impactos ambientais.

iii. Sistema produto-serviço: consiste no desenvolvimento de uma mistura comerciável de bens e serviços que, em conjunto, são capazes de atender às necessidades do cliente, 
com menor impacto ambiental ${ }^{1}$.

No entanto, os produtos que são fundamentais para a riqueza da nossa sociedade são os principais geradores dos impactos ambientais atuais (ex. poluição e esgotamento de recursos), causados principalmente pelo aumento do consumo desses produtos (COMISSÃO DAS COMUNIDADES EUROPÉIAS, 2001).

Nielsen e Wenzel (2002), Baumann, Boons e Bragd (2002), destacam que impactos ambientais são gerados em todas as etapas do ciclo de vida do produto, ou seja, desde a extração de matéria prima até o tratamento e disposição final dos produtos. O ciclo de vida material dos produtos pode ser analisado a partir de dois fluxos (Figura 1): o fluxo principal ou direto, que inicia com a extração da matéria prima, passando pela manufatura, uso até o descarte; e o fluxo secundário ou reverso que fecha o ciclo de vida do produto, destacadandose o uso das estratégias de fim de vida (EoL - End-of-Life): Reuso Reciclagem e Remanufatura.

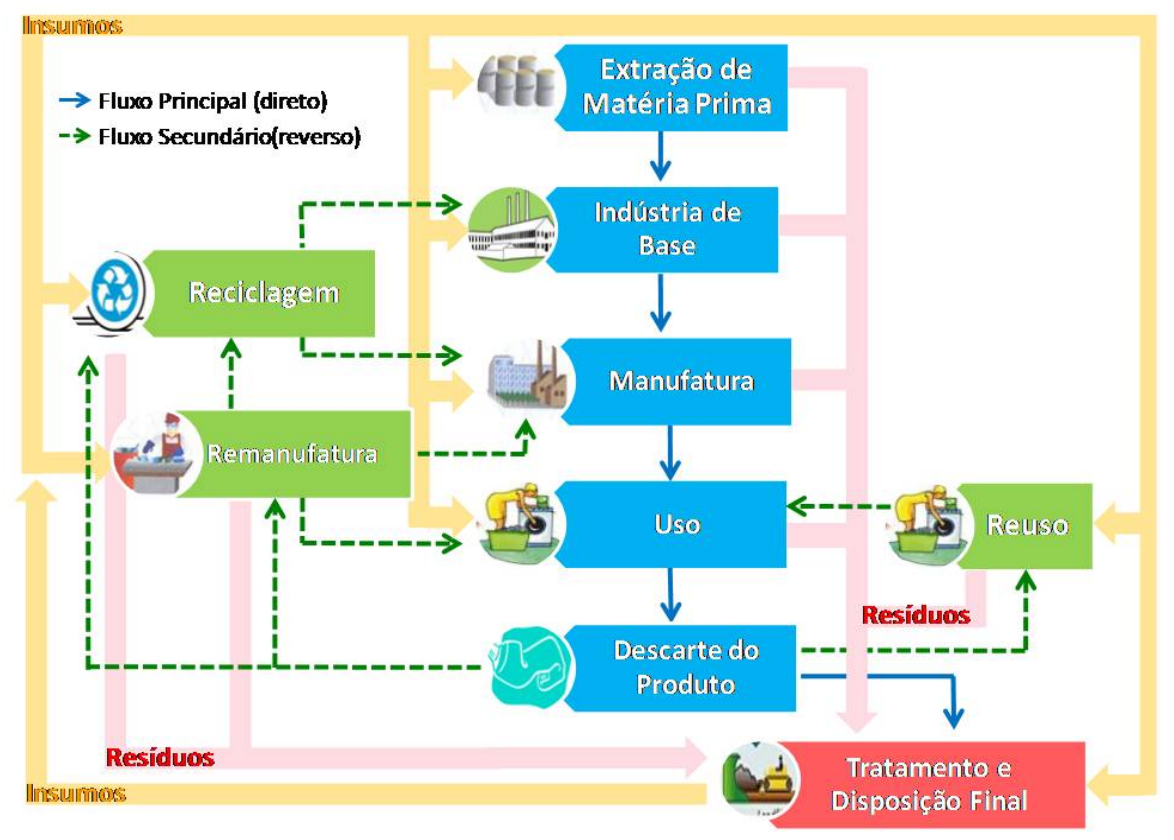

Figura 1- Ciclo de Vida Material dos Produtos

Fonte. Pigosso et al. (2010)

Neste sentido, aparecem legislações como parte de mecanismos que visam pressionar às empresas a oferecer produtos e processos mais sustentáveis, como é o caso das políticas de fabricação de produtos, leis ambientais mais restritivas e exigências para a responsabilidade

\footnotetext{
${ }^{1}$ Impacto Ambiental é qualquer modificação do meio ambiente adversa ou benéfica que resulte no todo ou em parte dos aspectos ambientais da organização. Por sua vez, aspecto Ambiental são os elementos de atividades ou produtos ou serviços de uma organização que pode interagir com o meio ambiente (ABNT, 2004).
} 
social. Alguns exemplos desse tipo de mecanismo são: a Política Integrada Relativa aos Produtos (IPP), que visa o desenvolvimento de produtos mais ecológicos, e o conceito de Responsabilidade Estendida do Produtor (REP), definida como a responsabilidade ambiental que as empresas devem dar aos seus produtos ao longo de seus ciclos de vida, incluindo, a etapa de pós-consumo ${ }^{2}$ (LINDHQVIST, 2000).

Desta forma, um dos desafios das empresas é buscar alternativas, cada vez mais próativas, que permitam desenvolver produtos mais sustentáveis e com melhor desempenho ambiental (JACOBSSON, 2000; KAEBERNICK, 2008; LEE et al., 2008; SELIGER; WEINERT; ZETTL, 2007; ZWOLINSKI; LOPEZ-ONTIVEROS; BRISSAUD, 2006). Xing, Loung e Abhary (2005) acrescentam o design como uma prática apropriada para melhorar e propor alternativas para recuperar os produtos com seus componentes ${ }^{3}$ e materiais durante o ciclo de vida.

Existem diversas formas de recuperação dos produtos que oferecem diferentes níveis de reaproveitamento, como por exemplo, a reciclagem considera a recuperação baseada a partir da transformação dos materiais provenientes dos produtos e a remanufatura recupera produtos baseado na mesma qualidade e garantia que um produto novo. Desta forma, as estratégias de fim de vida (End of life strategies-EoL) é um meio que permite reduzir os impactos ambientais e otimizar o ciclo de vida dos produtos (GEHIN et al., 2008; SEITZ e WELLS, 2006;THIERRY et al., 1995).

Uma das principais dificuldades para recuperar os produtos é que dificilmente são desenvolvidos para essa finalidade, o qual impede sua recuperação e, em alguns casos, a recuperação pode levar a aumentar os custos totais dos processos de desenvolvimento, produção, logística de distribuição, uso e de logística reversa (ZWOLINSKI; LOPEZONTIVEROS; BRISSAUD, 2006). Alem disso, quando os produtos não são desenvolvidos considerando as EoL, esses se limitam a recuperação de componentes e materiais, pois, geralmente é mais caro integrar as diferentes EoL nos produtos existentes do que manter as atividades usuais de descarte e disposição final.

Dentro do Processo de Desenvolvimento de Produtos (PDP) existem as maiores oportunidades para recuperar os produtos na fase de pós-consumo. Além disso, a tomada de decisão durante as fases iniciais do PDP são responsáveis pela maioria dos impactos

2 Pós-consumo se refere à etapa onde os produtos são descartados após sua utilidade original, e que podem ser dados pelas mudanças nas necessidades dos usuários.

${ }^{3}$ Neste trabalho os componentes fazem referência às partes e peças de um produto. Conforme Rozenfeld et al (2006 p. 275) 
ambientais ocasionados ao longo do ciclo de vida destes (HAUSCHILD; JESWIET; ALTING, 2005; JOHANSSON, 2002; LUTTROPP; LAGERSTEDT, 2006; NIELSEN; WENZEL, 2002;). Deste modo considera-se importante a integração das EoL no PDP para poder garantir que os produtos e processos de manufatura atendam critérios/requisitos relacionados com a recuperação de componentes e materiais nas fases finais do ciclo de vida e, especialmente, na fase de pós-consumo (GEHIN; ZWOLINSKI; BRISSAUD, 2008; SHU; FLOWERS, 1995; WILLEMS et al. 2003; ZWOLINSKI; SGHAIER; BRISSAUD, 2007).

A existência de diversos métodos, técnicas e ferramentas, que representam práticas ${ }^{4}$, visam auxiliar a adoção e integração de conceitos de fim de vida (EoL) dentro do PDP. Entretanto, o elevado número dessas, os diferentes objetivos considerados na aplicação, a quantidade elevada de dados de entrada necessários para utilizá-las, os diferentes procedimentos técnicos, a falta de sistematização das informações e o alto grau de complexidade acabam por reduzir e/ou limitar o uso (LEE et al., 2008; WILLIENS et al., 2003a;WILLIENS et al., 2008b).

Diante deste contexto, optou-se por estudar as práticas das estratégias de fim de vida (EoL) e, derivadas dessas, as práticas operacionais ${ }^{5}$ de forma aproximar e facilitar a adoção de alternativas pró-ativas dentro do PDP, neste caso específico, para a recuperação de produtos na etapa de pós-consumo.

\subsection{Questão da Pesquisa}

Conforme a contextualização e justificativa da pesquisa apresentada, este trabalho visa contribuir com a discussão de duas questões de pesquisa complementares:

i. Quais são as práticas de estratégias de fim de vida (EoL) que podem auxiliar o processo de desenvolvimento de produtos?

ii. Quais dentre essas práticas operacionais, derivadas das práticas de estratégias de fim de vida, estão sendo aplicadas por empresas que realizam a recuperação de produtos pós-consumo no Brasil?

\subsection{Objetivo Geral}

\footnotetext{
${ }^{4}$ Conforme Jarrar, Y.F.; Zairi, M. (2000) Uma prática é considerada como qualquer técnica, metodologia, procedimento ou processo que pode ser implementeda para melhorar os resultados dos processos de negocio de uma organização, satisfazendo as necessidades de seus clientes e seus stakeholders.

${ }^{5}$ Neste trabalho, são consideradas "práticas operacionais" aquelas identificadas a partir das práticas de estratégias de fim de vida (EoL) e que podem ser usadas dentro do processo de desenvolvimento de produtos para projetar produtos visando sua recuperação no pós-consumo.
} 
O objetivo do trabalho é levantar as práticas de estratégias de fim de vida (EoL) e as respectivas práticas operacionais que podem auxiliar o processo de desenvolvimento de produtos e verificar as que estão sendo aplicadas por empresas que realizam a recuperação de produtos pós-consumo.

\subsection{Objetivos Específicos}

Para alcançar esse objetivo geral, é necessário alcançar alguns objetivos específicos, sendo estes:

$\checkmark$ Revisar as práticas (métodos, técnicas e ferramentas) das estratégias de fim de vida voltadas ao desenvolvimento de produto;

$\checkmark$ Identificar as práticas operacionais a partir da revisão realizada e

$\checkmark$ Verificar quais são as práticas operacionais realizadas em algumas empresas que utilizam a recuperação de produtos pós-consumo no Brasil.

\subsection{Estrutura do Trabalho}

Além deste capítulo introdutório, neste trabalho são apresentados mais seis (6) capítulos, representados e discutidos resumidamente na Figura 2:

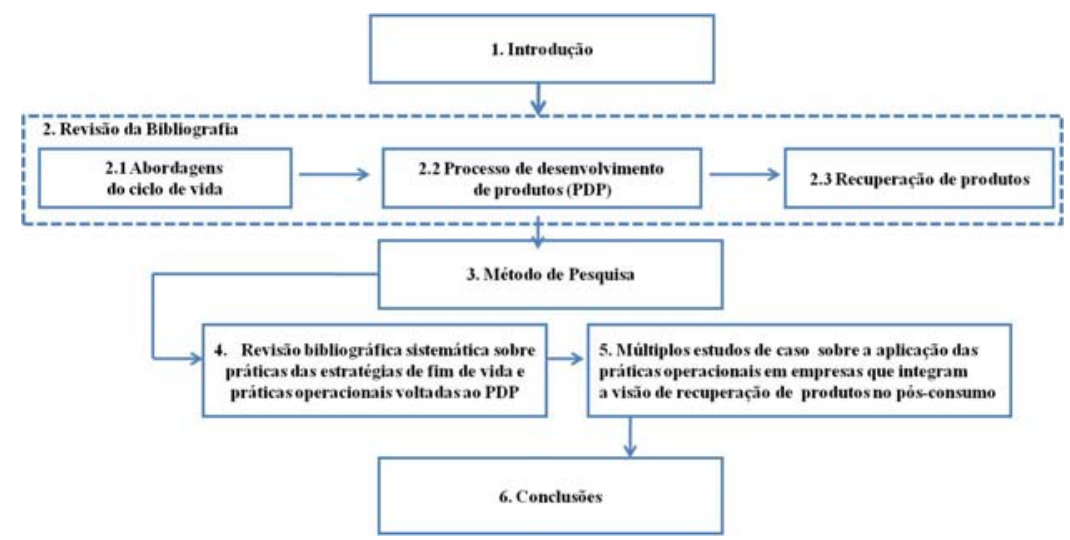

Figura 2- Estrutura do Texto ${ }^{6}$

\footnotetext{
${ }^{6}$ Todas as figuras, quadros e tabelas que não apresentem fonte, foram elaborados pela autora.
} 
O Capítulo 2 descreve a revisão bibliográfica. São discutidos os principais conceitos, abordagens e características dos temas centrais desta pesquisa: abordagens do ciclo de vida, o processo de desenvolvimento de produtos, o projeto para o meio ambiente, a recuperação de produtos com a regulamentação e as políticas relativas à recuperação desses produtos

No Capítulo 3 é exposta a metodologia utilizada para o desenvolvimento do trabalho. Em seguida, é definido o método científico adotado e os procedimentos de pesquisa do trabalho. Além disso, são apresentadas as etapas para o desenvolvimento da pesquisa.

Os Capítulos 4 e 5 relatam os resultados da pesquisa. Especificamente, o capítulo 4 apresenta os resultados da revisão bibliográfica sistemática (RS) e o capítulo 5 descreve a análise da verificação da aplicação das práticas operacionais, realizada a partir dos Múltiplos Estudos de Caso conduzidos pela pesquisadora em empresas de Remanufatura que atuam na recuperação de produtos na etapa do pós-consumo.

O Capítulo 6 apresenta as conclusões, destacando as principais contribuições do trabalho, as limitações da pesquisa e as sugestões para trabalhos futuros.

Na parte pós-textual do trabalho são apresentadas as referências da bibliografia consultada para realizar a pesquisa, os anexos e os apêndices elaborados pela autora durante o desenvolvimento do trabalho. 


\section{REVISÃO BIBLIOGRÁFICA}

Neste capítulo são abordados os principais tópicos da revisão bibliográfica. É destacado o conceito e as abordagens do ciclo de vida como mecanismos que permitem acompanhar / avaliar o produto em todas as fases, desde a extração da matéria prima até o descarte final. Neste contexto, o Processo de Desenvolvimento de Produtos (PDP) deve ser um meio na criação de alternativas que visem a incorporação de opções que permitam o desenvolvimento de produtos com melhor desempenho ambiental. Para isso, o projeto para meio ambiente auxilia na integração dessas questões ambientais dentro do PDP. Já a recuperação de produtos por meio das estratégias de fim de vida se apresenta como alternativas para serem integradas dentro do PDP de forma a auxiliar nesse desempenho ambiental.

\subsection{Abordagens do Ciclo de Vida}

O ciclo de vida se refere às diferentes etapas pelas quais um produto passa, desde a extração da matéria-prima, manufatura até sua recuperação e descarte final. Neste sentido, Heiskanen (2002) destaca que as empresas devem se responsabilizar pelos danos ambientais causados ao longo do ciclo de vida de seus produtos, levando a um maior comprometimento com relação às questões ambientais.

Pigosso et al. (2010) acrescenta que o conceito de ciclo de vida se refere à integração das perspectivas do ciclo de vida na estratégia global, planejamento e processo de decisão de uma organização, considerando aspectos ambientais, econômicos e sociais. Isto significa mudar o paradigma que tem orientado às organizações por meio de suas atividades.

Existem diversas áreas de estudo que integram a visão de ciclo de vida, sendo elas: a engenharia, a gestão e a tecnologia de informação. Na área da engenharia é destacado o conceito de Engenharia do Ciclo de Vida (ECV) ou Life Cycle Engineering (LCE), definido como a arte de projetar o ciclo de vida de produtos por meio de escolhas referentes ao conceito, a estrutura, aos materiais e aos processos, que integradas com as questões ambientais procuram um melhor desempenho ambiental (ALTING; LEGARTH, 1995).

Dentre os objetivos da ECV está a criação de soluções que garantam a proteção ao meio ambiente e a conservação dos recursos, promovendo um progresso econômico a partir de uma perspectiva de sustentabilidade (HAUSCHILD; JESWIET; ALTING, 2005). 
Wanyama et al. (2003) destacam o uso da ECV para auxiliar e fortalecer a tomada de decisão realizada nas fases iniciais do projeto, principalmente, avaliar as soluções que, durante o ciclo de vida ofereça, menores impactos ambientais.

Wenzel e Alting ${ }^{7}$ (2004 apud HAUSCHILD; JESWIET; ALTING, 2005) ressaltam que a ECV é uma abordagem que pode ser utilizada para melhorar a eco-eficiência das atividades industriais por meio de um processo de avaliação conduzido a partir de quatro níveis: i) Produto da empresa, onde são usadas ferramentas que visam otimizar a ecoeficiência dos produtos; ii) Produção do sistema de manufatura a fim de otimizar a produção, localizada entre o fabricante original e os serviços terceirizados, usando como auxilio diversas técnicas, como a avaliação do ciclo de vida e o projeto para o meio ambiente; iii) Processos envolvidos no sistema de produção, os quais investigam os processos individuais de modo a incorporar melhorias (ex. produção mais limpa); e iv) otimização dos níveis das emissões dos processos.

Na área de gestão se destaca a Gestão do Ciclo de vida ou Life Cycle Management (LCM), abordagem vista como um sistema de gestão do produto que visa a integração do conceito de ciclo de vida para minimizar as cargas econômicas, sociais e ambientais, associadas ao produto durante todo seu ciclo de vida (UNEP, 2007). O objetivo do LCM é auxiliar a empresa na tentativa de integrar políticas referentes ao produto e auxiliar a organização a alcançar metas referentes a melhorias de seus processos e produtos, aprimorando o relacionamento com stakeholders, auxilio na regulamentação etc.

A LCM foca a comunicação externa das organizações para incentivar uma apresentação de negócio mais visível, melhorar a imagem do produto, identificar novos mercados e agregar perspectivas de valor. A comunicação é estabelecida por meio de relatórios ambientais anuais, de contabilidade ambiental ou de sustentabilidade como, por exemplo, o Global Reporting Initiative ${ }^{8}$ (GRI), os Sistemas de Rótulos Ecológicos ${ }^{9}$ para produtos, os códigos de conduta, as auditorias etc.

Entre as diferentes áreas de uma organização que integram relação com a LCM podem ser destacadas: o relacionamento com os stakeholders, a sustentabilidade e o meio ambiente, produção e distribuição, desenvolvimento de produtos, economia e finanças, compras e,

\footnotetext{
Wenzel, H.; Alting, L. Architecture of life Cycle, Keynote at Global Conference on Sutainable Product Development and Life Cycle Engineering, sep 29th-oct 1st, PTZ Berlim, 2004.

Esta informação pode ser consultada no site www.globalreporting.org com acesso em: 20 de jun. 2009.

9 Os Rótulos Ecológicos salientam as vantagens ambientais de um produto quando comparado com outros produtos do mesmo grupo. Voltados para os consumidores no crescimento de consciência referente a aspectos ambientais de um produto.
} 
finalmente, vendas e marketing. Áreas organizacionais que devem focar o desenvolvimento de alternativas que levem a atender os três pilares da sustentabilidade (ambiental, econômico e social).

O LCM não é uma simples metodologia ou ferramenta, mas sim um sistema de administração que visa coletar, estruturar e disseminar a informação de distintos programas, conceitos e ferramentas. Esse sistema incorpora aspectos econômicos, ambientais e sociais dos produtos através de seu ciclo de vida. Desta maneira, a empresa deve ser capaz de ir além de seus limites para conseguir aumentar seu âmbito de aplicação (UNEP, 2007).

A tecnologia da informação dá suporte aos processos de criação, gestão, disseminação e o uso de informações de produtos ao longo do ciclo de vida. No âmbito organizacional, diversos mecanismos podem ser destacados para obter informações que contribuíram com a LCM: a lista de requisitos, as estruturas de produtos, os programa de controle numérico, os resultados de manutenções, modelos em CAD (Computer Aided Design), controle da qualidade, entre outros (ZANCUL, 2009).

Outra abordagem estratégica de negócios que merece destaque é a Gestão do Ciclo de Vida de Produtos ou Product Life Cycle Management (PLM). O objetivo é propor soluções que apoiem a criação, gestão, disseminação e o uso de informações dos produtos através de uma forma colaborativa na empresa, que se estende desde o conceito até o fim de ciclo de vida, integrando pessoas, processos, sistemas de negócios e informações (CIMData, 2009).

Zancul (2009) conclui, a partir da análise da literatura que aborda o PLM, que é uma abordagem comumente proposta para:

- $\quad$ a gestão integrada relacionada aos produtos (suporta os processos de negócio e apóia a gestão de informações dos produtos);

- $\quad$ aplicada desde o conceito até o fim de vida de produtos (apoiar a colaboração na empresa estendida); e

- demanda para sua implantação efetiva, a integração de Tecnológia de informação (TI).

Ou seja, a PLM pode ser uma gestão integrada dos processos de negócio e das informações relacionadas aos produtos. Além disso, demanda o uso de TI para promover e garantir a colaboração estendida da empresa ao longo de todo o ciclo de vida (ZANCUL, 2009). Garetti e Terzi (2005) acrescentam que o PLM é considerado como um desafio organizacional e tecnológico dentro das empresas de manufatura, pois devido à atual competitividade, a gestão da informação relacionada ao produto deve ser ágil e organizada, 
com o objetivo de lançar no mercado produtos em intervalos de tempos mais curtos.

Such et al. (2008) acrescentam benefícios que podem ser alcançados com a implementação do PLM: diminuir o tempo no mercado, melhorar a funcionalidade do produto e aumentar a habilidade de customização. As melhorias desenvolvidas resultam em mudanças dentro das empresas e seus processos. Além disso, o PLM é uma abordagem de negócios que pode ser utilizada para solucionar os problemas de gestão das informações do produto durante todo seu ciclo de vida (CIMData, 2009).

O Quadro 1 apresenta um resumo das principais características das abordagens discutidas anteriormente. Neste sentido, a Gestão do Ciclo de Vida, ou Life Cycle Management (LCM), e a Engenharia do Ciclo de Vida (ECV) se apresentam como formas de gestão e de engenharia do produto, respectivamente, voltadas para a redução dos impactos ambientais. A gestão do ciclo de vida dos produtos (PLM) integra todas as áreas do conhecimento para a gestão das informações dos processos de negócios.

\begin{tabular}{|c|c|c|c|c|c|c|}
\hline \multirow[b]{2}{*}{ Abordagem } & \multicolumn{6}{|c|}{ Características } \\
\hline & Origem & Definição & Objetivo & Resultados & $\begin{array}{c}\text { Áreas } \\
\text { Relacionadas }\end{array}$ & Fonte \\
\hline $\begin{array}{l}\text { Engenharia } \\
\text { do Ciclo de } \\
\text { Vida (ECV) }\end{array}$ & $\begin{array}{c}\text { Engenharia do } \\
\text { produto para a } \\
\text { área } \\
\text { ambiental }\end{array}$ & 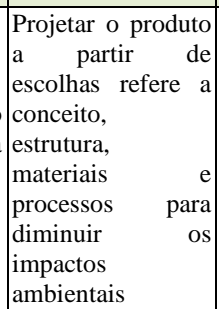 & 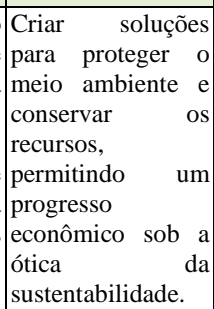 & 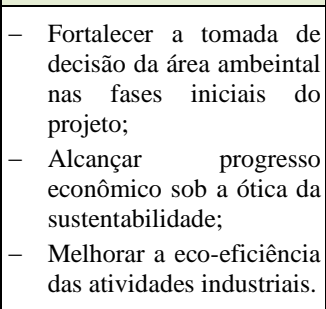 & $\begin{array}{l}\text { Produto, } \\
\text { produção, } \\
\text { processo e meio } \\
\text { ambiente }\end{array}$ & $\begin{array}{l}\text { (ALTING, } \\
\text { LEGARTH, 1995; } \\
\text { HAUSCHID, } \\
\text { JESWIET, } \\
\text { ALTING,2005; } \\
\text { WANYAMA et } \\
\text { al., 2003;) }\end{array}$ \\
\hline $\begin{array}{c}\text { Gestão do } \\
\text { Ciclo de } \\
\text { Vida (LCM) }\end{array}$ & Ambiental & $\begin{array}{l}\text { Sistema de gestão } \\
\text { que rer visa } \\
\text { minimizar ras } \\
\text { cargas ambientais, } \\
\text { econômicas re } \\
\text { sociais associadas } \\
\text { ao produto. }\end{array}$ & 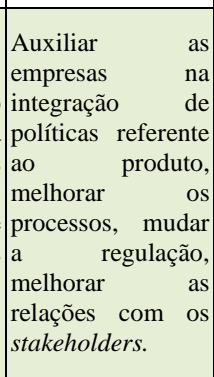 & $\begin{array}{l}\text { - Sistema de administração } \\
\text { que visa coletar, } \\
\text { estruturar e disseminar a } \\
\text { informação de distintos } \\
\text { programas, conceitos e } \\
\text { ferramentas } \\
\text { - Comunicação externa da } \\
\text { organização de modo a } \\
\text { melhorar a imagem do } \\
\text { produto, melhorar a } \\
\text { imagem e identificar } \\
\text { novos mercados }\end{array}$ & $\begin{array}{l}\text { Stakeholders, } \\
\text { sustentabilidade e } \\
\text { meio ambiente, } \\
\text { produção e } \\
\text { distribuição, } \\
\text { desenvolvimento } \\
\text { de produtos, } \\
\text { economia e } \\
\text { finanças, compras, } \\
\text { vendas e } \\
\text { marketing. }\end{array}$ & (UNEP, 2007) \\
\hline $\begin{array}{l}\text { Gestão do } \\
\text { Ciclo de } \\
\text { Vida de } \\
\text { Produtos } \\
\text { (PLM) }\end{array}$ & $\begin{array}{l}\text { Gestão de } \\
\text { dados dos } \\
\text { produtos e } \\
\text { avanços na } \\
\text { tecnologia }\end{array}$ & $\begin{array}{llr}\text { Gestão } & \text { integrada } \\
\text { dos processos } & \text { de } \\
\text { negócio } & \text { e } & \text { das } \\
\text { informações } & \\
\text { relacionadas } & \text { aos } \\
\text { produtos, } & \text { usando } \\
\text { sistemas } & \text { de } \\
\text { informação. } & \end{array}$ & $\begin{array}{l}\text { Apoiar a criação, } \\
\text { gestão r e } \\
\text { disseminação e o } \\
\text { uso re de } \\
\text { informações dos } \\
\text { produtos, através } \\
\text { do ciclo de vida. }\end{array}$ & $\begin{array}{ll}- & \text { Suportar os processos de } \\
& \text { negócio; } \\
- & \text { Apoiar a gestão de } \\
& \text { informações do produto; } \\
- & \text { Apoiar a colaboração na } \\
& \text { empresa estendida; } \\
- & \text { Diminuir o tempo no } \\
& \text { mercado; } \\
- & \text { Melhorar } \\
& \text { funcionalidade } \\
\text { produto; } & \text { do } \\
- & \text { Aumentar a habilidade de } \\
\text { customização }\end{array}$ & $\begin{array}{l}\text { Todas as etapas do } \\
\text { ciclo de vida do } \\
\text { produto, desde o } \\
\text { conceito até o } \\
\text { descarte. }\end{array}$ & $\begin{array}{l}\text { (CIMData (2009); } \\
\text { GARETTI, } \\
\text { TERZI, (2005); } \\
\text { SUCH et al.; } \\
\text { (2008); ZANCUL, } \\
(2009) \text { ) }\end{array}$ \\
\hline
\end{tabular}

Quadro 1 - Abordagens do Ciclo de Vida 
Conforme os diferentes processos de negocio mencionados pelas três abordagens, o PDP apresenta maiores oportunidades para recuperar os produtos na etapa de pós-consumo, além disso as decisões tomadas durante as fases iniciais são as responsáveis pelos impactos ambientais ocasionados ao longo do ciclo de vida desses produtos (HAUSCHILD; JESWIET; ALTING, 2005; JOHANSSON, 2002; LUTTROPP; LAGERSTEDT, 2006; NIELSEN; WENZEL, 2002). Wanyama et al. (2003) acrescenta que as decisões tomadas pelos designers na fase do projeto do produto influenciam entre $70 \%$ a $80 \%$ o custo total do mesmo. A seguir, são destacadas características do PDP que favorecem ou que podem contribuir com as abordagens do Ciclo de Vida dos Produtos.

\subsection{Processo de Desenvolvimento de Produtos (PDP)}

Conforme Clark e Fujimoto (1991), o PDP é o conjunto de atividades pelo qual uma organização transforma diferentes informações e dados referentes a oportunidades de mercado e tecnologias em produtos comerciáveis.

Para Rozenfeld et al. (2006), o PDP envolve o conjunto de atividades pela qual se busca chegar às especificidades de um produto com seus processos para que a manufatura seja capaz de produzi-lo, a partir das necessidades do mercado, restrições tecnológicas, estratégias competitivas e de produto da empresa. Neste sentido, mudanças eventuais podem ser apresentadas para essas especificações, o acompanhamento após o lançamento e a projeção de sua descontinuidade no mercado. Os mesmos autores mencionam como o registro de lições aprendidas ao longo do ciclo de vida ajuda a melhorar o desenvolvimento de novos produtos.

Para Machado e Toledo (2008), desenvolver um produto parte de uma idéia que pode ser materializada na forma de um bem fisico ou um serviço a ser prestado, sendo que nesse PDP podem ser encontradas diversas atividades planejadas, coordenadas e controladas, visando alcançar esse objetivo na criação de um novo produto.

O PDP é considerado como um dos processos de negócio mais importantes para as empresas, porém um dos mais difíceis de estruturar, por ser cada projeto único para cada produto desenvolvido. Aspectos que criam um alto grau de incerteza, baixa previsibilidade e criatividade, principalmente nas fases iniciais. Apesar dessa situação, é possível e necessário gerenciar o desenvolvimento de produtos para conseguir planejar, executar, controlar e melhorar as atividades envolvidas no processo (ROZENFELD et al., 2006).

Neste sentido, as práticas de gestão sistematizadas nos modelos de referência surgem 
como uma tentativa de promover o desempenho do PDP e para que este processo seja eficaz e eficiente, e possa alcançar os resultados esperados e estimular a competitividade da empresa. Os modelos de referência apresentam informações para as empresas sobre as atividades, os responsáveis, os resultados esperados, as entregas e os requisitos que devem ser considerados para o processo de desenvolvimento de produtos. Ou seja, um modelo ${ }^{10}$ representa uma coletânea de atividades, métodos, departamentos, entre outros, ao longo do PDP, que visa conseguir que todas as partes envolvidas das diversas áreas mantenham termos comuns, facilitando a comunicação e a integração entre eles (GUELERE FILHO; ROZENFELD, 2006; PIGOSSO, 2008; ROZENFELD et al., 2006).

Na literatura existem diversos modelos de referência como auxilio na gestão do ciclo de vida dos produtos (PLM), no entanto nem todos consideram as Estratégias de Fim de Vida (EoL), o que dificulta a integração desses no PDP. O Quadro 2 apresenta um resumo de alguns modelos de referência desenvolvidos e amplamente divulgados na literatura. É uma análise que permite determinar e avaliar qual dos modelos proposto pode ser considerado como referência para o objetivo deste trabalho.

A análise bibliográfica permite destacar que o modelo unificado do PDP desenvolvido por Rozenfeld et al. (2006) e o modelo de processo integrado de produtos-PRODIP desenvolvido por Romano (2003) e Back et al. (2008) apresentam características que favorecem a integração das EoL. Entretanto, a proposta de Rozenfeld et al. (2006) é desenhada com um conjunto maior de especificações quanto à integração de EoL nas diferentes fases do processo de desenvolvimento de produto, incluindo a parte de pósdesenvolvimento, etapa importante para recuperar os produtos e reintegrá-los novamente à cadeia produtiva.

\begin{tabular}{|c|c|c|c|}
\hline Título & Modelo Unificado do PDP & CMMI desenvolvimento & $\begin{array}{c}\text { Processo de Desenvolvimento } \\
\text { Integrado de Produtos- } \\
\text { PRODIP }\end{array}$ \\
\hline Fonte & Ronzenfeld et al. (2006) & $\begin{array}{c}\text { Chrissis; Konrad; Shrum } \\
11 \text { (2007 apud Zancul, 2009). }\end{array}$ & $\begin{array}{c}\text { Romano (2003); } \\
\text { Back et al. (2008) }\end{array}$ \\
\hline Idioma & Português & Inglês & Português \\
\hline $\begin{array}{c}\text { Setores da } \\
\text { indústria }\end{array}$ & $\begin{array}{c}\text { Bem de consumo duráveis e bens de } \\
\text { capital com ênfase na tecnologín } \\
\text { mecânica de fabricação }\end{array}$ & Manufatura discreta \\
\hline
\end{tabular}

(continua)

\footnotetext{
${ }^{10}$ Conforme Zancul (2009), um modelo é uma representação da realidade, que pode ser representada por meio de gráficos, tabelas os quais descreve o funcionamento dos processos de maneira esquemática.

11CHRISSIS, M.B.; KONRAD, M.; SHRUM, S. CMMI: Guidelines for Process Integration and Product Improvement. Adisson-Wesley, 2007. 676 p.
} 


\begin{tabular}{|c|c|c|c|}
\hline Escopo & $\begin{array}{l}\text { - Pré-desenvolvimento } \\
\text { - Desenvolvimento } \\
\text { - Pós-Desenvolvimento } \\
\text { - Processo de Apoio }\end{array}$ & $\begin{array}{l}\text { - Gestão de processo } \\
\text { - Gestão de projetos } \\
\text {-Eng. de desenvolvimento de } \\
\text { requisitos } \\
\text { - Suporte }\end{array}$ & $\begin{array}{l}\text { - Planejamento } \\
\text { - Elaboração do projeto do } \\
\text { produto } \\
\text { - Implementação do lote inicial }\end{array}$ \\
\hline $\begin{array}{l}\text { Fase (s) que } \\
\text { apresentam } \\
\text { integração } \\
\text { com EoL }\end{array}$ & $\begin{array}{l}\text { Macrofase Desenvolvimento } \\
\text { Projeto informacional (requisitos } \\
\text { relacionados ao meio ambiente, } \\
\text { considerando no projeto os impactos } \\
\text { ambientais do produto durante } \\
\text { produção, uso e descarte). } \\
\text { Projeto Conceitual (análise de SSCs- } \\
\text { Sistemas, subsitemas e componentes), } \\
\text { ferramentas de auxilio para prever os } \\
\text { impactos do produto (projeto para: ciclo } \\
\text { de vida, meio ambiente, desmontagem, } \\
\text { reciclagem, remanufatura, serviço, } \\
\text { montagem, modularidade etc.); } \\
\text { Projeto detlhado: criação de SSCs } \\
\text { projetando o fim de vida do produto } \\
\text { Macrofase de Pós-desenvolvimento } \\
\text { Descontinuidade e retirada do produto. }\end{array}$ & $\begin{array}{l}\text { Não apresenta integração das } \\
\text { EoL }\end{array}$ & 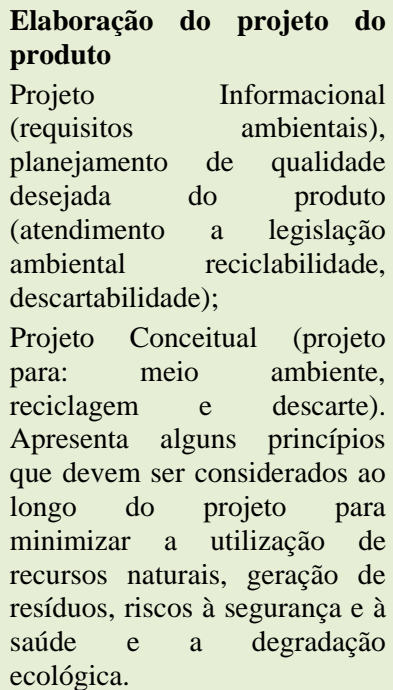 \\
\hline
\end{tabular}

Quadro 2 - Comparação de Modelos de Referência para o PDP

Fonte. Adaptado de Zancul (2009)

O modelo desenvolvido por Rozenfeld et al., (2006) foca nas diferentes atividades do PDP, apresenta uma divisão de três macrofases: pré-desenvolvimento, desenvolvimento e pós-desenvolvimento, conforme descritas, a seguir. A estrutura do modelo de referência proposta pelos autores pode ser observa na Figura 3, conforme será descrito, a seguir (ROZENFELD et al., 2006).

O que caracteriza uma fase são os resultados e a avaliação que proporcionam reflexão sobre o andamento do projeto, assim como na prevenção de futuros problemas e mesmo no aprendizado para a empresa. Essa avaliação é realizada por meio de um processo formalizado conhecido como de transição de fase (gate). Porém, apesar da representação seqüencial das fases, elas podem ser alteradas ou desenvolvidas paralelamente em um projeto real. O escopo de aplicação do modelo é claramente delimitado, ficando bastante explícito que ele foi criado para processos de desenvolvimento de produtos de bens de capital e de consumo duráveis. 


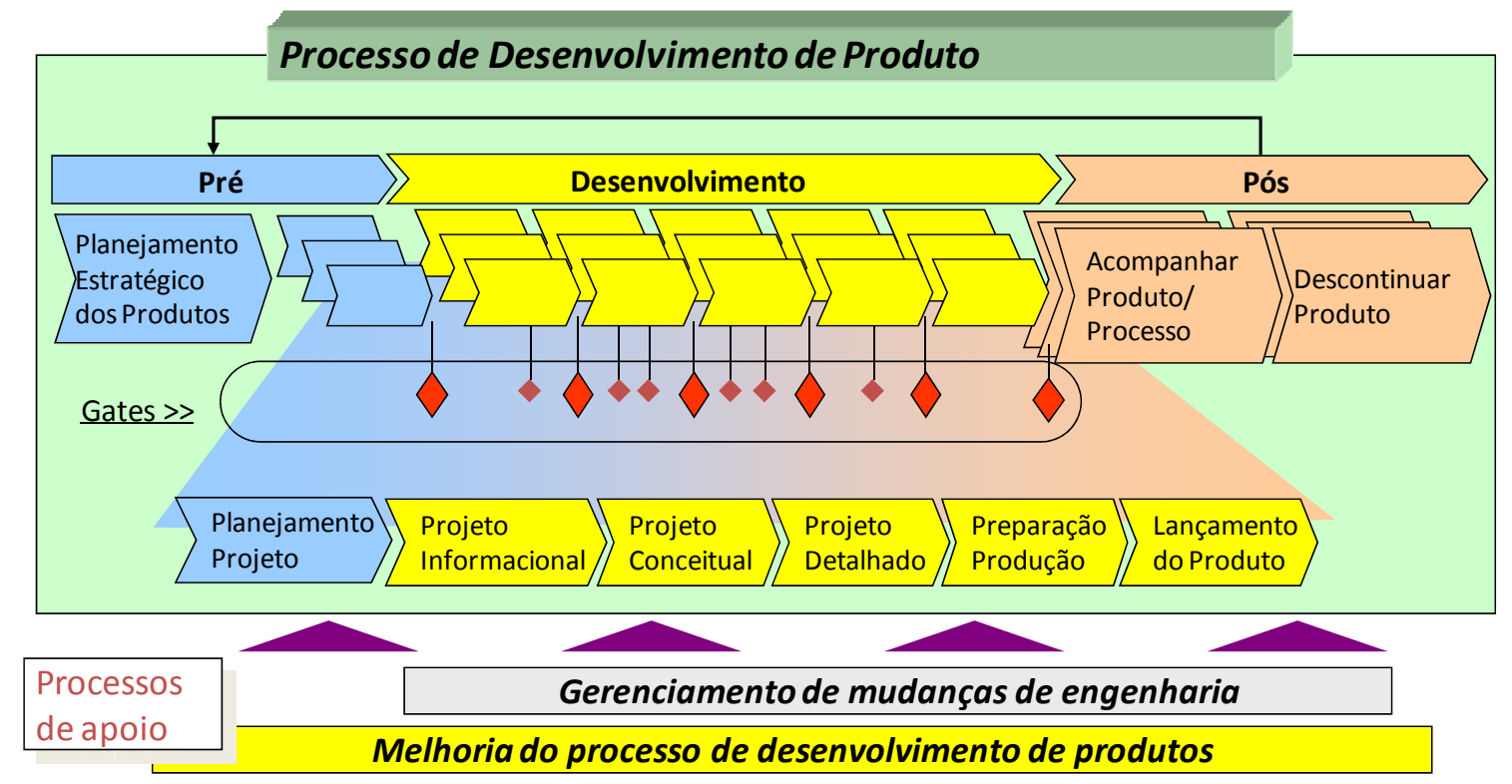

Figura 3 - Visão Geral do Modelo de Referência para o Processo de Desenvolvimento de Produtos Fonte: ROZENFELD et al. (2006)

A fase de pré-desenvolvimento compreende o Planejamento Estratégico do Produto e o Planejamento do Projeto e aquele deve garantir que o direcionamento estratégico, definido pela empresa no Planejamento Estratégico da Corporação seja considerado no desenvolvimento de produtos. As idéias de todos os atores internos e externos envolvidos e as oportunidades e restrições devem ser identificadas e transformadas em um conjunto de projetos bem definidos, isto é, no portfólio de projetos. Na fase de Planejamento do Projeto, são definidos o escopo, os recursos disponíveis, as pessoas responsáveis, a duração e os custos do projeto para um produto em particular do portfólio.

Na macro-fase de desenvolvimento, estão incluídas as fases de Projeto Informacional, Projeto Conceitual, Projeto Detalhado, Preparação da Produção e Lançamento do Produto.

O objetivo do Projeto Informacional é desenvolver um conjunto de informações, o mais completo possível chamado de especificações-meta do produto que refletem as necessidades dos clientes e orientam a geração de soluções que serão utilizadas nas etapas posteriores do processo de desenvolvimento. O mapeamento do ciclo de vida do produto, os seus requerimentos e as partes envolvidas são determinados na fase do projeto informacional.

No Projeto Conceitual, as atividades da equipe buscam a criação, representação e seleção de soluções para o problema de projeto. Inicialmente, é feita a modelagem (descrição) das funções que o produto deve apresentar, de forma abstrata, independente dos princípios físicos, sem pensar na solução para estas funções. A partir desta estrutura de funções, são 
propostos princípios de solução para cada uma das funções, utilizando os chamados métodos de criatividade, classificados em: intuitivos, sistemáticos ou orientados. A combinação de vários princípios de soluções define uma alternativa de solução ou arquitetura (componentes e suas conexões).

Empresas e pesquisadores desenvolveram vários métodos e ferramentas de auxílio na tomada de decisões do projeto envolvidas nesta fase do PDP e denominados de abordagens DFX (Design for $X$, sendo que o $\mathrm{X}$ representa várias considerações que ocorrem ao longo do ciclo de vida). Por exemplo, existe a abordagem design for manufacturing (fabricação), environment (meio-ambiente), assembly (montagem), disassembly (desmontagem), recycling (reciclagem), modularity (modularidade), remanufacturing (remanufatura), entre outros. A importância de qualquer metodologia DFX, principalmente no projeto conceitual se deve ao fato que nesta fase as decisões tomadas têm o maior efeito nos custos de um produto pelo menor investimento. Além disso, as decisões tomadas são responsáveis pela determinação de aspectos relacionados à funcionalidade, geometria e propriedades do produto, definindo-se o desempenho e competitividade do produto ao longo do seu ciclo de vida.

As atividades de detalhamento do projeto, a partir do projeto conceitual, até o nível de definição de quais sistemas, subsistemas e componentes (SSCs) serão comprados e a especificação de todos os parâmetros, variáveis e processos de SSCs a serem produzidos internamente, criação de material de suporte e projeto da embalagem e do fim de vida do produto, bem como seus testes e homologação, ocorrem na fase de Projeto Detalhado.

No projeto detalhado aparecem três ciclos que podem ocorrer com grau elevado de simultaneidade em relação aos diferentes SSCs: ciclo de detalhamento (criar e detalhar SSCs considerando as EoL, documentação e configuração), de aquisição (make or buy decision e desenvolver fornecedores) e de otimização (avaliar SSCs, configurar e documentar produto e processo).

Paralelamente a estes ciclos, ocorre o planejamento do processo de fabricação e montagem. Após a realização dos ciclos mencionados, acontece a documentação final do produto (ROZENFELD et al., 2006). Todos os recursos de manufatura são especificados, manuais do produto e instruções para a assistência técnica são também desenvolvidos, assim como sistemas de informação e suporte aos vendedores.

Na próxima fase, a Preparação da Produção, o primeiro novo produto é recebido, testado e, quando aprovado, um lote piloto é produzido e um novo processo de produção pode ser mapeado e estabilizado. A fase de Lançamento do Produto ocorre paralelamente à fase de Preparação da Produção, onde outros processos de negócio, como assistência técnica e serviço 
ao consumidor, são mapeados (GUELERE FILHO; ROZENFELD, 2006). Também é nesta fase que se faz a última atualização do plano de fim-de-vida, criado no Detalhamento antes de passá-lo para a responsabilidade da Produção.

Finalmente, a macro-fase de pós-desenvolvimento compreende as fases de monitoramento do processo e da produção e a gestão de fim de vida do produto. O acompanhamento sistemático e a documentação correspondente das melhorias de produtos ocorridas durante o seu ciclo de vida são atividades centrais do pós-desenvolvimento, que também compreende a retirada sistemática do produto do mercado, fazendo com que os requisitos de gestão do meio ambiente, como reuso, reciclagem, remanufatura ou descarte do produto, sejam considerados para que a experiência possa ser útil em desenvolvimentos futuros. As atividades operacionais incluem a avaliação da satisfação dos clientes, o monitoramento do desempenho técnico do produto, as auditorias, os acompanhamentos das modificações do produto e o registro das lições aprendidas. O planejamento do pósdesenvolvimento trata dessas questões somente do ponto de vista organizacional, pois as questões técnicas são consideradas durante a macro-fase de desenvolvimento (PIGOSSO, 2008).

As áreas de conhecimento inseridas no modelo de referência proposto incluem gestão de projeto, marketing, engenharia do produto, produção, fornecimento, qualidade, custos e meio ambiente. Especificamente, a área de meio ambiente compreende as atividades que envolvem a incorporação do desenvolvimento sustentável e dos métodos e ferramentas para executá-lo (PIGOSSO, 2008).

Rozenfeld et al., (2006) mencionam que as iniciativas de produção sustentável são integradas no PDP para otimizar ambientalmente o ciclo de vida do produto. É uma dinâmica de integração que, quando os requerimentos e conceitos de sustentabilidade são tomados durante o desenvolvimento de produtos, pode-se criar como conseqüência, uma manufatura mais sustentável, com produtos ambientalmente mais corretos (FIKSEL; MCDANIEL; SPITZLEY, 1998; GUELERE FILHO; ROZENFELD, 2006; ROZENFELD et al., 2006). A seguir, é discutido o Projeto para o Meio Ambiente ou Ecodesign como uma prática pró-ativa dentro da gestão ambiental das empresas.

\subsubsection{Projeto para o Meio Ambiente}

O Projeto para o Meio Ambiente é uma estratégia que visa integrar as ações tomadas durante o desenvolvimento de produtos, diminuir os impactos ambientais durante o ciclo de 
vida, sem comprometer características como desempenho, funcionalidade, qualidade e custo (JOHANSSON, 2002; NIELSEN, WENZEL, 2002; PIGOSSO, 2008; WEENEN, 1995).

O termo Projeto para o Meio Ambiente aparece com diversos sinônimos conforme o lugar onde é usado. Kurk e Eagan (2008) e Pigosso (2008) mencionam que na Europa é conhecido como Ecodesign e nos Estados Unidos é utilizado o termo Design for Environment (DFE). Hauschild, Jeswiet e Alting (2005) realçam que esses termos são usados simultaneamente para considerar questões de design relacionadas ao meio ambiente e saúde humana durante todo o ciclo de vida de um produto.

Conforme a Associação Brasileira de Normas Técnicas - ABNT (2004), as organizações estão cada vez mais conscientes da necessidade de integrar aspectos ambientais dentro de seus produtos (ABNT, 2004). Um grande número de empresas busca os benefícios que podem ser adquiridos a partir da inserção desses conceitos nos modelos de negócios. Entre os principais resultados, podem ser destacados: a redução de custos, o estimulo à inovação, a melhoria na qualidade, oportunidade de novos negócios, identificação de novos produtos (a partir de bens descartados), redução das infrações legais entre outros.

Junto com o ecodesign surgiram outros projetos correlatos e específicos para determinados objetivos, que visam auxiliar a tomada de decisões durante o projeto. Dentro destes podem ser ressaltados alguns que visam à recuperação do produto por meio da integração de estratégias de fim de vida (EoL) como é o caso do projeto para reciclagem (Design for Recycling - DFR) que define regras e recomendações para o reaproveitamento de materiais e componentes (HAUSCHILD; JESWIET; ALTING, 2005).

Também é destacado o Projeto para Remanufatura (Design for Remanufacturing DFReman) que trata da combinação de estratégias de Ecodesign incluindo projeto para múltiplos ciclos de vida, que orienta para outras estratégias, como o projeto para atualização, todos com a finalidade de conseguir manter as partes do produto a ser remanufaturado em condições de uso, e evitar os danos ocorridos na desmontagem destes (GRAY; CHARTER, 2006). Outra proposta é o Projeto para Desmontagem (Design for Disassembling - DFD), no qual são utilizadas técnicas que projetam a desmontagem do produto, considerando o descarte dessas peças. É um projeto que também tem uma interface com os descritos anteriormente (HAUSCHILD; JESWIET; ALTING, 2005; ROZENFELD et al., 2006).

Pigosso et al. (2010) destaca como o fim de vida de produtos é importante para diminuir os impactos ambientais associados à disposição final. Por meio do projeto para o meio ambiente, as escolhas das diferentes estratégias podem ser direcionadas conforme as necessidades ambientais, econômicas e sociais. Rose (2000) destaca como o interesse do 
consumidor e as pressões do mercado, especialmente nas atividades de negócio, levam as empresas a examinar melhor o fechamento e tratamento na fase final de seus produtos.

Neste contexto, o item seguinte apresenta, a recuperação de produtos com as estratégias de fim de vida como alternativas que devem ser adotadas nas empresas para a integração, especialmente no PDP, e deste modo poder melhorar o desempenho ambiental dos produtos e conseguir beneficios relacionados com os pilares propostos pelo conceito de sustentabilidade: Econômico, Ambiental e Social.

\subsection{Recuperação de Produtos e as Estratégias de Fim de Vida de Produtos (EoL)}

A recuperação de produtos com seus componentes e materiais visa incorporar valores econômicos e ambientais dos produtos na sua fase de pós-consumo, assim como diminuir os impactos ambientais e os resíduos gerados na etapa de disposição final (THIERRY et al., 1995).

Para apresentar as Estratégias de Fim de Vida de Produtos (EoL - End-of-Life), é necessário definir o conceito de fim de vida, junto com suas principais características. Neste sentido, o fim de vida se refere ao momento em que os produtos não satisfazem as necessidades dos usuários. King et al. (2006) e Rose (2000) destacam que o fim de vida dos produtos (descarte) é incentivado pela deterioração, tecnologia obsoleta ou pelas mudanças nas prioridades dos consumidores, também acrescentam o fato que as preferências dos usuários muitas vezes mudam mais rápido que a própria deterioração do produto.

Para Seliger, Basdere e Keil (2001), o descarte dos produtos na fase de pós-consumo é causado pela desvalorização das mudanças, tanto físicas como de desempenho. As primeiras podem ser dadas pelo envelhecimento, corrosão ou deterioração do produto e o segundo grupo ocorre por mudanças nas tendências de moda, valores ou progressos tecnológicos. Essa desvalorização conduz a uma restrição ou baixa funcionalidade, reduzindo a qualidade ambiental, perda de imagem, incremento na operação de custos ou perda na segurança dos produtos.

Rose (2000) menciona que as estratégias de fim de vida podem ser utilizadas para descrever e associar métodos ou soluções ao produto no estágio final do seu uso. O tratamento de fim de vida inclui as atividades associadas à recuperação dos produtos por meio de um trabalho manual ou mecânico. Além disso, incluem atividades relacionadas com o planejamento estratégico e execução, que vão desde a coleta dos produtos, tratamentos desses 
bens até os impactos associados ao meio ambiente e sociedade.

Para Thierry et al. (1995), as estratégias de fim de vida, vista pelos autores como recuperação de produtos, além de conseguir diminuir a quantidade de resíduos e suas áreas de disposição final, aparecem como uma alternativa promissória que visa recuperar valores, tanto econômicos como ambientais.

A Fígura 4 descreve as relações que podem existir entre o ciclo de vida dos produtos com as diferentes alternativas de recuperação. Os principais estágios podem ser determinados a partir do reuso direto, seguido da gestão de recuperação, onde aparecem o reparo, o recondicionamento, a remanufatura, a canibalização e a reciclagem como estratégias. No último estágio do fluxo reverso ou secundário do produto são destacadas as alternativas referentes à gestão de resíduos como a incineração e disposição em aterros sanitários.

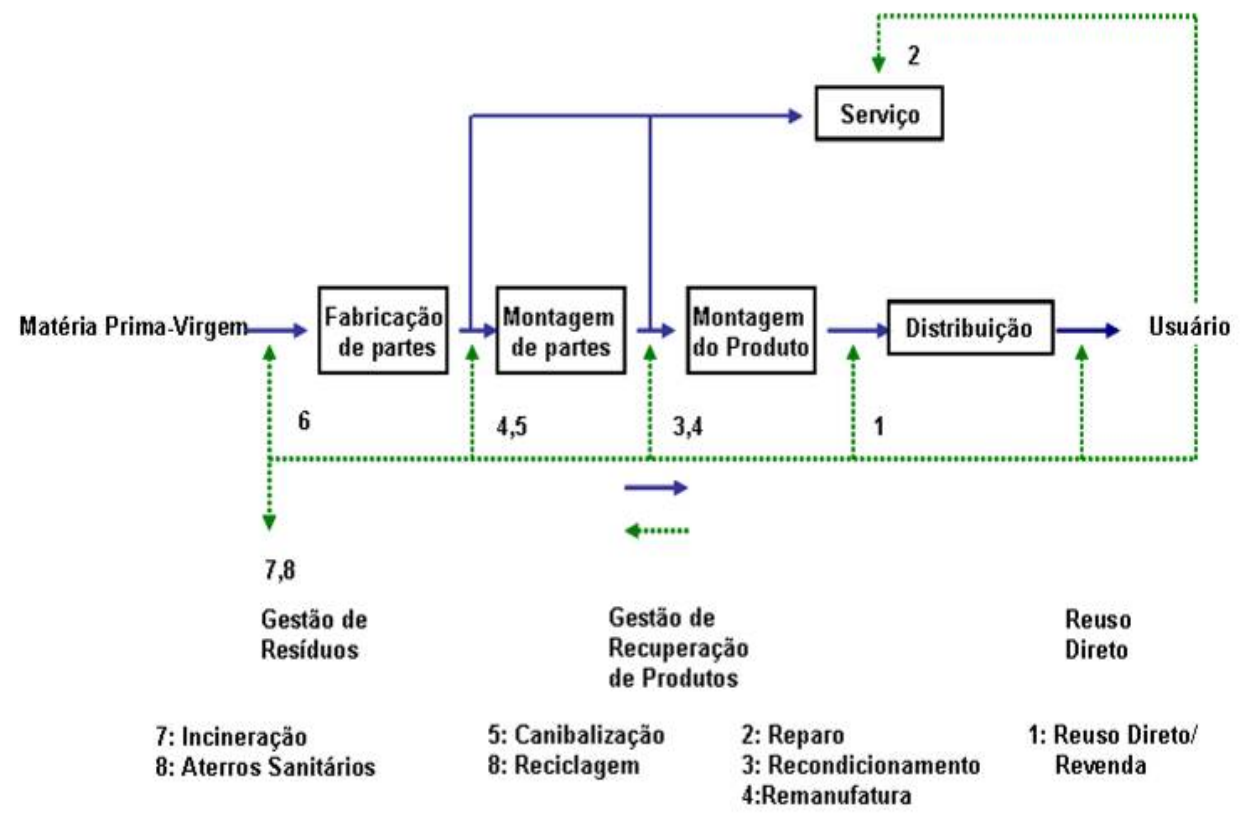

Fígura 4 - Ciclo de Vida do Produto e as Diferentes Formas de Recuperação Fonte: adaptado de Gehin et al. (2008); Seliger, Weinert e Zettl (2007) e Thierry et al. (1995)

Oiko et al. (2009) mencionam como o reparo, o recondicionamento e a remanufatura buscam melhorias na qualidade e/ou tecnologia dos produtos usados, diferindo quanto ao "grau de melhoria” que pode ser alcançada ou incorporada nas características funcionais do produto. Thierry et al. (1995), também mencionam que cada estratégia de fim de vida ou opção de recuperação de produtos envolve atividades relacionadas com a coleta de produtos 
usados (por meio do uso de logística reversa ${ }^{12}$ ), seus componentes, reprocessamento, desmontagem, montagem e redistribuição.

A atividade de desmontagem de produtos é considerada como uma atividade de interligação entre a recuperação de produtos e as EoL. O objetivo principal da desmontagem é separar ou fracionar em partes os produtos para que, posteriormente, sejam recuperadas pelas EoL. Neste sentido, o projeto para desmontagem deve ser considerado com o objetivo de otimizar o processo para que seja mais rápido e mais eficiente (HARJULA et al., 1996; KAEBERNICK; O’SHEA; GREWALL, 2000).

Rose (2000) menciona como a manutenção, neste caso representado pelo serviço entraria como alternativa que visa estender o ciclo de vida desses produtos, especificamente no serviço de troca de peças ou componentes, os quais podem ser reparados ou recondicionados dentro do produto no qual o serviço esta sendo prestado.

Neste sentido, o Sistema Produto-Serviço (SPS) ou Product Service System (PSS) aparece como uma alternativa para integrar produto e serviços que consigam, em conjunto, satisfazer as necessidades dos clientes. Assim, o uso das diferentes estratégias de fim de vida, como reparo, recondicionamento, remanufatura e reciclagem podem ser implantadas mais facilmente (PIGOSSO et al., 2010).

Goedkoop et al. (1999), destacam que, inicialmente, o SPS foi visto apenas como o conjunto comerciável de bens e serviços que conjuntamente são capazes de satisfazer as necessidades dos clientes. No entanto, Mont (2002), acrescenta que o SPS, além de satisfazer as necessidades do cliente, visa ter um menor impacto ambiental que os modelos de negócios convencionais, onde a desmaterialização dos produtos deve ser uma alternativa promissora, objetivando melhorias ambientais.

Saavedra, Sousa e Ometto (2009) acrescentam como a aplicação conjunta de sistemas produto-serviço (SPS) com estratégias de fim de vida pode potencializar melhorias no desempenho ambiental em todo o ciclo de vida dos sistemas fornecidos, desde sua concepção até o fim de vida de produtos.

A Figura 5 representa as diferentes EoL existentes para a recuperação de produtos e está organizada de acordo com o grau de recuperação de cada uma. Inicia-se com a canibalização, a qual busca recuperar componentes para que sejam usados nas outras EoL. Na

12 Conforme Leite (2003, p.16), logística reversa é a área da logística empresarial que planeja, opera e controla o fluxo e as informações logísticas correspondente ao retorno dos bens de pós-venda e pós-consumo, ciclo de negócios ou ciclo produtivo, por meio de canais de distribuição reversos, agregando valor de natureza econômica, ecológica, legal, imagem corporativa entre outros. 
remanufatura, os componentes que não são utilizados no processo, podem servir como matéria-prima nas outras EoL, exceto na canibalização. Já os componentes recuperados durante o reparo e/ou o recondicionamento podem fazer parte de um produto remanufaturado, sem que afetem sua qualidade e sua funcionalidade.

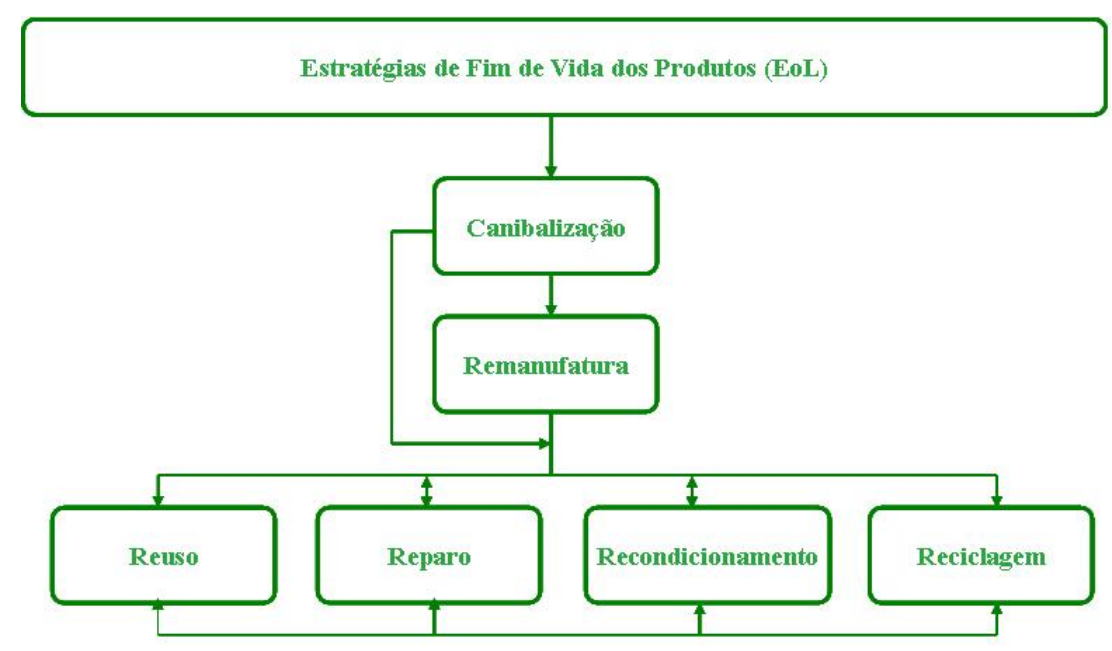

Figura 5 - Estratégias de Fim de Vida dos Produtos (EoL)

\section{- Canibalização}

A Canibalização tem como propósito conseguir a recuperação de componentes reusáveis, provenientes de produtos usados nas estratégias de reparo, recondicionamento, remanufatura e reciclagem. Além disso, a qualidade depende do processo onde os componentes irão ser reusados como, por exemplo, para a remanufatura os componentes devem ter uma maior qualidade que aquelas usadas para reparo. Outro aspecto importante é que a canibalização envolve uma desmontagem seletiva de produtos usados e a inspeção de potenciais componentes reusáveis (THIERRY et al., 1995).

\section{- Remanufatura}

A remanufatura visa à restauração de produtos a condição de novos, oferecendo a mesma qualidade e garantia (GRAY; CHARTER, 2006; HAUSER; LUND, 2003; JACOBSSON, 2000; STEINHILPER, 1998). Neste caso, a garantia é equivalente às fornecidas pelo Fabricante Original do Equipamento (Original Equipment Manufacture OEM) (IJOMAH et al., 2007). Sundin (2004) complementa afirmando que o sucesso da 
remanufatura depende da coleta do produto e da carcaça ou core - parte indispensável para o processo.

Segundo Hauser e Lund (2003) e Seliger et al. (2009), entre os setores que mais utilizam a remanufatura estão: o automobilístico, espacial, robótica, de autopeças, de equipamentos de comunicação, impressoras e cartuchos de impressão, eletro-eletrônicos, equipamentos médicos, entre outros, representados por setor no Quadro 3.

\begin{tabular}{|c|c|c|c|c|c|c|}
\hline Eletrodomésticos & $\begin{array}{l}\text { Equipamentos } \\
\text { médicos }\end{array}$ & $\begin{array}{l}\text { Componentes } \\
\text { de carros }\end{array}$ & $\begin{array}{c}\text { Materiais de } \\
\text { oficina }\end{array}$ & $\begin{array}{c}\text { Materiais de } \\
\text { computadores }\end{array}$ & Maquinaria & Outros \\
\hline $\begin{array}{l}\text { Máquina de } \\
\text { lavar roupa, } \\
\text { Geladeiras; } \\
\text { Televisão. }\end{array}$ & $\begin{array}{l}\text { Equipamento } \\
\text { médico; } \\
\text { Equipamento } \\
\text { de hospital } \\
\text { (camas). }\end{array}$ & \begin{tabular}{c|} 
Motores; \\
Alternadores; \\
Arrancadores; \\
Embreagens; \\
Juntas \\
universais.
\end{tabular} & $\begin{array}{l}\text { Fotocopiadoras; } \\
\text { Telefones; } \\
\text { Fax; } \\
\text { Impressoras; } \\
\text { Cartuchos de } \\
\text { impressão } \\
\text { (Toners). }\end{array}$ & Computadores & $\begin{array}{c}\text { Maquinas } \\
\text { para tecidos; } \\
\text { Limpadoras } \\
\text { de chão; } \\
\text { Tratores; } \\
\text { Pallet de } \\
\text { caminhão; } \\
\text { Máquinas a } \\
\text { vapor. }\end{array}$ & $\begin{array}{l}\text { Pneus; } \\
\text { Moveis de } \\
\text { oficina; } \\
\text { Pallet. }\end{array}$ \\
\hline
\end{tabular}

Quadro 3 - Produtos com Sucesso em Remanufatura Conforme sua Atividade Fonte: adaptado de Zwolinski et al. (2006).

Segundo Steinhilper (1998), o processo de remanufatura é realizado a partir de cinco etapas: desmontagem, limpeza de partes, inspeção e armazenamento, recondicionamento e troca, remontagem do produto e teste final, conforme ilustrado pela Figura 6. Entretanto, uma das atividades mais críticas é a coleta da carcaça (core). Isso ocorre pelas próprias dificuldades e barreiras que são enfrentadas do ponto de vista logístico, financeiro (vantagem econômica com esse processo), tecnológicos e gerenciais.

A seguir, as etapas do processo de remanufatura são brevemente descritas, conforme as informações destacadas por Steinhilper (1998).

- Desmontagem do produto: a finalidade desta etapa é a desmontagem total do produto. É uma das atividades que consome mais tempo devido ao grau de complexidade.

- Limpeza dos componentes: nesta etapa cada um dos componentes é limpo com diferentes substâncias para conseguir devolver o visual de novo. Podem ser citados quatro variantes de processo que contribuem para a limpeza: efeitos químicos (ex: detergentes), influência da temperatura (ex. calor), ação mecânica (ex. remoção por jato de água) e o tempo (ex. duração do processo). 
- Inspeção e armazenamento dos componentes: esta etapa propõe uma identificação para classificar os componentes, assim como, uma inspeção para saber quais devem ser trocados ou destinados para outra finalidade como: canibalização, reparo, recondicionamento ou reciclagem. Já o armazenamento se refere ao local onde o material será depositado para a montagem dos produtos posteriores.

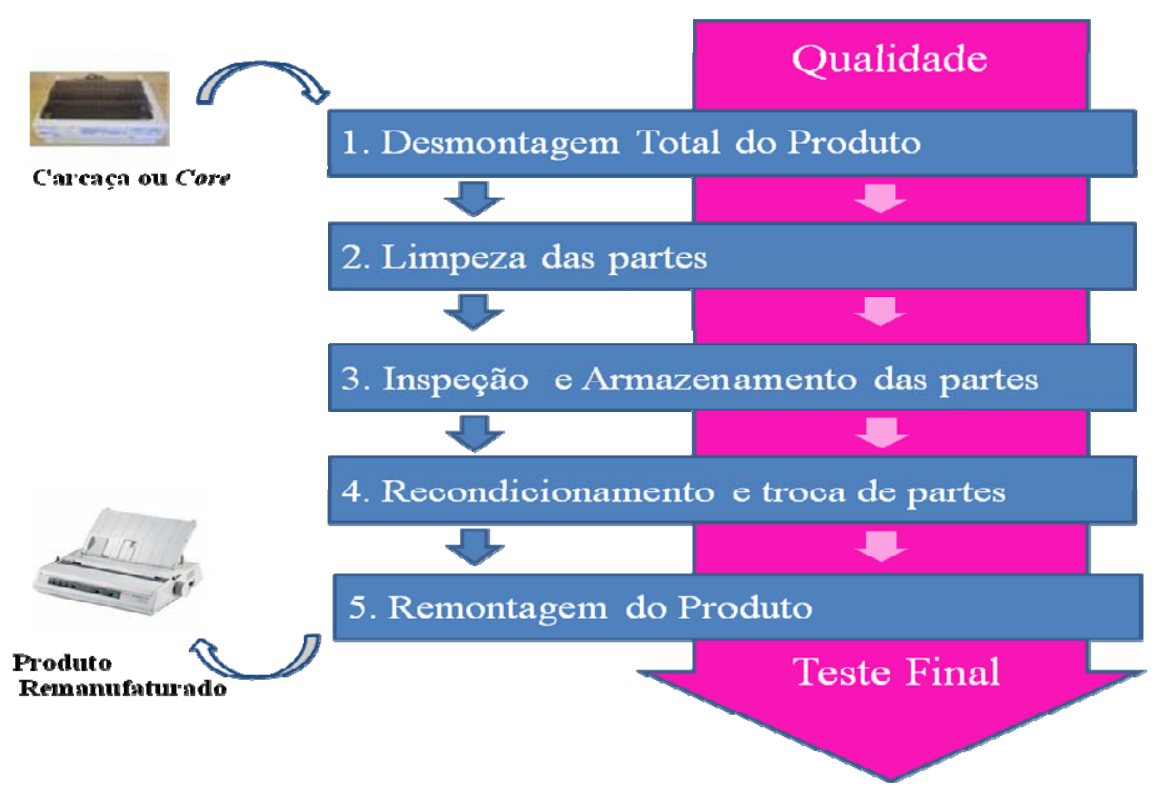

Figura 6 - Etapas do Processo de Remanufatura

Fonte: adaptado de Steinhilper (1998)

- Recondicionamento e troca de componentes: o produto é totalmente recondicionado. Neste caso, alguns componentes são trocados por novos porque não atendem os parâmetros mínimos necessários para remanufatura.

- $\quad$ Remontagem do produto: refere-se à nova montagem do novo produto. O teste final irá assegurar que o produto remanufaturado cumpra com a similaridade de um produto novo, obtendo as mesmas características e funcionalidades. Steinhilper (1998) afirma que o teste final não deve ser considerado como uma etapa, mas sim como uma certificação de que o produto vai oferecer as mesmas características de um novo. Contudo, as etapas podem seguir uma ordem diferente, dependendo do tipo de produto a ser remanufaturado.

A inserção do processo de remanufatura nas empresas pode trazer benefícios não apenas econômicos, mas também socioambientais (GIUNTINI; GAUDETTE, 2003; 
HAUSER; LUND, 2003). Porém, é importante identificar os principais desafios que precisam ser superados para a implementação desta estratégia. Gray e Charter (2006), Ijomah et al. (2007b), Shu e Flowers (1995), Thierry et al. (1995) e Zwolinski et al. (2006) destacam as principais diretrizes que devem ser seguidas no processo de desenvolvimento de produtos:

- Tecnologia: os produtos que visam a remanufatura devem possuir componentes adaptáveis que possibilitem a integração de novas tecnologias.

- Materiais e partes: dentro deste grupo é destacada a necessidade de produtos duráveis que sejam resistentes ao desgaste, principalmente pelo uso de químicos utilizados na etapa de limpeza da remanufatura. Materiais não duráveis não devem ser usados dentro do processo devido a que aumentam os custos e diminuem o ciclo de vida do produto.

É importante que o uso de partes seja livre de soldas porque é uma conexão que dificulta o processo de desmontagem do produto. Um número maior de quebra de peças pode aumentar a dificuldade e inviabilizar essa etapa do processo de remanufatura. Além disso, o uso de partes intercambiáveis pode auxiliar as diferentes etapas do processo.

Em alguns casos, o uso excessivo de rivets aumenta o tempo de desmontagem e remontagem. Observa-se que quanto maior o numero de componentes do produto maior o tempo gasto nas etapas, contudo este fator não impossibilita o processo de remanufatura.

- Demanda e Retorno do Produto: o sucesso na compra do produto no mercado depende da aceitação e distinção entre a qualidade, garantia e preço que oferece um produto remanufaturado. Para aumentar as chances do sucesso é necessário identificar mercados que ofereçam esse potencial. Em alguns casos, a falta de conhecimento do conceito de "remanufatura" impossibilita um aumento na aquisição desses produtos. Os consumidores ainda imaginam que esses produtos são reusados ou reparados e que oferecem qualidade inferior quando comparados com um produto novo.

Por outro lado, a importância de garantir o retorno do produto é indispensável para o sucesso da remanufatura. Parcerias entre distribuidores e consumidores pode ser uma garantia para obter o estoque necessário para conseguir suprir as necessidades que o mercado exige do produto. Entretanto, ainda se apresenta muita dificuldade no retorno devido à falta de integração de fluxos reversos que possa auxiliar e garantir a volta desses produtos para serem remanufaturados. 
- $\quad$ Legislação: a falta de legislação específica relacionada à responsabilidade estendida do produtor (EPR) dificulta o maior comprometimento da empresa no acompanhamento de seus produtos ao longo do ciclo de vida, assim como dificulta a identificação dos ganhos que podem ser obtidos com a implementação da remanufatura. Além disso, impossibilita que os consumidores identifiquem claramente os benefícios obtidos com a compra de produtos remanufaturados. De outra parte, outra barreira é a legislação atual, já que em muitos países como o Brasil, esses produtos são vistos como usados, o que dificulta sua expansão no mercado, dando, neste sentido maior importância para a reciclagem.

Sundin (2004) menciona quatro propriedades que devem possuir os produtos para ser remanufaturados: facilidade de acesso às partes, fácil identificação, resistência ao desgaste e fácil manipulação. Além disso, destaca que um projeto para desmontagem deve garantir facilidade de acesso às partes, princípio que deve ser considerado dentro do projeto para remanufatura.

A estratégia de remanufatura permite que os produtos apresentem um novo ciclo de vida completo, com beneficios para as esferas ambiental, econômica e social. No entanto, a remanufatura de um produto deve ser previamente avaliada para que se obtenha a maior parte de seus benefícios potenciais, como é o caso do giroscópio apresentado por Ijomah et al. (2007a), produto projetado inicialmente para remanufatura, mas que, após a adoção de novas tecnologias, teve seu desempenho ambiental otimizado, mesmo sendo utilizado em um único ciclo de vida.

\section{- Reuso}

O reuso é considerado, por Rose (2000), como aquele produto e componente que é usado logo após seu primeiro ciclo, ou seja, são bens de segunda mão, utilizados conforme suas características de design originais. Gray e Charter (2006) mencionam que os produtos reusados, retêm os possíveis problemas adquiridos durante sua vida anterior, não apresentando reparo algum e nenhum tipo de garantia.

\section{- Reparo}

O Reparo é descrito como uma estratégia na qual unicamente os componentes 
danificados / quebrados são trocados por outros para manter a funcionalidade original do produto, entretanto, os componentes trocados nem sempre apresentam condição de novos e podem ser utilizados de outros produtos iguais ou similares. Ijomah, Bennett e Pearce (1999) e King et al. (2006), mencionam que o reparo se refere ao processo de restabelecimento das condições funcionais nos componentes danificados do produto. Thierry et al. (1995) também destacam que a estratégia de reparo apresenta atividades limitadas de desmontagem e montagem. Gray e Charter (2006) e Ijomah et al. (2007) acrescentam que a garantia do produto e componentes é inferior aos equivalentes recém fabricados. Além disso, a garantia não pode cobrir o item inteiro, unicamente, os componentes que foram substituídos.

\section{- Recondicionamento}

O recondicionamento é um processo utilizado para retornar produtos e componentes as condições de uso. Em alguns casos, o desempenho pode ser menor que as condições originais de um produto novo. O produto final que passa por está estratégia tem uma garantia / qualidade inferior aos de um produto novo, característica aplicada unicamente para os componentes desgastados. Ijomah et al. (2007) e King et al. (2006) mencionam que o recondicionamento exige menos atividades de trabalho que a remanufatura, porém mais que o reparo do produto.

Com o processo de recondicionamento, a funcionalidade do produto é restaurada, sendo comum que o produto apresente desmontagem e limpeza parcial dos componentes, sendo trocados apenas os módulos críticos (THIERRY et al., 1995). Gray e Charter (2006) e King et al. (2006) também destacam que os produtos característicos desta estratégia são aqueles denominados no mercado de “produtos cinza”. O recondicionamento está combinado com a atualização tecnológica e busca estender o ciclo de vida dos produtos desenvolvidos com esses princípios.

\section{- Reciclagem}

Conforme Thierry et al. (1995), a finalidade da reciclagem é conseguir reusar os materiais dos produtos usados e de seus componentes. Neste caso, a energia incorporada, a identidade e a funcionalidade dos produtos e componentes são perdidas, e os materiais podem ser usados na produção de partes originais, quando a qualidade desse material é alta, ou também na produção de outras partes. A reciclagem começa quando os produtos e 
componentes são desmontados e, posteriormente, são separados dentro de distintas categorias de materiais.

Conforme Kriwet, Zussman e Seliger (1995), a atividade de reciclagem pode ser caracterizada dentro do ciclo de vida de um produto por três tipos:

- $\quad$ Reciclagem de uma parte da produção: se refere à utilização de resíduos dos processos de remanufatura, por exemplo, os refugos da injeção do molde;

- $\quad$ Reciclagem durante o uso do produto: utilização do produto depois de processos como reparo ou remanufatura; e

- $\quad$ Reciclagem pós-consumo: reciclagem na fase de fim de vida dos produtos.

Para Rose (2000), existem dois tipos de reciclagem: aquela que utiliza desmontagem, onde os componentes são desmontados com a finalidade de retirar materiais perigosos, contaminantes e componentes de alto valor. Os componentes são separados geralmente por métodos de desmontagem manual. O segundo tipo é a reciclagem sem desmontagem que é realizada para reduzir o tamanho dos materiais e facilitar a triagem. O material é separado por meio de métodos baseados em magnetismo, densidade e outras propriedades físico-químicas dos materiais (CARRELL; CHAO-ZANG; LI, 2008).

Manzini e Vezzoli (2002) mencionam como a reciclagem pode ser classificada conforme a fase do ciclo de vida na qual os materiais estão disponíveis. Existem materiais de pré-consumo que aparecem dos refugos e subprodutos de um determinado ciclo produtivo e os materiais que derivam dos refugos que se geram externamente ao processo produtivo original. Ainda, os autores destacam como neste caso os materiais são limpos, identificados e adaptados para possuir características de alta qualidade.

Outros materiais utilizados na reciclagem são os materiais pós-consumo que provêm de produtos de embalagens usadas e descartadas pelo consumidor final. A qualidade é inferior e a deteriorização e contaminação dificultam a reciclagem. Neste trabalho, é adotada a reciclagem pós-consumo, caracterizada pelas seguintes etapas, conforme Manzini e Vezzoli (2002):

- $\quad$ Recolha e transporte: se refere à coleta dos produtos eliminados. É importante que nesta etapa as operações de coleta não sejam subestimadas, principalmente, do ponto de vista do planejamento logístico (logística reversa) e impacto ambiental. Em algumas situações, é uma etapa que compromete os custos e as vantagens ambientais da reciclagem. 
- Identificação e separação: a identificação de materiais é importante para conseguir identificar as partes que podem ser recolhidas e quais devem ser descartadas. É uma etapa que também permite saber quais partes contêm substâncias contaminantes e perigosas.

- Desmontagem e/ou desmembramento: nesta etapa é importante a separação de materiais que consigam ser reciclados novamente. Existem diversos materiais que podem ser reciclados conjuntamente, sem que isso comprometa as características e qualidade proveniente dessa mistura. A identificação dos materiais pode ser feita por desmontagem e/ou desmembramento e sua sucessiva separação.

- Limpeza e/ou lavagem: nesta etapa os materiais são novamente lavados para certificar a inexistência de substâncias contaminantes, garantindo as características da reciclagem.

- Pré-produção de matérias primas secundárias: em alguns casos os materiais são usados diretamente, mas geralmente eles são melhorados através de aditivos e processos específicos conforme a necessidade do material.

A reciclagem se apresenta como uma alternativa na recuperação de materiais provenientes dos produtos. Entretanto, King et al. (2006) mencionam que os designers discordam em utilizar esses materiais devido à baixa qualidade que podem apresentar e, conseqüentemente, pode comprometer a qualidade, a funcionalidade, a estética e garantia do produto.

O Quadro 5 apresenta um resumo das principais características de cada EoL. Observase como a canibalização pode ser designada como um tipo de centro de distribuição, pois não é realizado nenhum tipo de conserto, simplesmente é realizada uma classificação para que posteriormente os componentes sejam usados nas outras EoL.

No caso do reparo e recondicionamento a diferença é dada pela finalidade de cada uma, ou seja, o reparo é mais relacionado aos componentes em si, e o recondicionamento é mais focado às atualizações tecnológicas. Por sua vez, a reciclagem transforma os produtos e componentes em materiais para que sejam usados na produção de outros produtos.

A remanufatura desmonta totalmente o produto, cuidando da funcionalidade dos componentes por meio de testes ao longo do processo. O objetivo é entregar um produto remanufaturado que atenda as mesmas características de um novo. 


\begin{tabular}{|c|c|c|c|c|}
\hline EoL & Nìvel de Desmontagem & Matéria Prima & $\begin{array}{c}\text { Características } \\
\text { Principais }\end{array}$ & Exemplos \\
\hline Canibalização & $\begin{array}{l}\text { Desmontagem total e } \\
\text { seletiva }\end{array}$ & Produtos usados & $\begin{array}{l}\text { Os componentes não } \\
\text { apresentam nenhum tipo } \\
\text { de conserto, podem ser } \\
\text { usados em outras EoL. }\end{array}$ & \begin{tabular}{|} 
Circuitos \\
eletricos, eletro- \\
eletrônicos, \\
eletrodomésticos.
\end{tabular} \\
\hline Remanufatura & Desmontagem Total & $\begin{array}{c}\text { Produto e } \\
\text { componentes } \\
\text { usados, conhecido } \\
\text { como carcaça ou } \\
\text { "core" }\end{array}$ & $\begin{array}{l}\text { Durante o processo, o } \\
\text { teste é um fator } \\
\text { importante para que o } \\
\text { produto remanufaturado } \\
\text { atenda as mesmas } \\
\text { condições do produto } \\
\text { novo em qualidade e } \\
\text { garantia. }\end{array}$ & $\begin{array}{l}\text { Equipamentos } \\
\text { médicos, } \\
\text { eletrodomésticos, } \\
\text { componentes de } \\
\text { carros, materiais } \\
\text { de oficina, eletro- } \\
\text { eletrônicos etc. }\end{array}$ \\
\hline Reparo & Desmontagem Parcial & $\begin{array}{l}\text { Produto e } \\
\text { componentes } \\
\text { usados }\end{array}$ & $\begin{array}{l}\text { O produto apresenta } \\
\text { componentes de diversos } \\
\text { produtos. Sendo que, a } \\
\text { qualidade é inferior e a } \\
\text { garantia é dada para os } \\
\text { componentes trocados e } \\
\text { não para o produto } \\
\text { enteiro. }\end{array}$ & $\begin{array}{l}\text { Fotocopiadoras, } \\
\text { impressoras }\end{array}$ \\
\hline Reuso & $\begin{array}{c}\text { Não existe } \\
\text { desmontagem }\end{array}$ & $\begin{array}{l}\text { Produto e } \\
\text { componentes } \\
\text { usados }\end{array}$ & $\begin{array}{l}\text { Oroduto } \\
\text { componente retêm os } \\
\text { problemas do ciclo de } \\
\text { vida anterior. Baixa } \\
\text { qualidade e nenhum tipo } \\
\text { de garantia. }\end{array}$ & $\begin{array}{l}\text { Eletrodomésticos, } \\
\text { componentes de } \\
\text { carros, materiais } \\
\text { de oficina, eletro- } \\
\text { eletrônicos etc. }\end{array}$ \\
\hline Recondicionamento & Desmontagem Parcial & $\begin{array}{l}\text { Produto e } \\
\text { componentes } \\
\text { usados }\end{array}$ & $\begin{array}{l}\text { O recondicionamento é } \\
\text { usado mais para } \\
\text { atualização, sendo que a } \\
\text { qualidade é inferior e a } \\
\text { garantia é unicamente } \\
\text { para os componentes } \\
\text { atualizados e não para o } \\
\text { produto inteiro. }\end{array}$ & $\begin{array}{l}\text { Computadores, } \\
\text { impressoras, }\end{array}$ \\
\hline Reciclagem & Desmontagem Total & $\begin{array}{l}\text { Produto e } \\
\text { componentes } \\
\text { usados }\end{array}$ & $\begin{array}{lr}\text { Os produtos } & \text { ou } \\
\text { componentes } & \text { são } \\
\text { transformados } & \text { em } \\
\text { materiais para ser } & \text { usados } \\
\text { na produção de } & \text { outros } \\
\text { produtos. } & \end{array}$ & $\begin{array}{c}\text { Materiais } \\
\text { recicláveis como } \\
\text { plástico, alumínio } \\
\text { etc. }\end{array}$ \\
\hline
\end{tabular}

Quadro 4 - Resumo das Estratégias de Fim de Vida (EoL)

O Quadro 5 apresenta os potenciais benefícios que podem ser alcançados com as EoL nas áreas da sustentabilidade sob as três dimensões: ambiental, econômico e social. É um conjunto de benefícios avaliados a partir da descrição da literatura que discute o tema (GIUNTINI; GAUDETTE, 2003, GRAY; CHARTER, 2006; HAUSER; LUND, 2003; MANZINI; VEZOLLI, 2002; STEINHILPER, 1998; THIERRY et al., 1995; ZWOLINSKI et al., 2006). 


\begin{tabular}{|c|c|c|c|c|c|c|}
\hline Área & Beneficios & 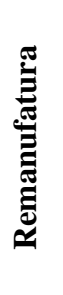 & $\underset{\mathscr{Q}}{\mathscr{Q}}$ & 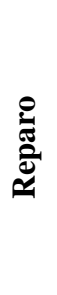 & 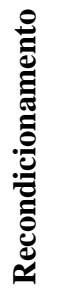 & 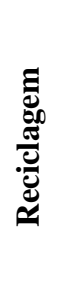 \\
\hline \multirow{7}{*}{ Ambiental } & Redução no consumo de agua & $\sqrt{ }$ & $\sqrt{ }$ & $\sqrt{ }$ & $\sqrt{ }$ & $\sqrt{ }$ \\
\hline & Redução no uso de energia & $\sqrt{ }$ & $\sqrt{ }$ & $\sqrt{ }$ & $\sqrt{ }$ & \\
\hline & Redução de emissões ao meio ambiente & $\sqrt{ }$ & $\sqrt{ }$ & $\sqrt{ }$ & $\sqrt{ }$ & \\
\hline & Redução no consumo de materiais & $\sqrt{ }$ & $\sqrt{ }$ & $\sqrt{ }$ & $\sqrt{ }$ & $\sqrt{ }$ \\
\hline & $\begin{array}{l}\text { Extensão no ciclo de vida do produto ou } \\
\text { componentes }\end{array}$ & $\sqrt{ }$ & $\sqrt{ }$ & $\sqrt{ }$ & $\sqrt{ }$ & $\sqrt{ }$ \\
\hline & $\begin{array}{l}\text { Extensão por mais de um ciclo de vida } \\
\text { completo o produto ou componente }\end{array}$ & $\sqrt{ }$ & & & & \\
\hline & $\begin{array}{l}\text { Redução na geração de resíduos e áreas de } \\
\text { disposição final }\end{array}$ & $\sqrt{ }$ & $\sqrt{ }$ & $\sqrt{ }$ & $\sqrt{ }$ & $\sqrt{ }$ \\
\hline \multirow{5}{*}{ Econômica } & Conservar a geometria original do produto & $\sqrt{ }$ & $\sqrt{ }$ & $\sqrt{ }$ & $\sqrt{ }$ & \\
\hline & Redução de custos de materiais & $\sqrt{ }$ & $\sqrt{ }$ & $\sqrt{ }$ & $\sqrt{ }$ & $\sqrt{ }$ \\
\hline & $\begin{array}{l}\text { Melhoramento na eficiência do processo } \\
\text { (maiores resultados com menores custos) }\end{array}$ & $\sqrt{ }$ & $\sqrt{ }$ & $\sqrt{ }$ & $\sqrt{ }$ & \\
\hline & Entrada a novos mercados & $\sqrt{ }$ & $\sqrt{ }$ & $\sqrt{ }$ & $\sqrt{ }$ & $\sqrt{ }$ \\
\hline & $\begin{array}{l}\text { Melhoramento na eficiência do processo } \\
\text { (maiores resultados com menores custos) }\end{array}$ & $\sqrt{ }$ & $\sqrt{ }$ & $\sqrt{ }$ & $\sqrt{ }$ & $\sqrt{ }$ \\
\hline \multirow{3}{*}{ Social } & Geração de empregos & $\sqrt{ }$ & $\sqrt{ }$ & $\sqrt{ }$ & $\sqrt{ }$ & $\sqrt{ }$ \\
\hline & Adquisição de produtos a menor custo & $\sqrt{ }$ & $\sqrt{ }$ & $\sqrt{ }$ & $\sqrt{ }$ & \\
\hline & $\begin{array}{l}\text { Aquisição de produtos a menor custo e } \\
\text { com a mesma garantia e qualidade de um } \\
\text { produto novo }\end{array}$ & $\sqrt{ }$ & & & & \\
\hline
\end{tabular}

Quadro 5 - Benefícios Potenciais da EoL no Contexto da Sustentabilidade

As EoL podem trazer benefícios no contexto da sustentabilidade. No entanto, a necessidade de integração nos processos de negocio da empresa é fundamental. Neste sentido, Zwolinski, Lopez-Ontiveros e Brissaud (2006) destacam que a principal barreira na recuperação dos produtos é o fato desses não serem projetados para essa finalidade, dificultando muitas vezes a sua recuperação pós-consumo e elevando os custos, levando a manter o tratamento atual de disposição final.

Desta forma, Zwolinski, Sghaier e Brissaud (2007) mencionam como o uso de práticas nas fases iniciais do PDP, especialmente na fase conceitual do produto, auxilia aos designers a determinar o modelo funcional à estrutura do produto, ajudando na definição dos componentes, das conexões e da primeira estrutura. Gehin et al. (2008) destacam como a 
complexidade da fase de design do produto requer o uso de práticas desenvolvidas para integrar as estratégias de fim de vida. Desta forma, a capacitação dos designers é importante para que eles sejam capazes de avaliar os impactos ambientais dos produtos e componentes selecionando atividades direcionadas à recuperação final do produto.

Observa-se que, na maioria das vezes, a recuperação de produtos é realizada de uma forma limitada, a incineração e a disposição final em aterros sanitários ${ }^{13}$ e $\operatorname{lixões}^{14}$ são as formas mais comuns de descartar os produtos. Para mudar essa situação, nos últimos anos tem surgido diversas legislações/políticas nos países que incentivam ou estabelecem normas para comprometer ou responsabilizar as empresas pelos resíduos gerados e decorrentes dos produtos na etapa de pós-consumo. Neste sentido, o Apêndice A apresenta as principais regulações e políticas referentes à recuperação de produtos.

\footnotetext{
${ }^{13}$ Conforme ABRELPE (2007), aterro sanitário é o local de disposição final de resíduos sólidos no qual são aplicadas todas as técnicas de engenharia e normas operacionais específicas para confinar os resídos com visas à efetiva proteção ao meio ambiente e à saúde pública.

${ }^{14}$ Conforme ABRELPE (2007), lixão é vazadouro a céu aberto, sem nenhum tipo de técnica de engenharia e normas operacionais.
} 


\section{MÉTODO DE PESQUISA}

Este capítulo descreve a abordagem metodológica adotada para realizar este trabalho. É apresentada uma breve revisão teórica dos métodos científicos e as diretrizes conceituais utilizadas para classificar a pesquisa, assim como as técnicas ou procedimentos técnicos utilizados na etapa de coleta de dados. Finalmente, são discutidas as etapas adotadas para o desenvolvimento da pesquisa.

\subsection{Definição do Método Científico}

O método científico é definido como o conjunto de processos ou operações mentais que são empregadas na investigação e ajudam a determinar uma linha de raciocínio durante o processo de pesquisa (GIL, 1999; LAKATOS; MARCONI, 1991). Conforme Gil (1999) e Silva e Meneses (2005). Os métodos de pesquisa podem ser classificados em:

- Método Dedutivo: proposto pelos racionalistas, onde é mencionado que a razão é a única que pode levar a um conhecimento válido. Parte-se de princípios reconhecidos como verdadeiros que possibilitam a formulação de uma conclusão lógica. A análise é feita do geral para o particular, chegando a uma conclusão final.

- $\quad$ Método Indutivo: proposto pelos empiristas, onde é considerado que o conhecimento é derivado da experiência, não levando em conta os princípios preestabelecidos, sendo que a generalização é derivada das observações de casos reais.

- Método Hipotético-dedutivo: o qual permite ao pesquisador, por meio de uma combinação e intuição científica, alcançar um conjunto de postulados que governam os fenômenos pelos quais está interessado e, a partir disso, por meio de experimentos, o cientista deduz as conseqüências e refuta postulados, substituindo-os por outros.

- $\quad$ Método Dialético: é um método que se baseia na interpretação da realidade, onde é considerado que os fatos não podem ser avaliados fora de um contexto social, político, econômico etc.

- $\quad$ Método Fenomenológico: descreve a experiência de uma forma real e direta, ou seja, tal como ela é entendida. Nesta abordagem, a realidade é resultado da interpretação e compreensão dos atores. O ator é reconhecidamente importante no processo da 
construção do conhecimento.

Neste trabalho, é utilizado o método Dedutivo. A análise científica dos princípios reconhecidos na literatura é realizada do geral para o particular, chegando a uma conclusão final lógica. A execução do trabalho pode ser definida a partir de um levantamento bibliográfico (revisão bibliográfica sistemática), que ajudou a identificar as práticas das estratégias de fim de vida- EoL, e derivadas destas, as práticas operacionais. Também é verificada a aplicação das práticas operacionais em empresas que integram a visão de recuperação de produtos na etapa de pós-consumo. Detalhes sobre os procedimentos de pesquisa adotados para o levantamento bibliográfico e a pesquisa de campo são destacados nos próximos itens.

\subsection{Classificação da Pesquisa}

Gil (2007) menciona que o objetivo da pesquisa científica é fornecer respostas para problemas não solucionados utilizando métodos, procedimentos e técnicas. Assim, esta é uma atividade que pode ser definida como um conjunto de ações realizadas com o intuito de encontrar uma solução a um problema previamente definido. Para Silva e Meneses (2005), as pesquisas são realizadas quando se apresenta um problema e existe incerteza na solução desse problema. Neste contexto, Gil (1999, 2007) e Silva e Meneses (2005) apresentam diversas formas de classificar a pesquisa. Conforme sua Natureza, a pesquisa pode ser:

- $\quad$ Pesquisa Básica: visa gerar conhecimentos novos e úteis para o avanço da ciência, sem aplicação prática prevista, envolvendo verdades e interesses universais; e

- $\quad$ Pesquisa Aplicada: busca gerar conhecimentos para a aplicação prática. É voltada para a solução dos problemas específicos, envolvendo verdades e interesses locais.

Do ponto de vista da forma de Abordagem do Problema, a pesquisa pode ser:

- Pesquisa Quantitativa: considera que todo pode ser quantificado e requer uso de recursos e técnicas de estatística (porcentagem, média, moda, análise de regressão etc.);

- $\quad$ Pesquisa Qualitativa: considera que a uma relação entre o mundo real e o sujeito, ou seja, a interpretação dos fenômenos e a atribuição de significados são subjetivas. Não são utilizados técnicas ou recursos de estatística, sendo que os dados são analisados intuitivamente. 
Do ponto de vista de seus Objetivos, a pesquisa pode ser classificada como:

- $\quad$ Exploratória: visa proporcionar uma maior familiaridade com o problema, alcançando um aprimoramento de idéias ou descoberta de intuições. Nesta abordagem são utilizados outros procedimentos para melhorar a compreensão do problema como, por exemplo, levantamento bibliográfico, entrevistas com pessoas que conhecem do tema e análises de exemplos similares;

- Descritivas: visa descrever as características de determinado fenômeno, para definí-lo melhor ou diferenciá-lo dos demais. Busca também estabelecer relações entre as variáveis de estudo, questionário e observação sistemática, assumindo, de forma geral, um tipo de levantamento;

- $\quad$ Explicativa: o objetivo principal é identificar fatores que determinam ou contribuem para a ocorrência dos fenômenos. A pesquisa explicativa é destacada como um tipo de pesquisa que mais se aprofunda no conhecimento da realidade, porém, é o tipo mais complexo pelo alto risco de cometer erros.

Gil (2007) considera que a escolha do procedimento técnico determina a forma de coleta de dados e por esta razão também classifica a pesquisa em oito tipos, conforme as técnicas utilizadas para reunir informações sobre o problema investigado. Nesse processo podem ser utilizados documentos, registros de arquivos, entrevistas, questionários, formulários, observação e artefatos físicos. Um breve resumo sobre os tipos de pesquisa propostos pelo autor são destacadas a seguir.

- $\quad$ Pesquisa Bibliográfica: Desenvolvida por meio de material já publicado, constituídas por livros, artigos científicos, publicações, e material disponibilizado na internet;

- $\quad$ Pesquisa Documental: Se baseia em materiais que ainda não receberam tratamento analítico ou que podem ser reelaborados conforme os objetos da pesquisa;

- $\quad$ Pesquisa Experimental: consiste em determinar um objeto de estudo, selecionar as variáveis que seriam capazes de influenciá-lo, definir as formas de controle e de observação dos efeitos que a variável produz no objeto;

- $\quad$ Pesquisa Ex-post facto: Neste caso o estudo é feito depois de ter passado a ocorrência das variações;

- $\quad$ Estudo de Corte: refere-se a um grupo de pessoas que têm alguma característica em comum, constituindo uma amostra da população. Tais pessoas são acompanhadas por certo período de tempo, observando e analisando o que acontece com elas; 
- Levantamento: refere-se à interrogação direta das pessoas cujo comportamento se deseja conhecer;

- $\quad$ Estudo de Campo: semelhante à pesquisa de levantamento, porém se apresenta com uma maior profundidade. Neste tipo de pesquisa é realizado um levantamento que procura ser representativo ao universo definido e oferece resultados caracterizados pela precisão estatística;

- $\quad$ Estudo de Caso: consiste no estudo exaustivo de um ou poucos objetos, de maneira que permita seu amplo e detalhado conhecimento;

- $\quad$ Pesquisa-ação: concebida e realizada em estreita associação com uma ação ou com a resolução de um problema coletivo, onde os pesquisadores e participantes representativos da situação ou do problema estão envolvidos de modo cooperativo ou participativo; e

- $\quad$ Pesquisa participante: desenvolvida a partir da interação entre os pesquisadores e membros das situações investigadas.

A Figura 7 ilustra as diferentes classificações da pesquisa adotadas para este trabalho. Quanto à metodologia utilizada, a pesquisa pode ser classificada como Aplicada, pois visa gerar resultados práticos. Neste sentido, as práticas operacionais visão auxiliar o processo de desenvolvimento de produtos, principalmente para integrar a visão de recuperação na etapa de pós-consumo. A pesquisa também pode ser considerada como uma abordagem Qualitativa, pois não utiliza métodos ou técnicas estatísticas durante a análise do problema investigado.

Conforme os objetivos, a pesquisa é classificada como Exploratória e Descritiva já que inicialmente é utilizado um levantamento das práticas das estratégias de fim de vida-EoL e, posteriormente, são extraídas as práticas operacionais.

As técnicas ou procedimentos científicos utilizados no presente trabalho consistem, inicialmente, de uma Pesquisa Bibliográfica, acrescida de uma revisão bibliográfica sistemática para identificar as práticas das EoL, e baseadas nessas, as práticas operacionais. Em seguida, são utilizados múltiplos estudo de caso para verificar a aplicação dessas práticas operacionais em empresas que integram a recuperação de produtos. 


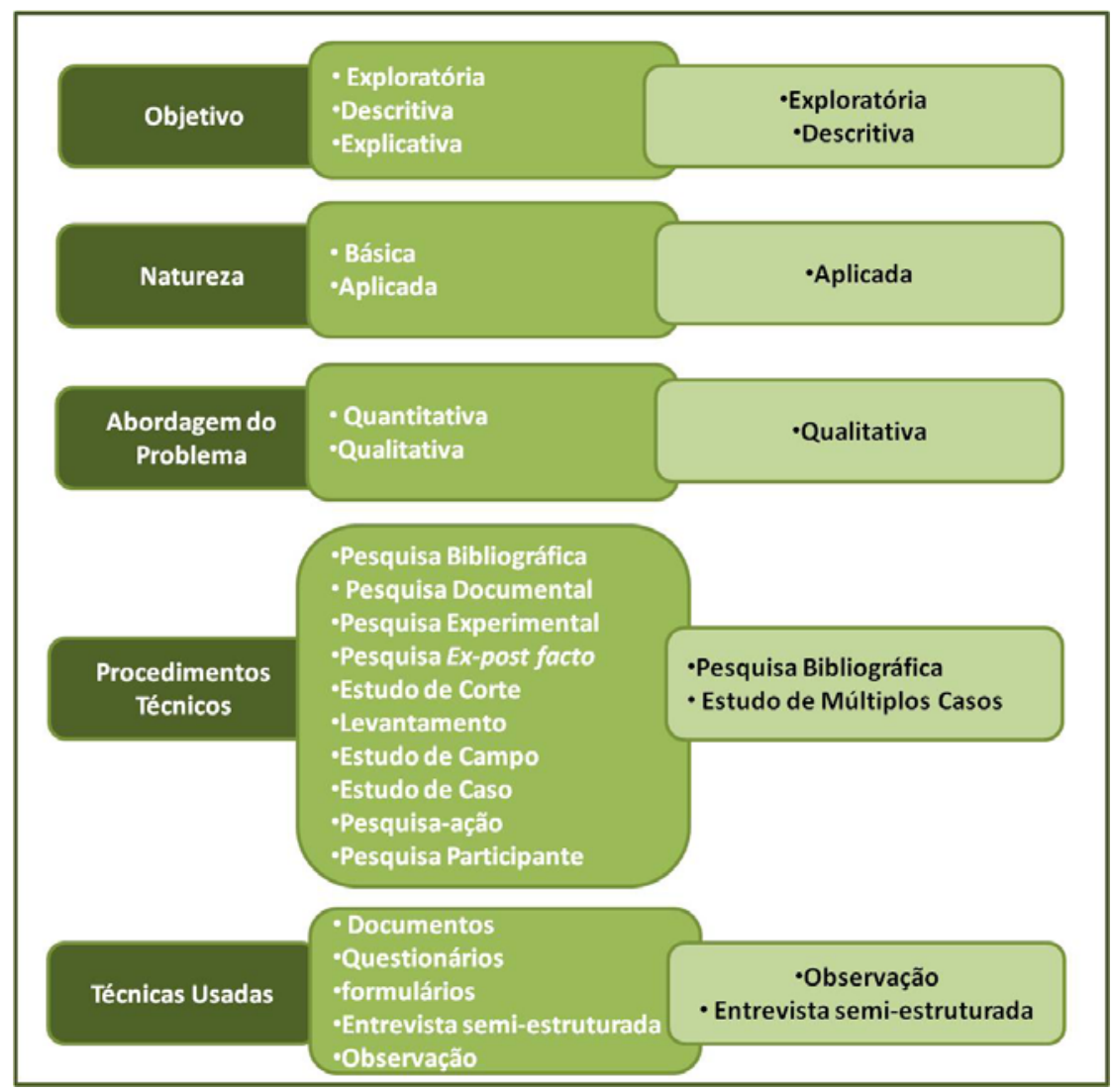

Figura 7 - Visão Geral do Projeto de Pesquisa

\subsection{Etapas da Pesquisa}

A Figura 8 descreve as principais etapas seguidas para desenvolver a pesquisa: Etapa 1 - Revisão Bibliográfica; Etapa 2 - Revisão Bibliográfica Sistemática e Identificação de Práticas EoL; Etapa 3 - Aplicação das Práticas EoL; e Etapa 4 - Análise da Aplicação das Práticas, conforme descritas nos próximos itens. 


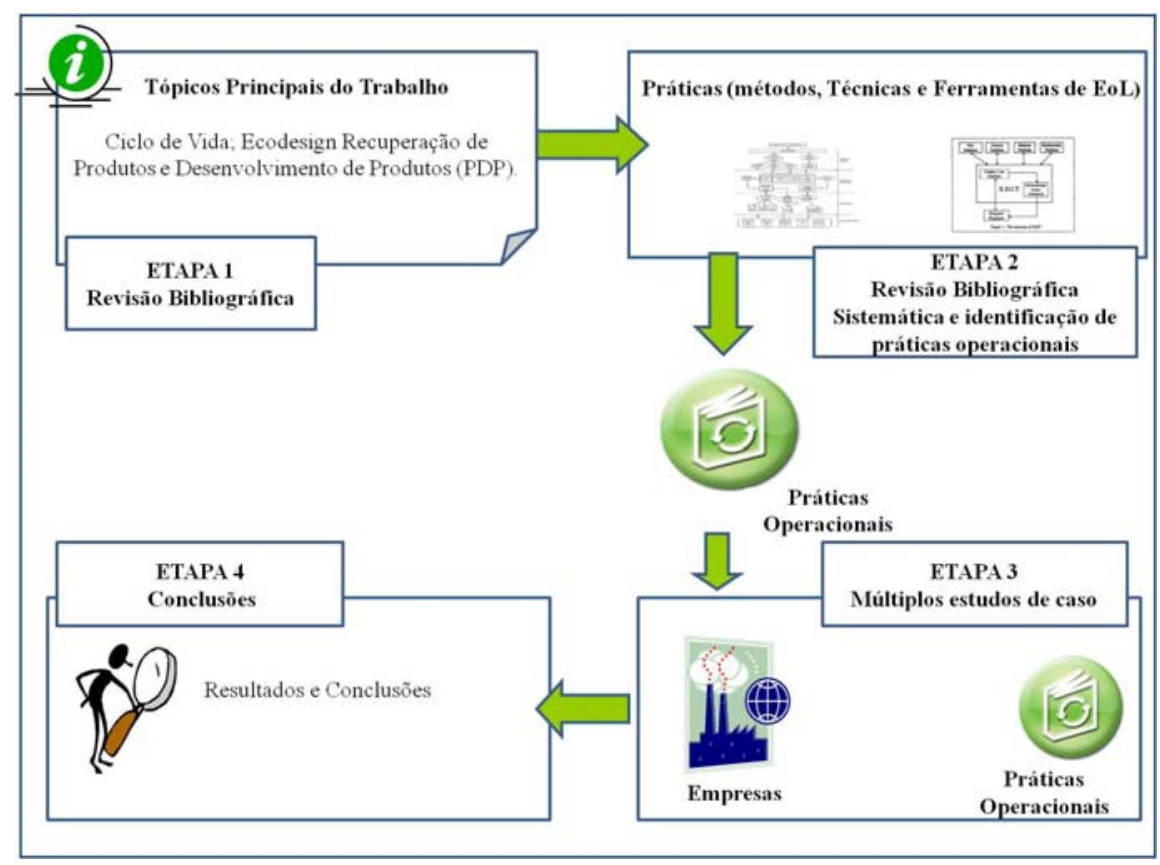

Figura 8 - Etapas da Pesquisa

\subsubsection{Etapa 1 - Revisão Bibliográfica}

Os tópicos apresentados na revisão bibliográfica (Capítulo 2) fornecem os fundamentos teóricos para a realização e o auxilio do desenvolvimento das próximas etapas deste trabalho. São pesquisados os seguintes temas:

- $\quad$ Ciclo de vida: se apresentam as principais características do tópico no que diz respeito ao acompanhamento ao longo de todas as etapas de um produto, desde a extração de matéria-prima até o descarte final, visando diminuir os impactos ambientais. Neste sentido, são apresentadas as principais abordagens: Engenharia do ciclo de vida, a Gestão do ciclo de vida e a Gestão do ciclo de vida dos produtos.

- $\quad$ Processo de desenvolvimento de produtos: são descritos os conceitos e as principais características do PDP, assim como os modelos de referência usados, especialmente aqueles que integram as EoL.

- $\quad$ Projeto para o meio ambiente: este tópico aborda a importância de integrar as questões ambientais dentro dos produtos, a fim de minimizar os impactos ambientais ao longo do ciclo de vida do produto;

- Recuperação de produtos: este tema é relevante para o desenvolvimento da pesquisa, pois apresenta as diversas alternativas para recuperar os produtos, como é o caso das estratégias de fim de vida-EoL: (remanufatura, canibalização, reuso, reparo, 
recondicionamento e reciclagem), finalmente, é feita uma comparação entre as EoL a fim de identificar suas principais diferenças.

\subsubsection{Etapa 2 - Revisão Bibliográfica Sistemática (RS)}

A Revisão Bibliográfica Sistemática (RS) apresentada no capítulo 4 é utilizada como uma ferramenta pelo pesquisador para o mapeamento e síntese de um tema específico da pesquisa (BIOLCHINI et al., 2005). A Figura 9 descreve o processo sistemático, definido por três etapas principais: 1) planejamento: onde os objetivos são listados e a revisão do protocolo é definida. O protocolo define a questão principal e os métodos que serão usados para executar a RS; 2) execução: onde são relizadas duas atividades - a execução da seleção dos estudos e a extração da informação (critérios de exclusão, formulários de extração de dados etc.); e 3) análise de resultados: que visa apresentar os dados dos estudos obtidos e as conclusões finais. A sumarização dessas informações é realizada ao longo de todo o processo. Antes de iniciar a execução da RS, o protocolo deve ser avaliado a fim de identificar possíveis problemas. Se eles existirem, deve-se retornar à fase de planejamento para revisar o protocolo. Mas, caso os problemas sejam identificados durante a execução, a RS deve ser refeita visando garantir que os resultados obtidos estejam conforme os objetivos definidos no protocolo.

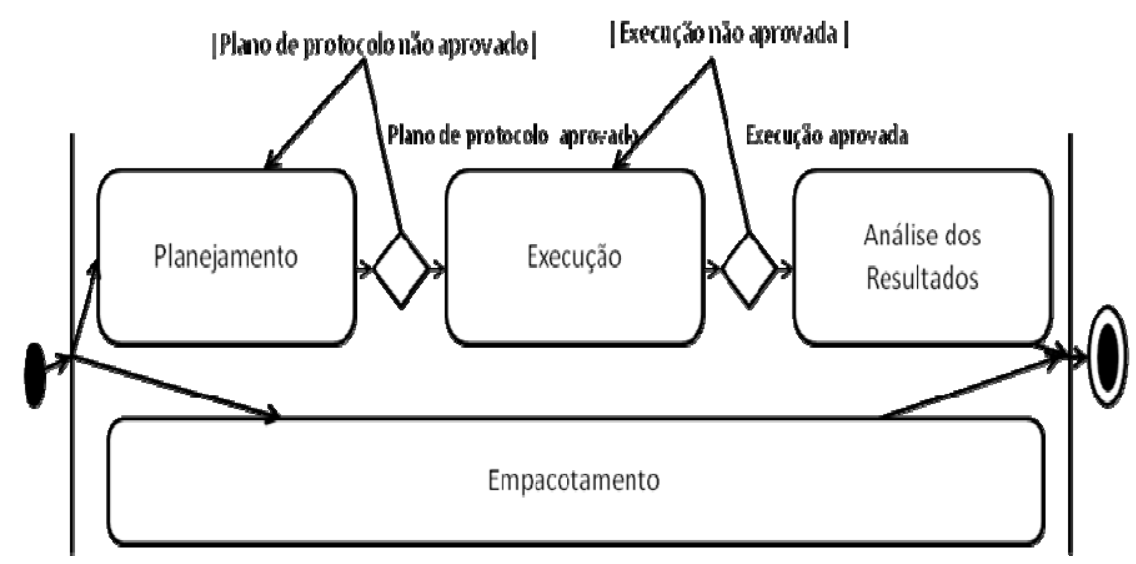

Figura 9 - Representação do Processo Sistemático

Fonte: Adaptado de Biolchini et al (2005)

A RS tem por objetivo proporcionar uma revisão que tenha uma base rigorosa e confiável, permitindo, assim, avaliar um tópico de pesquisa (BERETON et al., 2007).

Desta forma, para o desenvolvimento da revisão sistemática deste projeto foram 
executadas cinco fases que agrupam as atividades realizadas pela pesquisadora, conforme pode ser observado na Figura 10 e descritas posteriormente.

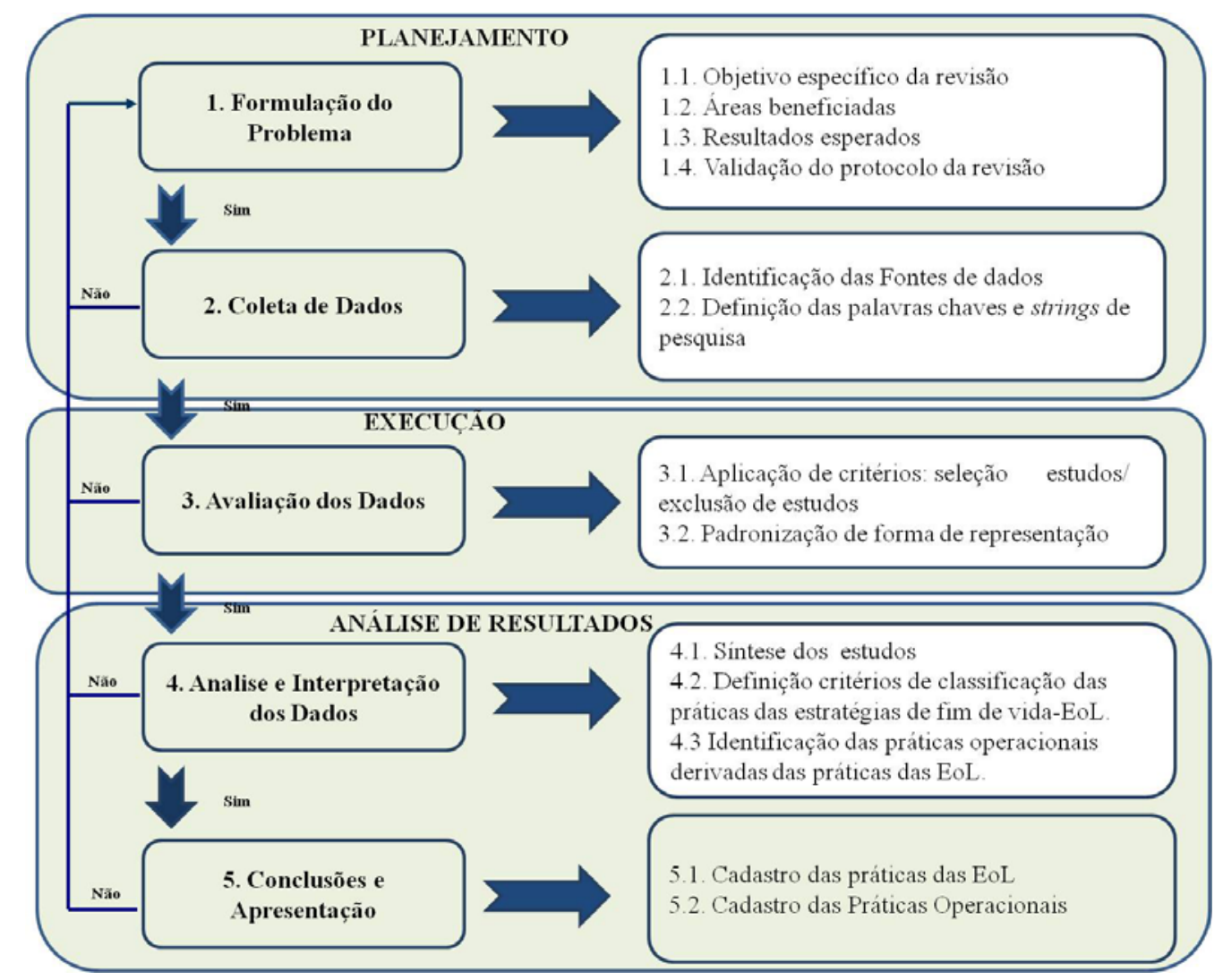

Figura 10 - Fases da Revisão Bibliográfica Sistemática

Na primeira fase (Formulação do problema) é definido e identificado o objetivo e o foco de interesse da revisão sistemática, sendo este: Identificar as práticas existentes das estratégias de fim de vida dos produtos-EoL.

Para alcançar esse objetivo proposto na revisão bibliográfica sistemática foi formulada uma questão principal: Quais são as práticas das estratégias de fim de vida de produtos existentes na literatura?

Dentro da revisão foram consultados artigos, publicações, dissertações e teses sobre estratégias de fim de vida (EoL), sendo escolhidos aqueles que apresentaram estudos de caso, estudos de aplicação e desenvolvimento de técnicas, métodos e ferramentas. A métrica usada foi o número de publicações e o número de incidência dos métodos, técnicas e ferramentas ao longo da RS.

Como os resultados desta RS, foram identificadas as práticas existentes na literatura referente às estratégias de fim de vida e derivadas dessas, as práticas operacionais, visando 
auxiliar as áreas de gestão ambiental, e, principalmente, a área de desenvolvimento de produtos para que sejam integradas as práticas operacionais nos projetos de novos produtos e, consequentemente, alcançar uma melhor recuperação de produtos, componentes e materiais na etapa de pós-consumo.

Na segunda fase da revisão sistemática, denominada de Coleta de dados, são apresentadas as fontes de dados selecionadas para identificar os estudos, assim como, definidas as palavraschave ou strings de pesquisa. Para implementar as estratégias de busca para seleção de estudos primários, foram definidos critérios de seleção de fontes, sendo consultadas bases de dados de caráter internacional. Geralmente os trabalhos são publicados nestas bases de dados, pois apresentam maior fator de impacto. A lista das fontes com uma breve explicação é apresentada no Apêndice D. As bases de dados consultadas são:

$\begin{array}{llll}- & \text { Compendex; } & - & \text { Scholar Google; } \\ \text { - } & \text { Emerald; } & - & \text { Scopus; } \\ - & \text { IEEE Explore; } & - & \text { Springer Link; } \\ -\quad & \text { Find articles; } & - & \text { Web of science; } \\ -\quad & \text { Science Direct; } & - & \text { Wiley Insterscence. }\end{array}$

Os parâmetros estabelecidos para executar a revisão sistemática foram os seguintes:

- Idioma: foram selecionadas pesquisas públicas no idioma inglês por ser este o mais aceito internacionalmente para a redação e a apresentação de estudos científicos. No entanto, bases de dados em outras línguas também foram revisadas, visando a inclusão de estudos relevantes para a RS.

- Palavras-chave: para o revisão sistemática foram definidas as seguintes palavraschave ou termos: remanufacturing, remanufature, remanufactured, remanufaturable, demanufacturing, retread, rebuild, recharged, remoulded, rewound, overhaul, reconstrution, cannibalization, refurbishment, reuse, recycling, recyclability, repair, recovery, retrofitting, disassembly, end-of-life, end of life, closed, loop, EoL, design, strategies, green, engineering, process, products, product, strategy, strategies, scenarios, use, options.

- $\quad$ Strings de Pesquisa: são as expressões lógicas que combinam as palavras-chave com seus sinônimos, sendo um mecanismo para reunir um maior número de estudos relevantes para a pesquisa. O Quadro 6 apresenta os strings de pesquisa utilizados na 
revisão sistemática.

\begin{tabular}{|c|c|}
\hline \multicolumn{2}{|c|}{ Strings de Pesquisa } \\
\hline Remanufacturing; & Refurbishment; \\
\hline Design for remanufacturing; & Reuse; \\
\hline Design-for-remanufacturing; & Recycling; \\
\hline Remanufacturing strategies; & Design for Recycling; \\
\hline Green remanufacturing; & Recyclability \\
\hline Remanufacturing engineering; & Design for recycllability; \\
\hline Remanufature; & Repair; \\
\hline Remanufature process & Recovery; \\
\hline Remanufactured products; & Product recovery; \\
\hline Remanufaturable & Recovery strategies; \\
\hline Demanufacturing; & Disassembly; \\
\hline Design for demanufacturing; & Design for disassembly; \\
\hline Retread; & End-of life-product; \\
\hline Rebuild; & End-of-use \\
\hline Recharged; & End-of life products ; \\
\hline Remoulded; & Design for end of life; \\
\hline Rewound; & Closed the loop; \\
\hline Overhaul; & EoL; \\
\hline Reconstrution; & EoL scenarios. \\
\hline Cannibalization; & End of life strategies \\
\hline Retrofitting & \\
\hline
\end{tabular}

Após terminar o protocolo de revisão foi feita uma consulta a especialistas de modo de garantir e constatar que a seleção das palavras chave e dos strings de pesquisa estava adequada para atingir o objetivo traçado para a RS. As palavras chave e os strings de pesquisa acrescentados pelos especialistas foram incluídos no protocolo. Os especialistas que auxiliaram essa verificação deste protocolo fazem parte do projeto intitulado de “Remanufacturing Oriented Production Equipment Development”, no qual participam a Universidade Federal de Santa Catarina (UFSC) e a Universidade Técnica de Berlim (TUB), financiado pela Coordenação de Aperfeiçoamento de Pessoal de Nível Superior (CAPES) e a Fundação para Pesquisa de Alemanha (DFG).

A terceira fase da revisão sistemática é a avaliação dos dados coletados. Os principais critérios e procedimentos utilizados para selecionar / avaliar os estudos a partir da leitura do resumo foram:

- Critérios de Inclusão: foram selecionados trabalhos que descrevem a utilização das 
práticas. Estudos de aplicação, estudos de caso reais nas empresas, desenvolvimento de metodologias, tanto qualitativos, como quantitativos

- Critérios de Exclusão: foram excluídos aqueles estudos teóricos que não apresentavam nenhum uso de práticas,

Unificação: o cadastro dos estudos foi realizado no software Mendeley, sistema utilizado para gerenciar bancos de dados bibliográficos, reconhecido internacionalmente, auxiliando na consolidação de informações em único banco de dados. Possui uma interface com os editores de texto da Microsoft. As informações também são padronizadas com a ajuda da ferramenta Excel.

A quarta fase de análise e interpretação dos dados da revisão sistemática foi realizada com base nos critérios pré-estabelecidos pela pesquisadora e compreensão dos objetivos e interesses definidos no processo de RS. Para a elaboração desta atividade foram considerados alguns dos critérios de classificação das técnicas, métodos e ferramentas ( tipo de ferramenta utilizado pela prática e grau de detalhamento da prática) propostos no trabalho realizado por Pigosso (2008). É uma pesquisa que sistematiza métodos e ferramentas de ecodesign e sua integração ao processo de desenvolvimento de produtos, a partir de uma revisão sistemática. A finalidade é apresentar uma classificação geral de alguns critérios que sejam de auxílio no momento de selecionar práticas pelos designers para serem utilizadas no PDP.

Para facilitar a gestão de informações das práticas foi selecionado o programa Access, pela sua facilidade e funcionalidade e sua interface com editores de texto. O formulário elaborado para o cadastro das práticas é ilustrado na Figura 11.

A seguir, são discutidos brevemente os critérios utilizados para clasificar as práticas identificadas, alguns baseados no trabalho de Pigosso (2008):

- $\quad$ Nome prática: campo destinado para o nome da técnica, método ou ferramenta.

- Referência: campo destinado para relacionar a referência bibliográfica da prática.

- Resumo: campo utilizado para elaborar uma explicação breve, onde são ressaltados os objetivos, características, dados de entrada e os resultados esperados dessa prática.

- Procedimentos Técnicos utilizados: neste campo são classificadas as técnicas, métodos e ferramentas conforme os procedimentos técnicos utilizados e 
descritos pelos autores:

- checklist: procedimento de natureza qualitativa ou semi-quantitativa, utilizado para conferir a utilização ou não de parâmetros / critérios considerados durante a aplicação da prática;

- guideline: é de natureza qualitativa ou semi-quantitativa e é utilizado para definir diretrizes que podem ser utilizados para melhorar o desenvolvimento de produtos, assim como, introduzir aspectos relacionados com as dimensões ambiental, econômica e social;

- matriz: é o procedimento utilizado para estabelecer uma série de escalas que permitem avaliar de uma maneira especifica os parâmetros estabelecidos dentro da prática estudada;

- software: Utilizada para a aplicação computacional da prática, que geralmente compila uma grande quantidade de dados e apresenta funcionalidade e rapidez de uso por parte dos usuários; e

- outros sistemas associados: este campo aparece como questão aberta para especificar outros sistemas que podem ser utilizados junto com a prática utilizada.

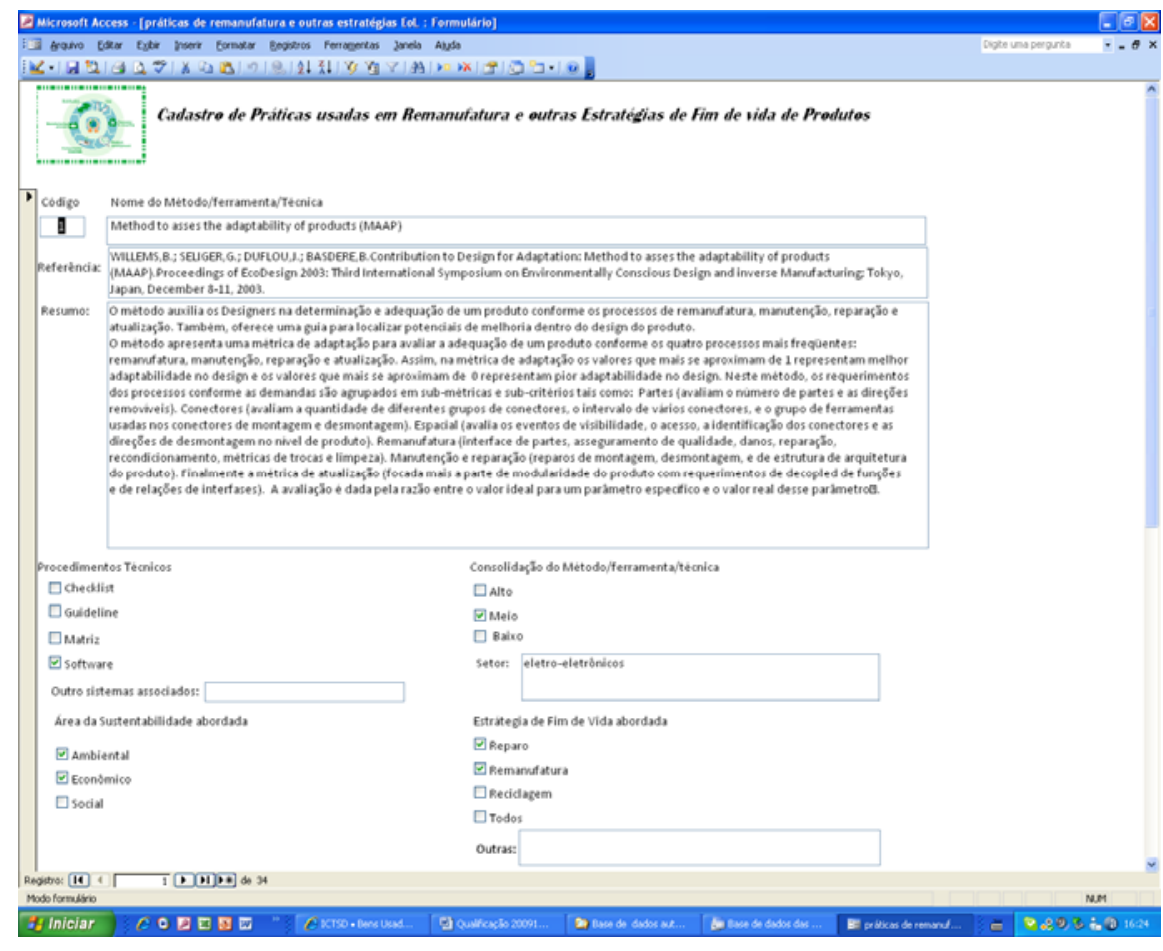

Figura 11 - Print Screen do Formulário de Cadastro das Técnicas, Métodos e Ferramentas no Programa Access 
- Consolidação da prática: é um campo que determina o grau de consolidação da prática, conforme as informações descritas no trabalho. Os níveis considerados são:

- baixo: apresenta apenas informações do desenvolvimento da prática, não apresenta um estudo de caso ilustrativo para validação;

- médio: a validação da prática foi realizada por meio de um estudo de caso real para constatar as contribuições teóricas da prática e destacadas no trabalho; e

- alto: a prática é normalmente utilizada nos diferentes processos das empresas.

- Setor: campo destinado para indicar em qual setor industrial a técnica, método ou ferramenta pode ser aplicada, conforme as próprias recomendações dos autores.

- Área da sustentabilidade abordada: neste campo é classificada a ténica, método ou ferramenta conforme a área / dimensão de sustentabilidade abordada. Os critérios considerados para a avaliação e classificação foram:

- ambiental: se refere à prática que destaca características e benefícios ambientais obtidos com sua aplicação (ex. diminuição de resíduos. uso no consumo de energia etc.);

- econômico: se refere à prática que destaca características e benefícios econômicos obtidos com sua aplicação (ex. redução de custos, redução de materiais etc.); e

- $\quad$ social: se refere à prática que destaca características e benefícios sociais obtidos com sua aplicação (ex. geração de emprego etc.).

- $\quad$ Estratégias de fim de vida abordada: é um campo utilizado para determinar as estratégias de fim de vida abordadas pelas práticas. As opções disponíveis são: reparo, remanufatura, reciclagem, todas ou outras: campo aberto para relacionar outras estratégias de fim de vida como reuso, recondicionamento, canibalização, outros (disposição final em aterro sanitário etc.).

- Informações relevantes: campo aberto para relacionar as informações referentes às práticas de EoL e que podem ser utilizadas no processo de desenvolvimento de produtos.

- $\quad$ Limitações do estudo: este campo é aberto para relacionar as possíveis limitações da 
prática e mencionadas pelos próprios autores do trabalho.

- $\quad$ Link do estudo: campo para relacionar o arquivo do estudo que descreve a prática.

- Outros estudos relacionados: é um campo utilizado para relacionar outros arquivos dos estudos que mencionam a prática analisada.

A quinta fase da revisão bibliográfica é a elaboração das conclusões e interpretação da RS. O uso de gráficos auxilia na discussão dos principais resultados alcançados referentes às publicações e às práticas obtidas. Além disso, se apresentam a lista das práticas operacionais identificadas dentro dessas práticas que podem auxiliar ao PDP a integrar a visão de recuperação de produtos no pós-consumo. Resultados proporcionados no capítulo 4 deste texto.

\subsubsection{Práticas Operacionais}

Durante a Revisão Sistemática realizada pela pesquisadora foram identificadas 87 práticas que são relacionadas com as estratégias de fim de vida (EoL). A partir desse conjunto foram definidas 64 práticas operacionais. É um trabalho realizado a partir da análise do objetivo geral e das guias destacadas em cada uma das práticas das EoL.

Com o desenvolvimento do trabalho foi observado que existia uma semelhança semântica entre algumas práticas operacionais, situação que obrigou a definir um agrupamento destas para evitar a repetição na proposta investigada. Os resultados das práticas operacionais são apresentados no item 4.3.

É destacado que o agrupamento das palavras foi fundamentado na construção de um tesauro. Conforme Cervantes (2009) e De Jesus (2002), o tesauro é uma forma de linguagem documentária com termos organizados semanticamente e logicamente, que ao lado de recursos terminológicos é um instrumento de apoio às pesquisas científicas nas áreas de conhecimento.

\subsubsection{Etapa 3 - Múltiplos estudos de caso}

Após a identificação das 64 práticas operacionais, se verificou a aplicação em empresas que integram a recuperação pós-consumo dentro de seus processos de negócios. Para realizar esse trabalho científico de campo, se adotou o estudo de caso. Método científico 
considerado por Yin (2005) como um estudo que investiga um (s) fenômeno (s) contemporâneo (s) dentro de seu contexto de vida real, especialmente quando os limites entre o fenômeno e o contexto não são claramente entendidos. Conforme Gil (2007), o estudo de caso pode ter diferentes propósitos:

a. Explorar situações de vida real cujos limites não estão claramente definidos;

b. Preservar o caráter unitário do objeto estudado;

c. Descrever a situação do contexto em que está sendo feita determinada investigação;

d. Explicar variáveis causais de determinado fenômeno em situações muito complexas que não possibilitam a utilização de levantamentos e experimentos.

Yin (2005) acrescenta que dentro das diversas estratégias de pesquisa, os estudos de caso são apropriados quando existem perguntas relacionadas ao "como" e "porque", especialmente quando a questão é construída sobre uma serie de acontecimentos onde o pesquisador tem pouco o nenhum controle.

Um estudo pode conter mais de um caso único, ou seja, múltilplos estudos de caso (YIN, 2005). Uma das principais vantagens que pode ser destacada é que os resultados alcançados com o uso de múltiplos estudos de caso são considerados mais convincentes, e o estudo global é visto, por conseguinte, como algo mais robusto.

Neste contexto, optou-se pela utlização de multiplos estudos de caso para verificar a aplicação das práticas operacionais. O Quadro 7 foi elaborado a partir dos trabalhos de Rossi (2009) e Barquet (2010), e apresenta a consolidação dos dados do estudo de caso, quanto a seleção de casos, as observações adicionais das empresas, o setor estudado, a forma de coletar os dados, os instrumentos de apoio, as empresas analisadas, a unidade geográfica estudada e período de coleta de dados.

Optou-se por analisar as práticas operacionais em empresas de remanufatura, pois como visto no capítulo 2 da revisão bibliográfica esta estratégia visa uma maior recuperação de produtos e componentes. Além disso, é uma estratégia que pode usar em alguns casos outras estratégias como, por exemplo, o reuso dentro de seus componentes, sem comprometer a qualidade final do produto, como é o caso dos parafusos que podem ser usados até duas vezes em impressoras (SHU; FLOWERS, 1995). O detalhamento dos estudos de caso será realizado no capítulo 4.

Para analisar os resultados dos estudos de caso adotou-se a síntese de casos cruzados, pois conforme Yin (2005) este tipo de técnica é adequada quando se apresenta mais de um estudo de caso, onde podem ser analisadas e comparadas informações de diversas fontes. Os 
resultados dessas análises permitem constatações mais precisas. Segundo o mesmo autor, neste tipo de análise é comum o uso de tabelas e quadros que permitam comparar os resultados dos estudos de caso realizados.

\begin{tabular}{|c|c|}
\hline Finalidade & Exploratório \\
\hline \multirow[t]{2}{*}{ Seleção dos Casos } & $\begin{array}{l}\text { A seleção das empresas foi feita através de um } \\
\text { levantamento exploratório. Auxiliado pelo trabalho } \\
\text { desenvolvido por Zanetti (2008) e por uma pesquisa } \\
\text { realizada em março de 2009, com participação ativa da } \\
\text { pesquisadora, a modo de auxiliar a realização de um } \\
\text { Workshop sobre Cenários de Remanufatura no Brasil em } \\
\text { 2020, efetuado no Instituto de Pesquisas Tecnológicas } \\
\text { (IPT), em São Paulo, em maio de } 2010 \text {. }\end{array}$ \\
\hline & $\begin{array}{l}\text { Os critérios utilizados para selecionar as empresas foram } \\
\text { baseados na disponibilidade das mesmas de participar na } \\
\text { pesquisa, a integração de recuperação de produtos pós- } \\
\text { consumo em seus processos e a disponibilidade para visitar } \\
\text { as empresas a fim de observar o processo. }\end{array}$ \\
\hline Observações Adicionais das Empresas & $\begin{array}{l}\text { Foram escolhidas quatro (4) empresas que fazem parte da } \\
\text { Associação Nacional dos Remanufaturadores de Autopeças } \\
\text { (ANRAP) e Empresas de excelência na recuperação de } \\
\text { produtos. O Protocolo-Carta de apresentação representado } \\
\text { no Apêndice A. }\end{array}$ \\
\hline Setor Industrial & Autopeças-automotivas. \\
\hline Forma de Coleta de Dados & $\begin{array}{l}\text { Entrevista semi-estruturada visita a sites, visita a empresas, } \\
\text { informações disponibilizadas pelas empresas e observação. }\end{array}$ \\
\hline Instrumento de Apoio & Roteiro semi-estruturado. Apresentado no Apêndice C. \\
\hline Unidade Geográfica Estudada & Estado de São Paulo-Brasil \\
\hline Período de Realização dos Estudos de Caso & Março a Junho de 2010 \\
\hline
\end{tabular}

Quadro 7 - Consolidação de Dados dos Estudos de Caso

\subsubsection{Etapa 4 - Resultados e Conclusões}

Os resultados da pesquisa são divididos em dois grupos. No capítulo 4, são apresentados os resultados da Revisão Bibliográfica Sistemática (RS), tanto da parte de unificação dos estudos obtidos (país de publicação, ano etc.) como dos resultados específicos das práticas (procedimentos, consolidação, EoL abordada etc.). Já no capítulo 5, são apresentados os resultados dos múltiplos estudos de caso que foram realizados para verificar a aplicação das 64 práticas operacionais nas empresas que integram a recuperação de produtos na etapa de pós-consumo. A partir dessas informações, são apresentadas no capítulo 6 as principais conclusões da pesquisa, as limitações e as contribuições para trabalhos futuros. 


\section{RESULTADOS DA REVISÃO BIBLIOGRÁFICA SISTEMÁTICA (RS)}

Este capítulo descreve os resultados alcançados com a revisão bibliográfica sistemática (RS). O capítulo é divido em duas sessões. Na primeira sessão são apresentados os resultados referentes à unificação dos estudos obtidos durante a RS, assim como os resultados específicos das práticas das estratégias de fim de vida. A segunda sessão apresenta os resultados das práticas operacionais identificadas dentro das práticas.

\subsection{Resultados da Revisão Sistemática}

Com a revisão bibliográfica sistemática (RS) obtiveram-se, entre artigos, teses e outros tipos de publicações (relatórios técnicos, relatos etc.), mais de 900 trabalhos. No entanto, como forma de garantir resultados mais focados à RS, aplicou-se um filtro, por meio do título do trabalho consultado, ou seja, foram descartados aqueles documentos que, mesmo apresentando palavras chaves ou strings de pesquisa, não eram focados à área de interesse. No final, foram utilizados 382 trabalhos. A RS foi realizada no período de abril a setembro de 2009. Inicialmente foi feita uma leitura inicial do resumo para avaliar sua inclusão ou exclusão. Além disso, foi realizada uma verificação dos artigos excluídos a fim de garantir que estudos relevantes não fossem desconsiderados.

O Apêndice E apresenta o cadastramento dos estudos obtidos na revisão sistemática. As informações utilizadas para o cadastramentos desses estudos são:

- $\quad$ Número: valor numérico utilizado para identificar o estudo;

- $\quad$ Título: campo relacionado ao título do trabalho;

- $\quad$ Palavras-chave: informações relacionadas às palavras-chave presentes no estudo;

- $\quad$ País de Origem: campo para destacar o país de origem do trabalho;

- $\quad$ Ano de Publicação: campo para destacar o ano de publicação do estudo;

- $\quad$ Tipo: item utilizado para classificar o trabalho (artigo, tese, publicação etc.); e

- $\quad$ Fonte: campo que é utilizado para indicar o nome da fonte de publicação.

Os 382 trabalhos identificados possibilitaram o cadastro de 87 práticas das estratégias de fim de vida, sendo que, em muitos casos, em um mesmo estudo se apresentavam várias práticas. Outro fator a ser considerado é a repetição de algumas ao longo da RS. O Apêndice F deste texto apresenta um resumo, com as características principais de cada prática e as referências correspondentes. 
A Figura 12 apresenta a distribuição dos estudos obtidos conforme seu tipo. Os resultados apontam que, dos 382 trabalhos reunidos a partir da revisão sistemática, 98\% são artigos, e apenas $2 \%$ correspondem a outro tipo de estudo (relatórios e teses). Uma característica identificada na revisão sistemática é o grande número de pesquisadores de diferentes universidades que participaram da elaboração das pesquisas. No entanto, destaca-se que muitos desses artigos têm sua origem em trabalhos de mestrado ou doutorado, como por exemplo, End-of-life Advisor (ELDA), resultado de uma tese de doutorado, onde os resultados foram publicados de forma parcial conforme o avanço da pesquisa.

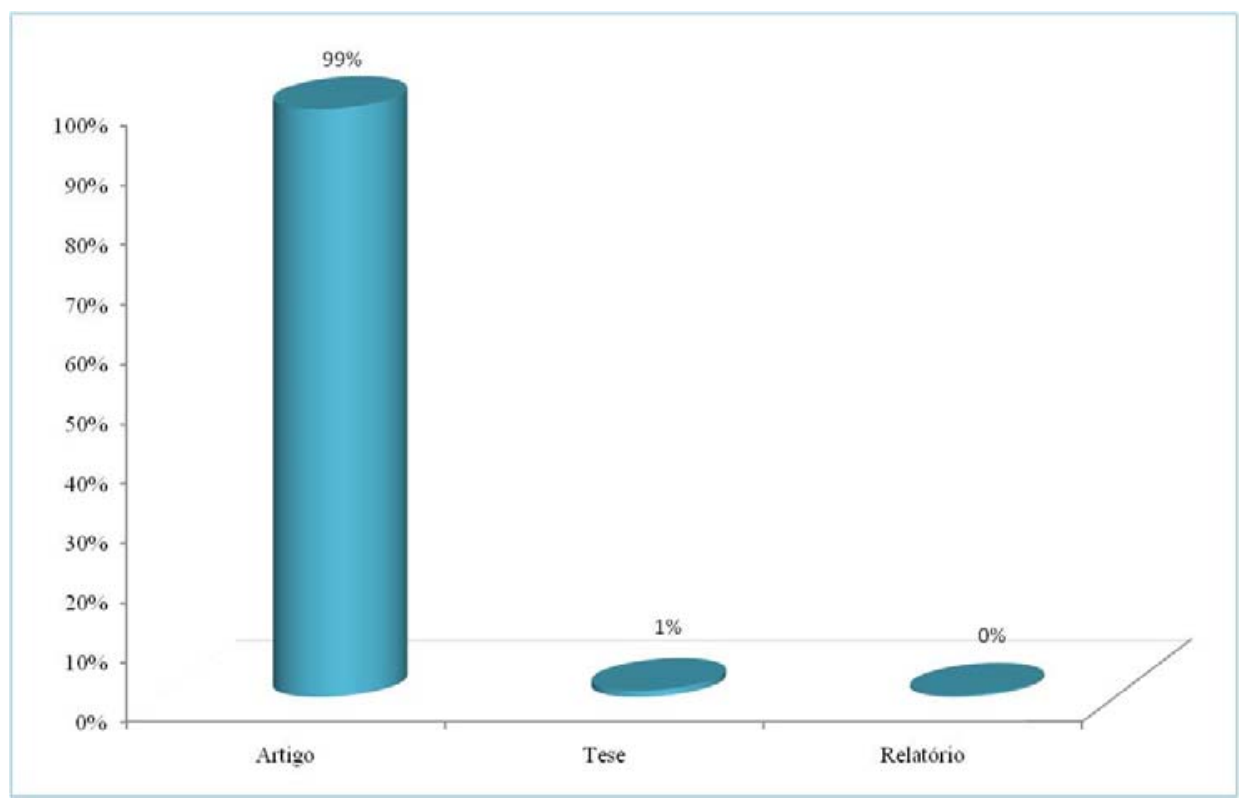

Figura 12 - Distribuição por Tipo de Estudo

Uma justificativa associada a essa concentração de estudo é o fator de impacto de uma publicação desse tipo no meio científico e empresarial. Além disso, existe um grande número de fontes que podem ser utilizadas para divulgar os resultados alcançados pelos pesquisadores.

As publicações aparecem em periódicos de alto fator de impacto como: Journal Cleaner Production, European Journal of Operational Research, Resources, Conservation and Recycling entre outros, os quais são considerados foros de comunicação internacional interdisciplinar, que permite o intercâmbio de informações de pesquisas científicas que visam o desenvolvimento da sociedade de uma forma mais sustentável. Além disso, muitas das publicações são apresentadas em congressos internacionais de alto reconhecimento, tais como, os congressos realizados pela Academia Internacional de Engenharia de Produção 
(College International pour la Recherche en Productique - CIRP).

A Figura 13 descreve a distribuição do número de estudos publicados por ano. Pode-se observar que entre os anos de 1980 a 1990 os estudos focados às estratégias de fim de vida não estavam presentes dentro das publicações científicas. Uma justificativa importante pode ser o fato de essa época mostrar uma postura reativa por parte das empresas frente aos impactos ambientais, ou seja, as ações eram feitas só no final da linha - uma abordagem conhecida como fim-de-tubo ou end-of-pipe. Como conseqüência, os estudos eram mais focados a tratamentos de efluentes e emissões no final do processo.

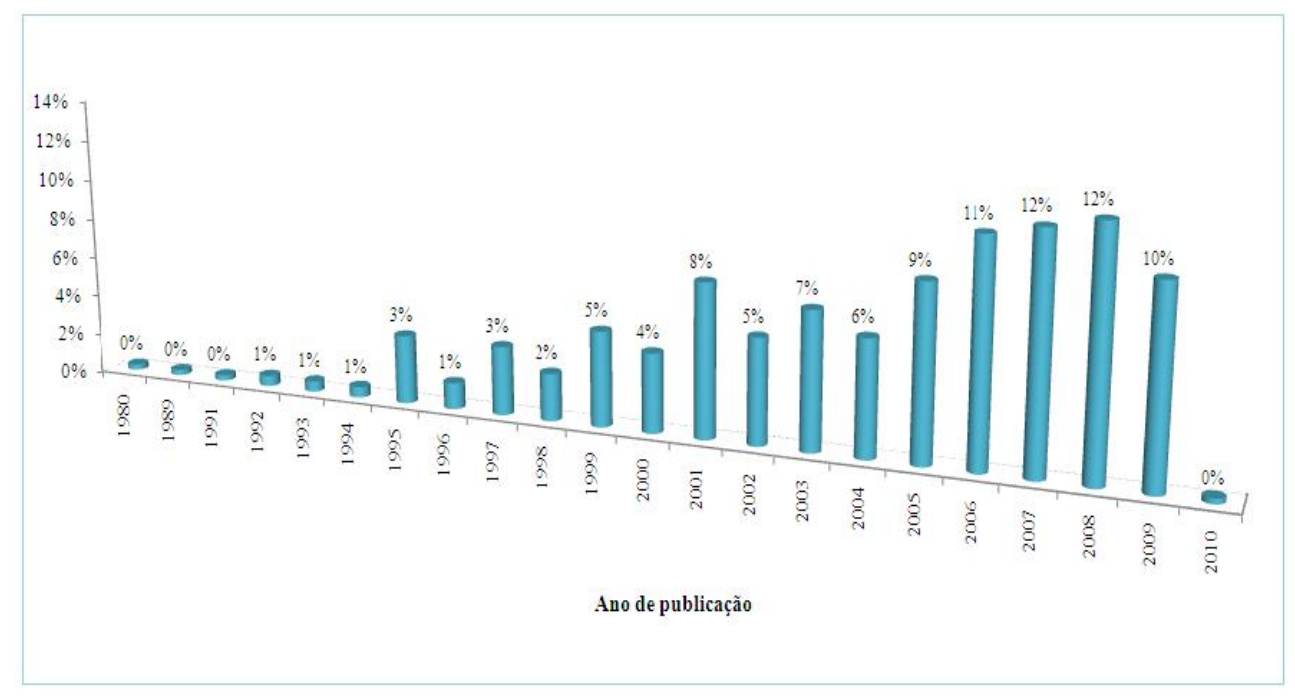

Figura 13 - Distribuição das Publicações por Ano

Desde 1995 os estudos foram aumentando gradualmente, pois a postura reativa das empresas começou a mudar para uma postura preventiva, com foco em métodos de prevenção à poluição e produção mais limpa, a fim de diminuir os resíduos sólidos, melhorar os processos produtivos e diminuir os custos por disposição final dos produtos.

Nos últimos cinco anos (2005-2010) ocorreu um crescimento significativo das publicações de pesquisas focadas nas estratégias de fim de vida de produtos. Nesse período foram publicados mais de 54\% dos artigos identificados com a revisão sistemática.

Os resultados podem ser associados com a preocupação mundial em encontrar soluções / estratégias que reduzam os impactos ambientais e que visem ações mais pró-ativas. As empresas, o governo e as universidades são os principais atores responsáveis e que vem trabalhando e desenvolvendo políticas, programas e projetos para financiar pesquisas ou estudos relacionados às questões ambientais, industriais e sociais, especificamente, pesquisas que foquem o desenvolvimento de produtos mais sustentáveis e de estratégias que visem a 
maior recuperação de produtos com seus componentes e materiais. Portanto, o crescimento dessas publicações pode ser considerado como um indicador dos resultados que vem sendo apresentados para a sociedade e para o governo pelas universidades, empresas e outros centros de investigação científica.

A Figura 14 destaca os países com maior número de publicações internacionais. Observa-se que os países mais desenvolvidos, Estados Unidos e Alemanha, aparecem como responsáveis pelo maior número de publicações referentes às estratégias de fim de vida. Especificamente, os Estados Unidos se destaca como uma dos principais países com o desenvolvimento de práticas das estratégias de fim de vida. Tal fato pode ser justificado pelo investimento desse país para o desenvolvimento de pesquisas voltadas à recuperação de produtos. Como exemplo pode ser mencionado os estudos realizados pela Universidade de Boston, referente à Remanufatura.

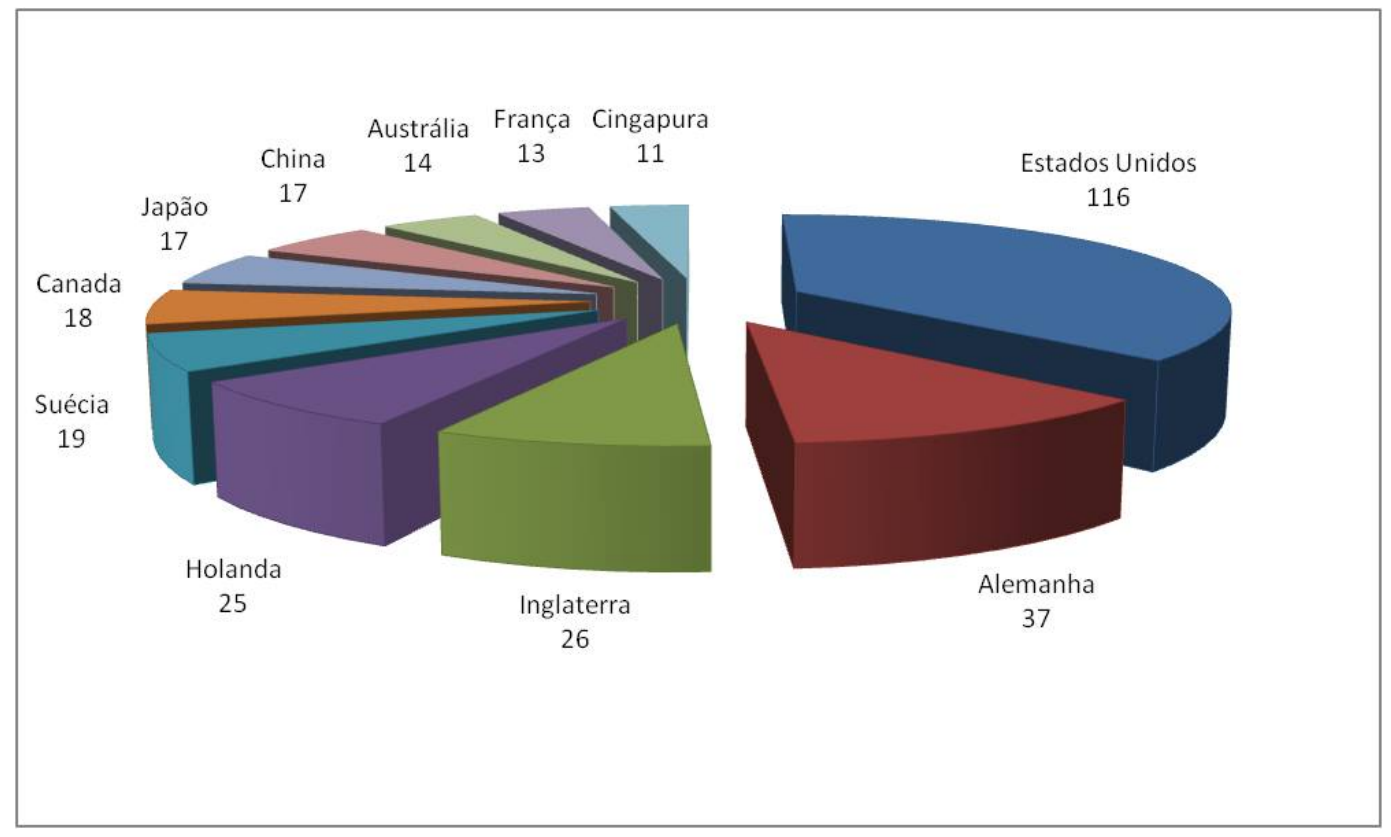

Figura 14 - Países com Maior Número de Publicações

A Figura 15 retrata o panorama para os países em desenvolvimento. Observa-se que países como Espanha, Grécia, Coréia e Turquia começam a ter uma maior participação nas pesquisas focadas a soluções ambientais mais pró-ativas. Entre os países em desenvolvimento, o Brasil é uma das nações com maior número de publicações internacionais na área. Observase que as publicações são resultados de trabalhos desenvolvidos em parceria com outras universidades internacionais. Certamente, a transferência de tecnologia / informações e o 
intercâmbio científico dos pesquisadores, ou grupo de pesquisadores, ajudam a criar soluções mais adequadas às características industriais (modelo de negócio) das empresas e processos de negócio (logística, produção, produto, gestão de negócios) desenvolvidos no país.

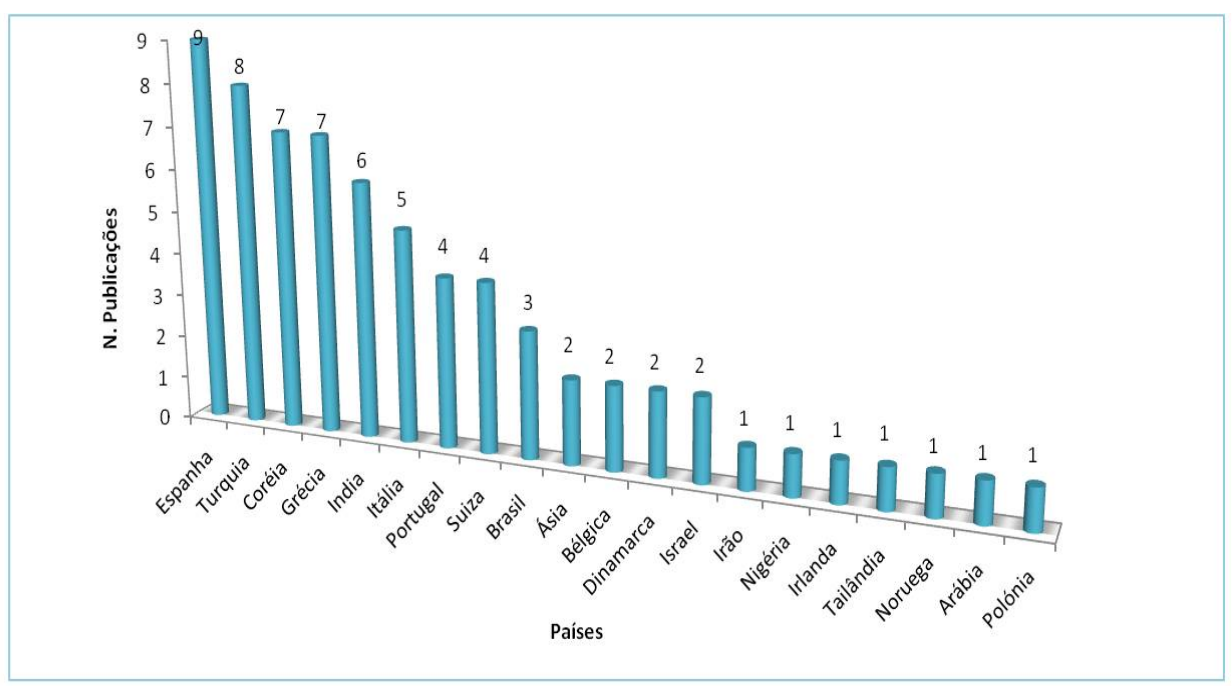

Figura 15- Países em Desenvolvimento em Pesquisas de EoL

\subsection{Resultados e análises das Práticas das Estratégias de Fim de Vida Identificadas na RS}

\subsubsection{Critérios de classificação das técnicas, métodos e ferramentas das estratégias de fim de vida-EoL}

Os critérios para classificar as técnicas, métodos e ferramentas identificadas na RS foram explicados no item 3.3 deste trabalho, porém, considera-se importante resgatar estas informações para um melhor entendimento dos resultados analisados.

1. Procedimentos técnicos utilizados: é um critério utilizado para avaliar, na técnica, método ou ferramenta, o uso de procedimentos como: checklist (utilizado para conferir a utilização ou não de parâmetros na aplicação da técnica, método ou ferramenta), guideline (utilizado para definir diretrizes que podem ser utilizados para melhorar o desenvolvimento de produtos, assim como introduzir aspectos relacionados com as dimensões da sustentabilidade), matriz (procedimento utilizado para estabelecer uma série de escalas que permitem avaliar de uma maneira especifica os parâmetros estabelecidos dentro da técnica, método ou ferramenta), software (utilizada para a aplicação 
computacional da técnica, método ou ferramenta) e outros sistemas associados (questão aberta para especificar outros sistemas que podem ser utilizados junto com a técnica, método ou ferramenta).

2. Consolidação da prática: é um critério utilizado para determinar o grau de consolidação, conforme as informações descritas no trabalho. Os níveis considerados são: baixo (apresenta apenas informações sobre o desenvolvimento da técnica, método ou ferramenta, não apresentando um estudo de caso ilustrativo para validação), médio (a validação foi realizada por meio de um estudo de caso real, para constatar as contribuições teóricas da técnica, método ou ferramenta e destacadas no trabalho) e alto (a técnica, método ou ferramenta é normalmente utilizado nos diferentes processos das empresas).

3. Setor Industrial de aplicação da prática: É um campo destinado a indicar em qual setor industrial pode ser aplicada a técnica, método ou ferramenta estudada, conforme as próprias recomendações dos autores.

4. Área da sustentabilidade abordada: neste campo é classificada a técnica, método ou ferramenta conforme a área. Os critérios considerados para a avaliação e classificação foram: ambiental (destaca características e benefícios ambientais), econômico (destaca características e benefícios econômicos) e social (destaca características e benefícios sociais).

5. Estratégias de fim de vida abordada: é um campo utilizado para determinar as estratégias de fim de vida abordadas pelas técnicas, métodos e ferramentas. As opções disponíveis são: reparo, remanufatura, reciclagem, Todas ou outras: campo aberto para relacionar outras estratégias de fim de vida como reuso, recondicionamento, canibalização, outros (disposição final em aterro sanitário etc.).

\subsubsection{Análise das Práticas das Estratégias de Fim de Vida identificadas na RS}

No Apêndice $\mathrm{F}$ é destacado o resumo das práticas das estratégias de fim de vida identificadas na RS. Neste resumo apresentam-se os principais objetivos, características e dados de entrada necessários para sua aplicação, assim como outras informações relevantes. Além disso, neste quadro os estudos são referenciados.

A Figura 16 apresenta as incidências das práticas identificadas na revisão sistemática 
das estratégias de fim de vida de produtos. A análise comparativa dos dados demonstra que a prática Avaliação do Ciclo de Vida (ACV) ou Life Cycle Assessment (LCA) é a mais citada ao longo dos estudos. Esta prática é atualmente reconhecida e utilizada pelas empresas, pois visa identificar os impactos ambientais ao longo do ciclo de vida, desde a extração até o descarte final, propondo melhorias e auxiliando na tomada de decisão. Além disso, é uma prática já considerada em diversas leis como é o caso da Política Nacional de Resíduos Sólidos do Brasil, na qual o uso desta prática visa otimizar o ciclo de vida dos produtos.

Outra prática que apresenta maior citação é a End-of-life Advisor (ELDA). É resultado de um trabalho de doutorado e as publicações foram realizadas conforme o avanço da pesquisa. O objetivo desta prática é analisar as diferentes informações do produto para determinar estratégias de fim de vida, tais como reuso, serviço, remanufatura, reciclagem com desmontagem e sem desmontagem. Além disso, fortalece a tomada de decisão e apresenta opções para comparar soluções do produto estudado com outros estabelecidos na própria ferramenta.

Finalmente a prática RemPro Matrix que é resultado de um trabalho de doutorado, cujos resultados parciais também foram publicados ao longo do período de execução da pesquisa. A prática oferece ao usuário uma matriz de relação entre as diferentes etapas de remanufatura (por exemplo: desmontagem, limpeza, armazenamento, recondicionamento, remontagem, outros) e as propriedades do produto para que sejam remanufaturados (por exemplo: facilidade de verificação, facilidade de acesso, facilidade de separação entre outras). Também pode ser utilizada como uma ferramenta para introduzir características ou propriedades necessárias para que os produtos projetados sejam remanufaturados.

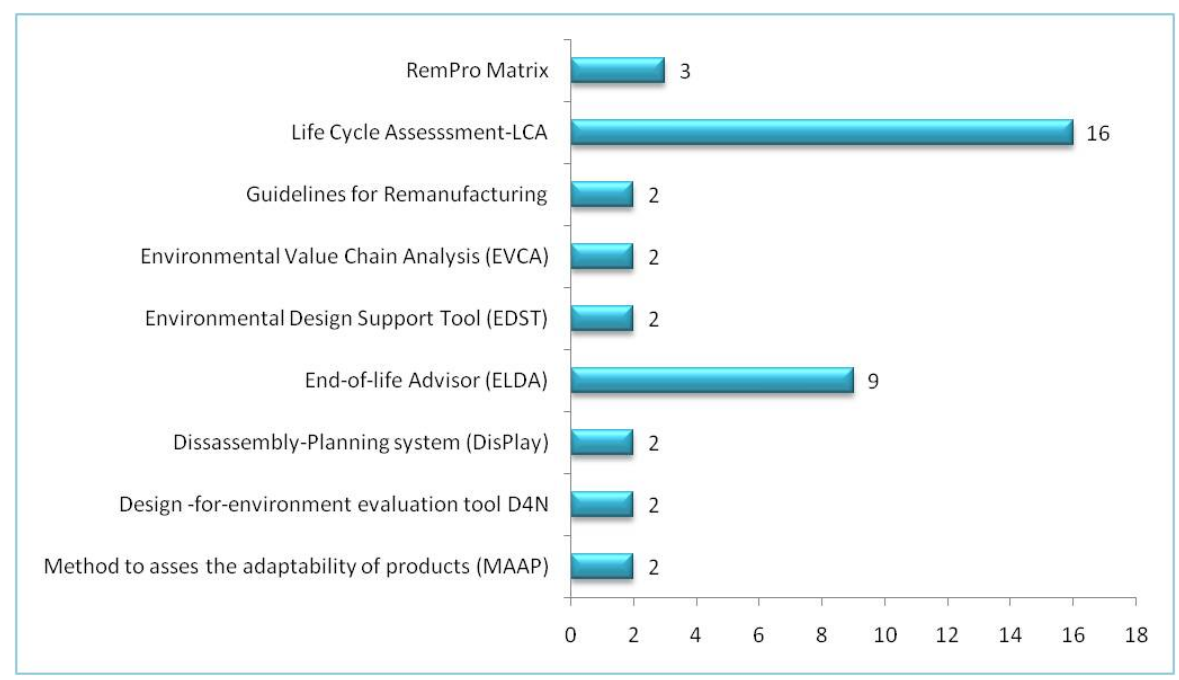

Figura 16 - Incidência de Práticas Identificadas na RS 
Outro critério utilizado na análise dos dados é referente aos procedimentos técnicos utilizados para a avaliação dentro das próprias práticas. Os resultados são destacados na Figura 17 e a análise individual é destacada no Apêndice G. Observa-se que o software é o procedimento mais utilizado para implantar as práticas. As principais justificativas são as vantagens de facilidade de uso (design, ferramentas e aplicativos para a interface usuário e hardware) no momento da aplicação e maior capacidade de armazenamento de dados, permitindo a análise comparativa dos resultados. Além disso, se observa que as ferramentas também oferecem uma integração com outros sistemas (Visual Basic e Microsoft Access) para avaliar, trocar e validar informações.

Foi observado também que em alguns casos, os autores propõem o uso múltiplo de práticas de análise dos produtos. A integração com outra ferramenta permite a consolidação das informações em uma mesma base de dados. Uma característica também é a troca de informações entre os usuários que participam de cada etapa de análise do produto. Um dos casos que pode ser observado é o sistema Recycling Engineering-Tool Kit (RecyKon) utilizada para analisar os requisitos de reciclagem e desmontagem do produto. Para completar a análise prática utiliza-se gráficos de reciclagem, fornecidos pelo módulo Recycling Grapheditor (ReGrEd) e importantes para a avaliação do desempenho do processo de reciclagem, pois durante a fase conceitual ainda não é possível avaliar a geometria do produto e isso pode dificultar a implantação do processo.

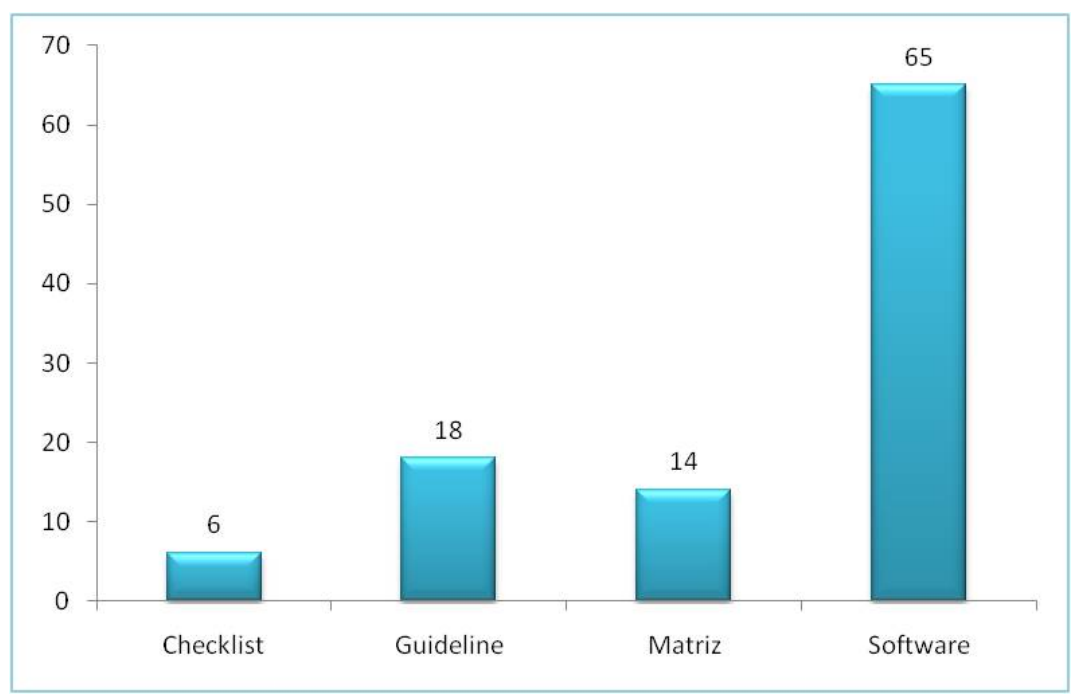

Figura 17 - Classificação dos Procedimentos Técnicos Utilizados nas Práticas

O nível/grau de consolidação da prática é observado na Figura 18. A consolidação é determinada a partir da apresentação de resultados práticos alcançados com a implantação da 
ferramenta e descritos no trabalho analisado. Os resultados demonstram que a maioria das práticas (42) podem ser consideradas de nível médio. Significa que a validação da prática foi realizada por meio de um estudo de caso e foram constatadas / descritas as contribuições das práticas. Já no caso do nível baixo aparece uma freqüência menor (38), o que significa que não existe uma validação real e as informações oferecidas apenas destacam caracteríticas de desenvolvimento da prática. Já o nível alto aparece com uma freqüência de (7) práticas, o que significa o reconhecimento a nível empresarial, de práticas como a Avaliação do Ciclo de Vida (ACV), que atualmente e usada para avaliação ambiental, econômica e social de processos e produtos. Detalhes sobre o nível de consolidação das práticas são destacados no Apêndice $H$.

Ao avaliar o nível de consolidação da prática também é possível determinar o setor industrial da aplicação. A análise demonstra que as práticas foram utilizadas em vários setores industriais. Entretanto, merecem destaque os setores do Eletro-eletrônico e Automobilístico. A presença de um marco legal que estabelece a recuperação de produtos com seus componentes e materiais, e a eliminação de substâncias tóxicas presentes nesses produtos (WEEE, RoHS e Fim de Vida dos Veículos), certamente incentiva o desenvolvimento de soluções inovadoras que reduzam os impactos ambientais e promovam o crescimento econômico das empresas. Os resultados são destacados no Apêndice H.

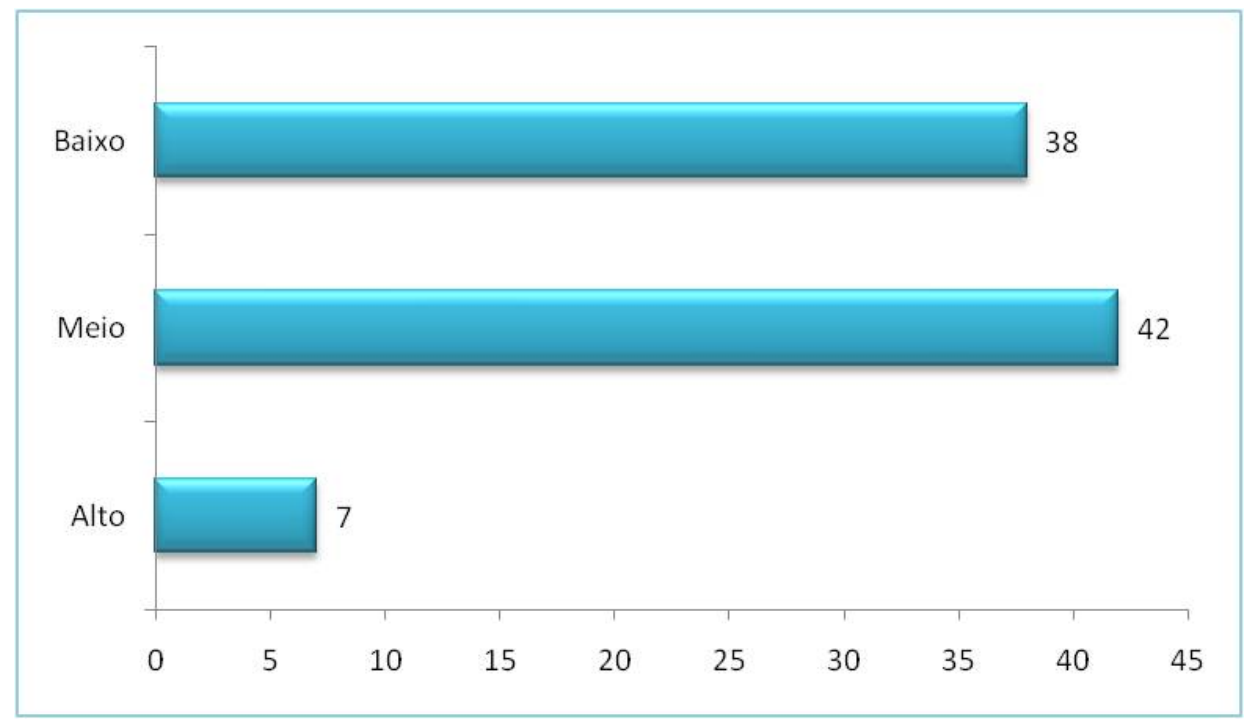

Figura 18 - Classificação conforme a Consolidação da Prática

Ao classificar a prática em relação ao tipo de estratégia de fim de vida abordada, duas estratégias ficaram destacadas: Reciclagem e Remanufatura, conforme pode ser observado na 
Figura 19. A classificação também indica que um conjunto de práticas são propostas para todas as estratégias de fim de vida dos produtos. Detalhes podem ser observados no Apêndice I. A Reciclagem e Remanufatura são destacadas porque as próprias características (benefícios destacados no Capítulo 2) dos processos de implantação permitem que seja alcançado nível maior de recuperação dos produtos, componentes e materiais. A Reciclagem recupera materiais, que podem ser integrados novamente ao processo para desenvolvimento de novos produtos. Do mesmo modo, a Remanufatura recupera os produtos, conservando sua geometria, seu valor inicial, estendendo o ciclo de vida e, conseqüentemente, alcançando um melhor fechamento do ciclo.

Assim, ressalta-se que práticas que abordam todas as estratégias de fim de vida estão sendo mais utilizadas, pois com a integração das diversas estratégias pode-se recuperar maior quantidade de componentes. No caso da remanufatura, os componentes que não podem ser recuperados são enviados para reaproveitamento por meio de outras estratégias de fim de vida, como reuso, reparo, reciclagem. Os dados são apresentados no Apêndice I. Além disso, a desmontagem se apresenta como foco de preocupação no desenvolvimento de práticas que visam diminuir os tempos de desmontagem, pois é considerada, conforme a literatura, como a etapa que consome mais tempo de realização e a etapa que representa maior recuperação de componentes.

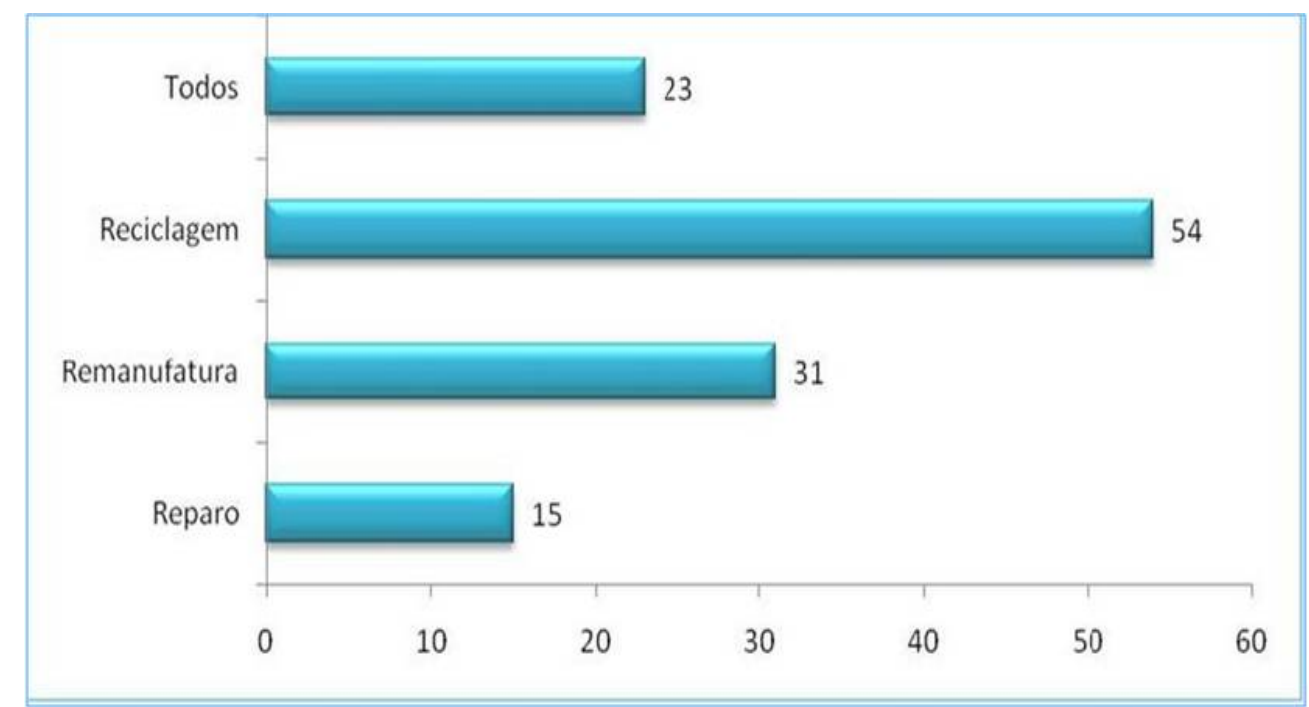

Figura 19 - Classificação Conforme a Estratégia de Fim de Vida Aplicada 
A Figura 20 apresenta a área de sustentabilidade abordada pela prática. Das três dimensões consideradas no conceito a área ambiental e econômica são as mais favorecidas com a aplicação das práticas nas estratégias de fim de vida do produto. No Apêndice J são destacadas as informações desta classificação. Uma justificativa pode ser relacionada com a necessidade que as empresas têm de alcançar resultados imediatos nas questões ambientais e porque o crescimento econômico da empresa é o principal pilar para dar suporte às outras áreas. As soluções ambientais que levam a melhorar o desempenho dos produtos e processos industriais são fundamentais para alcançar novas oportunidades de negócio e, conseqüentemente, conseguir resultados econômicos.

Apenas uma prática apresentou diretamente uma opção / solução que leve em conta benefícios para a área social, no entanto, algumas práticas apresentam recomendações referente à segurança com manuseio dos materiais tóxicos presentes no produto, o que suscita uma avaliação social indireta, neste caso, de trabalhadores e usuários expostos ao produto. Deduz-se, portanto que ainda é uma área pouco explorada pelas pesquisas. O desenvolvimento social ainda contínua carente de soluções tecnológicas integradas.

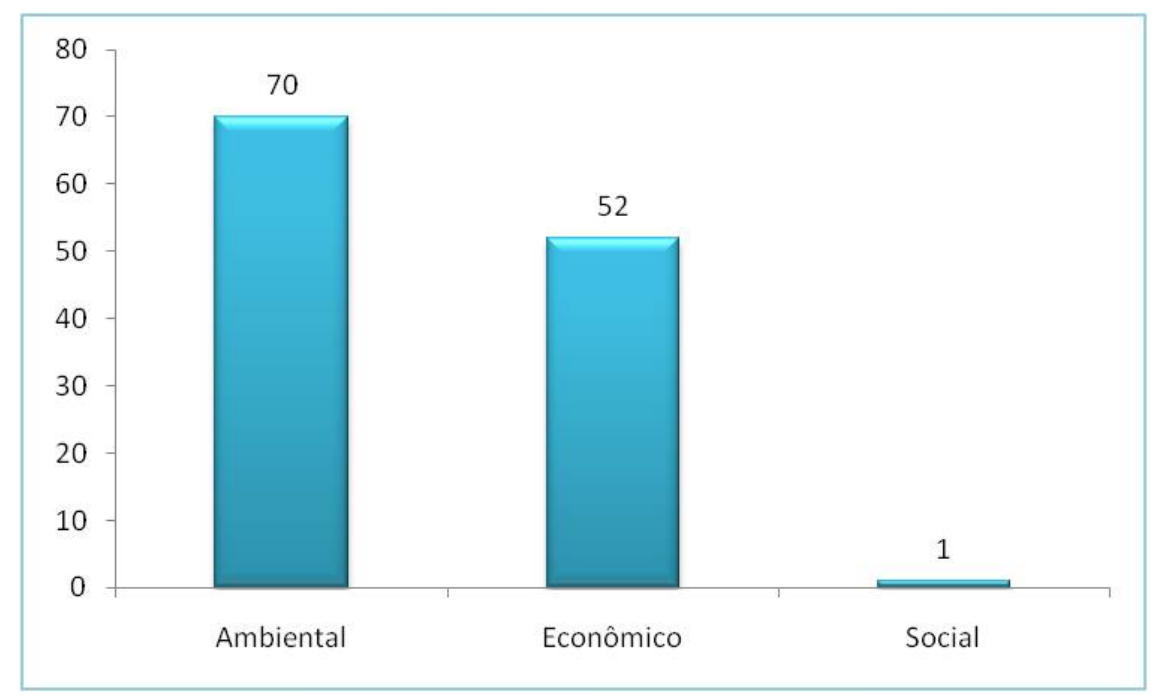

Figura 20 - Classificação da Área da Sustentabilidade Abordada pela Prática

\subsection{Resultados das Práticas Operacionais}

O Quadro 8 apresenta a lista final das 64 práticas operacionais identificadas. De forma a facilitar sua compreensão, foram adotadas quatro atividades principais, sendo elas: desmontagem e remontagem, limpeza, recuperação e impactos ambientais. As práticas foram 
classificadas em gerais (em negrito) e em específicas. As primeiras fazem referência a especificações gerais que devem ser consideradas dentro do PDP (ex. projetar a desmontagem dos produtos) e as segundas fazem referência a especificações mais detalhadas a modo de auxiliar às gerais ( ex. minimizar o número de componentes dentro do produto).

Observa-se que as práticas operacionais decorrem de mais de uma prática, o que deriva de uma consolidação teórica baseada em estudos reais que validam tais práticas. No entanto, destacam-se as práticas operacionais 1.6 "Evitar o uso de metais dentro das partes plásticas para diminuir a quebra dos componentes” e 1.5 "Identificar os componentes e materiais recuperáveis do produto” por apresentarem maior citação ao longo dos estudos analisados. 


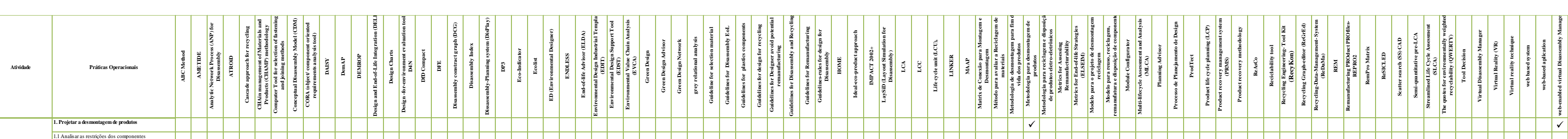

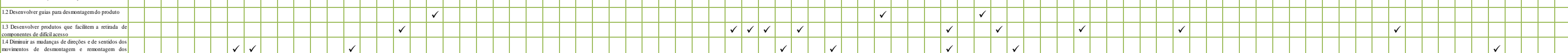

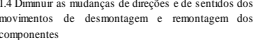

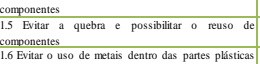

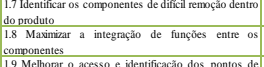

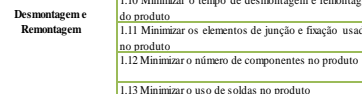

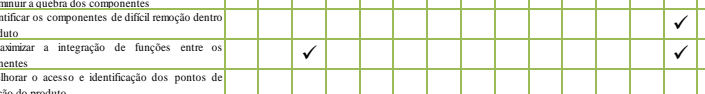

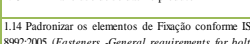

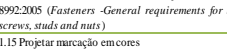

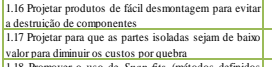

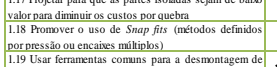

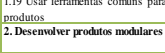

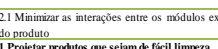

twas

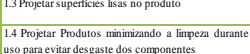

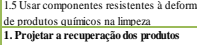

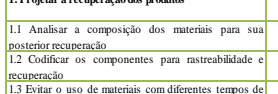

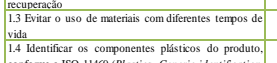

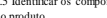

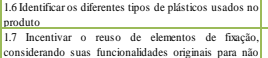

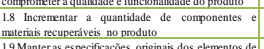

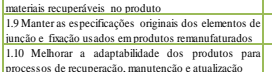

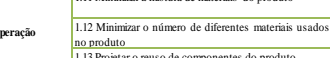

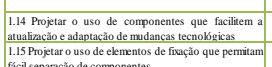

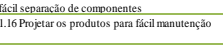

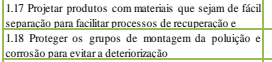

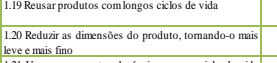

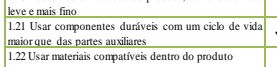

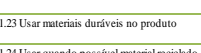

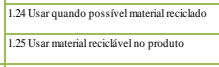

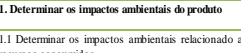

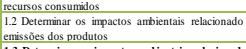

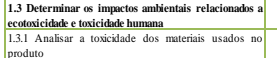

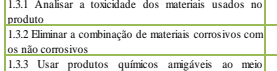

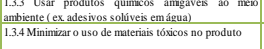

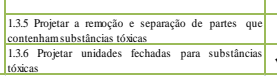




\section{$5 \quad$ MÚLTIPLOS ESTUdOS DE CASO}

Este capítulo apresenta os resultados e a análise da aplicação das práticas operacionais nas empresas. São destacados os resultados obtidos com os quatro (4) estudos de caso realizados com empresas que fabricam produtos e integram a recuperação na etapa de pósconsumo.

\subsection{Empresa A}

Neste item são apresentados os resultados do estudo de caso realizado na Empresa A. Inicialmente é caracterizada a empresa e o produto recuperado. Em seguida, são destacadas informações sobre a aplicação das práticas operacionais na empresa.

\subsubsection{Caracterização da Empresa A}

A Empresa A é uma multinacional alemã que começou suas operações no ano de 1953. Atualmente possui duas unidades de negócio que estão localizadas no interior de São Paulo e que comercializam câmbios, sistemas de direção e suspensão, consideradas como as maiores fabricantes de linha pesada do país. As principais atividades industriais da empresa são relacionadas com o revestimento, tratamento térmico, fabricação de mancais de embreagem e operações de remanufatura (embreagens com seus componentes platô, disco e mancal). Também é considerada como referência para bechmarking em remanufatura.

As operações de recuperação de produtos pós-consumo se iniciaram em 1991, considerada como uma atividade pioneira no Brasil. Primeiramente, o mercado foi focado em produtos da linha leve. No entanto, por fins lucrativos, a empresa decidiu, a partir de 1995, remanufaturar embreagens (platô, disco e rolamentos) de linha pesada voltados ao mercado de frotistas (ônibus, caminhão e equipamentos de usina). Tais produtos remanufaturados apresentam preços 50\% mais baratos quando comparado com um produto novo. Os principais motivos que levaram a empresa a integrar a recuperação de produtos pós-consumo foram:

- Concorrência: os produtos descartados eram usados por empresas independentes que ofereciam um produto de menor qualidade com o logo da empresa, o que levava a uma desconfiança dos clientes por causa da baixa qualidade do produto;

- Novas oportunidades de mercado: por ser um produto mais barato e com 
características e qualidade de um novo. Dos lucros da empresa, 55 \% correspondem à parte de After market, sendo que, dessas atividades, a remanufatura aporta $30 \%$ dos lucros;

- $\quad$ Preocupação ambiental: diminuir o uso de recursos foi um dos grandes incentivos da empresa para integrar a recuperação de produtos pós-consumo (uso de ferro).

O Quadro 9 destaca informações gerais sobre o perfil da empresa e dos colaboradores entrevistado.

\begin{tabular}{|c|c|}
\hline Nome da Empresa & Empresa A \\
\hline $\begin{array}{l}\text { Número de funcionários no processo de recuperação } \\
\text { de produtos (remanufatura) }\end{array}$ & 180 funcionários \\
\hline Cargo do Professional (entrevistado) & Gerente Comercial \\
\hline Número de pessoas que auxiliaram na pesquisa & 1 \\
\hline Tempo de experiência & 40 anos \\
\hline Duração da entrevista & 8 horas (incluindo a visita ao processo) \\
\hline Fonte de evidências & $\begin{array}{l}\text { Roteiro, informações disponibilizadas pela empresa e } \\
\text { observação direta do processo. }\end{array}$ \\
\hline \multirow[t]{3}{*}{ Outras observações } & A empresa forma parte da ANRAP. \\
\hline & $\begin{array}{l}\text { O entrevistado iniciou o processo de remanufatura na } \\
\text { empresa. }\end{array}$ \\
\hline & $\begin{array}{l}\text { A empresa é reconhecida como referência em } \\
\text { benchmarking de remanufatura. }\end{array}$ \\
\hline
\end{tabular}

\subsubsection{Caracterização do Produto Recuperado}

As etapas que compõem o processo de recuperação são: inspeção, armazenagem, desmontagem, triagem e limpeza. Testes são realizados ao longo do processo com o objetivo de garantir a qualidade e a garantia do produto.

Os produtos recuperados no pós-consumo são: as embreagens e seus componentes (platô, mancal e disco). Para garantir o estoque de matéria prima (carcaça) durante o processo de remanufatura, a empresa trabalha à base de troca, ou seja, se os clientes (distribuidores) requerem produtos remanufaturados devem levar a quantidade desejada em produtos usados. Outra forma empregada pela empresa é a compra de sucata de seus próprios produtos para evitar que a concorrência os use. A garantia oferecida para os remanufaturados é de 6 meses, igual aos produtos novos. No entanto, o entrevistado afirma que a garantia pode ser considerada por tempo indeterminado, devido à disponibilização de técnicos para manutenção 
e reparação do produto durante todo seu ciclo de vida.

Os produtos são classificados conforme o grau de recuperação, sendo que A é aquele produto que apresenta maior recuperação e $C$ aquele que apresenta menor recuperação. Além disso, a empresa já possui uma estatística que mostra as peças novas que devem ser inseridas no produto a remanufaturar. Aqueles produtos e componentes que não estejam em condições de serem remanufaturados, são enviados para serem destruídos e usados em outras EoL (ex. reciclagem), quando os componentes são reusados, eles são inspeccionados previamente . Já os rebites e os revestimentos são enviados para uma empresa certificada pela Companhia Ambiental do estado de São Paulo (CETESB) no Rio de Janeiro para serem incinerados.

Por ser o fabricante original do produto (OEM), a empresa conta com informações referentes ao produto, sendo usados os desenhos originais durante sua remanufatura, auxiliando na integração do conceito de recuperação pós-consumo no PDP por meio do projeto para a remanufatura. Entretanto, o entrevistado desconhecia se era utilizada alguma prática dentro do PDP que facilitira aos designers projetar os produtos baseados no conceito de recuperação pós-consumo.

\subsubsection{Uso de Práticas Operacionais na Empresa A}

No Quadro 10, são listadas as práticas operacionais identificadas na Empresa A por atividade relacionada com a recuperação de produtos remanufaturados. Um resumo geral é destacado na Figura 21, conforme será detalhado, a seguir.

\begin{tabular}{|c|c|c|}
\hline Atividade & Práticas Operacionais & $\begin{array}{l}\text { Aplicação } \\
\text { da Prática }\end{array}$ \\
\hline \multirow{11}{*}{$\begin{array}{l}\text { Desmontagem } \\
\text { e Remontagem }\end{array}$} & 1. Projetar a desmontagem de produtos & $\checkmark$ \\
\hline & 1.1 Analisar as restrições dos componentes & $\checkmark$ \\
\hline & 1.2 Desenvolver guias para desmontagem do produto & $\checkmark$ \\
\hline & $\begin{array}{l}\text { 1.3 Desenvolver produtos que facilitem a retirada de componentes de difícil } \\
\text { acesso }\end{array}$ & $\checkmark$ \\
\hline & $\begin{array}{l}\text { 1.4 Diminuir as mudanças de direções e de sentidos dos movimentos de } \\
\text { desmontagem e remontagem dos componentes }\end{array}$ & $\checkmark$ \\
\hline & 1.5 Evitar a quebra e possibilitar o reuso de componentes & $\checkmark$ \\
\hline & $\begin{array}{l}\text { 1.6 Evitar o uso de metais dentro das partes plásticas para diminuir a quebra dos } \\
\text { componentes }\end{array}$ & NA* \\
\hline & 1.7 Identificar os componentes de difícil remoção dentro do produto & NA \\
\hline & 1.8 Maximizar a integração de funções entre os componentes & NA \\
\hline & 1.9 Melhorar o acesso e identificação dos pontos de separação do produto & $\checkmark$ \\
\hline & 1.10 Minimizar o tempo de desmontagem e remontagem do produto & $\checkmark$ \\
\hline
\end{tabular}

(continua) 


\begin{tabular}{|c|c|c|}
\hline & 1.11 Minimizar os elementos de junção e fixação usadas no produto & $\checkmark$ \\
\hline & 1.12 Minimizar o número de componentes no produto & NA \\
\hline & 1.13 Minimizar o uso de soldas no produto & NA* \\
\hline & $\begin{array}{l}\text { 1.14 Padronizar os elementos de Fixação conforme ISO 8992:2005 (Fasteners - } \\
\text { General requirements for bolts, screws, studs and nuts) }\end{array}$ & NA \\
\hline & 1.15 Projetar marcação em cores & NA \\
\hline & $\begin{array}{l}\text { 1.16 Projetar produtos de fácil desmontagem para evitar a destruição de } \\
\text { componentes }\end{array}$ & $\checkmark$ \\
\hline & $\begin{array}{l}\text { 1.17 Projetar para que as partes isoladas sejam de baixo valor para diminuir os } \\
\text { custos por quebra }\end{array}$ & NA \\
\hline \multirow{10}{*}{ Limpeza } & $\begin{array}{l}\text { 1.18 Promover o uso de Snap fits (métodos definidos por pressão ou encaixes } \\
\text { múltiplos) }\end{array}$ & NA \\
\hline & 1.19 Usar ferramentas comuns para a desmontagem de produtos & NA \\
\hline & 2. Desenvolver produtos modulares & $\checkmark$ \\
\hline & 2.1 Minimizar as interações entre os módulos existentes do produto & NA \\
\hline & 1 Projetar produtos que sejam de fácil limpeza & \\
\hline & 1.1 Evitar o uso de adesivos & NA* \\
\hline & 1.2 Identificar os componentes que requeiram limpeza similar & $\mathrm{X}$ \\
\hline & 1.3 Projetar superfícies lisas no produto & NA \\
\hline & $\begin{array}{l}\text { 1.4 Projetar Produtos minimizando a limpeza durante o uso para evitar desgaste } \\
\text { dos componentes }\end{array}$ & NA \\
\hline & $\begin{array}{l}1.5 \text { Usar componentes resistentes à deformação pelo uso de produtos químicos } \\
\text { na limpeza }\end{array}$ & NA \\
\hline \multirow{21}{*}{ Recuperação } & 1. Projetar a recuperação dos produtos & $\checkmark$ \\
\hline & 1.1 Analisar a composição dos materiais para sua posterior recuperação & NA \\
\hline & 1.2 Codificar os componentes para rastreabilidade e recuperação & NA \\
\hline & 1.3 Evitar o uso de materiais com diferentes tempos de vida & $\checkmark$ \\
\hline & $\begin{array}{l}\text { 1.4 Identificar os componentes plásticos do produto, conforme a ISO } 11469 \\
\text { (Plastics -Generic identification and marking of plastics products) }\end{array}$ & NA* \\
\hline & 1.5 Identificar os componentes e materiais recuperáveis do produto & NA \\
\hline & 1.6 Identificar os diferentes tipos de plásticos usados no produto & NA* \\
\hline & $\begin{array}{l}\text { 1.7 Incentivar o reuso de elementos de fixação, considerando suas } \\
\text { funcionalidades originais para não comprometer a qualidade e funcionalidade } \\
\text { do produto }\end{array}$ & NA \\
\hline & $\begin{array}{l}\text { 1.8 Incrementar a quantidade de componentes e materiais recuperáveis no } \\
\text { produto }\end{array}$ & NA \\
\hline & $\begin{array}{l}\text { 1.9 Manter as especificações originais dos elementos de junção e fixação } \\
\text { usados em produtos remanufaturados }\end{array}$ & $\checkmark$ \\
\hline & $\begin{array}{l}\text { 1.10 Melhorar a adaptabilidade dos produtos para processos de recuperação, } \\
\text { manutenção e atualização }\end{array}$ & $\checkmark$ \\
\hline & 1.11 Minimizar a mistura de materiais do produto & NA \\
\hline & 1.12 Minimizar o número de diferentes materiais usados no produto & NA \\
\hline & 1.13 Projetar o reuso de componentes do produto & NA \\
\hline & $\begin{array}{l}\text { 1.14 Projetar o uso de componentes que facilitem a atualização e adaptação de } \\
\text { mudanças tecnológicas }\end{array}$ & $\checkmark$ \\
\hline & $\begin{array}{l}1.15 \text { Projetar o uso de elementos de fixação que permitam fácil separação de } \\
\text { componentes }\end{array}$ & NA \\
\hline & 1.16 Projetar os produtos para fácil manutenção & NA \\
\hline & $\begin{array}{l}\text { 1.17 Projetar produtos com materiais que sejam de fácil separação para facilitar } \\
\text { processos de recuperação e triagem }\end{array}$ & NA \\
\hline & $\begin{array}{l}\text { 1.18 Proteger os grupos de montagem da poluição e corrosão para evitar a } \\
\text { deteriorização }\end{array}$ & NA \\
\hline & 1.19 Reusar produtos com longos ciclos de vida & $\checkmark$ \\
\hline & 1.20 Reduzir as dimensões do produto, tornando-o mais leve e mais fino & NA \\
\hline
\end{tabular}

(continuação) 


\begin{tabular}{|c|c|c|}
\hline & $\begin{array}{l}1.21 \text { Usar componentes duráveis com um ciclo de vida maior que das partes } \\
\text { auxiliares }\end{array}$ & $\checkmark$ \\
\hline & 1.22 Usar materiais compatíveis dentro do produto & $\checkmark$ \\
\hline & 1.23 Usar materiais duráveis no produto & $\checkmark$ \\
\hline & 1.24 Usar quando possível material reciclado & $\checkmark$ \\
\hline & 1.25 Usar material reciclável no produto & NA \\
\hline \multirow{10}{*}{$\begin{array}{c}\text { Impactos } \\
\text { ambientais }\end{array}$} & 1. Determinar os impactos ambientais do produto & $\checkmark$ \\
\hline & 1.1 Determinar os impactos ambientais relacionado aos recursos consumidos & NA \\
\hline & 1.2 Determinar os impactos ambientais relacionado às emissões dos produtos & $\checkmark$ \\
\hline & $\begin{array}{l}\text { 1.3 Determinar os impactos ambientais relacionados a ecotoxicidade e } \\
\text { toxicidade humana }\end{array}$ & $\checkmark$ \\
\hline & 1.3.1 Analisar a toxicidade dos materiais usados no produto & NA* \\
\hline & 1.3.2 Eliminar a combinação de materiais corrosivos com os não corrosivos & NA* \\
\hline & $\begin{array}{l}\text { 1.3.3 Usar produtos químicos amigáveis ao meio ambiente ( ex. adesivos } \\
\text { solúveis em água) }\end{array}$ & $\checkmark$ \\
\hline & 1.3.4 Minimizar o uso de materiais tóxicos no produto & NA* \\
\hline & $\begin{array}{l}\text { 1.3.5 Projetar a remoção e separação de partes que contenham substâncias } \\
\text { tóxicas }\end{array}$ & NA* \\
\hline & 1.3.6 Projetar unidades fechadas para substâncias tóxicas & NA* \\
\hline & Aplica (X) Não Aplica (NA) Não Aplica para o Produto (NA*) & \\
\hline
\end{tabular}

Quadro 10 -Relação das Práticas Operacionais Empresa A

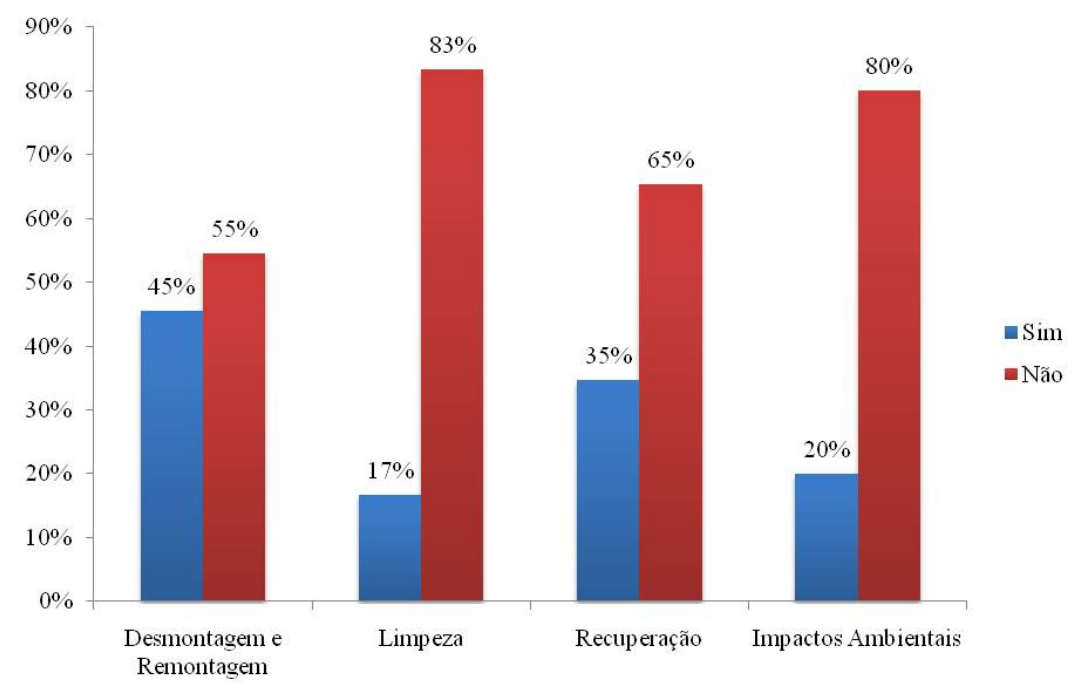

Figura 21 - Visão Geral da Aplicação das Práticas Operacionais na Empresa A

A atividade de desmontagem e remontagem representa uma aplicação de $45 \%$ das práticas operacionais. Neste grupo foram investigadas práticas operacionais relacionadas com os seguintes requisitos das EoL: Projetar a desmontagem de produtos e desenvolver produtos modulares.

Durante a pesquisa de campo foi observado que a aplicação das práticas operacionais é decorrente do manual do produto, elaborado pela empresa e atualizado de forma contínua, que discute os problemas, causas e soluções dos produtos remanufaturados na empresa 
(embreagens). Por exemplo, no caso dos componentes, após a desmontagem, estes são analisados de modo a verificar as possíveis restrições apresentadas, aquelas que não estão presentes no manual são acrescentadas com suas possíveis causas e soluções. Atividade que favorece a aplicação da maior parte de práticas operacionais relacionadas com o requisito de Projetar a Desmontagem de Produtos.

Na empresa, o projeto de desmontagem é acompanhado pelo departamento de engenharia. A etapa de desmontagem é considerada como crítica para direcionar investimentos anuais da empresa. O principal objetivo é aumentar a produtividade do processo. Steinhilper (1998) acrescenta que esta etapa dentro do processo de remanufatura é uma das atividades que mais consome tempo, devido ao grau de complexidade. Harjula et al. (1996); Kaebernick, O’Shea e Grewall (2000), também destacam como o projeto para desmontagem deve ser considerado de modo a otimizar o processo para que seja mais rápido e eficiente.

Referente às práticas operacionais que a empresa não aplica como, por exemplo, a prática operacional 1.15 Projetar marcação em cores, a empresa menciona a impossibilidade de utilizar tal marcação, pois é usado jato de granalha, causando a retirada da pintura dos componentes. Referente à prática operacional 1.19 Usar ferramentas comuns para a desmontagem de produtos, observa-se a impossibilidade de adotar uma ferramenta comum, pois as ferramentas são específicas conforme a família e o diâmetro dos componentes.

Um dos principais requisitos que deve ser atendido durante a remanufatura é a necessidade de projetar produtos que sejam de fácil limpeza. Na empresa, para a atividade de limpeza foi constatado um nível de $17 \%$ de aplicação das práticas operacionais. Isto é, a empresa apenas identifica os componentes que requeiran limpeza similar durante a recuperação dos produtos. Especificamente, é utilizado o sistema de jato de água, considerado por Steinhilper (1998), como um processo de limpeza de ação mecânica que visa retirar a sujeira e a corrosividade dos componentes.

A atividade denominada de recuperação apresenta uma aplicação de apenas 35\% de práticas operacionais. Referente à prática operacional 1.10 Melhorar a adaptabilidade dos produtos para processos de recuperação, manutenção e atualização, existem investimentos freqüentes para realizar melhorias e atualizações nos produtos. A 1.9 Manter as especificações originais dos elementos de junção e fixação usados em produtos remanufaturados, é destacado pela empresa como um princípio inserido dentro do processo de remanufatura. A prática operacional 1.13 Projetar o reuso de componentes do produto, a empresa menciona como são usados dentro dos produtos remanufaturados componentes de outros produtos iguais. 
Algumas práticas operacionais que não são usadas pela empresa, como: o uso de soldas no produto, o uso de adesivos, os componentes plásticos do produto, conforme a ISO 11469 (Plastics -Generic identification and marking of plastics products) e os diferentes tipos de plásticos usados no produto, é destacado que estas são mais usadas para outro tipo de produtos, por exemplo, os eletro-eletrônicos.

A atividade de impactos ambientais apresenta apenas uma aplicação de 20\%, sendo que aquelas práticas operacionais que não são aplicadas fazem referência específica a sustâncias tóxicas, as quais não são usadas dentro do produto recuperado da empresa estudada.

\subsection{Empresa B}

Este item apresenta uma caracterização da empresa B e os resultados do estudo de caso na empresa. Em seguida é feita uma discussão da aplicação das práticas operacionais durante o processo de recuperação de produtos.

\subsubsection{Caracterização da Empresa B}

A empresa B é uma multinacional americana, fundada em 1919. Iniciou a produção de motores a diesel para caminhões e ônibus, proporcionando ao mercado produtos com preços mais econômicos que os oferecidos pelos motores à gasolina utilizados na época. No Brasil, as operações comerciais começaram em 1971. Em 1974, iniciou suas atividades industriais em Guarulhos (SP). Os produtos produzidos pela empresa são motores para diversos segmentos do mercado como: caminhões de todos os portes, ônibus, aplicações estacionárias, máquinas de construção, equipamentos agrícolas, máquinas para mineração e aplicações marítimas. Desde 2000, a empresa entra na fabricação de geradores de energia por meio de colaboradores credenciados.

A recuperação de produtos por parte da empresa começou em 1960 estabelecendo 5 centros de remanufatura. Em 1962 foi adotado o nome ReCon (Remanufactured Concept). No Brasil, a operação teve início no ano de 1989. Dentro das vantagens oferecidas pelos produtos remanufaturados estão: redução do custo operacional, racionalização de mão de obra, redução de inventário, maior vida útil do equipamento, padronização e modernização da frota ou equipamento, garantia com um tempo igual ao do produto novo, menor tempo de parada do 
veículo e suporte em todo o território brasileiro. Entre os principais motivos para empresa adotar a recuperação de produtos destaca-se:

- $\quad$ Tendências do mercado: produtos mais compactos e complexos, maior exigência dos clientes para se obter uma reparação rápida e confiável,

- $\quad$ Ambiental: estender o ciclo de vida dos produtos, diminuição dos impactos ambientais e recuperação de produtos e materiais;

- $\quad$ Econômica: redução de custo no uso de materiais e novas oportunidades de negócio.

O Quadro 11 apresenta informações gerais sobre o perfil da empresa e do colaborador que participou durante a entrevista.

\begin{tabular}{|ll}
\hline Nome da empresa & Empresa B \\
\hline $\begin{array}{l}\text { Número de funcionários no processo de } \\
\text { recuperação de produtos (remanufatura) }\end{array}$ & 18 funcionários \\
\hline Número de pessoas que auxiliaram na pesquisa & 1 \\
\hline Cargo do Professional (entrevistado) & Supervisor Remanufatura \\
\hline Tempo de experiência & 16 anos \\
\hline Duração da entrevista & 5 horas (incluindo a visita ao processo) \\
\hline Fonte de evidências & $\begin{array}{l}\text { Roteiro, informações disponibilizadas pela empresa e } \\
\text { observação direta ao processo. }\end{array}$ \\
\hline Outras observações & \begin{tabular}{l} 
A empresa é membro da ANRAP. \\
O entrevistado é lider do processo de remanufatura a \\
\hline
\end{tabular} \\
\hline
\end{tabular}

Quadro 11- Informações Gerais da Empresa B

\subsubsection{Caracterização do Produto Recuperado}

Os produtos remanufaturados oferecidos pela empresa são: motor, motor básico, motor parcial e cabeçotes. Recentemente, a empresa iniciou a fabricação de injetores B e C. A empresa trabalha com o sistema de troca, ou seja, os clientes levam os componentes ou motores danificados como forma de pagamento no momento de adquirir um produto remanufaturado. É destacado que a empresa aconselha seus clientes em evitar desmontar o produto, pois, além de ter que pagar pelos componentes danificados, isso pode diminuir o grau de recuperação dos mesmos. Os produtos remanufaturados apresentam preços $40 \%$ menores que os novos. A garantia dada aos produtos é de 12 meses para motores completos e de 6 meses para os componentes. Como requisito, é necessário que a garantia seja efetivada 
unicamente nos centros autorizados pela empresa.

O processo é realizado através de layout celular e as etapas que compõem o processo são: coleta, inspeção, remontagem e teste final. A desmontagem e limpeza são terceirizadas devido à falta de disponibilidade de espaço na empresa para realizar essas etapas. Dada a experiência da empresa na recuperação de produtos, foi desenvolvido um manual de aceitação de produtos usados que possuem folhas de inspeção para os motores e para os componentes. O manual possui informações detalhadas de cada produto com seus componentes e das condições exigidas para serem aceitos. Por exemplo, no caso de motores completos, não devem aparecer trincas, componentes com presença de danos causados por fatores não operacionais tais como: ferrugem, manuseio inadequado ou fogo, entre outros requisitos destacados no manual e que devem ser inspecionados.

Na parte de substituição de componentes, a empresa conta com uma base de dados estabelecida para o nível de remanufatura do produto, ou seja, cada produto apresenta componentes novos e remanufaturados. Por exemplo, os motores completos, básicos e parciais apresentam os pistões, anéis de pistões, bucha de comando, comando de válvulas, tucha e tuchos de válvulas 100\% substituídos, por terem um grau de desgaste maior na etapa de uso. Já o bloco de cilindros, virabrequim, bielas, cabeçote de cilindros, bomba de água, bomba de óleo, bomba injetora, injetores, turbo (Holset) são 100\% remanufaturados. Entre os principais problemas que apresentam os produtos remanufaturados está o vazamento de fluídos, foi destacado que a empresa vem realizando investimentos para desenvolver sistemas para diminuir esse problema.

\subsubsection{Uso de Práticas Operacionais}

O Quadro 12 e a Figura 22 destacam os dados correspondentes às práticas operacionais aplicadas pela empresa B. Uma ação da empresa é que foi elaborado um conjunto de instruções de trabalho para direcionar as pessoas sobre como realizar corretamente as diferentes atividades do processo de remanufatura.

\begin{tabular}{|c|l|c|}
\hline \multirow{2}{*}{ Atividade } & \multicolumn{1}{|c|}{ Práticas Operacionais } & $\begin{array}{c}\text { Aplicação } \\
\text { da Prática }\end{array}$ \\
\hline \multirow{2}{*}{ Desmontagem } & 1. Projetar a desmontagem de produtos & \\
\cline { 2 - 3 } e remontagem & 1.1 Analisar as restrições dos componentes & $\checkmark$ \\
\cline { 2 - 3 } & 1.2 Desenvolver guias para desmontagem do produto & $\checkmark$ \\
\hline
\end{tabular}

(continua) 


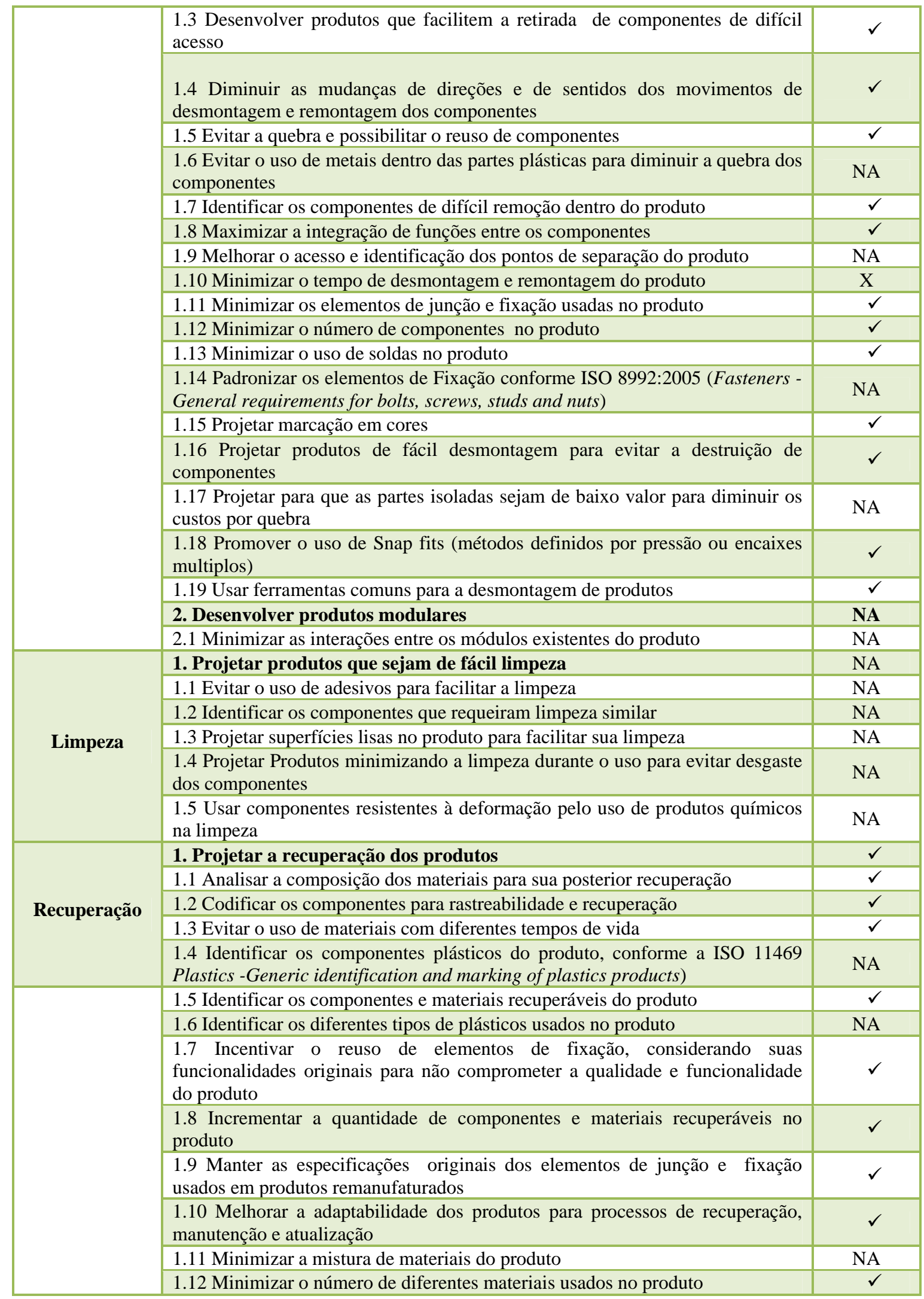

(continuação) 


\begin{tabular}{|c|c|c|}
\hline & 1.13 Projetar o reuso de componentes do produto & $\checkmark$ \\
\hline & $\begin{array}{l}\text { 1.14 Projetar o uso de componentes que facilitem a atualização e adaptação de } \\
\text { mudanças tecnológicas }\end{array}$ & $\checkmark$ \\
\hline & $\begin{array}{l}\text { 1.15 Projetar o uso de elementos de fixação que permitam fácil separação de } \\
\text { componentes }\end{array}$ & $\checkmark$ \\
\hline & 1.16 Projetar os produtos para fácil manutenção & $\checkmark$ \\
\hline & $\begin{array}{l}\text { 1.17 Projetar produtos com materiais que sejam de fácil separação para facilitar } \\
\text { processos de recuperação e triagem }\end{array}$ & $\checkmark$ \\
\hline & $\begin{array}{l}\text { 1.18 Proteger os grupos de montagem da poluição e corrosão para evitar a } \\
\text { deteriorização }\end{array}$ & NA \\
\hline & 1.19 Reusar produtos com longos ciclos de vida & $\checkmark$ \\
\hline & 1.20 Reduzir as dimensões do produto, tornando-o mais leve e mais fino & $\checkmark$ \\
\hline & $\begin{array}{l}1.21 \text { Usar componentes duráveis com um ciclo de vida maior que das partes } \\
\text { auxiliares }\end{array}$ & NA \\
\hline & 1.22 Usar materiais compatíveis dentro do produto & $\checkmark$ \\
\hline & 1.23 Usar materiais duráveis no produto & $\checkmark$ \\
\hline & 1.24 Usar quando possível material reciclado & $\checkmark$ \\
\hline & 1.25 Usar material reciclável no produto & $\checkmark$ \\
\hline \multirow{10}{*}{$\begin{array}{l}\text { Impactos } \\
\text { ambientais }\end{array}$} & 1. Determinar os impactos ambientais do produto & \\
\hline & 1.1 Determinar os impactos ambientais relacionado aos recursos consumidos & $\checkmark$ \\
\hline & 1.2 Determinar os impactos ambientais relacionado as emissões dos produtos & $\checkmark$ \\
\hline & $\begin{array}{l}\text { 1.3 Determinar os impactos ambientais relacionados a ecotoxicidade e } \\
\text { toxicidade humana }\end{array}$ & $\checkmark$ \\
\hline & 1.3.1 Analisar a toxicidade dos materiais usados no produto & $\checkmark$ \\
\hline & 1.3.2 Eliminar a combinação de materiais corrosivos com os não corrosivos & NA \\
\hline & $\begin{array}{l}\text { 1.3.3 Usar produtos químicos amigavéis ao meio ambiente ( ex. adesivos } \\
\text { solúveis em água) }\end{array}$ & $\checkmark$ \\
\hline & 1.3.4 Minimizar o uso de materiais tóxicos no produto & $\checkmark$ \\
\hline & $\begin{array}{l}\text { 1.3.5 Projetar a remoção e separação de partes que contenham substâncias } \\
\text { tóxicas }\end{array}$ & $\checkmark$ \\
\hline & 1.3.6 Projetar unidades fechadas para substâncias tóxicas & NA \\
\hline
\end{tabular}

Quadro 12 - Relação das Práticas Operacionais Empresa B

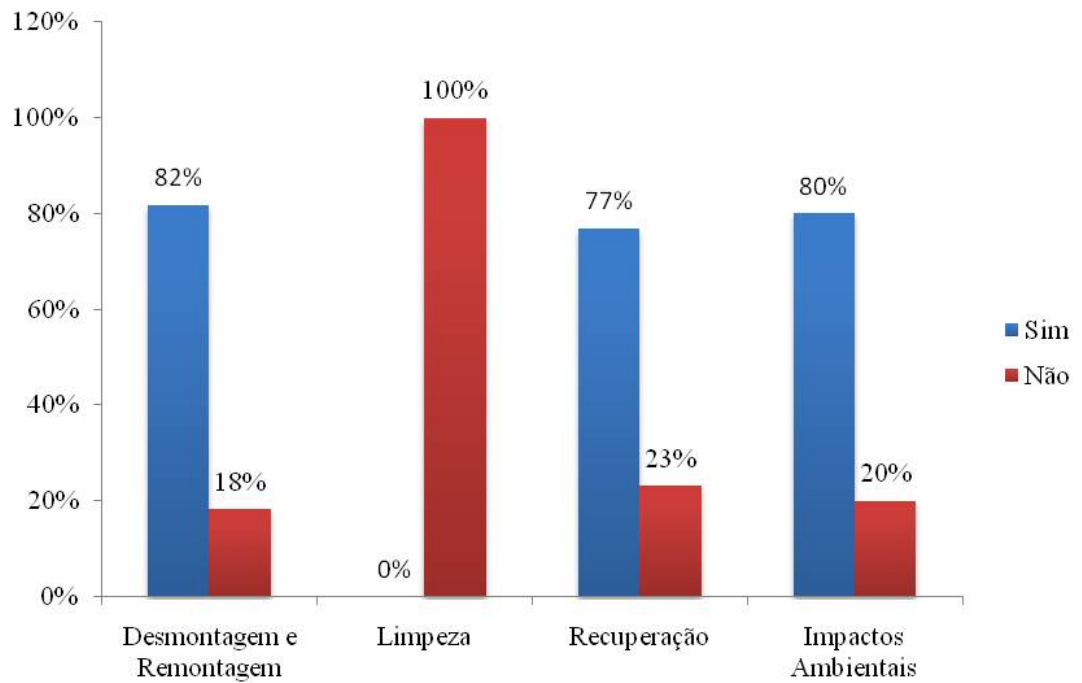

Figura 22 - Visão Geral da Aplicação de Práticas na Empresa B 
As atividades de desmontagem e remontagem obtiveram uma aplicação de $82 \%$ e a limpeza por não ser realizada dentro da empresa não obteve nenhum tipo de aplicação. Ainda, a atividade de recuperação apresenta uma aplicação de $77 \%$ e para o caso da atividade de impactos ambientais é relatado uma aplicação de $80 \%$ das práticas operacionais

Para as atividades de desmontagem e remontagem observa-se que existem diferentes programas de melhoria contínua que são utilizados para aumentar a produtividade dos processos. Neste caso, é uma prática que pode ser relacionada à prática operacional 1.10 Minimizar o tempo de desmontagem e remontagem do produto. Além disso, a desmontagem dos produtos e limpeza são atividades tercerizadas e realizadas fora da empresa, características que limitaram durante a visita à empresa a verificação das práticas operacionais propostas.

Durante a atividade de recuperação, quanto à prática operacional 1.2 Codificar os componentes para rastreabilidade e recuperação, pode ser mencionado o programa de rastreabilidade dos remanufaturados que a empresa utiliza por meio de uma codificação de produtos. Esta codificação apresenta as seguintes informações: empresa, mês da montagem, ano da montagem e seqüência de montagem. Além disso, o programa conta com outras informações adicionais como: nome de montador, número de produto, data precisa da montagem, peça aplicada "nova ou remanufaturada”, medidas das peças usinadas, folgas encontradas na montagem de cada componente entre outros dados. Caso seja necessário rastrear algum componente, a base de dados existente no programa facilita sua identificação e localização.

Outra prática operacional observada é a 1.13 Projetar o reuso de componentes do produto, também é destacada por usar dentro do motor, componentes de outros motores usados. A prática operacional 1.14 Projetar o uso de componentes que facilitem a atualização e adaptação de mudanças tecnológicas é enfrentado pela empresa por meio de um programa de atualizações para os motores, sendo um dos objetivos estender o ciclo de vida desses motores. Além disso, as peças obsoletas são substituídas por peças atuais, ou seja, o produto remanufaturado apresenta constante atualização.

No intento de alcançar maiores níveis de recuperação dos componentes, a empresa exige dos seus clientes carcaças em bom estado de conservação, ou seja, sem danos causados por fatores não operacionais tais como: ferrugem, manuseio inadequado ou fogo. As carcaças que apresentem danos são consideradas com um valor menor no momento de adquirir um novo produto remanufaturado. Em alguns casos, pode ser estabelecido um custo adicional por falta de peças ou peças danificadas. 
$\mathrm{Na}$ atividade de impactos ambientais pode ser destacado como a empresa constantemente faz investimentos para utilizar novos materiais e produtos que permitam reduzir os impactos ambientais. É previsto que a partir de 2012, os motores da empresa atenderão a Norma CONAMA P7 (norma rigorosa de controle de emissões que entrará em vigor no mesmo ano). Além disso, a empresa já esta aprovada para utilizar até $20 \%$ de Biodiesel no diesel- B20, o que significa que nos futuros produtos remanufaturados vão ser inseridas essas tecnologias mais limpas.

\subsection{Empresa C}

Neste item são destacados os resultados do estudo de caso realizado na empresa C. Inicialmente a empresa e o produto recuperado são caracterizados e, em seguida, é realizada uma análise das práticas operacionais utilizadas durante o processo de remanufatura de produtos.

\subsubsection{Caracterização da Empresa C}

A empresa C é uma multinacional de origem alemã que se destaca no mercado pela produção de veículos, caminhões, chassis e plataformas para ônibus. Por meio do desenvolvimento de tecnologias inovadoras e marcas automotivas fortes, a empresa tornou-se ao longo dos anos respeitada em nível internacional, especialmente no mercado americano. A sede onde foi realizada a pesquisa foi inagurada em 1979 e estão concentradas atualmente as atividades de pós-venda, ou seja, assistência técnica e comercialização de peças, além de áreas de treinamento e desenvolvimento da rede de concessionários. Além disso, em 2004 foram lançados produtos recuperados pós-consumo (remanufatura) que inclui motores mecânicos e eletrônicos. Em 2006, foi acrescentada uma linha de modelos de câmbios remanufaturados para caminhões e ônibus. Os remanufaturados da empresa oferecem as seguintes vantagens para os clientes: possibilidade de renovar os seus veículos, preços competitivos (40\% mais baratos que os motores novos) e menor tempo de parada dos veículos. Entre os incentivos da empresa para integrar o processo de recuperação pósconsumo, estão:

- $\quad$ Ambiental: diminuir os impactos ambientais; diminuir o consumo de recursos, geração de menos poluentes resultantes do desgaste de componentes; 
- Econômica: redução de custos, novas oportunidades de negócio; ganho de competitividade na pós-venda, possibilidade de reuso da carcaça, parcerias com terceiros;

- $\quad$ Fidelização dos clientes: com os produtos remanufaturados a empresa incentiva os clientes a adquirir estes produtos respaldados pelo nome da empresa, dando maior confiabilidade na aquisição do produto.

O Quadro 13 apresenta informações gerais sobre o perfil da empresa e do colaborador que participou durante a entrevista.

\begin{tabular}{|ll}
\hline Nome da empresa & Empresa C \\
\hline $\begin{array}{l}\text { Número de funcionários no processo de } \\
\text { recuperação de produtos (remanufatura) }\end{array}$ & 200 funcionários \\
\hline Número de pessoas que auxiliaram na pesquisa & 3 \\
\hline Cargo do Professional (entrevistado) & $\begin{array}{l}\text { Supervisor Remanufatura } \\
\text { Engenheiro de Produção (membro da equipe de PDP da } \\
\text { empresa) } \\
\text { Lider de Produção }\end{array}$ \\
\hline Tempo de experiência (empresa) & $\begin{array}{l}\text { 6 anos em produtos remanufaturados } \\
\text { Duração da entrevista }\end{array}$ \\
\hline Fonte de evidências & $\begin{array}{l}\text { Roteiro, informações disponibilizadas pela empresa e } \\
\text { observação direta ao processo. }\end{array}$ \\
\hline Outras observações & $\begin{array}{l}\text { Empresa de excelência no processo de recuperação de } \\
\text { produtos-remanufatura. }\end{array}$ \\
\hline
\end{tabular}

Quadro 13 - Informações Gerais da Empresa C

\subsubsection{Caracterização do Produto Recuperado}

Os produtos recuperados (remanufaturados) pela empresa são motores mecânicos, eletrônicos, embreagens e câmbios. De forma a incentivar a compra de remanufaturados e de auxiliar na aquisição de matéria prima (carcaça) a empresa aceita como parte do pagamento o produto usado. Além disso, os produtos podem ser adquiridos nas diferentes concessionárias do país. A garantia oferecida para o remanufaturado é de 12 meses e também é disponibilizado atendimento especializado com infra-estrutura completa para orientação dos clientes.

O processo se inicia com a avaliação do core (carcaça) por meio de inspeção visual. Especificamente, a empresa desenvolveu um checklist para os requisitos que devem ser avaliados ao receber os produtos. Por exemplo, no caso do motor compacto, são verificados: motor, bloco, virabrequim, eixo de comando de válvulas, bomba de óleo, cabeçote e unidades 
injetoras todos com pontos específicos.

Após concluir essa atividade é realizado um teste parcial para verificar trincas e imperfeições. Em seguida, as etapas de desmontagem, limpeza (uso de equipamentos que atingem lugares de difícil acesso), usinagem, armazenagem, remontagem, limpeza (aplica para peças em estoque), e teste final (feito unicamente para motor completo). Além disso, são realizadas melhorias e atualizações técnicas para garantir constantemente o último estagio técnico do produto. Os principais componentes substituídos por componentes genuínos ${ }^{15}$ são: anéis sincronizadores, rolamentos, retentores, gaxetas, anéis o’rings e molas de anéis de sincronização. Já os componentes que não podem ser usados dentro do processo são descartados para serem integrados em processos de reciclagem (fundição para transformação de materiais).

A empresa apresenta guias ao longo do processo, de modo a facilitar e garantir que cada etapa seja realizada de forma adequada. Além disso, a empresa conta com programas que visam melhorar a produtividade do processo, como programa de qualidade, auditoria interna do produto, seguimento dos problemas apresentados em campo, benchmarking (detectar materiais que sejam mais duráveis e mais adequados ambientalmente).

Por fim, existem algumas iniciativas para estender a garantia dos produtos remanufaturados já que, segundo o entrevistado, esses produtos podem apresentar uma garantia maior que os novos pelo fato de já terem passado por um ciclo de vida completo, onde foram detectadas e corrigidas as possíveis falhas presentes. No entanto, existem discussões pelo fato de ser mencionado que a extensão da garantia em produtos remanufaturados pode influenciar diretamente a venda de produtos novos, foco principal da empresa.

\subsubsection{Uso de Práticas Operacionais}

As observações relacionadas às práticas operacionais foram realizadas de uma forma limitada. A empresa não autoriza a publicação de informações mais específicas sobre o processo de recuperação de produtos por razões de concorrência. Portanto, serão discutidas somente as práticas operacionais discutidas durante a visita e aplicação do questionário.

No Quadro 14, são listadas as práticas operacionais identificadas na Empresa C por atividade relacionada à recuperação de produtos remanufaturados. Um resumo geral é

\footnotetext{
${ }^{15}$ Componentes genuínos referem-se aos componentes fabricados pela empresa original do equipamento.
} 
destacado também na Figura 23, conforme detalhado a seguir.

\begin{tabular}{|c|c|c|}
\hline Atividade & Práticas Operacionais & $\begin{array}{l}\text { Aplicação } \\
\text { da Prática }\end{array}$ \\
\hline \multirow{22}{*}{$\begin{array}{l}\text { Desmontagem } \\
\text { e remontagem }\end{array}$} & 1. Projetar a desmontagem de produtos & NA \\
\hline & 1.1 Analisar as restrições dos componentes & NA \\
\hline & 1.2 Desenvolver guias para desmontagem do produto & $\checkmark$ \\
\hline & $\begin{array}{l}\text { 1.3 Desenvolver produtos que facilitem a retirada de componentes de difícil } \\
\text { acesso }\end{array}$ & NA \\
\hline & $\begin{array}{l}\text { 1.4 Diminuir as mudanças de direções e de sentidos dos movimentos de } \\
\text { desmontagem e remontagem dos componentes }\end{array}$ & NA \\
\hline & 1.5 Evitar a quebra e possibilitar o reuso de componentes & NA \\
\hline & $\begin{array}{l}\text { 1.6 Evitar o uso de metais dentro das partes plásticas para diminuir a quebra dos } \\
\text { componentes }\end{array}$ & NA \\
\hline & 1.7 Identificar os componentes de difícil remoção dentro do produto & NA \\
\hline & 1.8 Maximizar a integração de funções entre os componentes & NA \\
\hline & 1.9 Melhorar o acesso e identificação dos pontos de separação do produto & NA \\
\hline & 1.10 Minimizar o tempo de desmontagem e remontagem do produto & NA \\
\hline & 1.11 Minimizar os elementos de junção e fixação usadas no produto & NA \\
\hline & 1.12 Minimizar o número de componentes no produto & NA \\
\hline & 1.13 Minimizar o uso de soldas no produto & NA \\
\hline & $\begin{array}{l}\text { 1.14 Padronizar os elementos de Fixação conforme ISO 8992:2005 (Fasteners - } \\
\text { General requirements for bolts, screws, studs and nuts) }\end{array}$ & NA \\
\hline & 1.15 Projetar marcação em cores & NA \\
\hline & $\begin{array}{l}\text { 1.16 Projetar produtos de fácil desmontagem para evitar a destruição de } \\
\text { componentes }\end{array}$ & NA \\
\hline & $\begin{array}{l}\text { 1.17 Projetar para que as partes isoladas sejam de baixo valor para diminuir os } \\
\text { custos por quebra }\end{array}$ & NA \\
\hline & $\begin{array}{l}\text { 1.18 Promover o uso de Snap fits (métodos definidos por pressão ou encaixes } \\
\text { multiplos) }\end{array}$ & NA \\
\hline & 1.19 Usar ferramentas comuns para a desmontagem de produtos & NA \\
\hline & 2. Desenvolver produtos modulares & NA \\
\hline & 2.1 Minimizar as interações entre os módulos existentes do produto & NA \\
\hline \multirow{6}{*}{ Limpeza } & 1. Projetar produtos que sejam de fácil limpeza & NA \\
\hline & 1.1 Evitar o uso de adesivos para facilitar a limpeza & NA \\
\hline & 1.2 Identificar os componentes que requeiram limpeza similar & NA \\
\hline & 1.3 Projetar superfícies lisas no produto para facilitar sua limpeza & NA \\
\hline & $\begin{array}{l}\text { 1.4 Projetar Produtos minimizando a limpeza durante o uso para evitar desgaste } \\
\text { dos componentes }\end{array}$ & NA \\
\hline & $\begin{array}{l}1.5 \text { Usar componentes resistentes à deformação pelo uso de produtos químicos } \\
\text { na limpeza }\end{array}$ & NA \\
\hline \multirow{8}{*}{ Recuperação } & 1. Projetar a recuperação dos produtos & $\checkmark$ \\
\hline & 1.1 Analisar a composição dos materiais para sua posterior recuperação & $\checkmark$ \\
\hline & 1.2 Codificar os componentes para rastreabilidade e recuperação & $\checkmark$ \\
\hline & 1.3 Evitar o uso de materiais com diferentes tempos de vida & $\checkmark$ \\
\hline & $\begin{array}{l}\text { 1.4 Identificar os componentes plásticos do produto, conforme a ISO } 11469 \\
\text { Plastics -Generic identification and marking of plastics products) }\end{array}$ & $\checkmark$ \\
\hline & 1.5 Identificar os componentes e materiais recuperáveis do produto & $\checkmark$ \\
\hline & 1.6 Identificar os diferentes tipos de plásticos usados no produto & NA \\
\hline & $\begin{array}{l}\text { 1.7 Incentivar o reuso de elementos de fixação, considerando suas } \\
\text { funcionalidades originais para não comprometer a qualidade e funcionalidade } \\
\text { do produto }\end{array}$ & $\checkmark$ \\
\hline
\end{tabular}

(continua) 


\begin{tabular}{|c|c|c|}
\hline & $\begin{array}{l}\text { 1.8 Incrementar a quantidade de componentes e materiais recuperáveis no } \\
\text { produto }\end{array}$ & $\checkmark$ \\
\hline & $\begin{array}{l}\text { 1.9 Manter as especificações originais dos elementos de junção e fixação } \\
\text { usados em produtos remanufaturados }\end{array}$ & $\checkmark$ \\
\hline & $\begin{array}{l}\text { 1.10 Melhorar a adaptabilidade dos produtos para processos de recuperação, } \\
\text { manutenção e atualização }\end{array}$ & $\checkmark$ \\
\hline & 1.11 Minimizar a mistura de materiais do produto & $\checkmark$ \\
\hline & 1.12 Minimizar o número de diferentes materiais usados no produto & $\checkmark$ \\
\hline & 1.13 Projetar o reuso de componentes do produto & $\checkmark$ \\
\hline & $\begin{array}{l}\text { 1.14 Projetar o uso de componentes que facilitem a atualização e adaptação de } \\
\text { mudanças tecnológicas }\end{array}$ & $\checkmark$ \\
\hline & $\begin{array}{l}\text { 1.15 Projetar o uso de elementos de fixação que permitam fácil separação de } \\
\text { componentes }\end{array}$ & $\checkmark$ \\
\hline & 1.16 Projetar os produtos para fácil manutenção & $\checkmark$ \\
\hline & $\begin{array}{l}\text { 1.17 Projetar produtos com materiais que sejam de fácil separação para facilitar } \\
\text { processos de recuperação e triagem }\end{array}$ & $\checkmark$ \\
\hline \multirow{18}{*}{$\begin{array}{l}\text { Impactos } \\
\text { ambientais }\end{array}$} & $\begin{array}{l}\text { 1.18 Proteger os grupos de montagem da poluição e corrosão para evitar a } \\
\text { deteriorização }\end{array}$ & NA \\
\hline & 1.19 Reusar produtos com longos ciclos de vida & $\checkmark$ \\
\hline & 1.20 Reduzir as dimensões do produto, tornando-o mais leve e mais fino & NA \\
\hline & $\begin{array}{l}\text { 1.21 Usar componentes duráveis com um ciclo de vida maior que das partes } \\
\text { auxiliares }\end{array}$ & $\checkmark$ \\
\hline & 1.22 Usar materiais compatíveis dentro do produto & $\checkmark$ \\
\hline & 1.23 Usar materiais duráveis no produto & $\checkmark$ \\
\hline & 1.24 Usar quando possível material reciclado & $\checkmark$ \\
\hline & 1.25 Usar material reciclável no produto & $\checkmark$ \\
\hline & 1. Determinar os impactos ambientais do produto & \\
\hline & 1.1 Determinar os impactos ambientais relacionado aos recursos consumidos & $\checkmark$ \\
\hline & 1.2 Determinar os impactos ambientais relacionado às emissões dos produtos & $\checkmark$ \\
\hline & $\begin{array}{l}\text { 1.3 Determinar os impactos ambientais relacionados a ecotoxicidade e } \\
\text { toxicidade humana }\end{array}$ & $\checkmark$ \\
\hline & 1.3.1 Analisar a toxicidade dos materiais usados no produto & $\checkmark$ \\
\hline & 1.3.2 Eliminar a combinação de materiais corrosivos com os não corrosivos & $\checkmark$ \\
\hline & $\begin{array}{l}\text { 1.3.3 Usar produtos químicos amigavéis ao meio ambiente ( ex. adesivos } \\
\text { solúveis em água) }\end{array}$ & $\checkmark$ \\
\hline & 1.3.4 Minimizar o uso de materiais tóxicos no produto & $\checkmark$ \\
\hline & $\begin{array}{l}\text { 1.3.5 Projetar a remoção e separação de partes que contenham substâncias } \\
\text { tóxicas }\end{array}$ & $\checkmark$ \\
\hline & 1.3.6 Projetar unidades fechadas para substâncias tóxicas & $\checkmark$ \\
\hline
\end{tabular}

Quadro 14 - Verificação das Práticas Operacionais Empresa C 


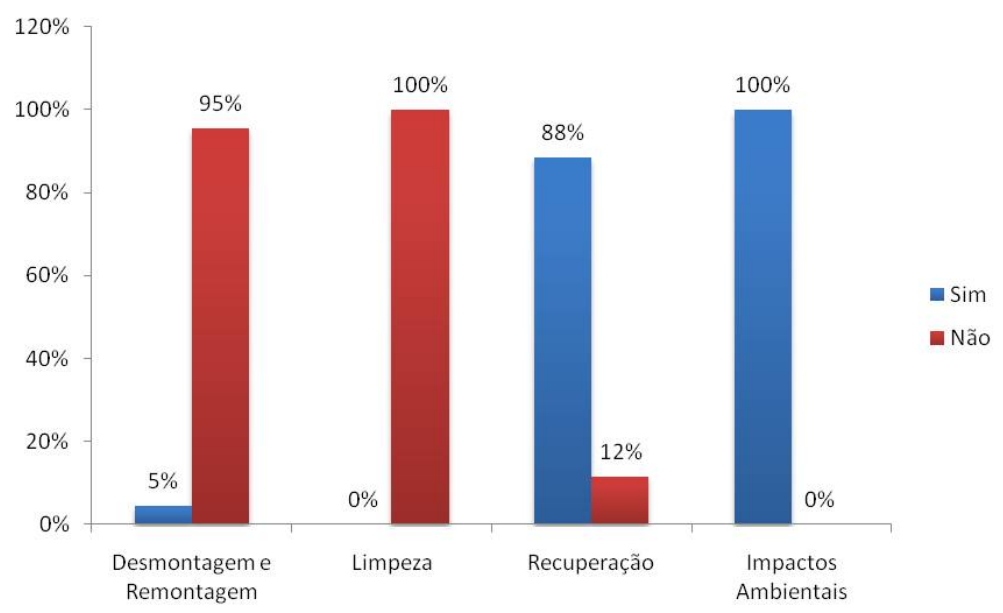

Figura 23 - Visão Geral da Aplicação das Práticas na Empresa C

A atividade de desmontagem e remontagem apresenta uma aplicação de 5\%, referente às guias desenvolvidas para realizar a desmontagem do produto. Porém, o entrevistado destacou que nos novos projetos de motores, a empresa visa integrar práticas operacionais que permitam a desmontagem e remontagem. Observou-se que algumas práticas operacionais são indiretamente aplicadas, como é o caso da prática operacional 1.10 Minimizar o tempo de desmontagem e remontagem do produto, pois a empresa destaca programas para melhorar a produtividade dos processos, onde é inserida a redução de tempos nas etapas dos processos.

Referente à prática operacional 1.13 Minimizar o uso de soldas no produto, foi avaliada como não aplicada. Entretanto, durante a visita ao processo, observou-se que o uso de soldas é realizado na etapa de desmontagem em mínimas quantidades.

$\mathrm{Na}$ atividade de limpeza a empresa não apresenta nenhuma aplicação das práticas operacionais. No entanto, pode ser destacado como a empresa usa um acabamento especial anticorrosão para cuidar da durabilidade dos componentes, tecnologia que permite atender esse requisito da remanufatura.

$\mathrm{Na}$ atividade de recuperação, a empresa apresenta uma aplicação de $88 \%$. A prática operacional 1.2 Codificar os componentes para rastreabilidade e recuperação foi destacado pelo entrevistado como uma prática incoportada pela empresa para rastrear os produtos remanufaturados. É observado também que a rastreabilidade (Número do Motor) do produto ocorre por meio do checklist realizado na inspeção visual da carcaça. Informação que ajuda a acompanhar a recuperação dos produtos em todo o processo de remanufatura utilizado pela empresa. 
Na atividade de impactos ambientais a empresa apresenta uma aplicação de 100\%. Destaca-se a implementação de produção mais limpa desde o ano de 2005, que visa buscar a causa raiz dos problemas de poluição gerada em processos, produtos e serviços e criar alternativas que permitam diminuir essa poluição.

Por fim, a empresa realçou os esforços constantes em integrar alternativas mais próativas. Destacando-se, a projeção de novos produtos que usem a avaliação do ciclo de vida (ACV) como meio para determinar os impactos ambientais em todas as etapas e inserir melhorias que permitam diminuir esses impactos. Além disso, é destacada a projeção de produtos que integrem desde o processo de desenvolvimento de produtos a sua recuperação no pós-consumo.

\subsection{Empresa D}

Neste item, são destacados os resultados do estudo de caso realizado na empresa D. Primeiro, é caracterizada a empresa e o produto recuperado e, em seguida, é realizada uma analise das práticas operacionais utilizadas durante o processo de remanufatura de produtos.

\subsubsection{Caracterização da Empresa D}

A empresa D é uma multinacional de origem alemã que começou suas operações em 1905 com o fornecimento de sistemas de frenagem. A segunda maior área de atividade da empresa surgiu em 1922, quando a empresa mudou para sistemas de frenagem a ar para veículos rodoviários comerciais. Foi a primeira empresa da Europa a desenvolver um novo tipo de sistema de ar que aplicava frenagem simultaneamente nas quatro rodas de um caminhão e também a sua carroceria. No Brasil, a empresa atua no desenvolvimento e fabricação de componentes para sistemas de freio a ar comprimido e circuitos pneumáticos para sistemas de carro de passageiros e sistemas de carga, além, de sistema de portas para carros de passageiros.

Os produtos recuperados pela empresa são componentes e acessórios remanufaturados, para que a venda desses produtos seja estimulada, a empresa fornece informações nos centros de distribuição sobre as vantagens de sua utilização. Entres os motivos que levaram a empresa a incorporar a remanufatura de produtos estão:

- $\quad$ Menor custo para os consumidores: os preços são 50\% mais baratos que os 
produtos novos, além disso, a garantia e qualidade são iguais às dadas ao produto novo.

- $\quad$ Novas oportunidades de negócio: aceitação por parte dos clientes em relação aos produtos remanufaturados, menor custo envolvido no produto e menor inventário para peças de reposição.

- Ambiental: preservação de recursos, menor consumo de energia, menor poluição na produção, reaproveitamento de matérias primas e responsabilidade dos fabricantes sobre seus produtos ao longo do ciclo de vida.

O Quadro 15 apresenta informações gerais sobre o perfil da empresa e do colaborador que participou durante a entrevista.

\begin{tabular}{|ll}
\hline Nome da empresa & Empresa D \\
\hline $\begin{array}{l}\text { Número de funcionários no processo de } \\
\text { recuperação de produtos (remanufatura) }\end{array}$ & 6 funcionários \\
\hline Número de pessoas que auxiliaram na pesquisa & 1 \\
\hline Cargo do Professional (entrevistado) & Marketing \\
\hline Tempo de experiência (empresa) & 6 anos em produtos remanufaturados \\
\hline Duração da entrevista & 3 horas (incluindo a visita ao processo) \\
\hline Fonte de evidências & $\begin{array}{l}\text { Roteiro, informações disponibilizadas pela empresa e } \\
\text { observação direta ao processo. }\end{array}$ \\
\hline Outras observações & A empresa é membro da ANRAP. \\
\hline
\end{tabular}

Quadro 15- Informações Gerais da Empresa D

\subsubsection{Caracterização do Produto Recuperado}

Os produtos recuperados pela empresa (remanufaturados) são freios e discos. A empresa trabalha sobre sistema de troca, onde os clientes levam os produtos usados como forma de pagamento do produto remanufaturado. Para avaliar o grau de recuperação, foi adotada uma classificação para as carcaças (core), sendo que A é aquela carcaça que não apresenta nenhuma reparação e $\mathrm{C}$ aquela que apresenta mais de uma reparação, destinada à sucata por não atender aos requisitos mínimos para entrar no processo de remanufatura. Destaca-se que os produtos voltam ao mercado de forma a serem utilizados em outras estratégias de fim de vida, como a fundição de materiais para serem utilizadas na reciclagem. A garantia oferecida para os produtos remanufaturados é de seis (6) meses, sendo a mesma dada para os produtos novos.

As etapas realizadas no processo iniciam com a chegada da carcaça, onde é realizada 
uma inspeção visual, sendo classificadas conforme descrito acima. Em seguida, têm-se as etapas de desmontagem, limpeza, jateamento, preparação do componente, remontagem e, por fim, o teste. O colaborador durante a entrevista mencionou como as carcaças nas classificações A e B apresentam uma taxa de recuperabilidade promédio de 90\%, destacando que os principais problemas apresentados são: espelhamento dos cilindros, quebra do virabrecrim, trinca na carcaça e roscas danificadas, sendo a maior causa dada pelo desgaste adquirido na fase de uso do produto.

\subsubsection{Uso de Práticas Operacionais}

As observações relacionadas às práticas operacionais foram realizadas de forma limitada. A empresa não disponibiliza informações mais específicas sobre o processo de recuperação de produtos por razões de concorrência. Destaca-se que a verificação foi feita de uma forma limitada baseada na observação no processo. O Quadro 16 apresenta as práticas aplicadas pela empresa e a Figura 24 apresenta uma visão geral dessa aplicação.

\begin{tabular}{|c|c|c|}
\hline Atividade & Práticas Operacionais & $\begin{array}{l}\text { Aplicação } \\
\text { da Prática }\end{array}$ \\
\hline \multirow{18}{*}{$\begin{array}{l}\text { Desmontagem } \\
\text { e remontagem }\end{array}$} & 1. Projetar a desmontagem de produtos & NA \\
\hline & 1.1 Analisar as restrições dos componentes & NA \\
\hline & 1.2 Desenvolver guias para desmontagem do produto & $\checkmark$ \\
\hline & $\begin{array}{l}\text { 1.3 Desenvolver produtos que facilitem a retirada de componentes de difícil } \\
\text { acesso }\end{array}$ & NA \\
\hline & $\begin{array}{l}\text { 1.4 Diminuir as mudanças de direções e de sentidos dos movimentos de } \\
\text { desmontagem e remontagem dos componentes }\end{array}$ & NA \\
\hline & 1.5 Evitar a quebra e possibilitar o reuso de componentes & NA \\
\hline & $\begin{array}{l}\text { 1.6 Evitar o uso de metais dentro das partes plásticas para diminuir a quebra dos } \\
\text { componentes }\end{array}$ & NA \\
\hline & 1.7 Identificar os componentes de difícil remoção dentro do produto & NA \\
\hline & 1.8 Maximizar a integração de funções entre os componentes & NA \\
\hline & 1.9 Melhorar o acesso e identificação dos pontos de separação do produto & NA \\
\hline & 1.10 Minimizar o tempo de desmontagem e remontagem do produto & NA \\
\hline & 1.11 Minimizar os elementos de junção e fixação usadas no produto & NA \\
\hline & 1.12 Minimizar o número de componentes no produto & NA \\
\hline & 1.13 Minimizar o uso de soldas no produto & NA \\
\hline & $\begin{array}{l}\text { 1.14 Padronizar os elementos de Fixação conforme ISO 8992:2005 (Fasteners - } \\
\text { General requirements for bolts, screws, studs and nuts) }\end{array}$ & NA \\
\hline & 1.15 Projetar marcação em cores & $\checkmark$ \\
\hline & $\begin{array}{l}\text { 1.16 Projetar produtos de fácil desmontagem para evitar a destruição de } \\
\text { componentes }\end{array}$ & NA \\
\hline & $\begin{array}{l}\text { 1.17 Projetar para que as partes isoladas sejam de baixo valor para diminuir os } \\
\text { custos por quebra }\end{array}$ & NA \\
\hline
\end{tabular}

(continua) 


\begin{tabular}{|c|c|c|}
\hline & $\begin{array}{l}1.18 \text { Promover o uso de Snap fits (métodos definidos por pressão ou encaixes } \\
\text { multiplos) }\end{array}$ & NA \\
\hline & 1.19 Usar ferramentas comuns para a desmontagem de produtos & NA \\
\hline & 2. Desenvolver produtos modulares & NA \\
\hline & 2.1 Minimizar as interações entre os módulos existentes do produto & NA \\
\hline \multirow{6}{*}{ Limpeza } & 1. Projetar produtos que sejam de fácil limpeza & NA \\
\hline & 1.1 Evitar o uso de adesivos para facilitar a limpeza & NA \\
\hline & 1.2 Identificar os componentes que requeiram limpeza similar & NA \\
\hline & 1.3 Projetar superfícies lisas no produto para facilitar sua limpeza & NA \\
\hline & $\begin{array}{l}\text { 1.4 Projetar Produtos minimizando a limpeza durante o uso para evitar desgaste } \\
\text { dos componentes }\end{array}$ & NA \\
\hline & $\begin{array}{l}1.5 \text { Usar componentes resistentes à deformação pelo uso de produtos químicos } \\
\text { na limpeza }\end{array}$ & NA \\
\hline \multirow{26}{*}{ Recuperação } & 1. Projetar a recuperação dos produtos & NA \\
\hline & 1.1 Analisar a composição dos materiais para sua posterior recuperação & NA \\
\hline & 1.2 Codificar os componentes para rastreabilidade e recuperação & $\checkmark$ \\
\hline & 1.3 Evitar o uso de materiais com diferentes tempos de vida & NA \\
\hline & $\begin{array}{l}\text { 1.4 Identificar os componentes plásticos do produto, conforme a ISO } 11469 \\
\text { Plastics -Generic identification and marking of plastics products) }\end{array}$ & NA \\
\hline & 1.5 Identificar os componentes e materiais recuperáveis do produto & $\checkmark$ \\
\hline & 1.6 Identificar os diferentes tipos de plásticos usados no produto & NA \\
\hline & $\begin{array}{l}\text { 1.7 Incentivar o reuso de elementos de fixação, considerando suas } \\
\text { funcionalidades originais para não comprometer a qualidade e funcionalidade } \\
\text { do produto }\end{array}$ & NA \\
\hline & $\begin{array}{l}1.8 \text { Incrementar a quantidade de componentes e materiais recuperáveis no } \\
\text { produto }\end{array}$ & NA \\
\hline & $\begin{array}{l}\text { 1.9 Manter as especificações originais dos elementos de junção e fixação } \\
\text { usados em produtos remanufaturados }\end{array}$ & NA \\
\hline & $\begin{array}{l}\text { 1.10 Melhorar a adaptabilidade dos produtos para processos de recuperação, } \\
\text { manutenção e atualização }\end{array}$ & NA \\
\hline & 1.11 Minimizar a mistura de materiais do produto & NA \\
\hline & 1.12 Minimizar o número de diferentes materiais usados no produto & NA \\
\hline & 1.13 Projetar o reuso de componentes do produto & NA \\
\hline & $\begin{array}{l}\text { 1.14 Projetar o uso de componentes que facilitem a atualização e adaptação de } \\
\text { mudanças tecnológicas }\end{array}$ & $\checkmark$ \\
\hline & $\begin{array}{l}\text { 1.15 Projetar o uso de elementos de fixação que permitam fácil separação de } \\
\text { componentes }\end{array}$ & NA \\
\hline & 1.16 Projetar os produtos para fácil manutenção & NA \\
\hline & $\begin{array}{l}\text { 1.17 Projetar produtos com materiais que sejam de fácil separação para facilitar } \\
\text { processos de recuperação e triagem }\end{array}$ & NA \\
\hline & $\begin{array}{l}\text { 1.18 Proteger os grupos de montagem da poluição e corrosão para evitar a } \\
\text { deteriorização }\end{array}$ & NA \\
\hline & 1.19 Reusar produtos com longos ciclos de vida & NA \\
\hline & 1.20 Reduzir as dimensões do produto, tornando-o mais leve e mais fino & NA \\
\hline & $\begin{array}{l}1.21 \text { Usar componentes duráveis com um ciclo de vida maior que das partes } \\
\text { auxiliares }\end{array}$ & NA \\
\hline & 1.22 Usar materiais compatíveis dentro do produto & NA \\
\hline & 1.23 Usar materiais duráveis no produto & NA \\
\hline & 1.24 Usar quando possível material reciclado & NA \\
\hline & 1.25 Usar material reciclável no produto & NA \\
\hline \multirow{3}{*}{$\begin{array}{l}\text { Impactos } \\
\text { ambientais }\end{array}$} & 1. Determinar os impactos ambientais do produto & \\
\hline & 1.1 Determinar os impactos ambientais relacionado aos recursos consumidos & NA \\
\hline & 1.2 Determinar os impactos ambientais relacionado às emissões dos produtos & NA \\
\hline
\end{tabular}

(continuação) 


\begin{tabular}{|l|l|c|}
\hline & $\begin{array}{l}\text { 1.3 Determinar os impactos ambientais relacionados a ecotoxicidade e } \\
\text { toxicidade humana }\end{array}$ & NA \\
\hline & 1.3.1 Analisar a toxicidade dos materiais usados no produto & NA \\
\hline 1.3.2 Eliminar a combinação de materiais corrosivos com os não corrosivos & NA \\
\hline $\begin{array}{l}\text { 1.3.3 Usar produtos químicos amigavéis ao meio ambiente ( ex. adesivos } \\
\text { solúveis em água) }\end{array}$ & NA \\
\hline & $\begin{array}{l}\text { 1.3.4 Minimizar o uso de materiais tóxicos no produto } \\
\text { 1.3.5 Projetar a remoção e separação de partes que contenham substâncias } \\
\text { tóxicas }\end{array}$ & NA \\
\hline & 1.3.6 Projetar unidades fechadas para substâncias tóxicas & NA \\
\hline Aplica (X) Não Aplica (NA) Não aplica para o produto (NA*)
\end{tabular}

Quadro 16- Verificação das Práticas Operacionais Empresa D

Observa-se que nas atividades de desmontagem e remontagem existem apenas 5\% de aplicação das práticas operacionais, observadas por meio das guias de desmontagem que visam facilitar e diminuir a quebra de componentes. Na atividade de limpeza não se apresenta nenhuma aplicação das práticas operacionais propostas. A atividade de recuperação apresenta uma aplicação de $12 \%$ das práticas operacionais, destacando-se a identificação de componentes por meio de codificação.

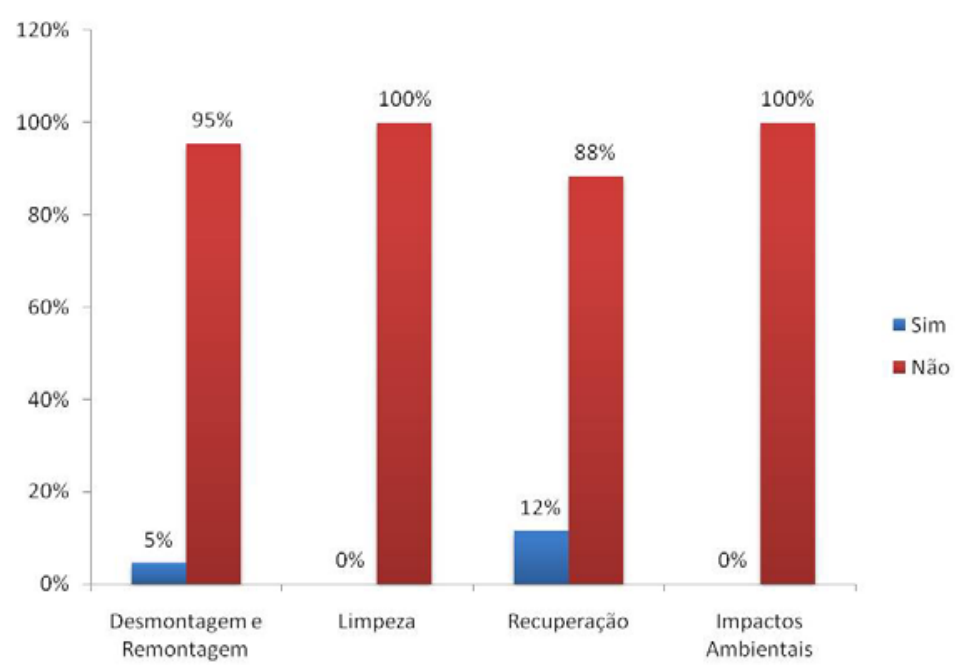

Figura 24 - Visão Geral da Aplicação das Práticas na Empresa D

A atividade de impactos ambientais, segundo o entrevistado, não apresenta nenhuma aplicação. No entanto, percebe-se o esforço da empresa por integrar alternativas que visem à melhoria ambiental do produto, integrados dentro do sistema de gestão ambiental da empresa. Maiores informações sobre a aplicação das práticas operacionais não foram possíveis de serem coletadas devido à parada do processo de remanufatura no dia da visita. 


\subsection{Análise dos Múltiplos Estudos de Caso}

Este item é apresentado a análise feita aos resultados dos múltiplos estudos de caso. Adotou-se o uso de quadros comparativos com o objetivo de discutir a ocorrência na aplicação das práticas operacionais verificadas nas empresas estudadas. Inicia-se com o Quadro 17 que apresenta a verificação das práticas operacionais das atividades de desmontagem e remontagem.

\begin{tabular}{|c|c|c|c|c|c|}
\hline Atividade & Práticas Operacionais & A & B & C & D \\
\hline \multirow{17}{*}{$\begin{array}{l}\text { Desmontagem e } \\
\text { Remontagem }\end{array}$} & 1. Projetar a desmontagem de produtos & & & & \\
\hline & 1.1 Analisar as restrições dos componentes & & & & \\
\hline & $\begin{array}{l}\text { 1.2 Desenvolver guias para desmontagem do } \\
\text { produto }\end{array}$ & & & & \\
\hline & $\begin{array}{l}\text { 1.3 Desenvolver produtos que facilitem a } \\
\text { retirada de componentes de difícil acesso }\end{array}$ & & & & \\
\hline & $\begin{array}{l}\text { 1.4 Diminuir as mudanças de direções e de } \\
\text { sentidos dos movimentos de desmontagem e } \\
\text { remontagem dos componentes }\end{array}$ & & & & \\
\hline & $\begin{array}{l}\text { 1.5 Evitar a quebra e possibilitar o reuso de } \\
\text { componentes }\end{array}$ & & & & \\
\hline & $\begin{array}{l}\text { 1.6 Evitar o uso de metais dentro das partes } \\
\text { plásticas para diminuir a quebra dos } \\
\text { componentes }\end{array}$ & & & & \\
\hline & $\begin{array}{l}1.7 \text { Identificar os componentes de difícil } \\
\text { remoção dentro do produto }\end{array}$ & & & & \\
\hline & $\begin{array}{l}\text { 1.8 Maximizar a integração de funções entre os } \\
\text { componentes }\end{array}$ & & & & \\
\hline & $\begin{array}{l}\text { 1.9 Melhorar o acesso e identificação dos pontos } \\
\text { de separação do produto }\end{array}$ & & & & \\
\hline & $\begin{array}{l}1.10 \text { Minimizar o tempo de desmontagem e } \\
\text { remontagem do produto }\end{array}$ & & & & \\
\hline & $\begin{array}{l}1.11 \text { Minimizar os elementos de junção e } \\
\text { fixação usadas no produto }\end{array}$ & & & & \\
\hline & $\begin{array}{l}\text { 1.12 Minimizar o número de componentes no } \\
\text { produto }\end{array}$ & & & & \\
\hline & 1.13 Minimizar o uso de soldas no produto & & & & \\
\hline & $\begin{array}{l}1.14 \text { Padronizar os elementos de Fixação } \\
\text { conforme ISO 8992:2005 (Fasteners -General } \\
\text { requirements for bolts, screws, studs and nuts) }\end{array}$ & & & & \\
\hline & 1.15 Projetar marcação em cores & & & & \\
\hline & $\begin{array}{l}\text { 1.16 Projetar produtos de fácil desmontagem } \\
\text { para evitar a destruição de componentes }\end{array}$ & & & & \\
\hline
\end{tabular}

(continua) 


\begin{tabular}{l}
$\begin{array}{l}1.17 \text { Projetar para que as partes isoladas sejam } \\
\text { de baixo valor para diminuir os custos por } \\
\text { quebra }\end{array}$ \\
$\begin{array}{l}1.18 \text { Promover o uso de Snap fits (métodos } \\
\text { definidos por pressão ou encaixes múltiplos) }\end{array}$ \\
\hline $\begin{array}{l}1.19 \text { Usar ferramentas comuns para a } \\
\text { desmontagem de produtos }\end{array}$ \\
\hline 2. Desenvolver produtos modulares \\
\hline $\begin{array}{l}\text { 2.1 Minimizar as interações entre os módulos } \\
\text { existentes do produto }\end{array}$
\end{tabular}

Legenda: Aplica (verde) Não aplica (vermelho) Não aplica ao produto (branco)

Quadro 17 Comparação da aplicação das Práticas Operacionais das Empresas nas Atividades de Desmontagem e Remontagem

Ao analisar as práticas operacionais das atividades de desmontagem e remontagem, pode ser observado que duas empresas apresentam uma maior aplicação das práticas operacionais. Estes resultados podem ser relacionados com o nível de experiência destas empresas na recuperação de produtos (remanufatura).

Segundo apresentado no capitulo 2 da revisão da bibliografia, dentro do processo de remanufatura a etapa de desmontagem é a etapa que consome maior tempo de realização. Além disso, nesta etapa se apresenta maior probabilidade de quebras de componentes. Neste sentido, pode ser verificado nos resultados das empresas que utilizam as práticas operacionais para desmontagem e remontagem, os esforços que elas apresentam no desenvolvimento de tecnologias e guias que permitam melhorar a produtividade desse processo.

No entanto, pode ser destacado como um fator relevante o fato duas empresas C e D apresentarem um nível baixo de maturidade no processo de remanufatura, por estar no mercado de recuperação de produtos pós-consumo há menos tempo que as empresas A e B. Além disso, a empresa $\mathrm{D}$ não possui uma planta industrial somente para o processo de remanufatura. Contudo, as empresas comentam os esforços de melhoria contínua para melhorar o processo e a possibilidade da empresa D possuir, no futuro próximo, uma planta exclusiva para a remanufatura.

Outra tendência presente no Quadro 18 refere-se a não aplicação de algumas práticas operacionais dentro dos produtos recuperados (remanufaturados) da empresa por não ser do setor industrial destas empresas analisadas. Isso é o caso da prática operacional "Evitar o uso de metais dentro das partes plásticas para diminuir a quebra dos componentes”, que se aplica mais para produtos eletro-eletrônicos. 


\begin{tabular}{|c|c|c|c|c|c|}
\hline Atividade & Práticas Operacionais & $\mathbf{A}$ & B & $\mathbf{C}$ & $\mathbf{D}$ \\
\hline \multirow[t]{6}{*}{ Limpeza } & 1. Projetar produtos que sejam de fácil limpeza & & & & \\
\hline & 1.1 Evitar o uso de adesivos para facilitar a limpeza & & & & \\
\hline & $\begin{array}{l}1.2 \text { Identificar os componentes que requerem } \\
\text { limpeza similar }\end{array}$ & & & & \\
\hline & $\begin{array}{l}\text { 1.3 Projetar superfícies lisas no produto para } \\
\text { facilitar sua limpeza }\end{array}$ & & & & \\
\hline & $\begin{array}{l}\text { 1.4 Projetar produtos minimizando a limpeza } \\
\text { durante o uso para evitar desgaste dos componentes }\end{array}$ & & & & \\
\hline & $\begin{array}{l}1.5 \text { Usar componentes resistentes à deformação pelo } \\
\text { uso de produtos químicos na limpeza }\end{array}$ & & & & \\
\hline
\end{tabular}

Quadro 18 - Comparação da Aplicação das Práticas Operacionais das Empresas na Atividade de Limpeza

Verificou-se que apenas duas, das quatro empresas, apresentam a aplicação de algumas práticas operacionais propostas na atividade de limpeza (identificar os componentes que requeiram limpeza similar e usar componentes resistentes à deformação pelo uso de produtos químicos na limpeza). No entanto, observou-se a preocupação das empresas pela procura de produtos e materiais mais resistentes que facilitem essa atividade. Em uma das empresas é utilizado o Bencharmarking, que tem por objetivo procurar materiais mais duráveis e mais amigáveis com o meio ambiente.

O Quadro 19 apresenta a verificação das práticas operacionais da atividade de recuperação, aplicadas pelas empresas. Destaca-se a conscientização por parte das empresas da integração das questões ambientais dentro de seus produtos. A aplicação das práticas operacionais, referente à recuperação, reuso e reciclagem de componentes, assim como o uso de materiais mais duráveis, levam a diminuir o consumo de recursos e os impactos ambientais decorrentes desses consumos.

Ressalta-se que duas das empresas estudadas não realizam o reuso de elementos de fixação, pois mencionam que isso pode comprometer a funcionalidade e garantia do produto. No entanto, conforme a literatura consultada, em alguns casos, como nas impressoras remanufaturadas, os parafusos podem ser usados até duas vezes sem comprometer a funcionalidade do produto.

Outro destaque é a aplicação, por parte das quatro empresas estudadas, da prática operacional "Projetar o uso de componentes que facilitem a atualização e adaptação de mudanças tecnológicas”. Isso reflete o uso desta prática operacional no Processo de 
Desenvolvimento de Produto para garantir o princípio da remanufatura de oferecer um produto com a mesma funcionalidade, garantia e qualidade de um produto novo. Além disso, a facilidade de poder atualizar os produtos também se reflete na sua extensão do ciclo de vida. Além disso, duas empresas utilizam projetos modulares nos seus produtos.

Verificou-se o baixo nível de integração entre essas práticas no processo de desenvolvimento de produtos, o que dificulta obter maiores níveis de recuperação dos produtos com seus componentes e materiais. No entanto, uma das empresas destacou a integração da recuperação, desde o processo de desenvolvimento de produtos, para os próximos produtos da empresa. Ainda, foi destacado que os ganhos alcançados com essa integração podem refletir diretamente no triple da sustentabilidade (ambiental, econômico e social).

\begin{tabular}{|c|c|c|c|c|c|}
\hline Atividade & Práticas Operacionais & A & B & $\mathbf{C}$ & D \\
\hline \multirow[t]{15}{*}{ Recuperação } & 1. Projetar a recuperação dos produtos & & & & \\
\hline & $\begin{array}{l}\text { 1.1 Analisar a composição dos materiais para sua } \\
\text { posterior recuperação }\end{array}$ & & & & \\
\hline & $\begin{array}{l}\text { 1.2 Codificar os componentes para rastreabilidade e } \\
\text { recuperação }\end{array}$ & & & & \\
\hline & $\begin{array}{l}1.3 \text { Evitar o uso de materiais com diferentes tempos } \\
\text { de vida }\end{array}$ & & & & \\
\hline & $\begin{array}{l}\text { 1.4 Identificar os componentes plásticos do produto, } \\
\text { conforme a ISO } 11469 \text { (Plastics -Generic } \\
\text { identification and marking of plastics products) }\end{array}$ & & & & \\
\hline & $\begin{array}{l}1.5 \text { Identificar os componentes e materiais } \\
\text { recuperáveis do produto }\end{array}$ & & & & \\
\hline & $\begin{array}{l}\text { 1.6 Identificar os diferentes tipos de plásticos } \\
\text { usados no produto }\end{array}$ & & & & \\
\hline & $\begin{array}{l}\text { 1.7 Incentivar o reuso de elementos de fixação, } \\
\text { considerando suas funcionalidades originais para } \\
\text { não comprometer a qualidade e funcionalidade do } \\
\text { produto }\end{array}$ & & & & \\
\hline & $\begin{array}{l}\text { 1.8 Incrementar a quantidade de componentes e } \\
\text { materiais recuperáveis no produto }\end{array}$ & & & & \\
\hline & $\begin{array}{l}\text { 1.9 Manter as especificações originais dos } \\
\text { elementos de junção e fixação usados em produtos } \\
\text { remanufaturados }\end{array}$ & & & & \\
\hline & $\begin{array}{l}\text { 1.10 Melhorar a adaptabilidade dos produtos para } \\
\text { processos de recuperação, manutenção e atualização }\end{array}$ & & & & \\
\hline & 1.11 Minimizar a mistura de materiais do produto & & & & \\
\hline & $\begin{array}{l}\text { 1.12 Minimizar o número de diferentes materiais } \\
\text { usados no produto }\end{array}$ & & & & \\
\hline & 1.13 Projetar o reuso de componentes do produto & & & & \\
\hline & $\begin{array}{l}\text { 1.14 Projetar o uso de componentes que facilitem a } \\
\text { atualização e adaptação de mudanças tecnológicas }\end{array}$ & & & & \\
\hline
\end{tabular}

(continua) 


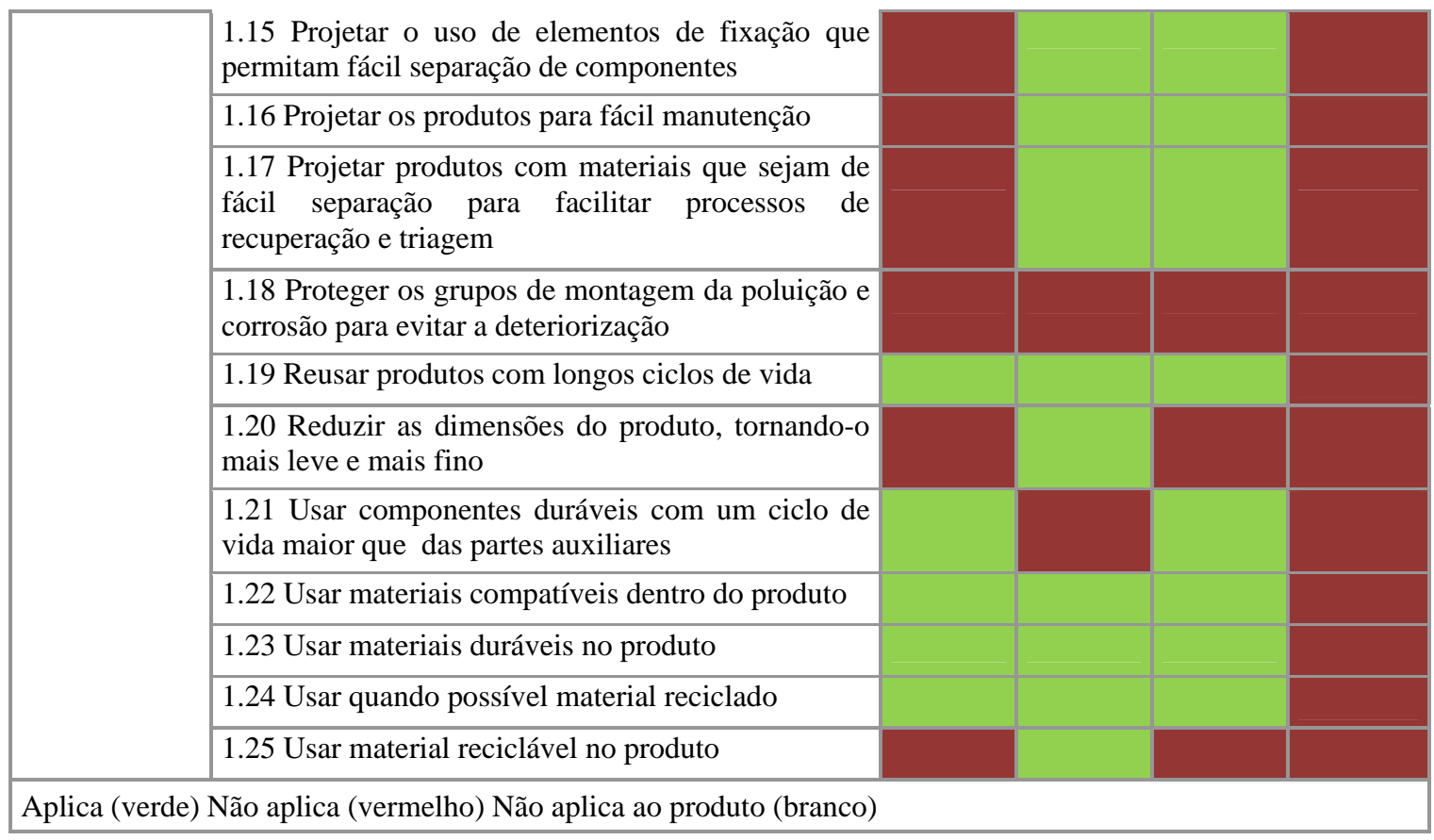

Quadro 19- Comparação da aplicação das Práticas Operacionais das Empresas na Atividade de Recuperação

O Quadro 20 apresenta a aplicação das práticas operacionais da atividade de impactos ambientais por parte das empresas. Verifica-se que três, das quatro empresas estudadas, apresentam preocupação com os impactos ambientais de seus produtos. No entanto, deve-se destacar que a preocupação desses impactos esta baseada no Sistema de Gestão Ambiental da empresa, e não na aplicação de alternativas que visem criar ações mais pró-ativas. Verifica-se, portanto, a necessidade de integrar essas ações pró-ativas desde o processo de desenvolvimento de produtos. Especialmente nas suas fases iniciais, onde são tomadas as decisões, responsáveis pela maioria dos impactos ambientais dos produtos ao longo do seu ciclo de vida.

Outro grande destaque é mencionado por uma empresa, na intenção de usar a Avaliação do Ciclo de Vida (ACV) dentro de seus produtos, com o objetivo de determinar em quais fases se apresentam os maiores impactos ambientais e quais poderiam ser as ações que poderiam ser inseridas para diminuir esses impactos e desenvolver produtos com melhor desempenho ambiental.

De forma geral, pode-se observar que a aplicação das práticas operacionais dentro das empresas que recuperam produtos ainda é limitada, sendo sua origem baseada em ações reativas, e não pró-ativas. No entanto, destaca-se que as empresas começam a perceber como 
a integração dessas práticas operacionais no PDP pode auxiliar a melhorar a produtividade dos processos e a atingir melhores resultados no âmbito da sustentabilidade.

\begin{tabular}{|c|c|c|c|c|c|}
\hline Atividade & Práticas Operacionais & A & B & C & $\mathbf{D}$ \\
\hline \multirow[t]{10}{*}{$\begin{array}{l}\text { Impactos } \\
\text { ambientais }\end{array}$} & $\begin{array}{l}\text { 1. Determinar os impactos ambientais do } \\
\text { produto }\end{array}$ & & & & \\
\hline & $\begin{array}{l}1.1 \text { Determinar os impactos ambientais relacionado } \\
\text { aos recursos consumidos }\end{array}$ & & & & \\
\hline & $\begin{array}{l}1.2 \text { Determinar os impactos ambientais relacionado } \\
\text { às emissões dos produtos }\end{array}$ & & & & \\
\hline & $\begin{array}{l}\text { 1.3 Determinar os impactos } \\
\text { relacionados a ecotoxicidade e exicidade } \\
\text { humana }\end{array}$ & & & & \\
\hline & $\begin{array}{l}\text { 1.3.1 Analisar a toxicidade dos materiais usados no } \\
\text { produto }\end{array}$ & & & & \\
\hline & $\begin{array}{l}\text { 1.3.2 Eliminar a combinação de materiais } \\
\text { corrosivos com os não corrosivos }\end{array}$ & & & & \\
\hline & $\begin{array}{l}\text { 1.3.3 Usar produtos químicos amigáveis ao meio } \\
\text { ambiente ( ex. adesivos solúveis em água) }\end{array}$ & & & & \\
\hline & $\begin{array}{l}\text { 1.3.4 Minimizar o uso de materiais tóxicos no } \\
\text { produto }\end{array}$ & & & & \\
\hline & $\begin{array}{l}\text { 1.3.5 Projetar a remoção e separação de partes que } \\
\text { contenham substâncias tóxicas }\end{array}$ & & & & \\
\hline & $\begin{array}{l}\text { 1.3.6 Projetar unidades fechadas para substâncias } \\
\text { tóxicas }\end{array}$ & & & & \\
\hline \multicolumn{6}{|c|}{ Aplica (verde) Não aplica (vermelho) Não aplica ao produto (branco) } \\
\hline
\end{tabular}




\section{CONCLUSÕES}

Este capítulo descreve as principais conclusões da pesquisa. Inicialmente são destacadas as contribuições conforme as questões e os objetivos traçados no trabalho. Em seguida, são apresentadas as limitações da pesquisa e finalmente as considerações para futuros trabalhos.

\subsection{Contribuições Principais da Pesquisa}

O Quadro 21 apresenta a relação entre as questões da pesquisa, os objetivos e os ressultados obtidos com o trabalho. Destacam-se três resultados principais: 1. A revisão bibliográfica sistemática (RS) que permitiu identificar as 87 práticas de estratégias de fim de vida-EoL, 2. A identificação de 64 práticas operacionais baseadas nessas práticas EoL e 3. A verificação da aplicação das práticas operacionais dentro de empresas que usam a recuperação pos-consumo. Baseado nestes resultados as questões de pesquisa foram respondidas, assim como o objetivo geral traçado dentro do trabalho foi atingido.

\begin{tabular}{|c|c|c|}
\hline Questões da Pesquisa & Objetivos & Resultados \\
\hline $\begin{array}{l}\text { 1. Quais são as práticas de } \\
\text { estratégias de fim de vida } \\
\text { que podem auxiliar o } \\
\text { processo } \\
\text { desenvolvimento de } \\
\text { produtos? }\end{array}$ & $\begin{array}{l}\text { O objetivo do trabalho é levantar as } \\
\text { práticas das estratégias de fim de vida } \\
\text { (EoL) e suas respectivas práticas }\end{array}$ & $\begin{array}{l}87 \text { Práticas de estratégias de } \\
\text { fim de vida-EoL (Capítulo 4). }\end{array}$ \\
\hline $\begin{array}{l}\text { 2. Quais práticas } \\
\text { operacionais, derivadas } \\
\text { das práticas de estratégias } \\
\text { de fim de vida, estão } \\
\text { sendo aplicadas por } \\
\text { empresas que realizam a } \\
\text { recuperação de produtos } \\
\text { pós-consumo no Brasil? }\end{array}$ & $\begin{array}{l}\text { processo de desenvolvimento de } \\
\text { produtos e verificar as que estão sendo } \\
\text { aplicadas por algumas empresas que } \\
\text { realizam a recuperação de produtos pós- } \\
\text { consumo }\end{array}$ & $\begin{array}{l}\text { Derivação das } 64 \text { Práticas } \\
\text { operacionais a partir das } \\
\text { práticas EoL (Capítulo 4). } \\
\text { Verificação da aplicação das } \\
\text { práticas operacionais em } \\
\text { múltiplos estudos de casos } \\
\text { (Capítulo 5). }\end{array}$ \\
\hline
\end{tabular}

Quadro 21 Relação entre as Questões da Pesquisa, os Objetivos e os Resultados do Trabalho

Inicialmente a contribuição geral deste trabalho é preencher a lacuna quanto à falta de trabalhos que visem integrar as questões ambientais dentro do processo de desenvolvimento de produtos (PDP). Neste contexto, a revisão bibliográfica sistemática (RS) trouxe uma 
coletânea de 87 práticas de estratégias de fim de vida (EoL) representadas em diversas técnicas, métodos e ferramentas, que podem ser usadas no PDP junto com seus designers para desenvolvimento de produtos que possam ser recuperados na etapa de pós-consumo. Nessa aplicação podem ser usadas desde guidelines até software que possibilitam a geração e análises de informações e cenários que auxiliam na tomada de decisão à respeito da estratégia de fim de vida mais adequada para o produto a ser desenvolvido. No entanto, observou-se que, em muitos casos, as aplicações das práticas exigem certo nível de conhecimento sobre questões ambientais, o que ressalta a importância da existência de um time multidicisplinar dentro do PDP de forma a alcançar resultados mais adequados dentro do contexto de desempenho ambiental dos produtos.

Outra contribuição do trabalho foi a identificação de práticas focadas para a desmontagem que podem auxiliar os designers a projetar produtos que facilitem essa atividade, assim como, a implementação de programas que visem diminuir os tempos de desmontagem. A desmontagem é uma atividade crucial para uma maior recuperação dos componentes dos produtos no pós-consumo

Com a identificação das 64 práticas operacionais baseadas nas 87 práticas EoL, foi possível realizar uma verificação inicial da aplicação dentro de empresas que praticam a recuperação pós-consumo. Neste sentido, observou-se ainda a pouca aplicação por parte das empresas das práticas operacionais. Na prática, a melhoria contínua do produto decorre pelo feedback dos processos de remanufatura e não pela integração desde o PDP. Além disso, a existência de algumas práticas operacionais que devem ser inseridas, necessariamente, desde as fases iniciais do PDP, impossibilita sua aplicação em fases posteriores do processo de remanufatura (ex. projetar o uso de elementos de fixação que permitam fácil separação de componentes, projetar superfícies lisas no produto para facilitar sua limpeza etc.).

Com a realização da pesquisa de campo, observou-se que as empresas percebem a importância da integração das práticas operacionais identificadas desde o PDP, possibilitando a melhoria do desempenho ambiental dos produtos e aumento das oportunidades que podem ser oferecidas na recuperação de produtos, componentes e materiais. No entanto, ainda existe um nível de maturidade baixo nessa integração, sendo que apenas uma empresa menciona projetos futuros de produtos que já integram a recuperação de produtos pós-consumo desde o PDP.

A inexistência de legislação, caso específico da remanufatura, impede que a recuperação de produtos, seja um mercado totalmente estruturado no Brasil. Além disso, as 
leis atuais não exigem dos fabricantes a integração de programas para a recuperação de materiais que são descartados no pós-consumo.

Finalmente, conclui-se que há um paradoxo entre a teoria e a aplicação nas empresas com relação às práticas operacionais de fim de vida do produto, desde o PDP. Isto é ratificado pelo grande número de práticas existentes na literatura, quando comparadas com a aplicação destas práticas operacionais nas empresas estudadas.

\subsection{Limitações do trabalho}

Durante a fase de execução do trabalho da revisão bibliográfica (RS) surgiu a impossibilidade de consultar alguns estudos que constam em bases de dados não assinadas pela Escola de Engenharia de São Carlos- Universidade de São Paulo (EESC-USP), limitando os resultados dos estudos da RS.

Referente às práticas EoL, não foi possível identificar informações detalhadas de como pode ser realizada a integração desde as fases iniciais do PDP o que leva a uma limitação na integração por parte das empresas, pois muitas delas ainda apresentam um nível baixo nesta visão de integrar desde o PDP a recuperação de produtos pós-consumo.

A não abertura da área de PDP dentro das empresas impossibilitou a verificação das práticas operacionais. Sendo que tal verificação foi realizada desde a percepção do colaborador entrevistado da empresa e pela observação durante a visita técnica.

A verificação das práticas operacionais foi realizada apenas em empresas do setor automótivo. No entanto, muitas das práticas operacionais foram identificadas em práticas EoL que usaram para sua aplicação, estudos de caso no setor eletro-eletrônico o que levou à não aplicação de algumas práticas operacionais por parte das empresas foco deste estudo.

\subsection{Considerações para futuros trabalhos}

A partir deste trabalho, há a possibilidade de sua continuação de forma que possam ser avaliadas e integradas as práticas das estratégias de fim de vida com o PDP.

Realizar estudos focados às características necessárias dos componentes para serem usados em processos que visem a recuperação de produtos.

Observa-se, também, a oportunidade de se agrupar as práticas operacionais identificadas, por grupo de produtos, divididos por setores industriais, de modo a sua futura aplicação por parte dos designers. 
Outra consideração para pesquisas futuras é a realização de outros estudos de caso em empresas que não integrem a recuperação pós-consumo, especificamente na área de PDP, de modo a identificar as possíveis barreiras que os designers podem apresentar no momento de considerar as práticas operacionais dentro do projeto de produtos. 


\section{REFERÊNCIAS ${ }^{16}$}

ALTING, L.; HAUSCHILD, M.; WENZEL, H. Life cycle Engineering and Management. Status and Perspectives In: SELIGER, G. (Ed.). Sustainability in Manufacturing: Recovery of Resources in Product and Material Cycles. Berlin: Springer-Verlag, 2007. Cap. 3, p.3167.

ALTING, L.; LEGARTH, J.B. Life cycle engineering. Annals CIRP, Paris, v.44, n.2, p.569.578, 1995.

ARDENTE, F.; BECCALI, G.; CELLURA, M. Eco-sustainable energy and environmental strategies in design for recycling: the software "ENDLESS". Ecological Modelling, Amsterdam, v.163, n.1/2, p.101-118, May 2003.

ASSOCIAÇÃO BRASILEIRA DE EMPRESAS DE LIMPEZA PÚBLICA E RESÍDUOS ESPECIAIS. Panorama dos resíduos sólidos no Brasil. 2007. Disponível em:<http://www.abrelpe.org.br/panorama_2007.php>. Acesso em: 20 nov. 2009.

ASSOCIAÇÃO BRASILEIRA DE NORMAS TÉCNICAS. ISO/NBR 14.062: Gestão ambiental - integração de aspectos ambientais no projeto e desenvolvimento de produtos. Rio de Janeiro, 2004.

BACK, N. et al. Projeto integrado de produtos: planejamento, concepção e modelagem. São Paulo : Manole, 2008.

BARBIERI, J.C. Desenvolvimento e Meio Ambiente: as Estratégias de mudanças da agenda 21. Petrópolis. Vozes. 1997.

BARQUET, A.P.B. Barreiras e diretrizes para a implementação de um sistema de remanufatura. 2010.246p.Dissertação (Mestre em Engenharia) Departamento de Produção. Universidade Federal de Santa Catarina, Florianopolis, 2010.

BAUMANN, H.; BOONS, F.; BRAGD, A. Mapping the green product development field: engineering, policy and business perspectives. Journal of Cleaner Production, Amsterda, v.10, n.5, p.409-425, Oct. 2002.

BERETON et al., 2007. Lessons from Applying the Sistematic Literature Review Process within the Software Engineering Domain. The Journal of System and Software. v. 80, p.571-583, 2007.

BIOLCHINI, J. et al. Systematic Review in Software Engineering, Technical Report RT ES 679/05, Systems Engineering and Computer Science Department, Universidade Federal do Rio de Janeiro, Brazil. 2005.

\footnotetext{
${ }^{16}$ De acordo com a Associação Brasileira de Normas Técnicas. NBR 6023.
} 
BRAS B., HAMMOND, R.. Towards design for remanufacturing-Metrics for assessing remanufacturability. S. D. Flapper, A. J. de Ron, eds. Proc. 1st Internat. Workshop Reuse (November 11-13). Eindhoven, The Netherlands, 35-52. 1996

BRASIL. Departamento de Negociações Internacionais. Nota Técnica DEINT n 67/2006 Bens Remanufaturados. Brasília, DF, 30 Agosto de 2006.

.Departamento de Comércio Exterior. Portaria DECEX 235/2006. Brasília, DF, 07 de dezembro de 2006.

maio de 1991.

. Departamento de Comércio Exterior. Portaria DECEX 8/1991. Brasília, DF, 13 de

. Presidência da República Casa Civil Subchefia para Assuntos Jurídicos. Lei n. ${ }^{\circ}$ 9.974, de 6 de Junho de 2000.

CARRELL, J.; CHAO ZHANG, H.; LI, H. Review of Current End-of-Life Options for Electronics and Future Automatic Disassembly Options with Shape Memory Materials with Carbon Nanotubes for Electronics. Proceedings of the 15th CIRP Conference on life Cycle Engineering. 2008, Austrália. Annals, 2008. p. 470-475.

CERVANTES, B.M.N. A Construção de tesauros com a integração de procedimentos terminigpraficos. 2009. 210p. Dissertação (Doutor em Ciencias) - Universidade Estadual Paulista, Marilia, 2009.

CHAN, J.W.K.; TONG, T.K.L. Multi-criteria material selections and end-of-life product strategy: Grey relational analysis approach. Materials \& Design. v. 28. P. 1539- 1546. 2007.

CHEN, J.L.; WU, J.N. Neural Network Model for Product End-of-Life- Strategies. Proceedings of the Electronics and the Environment, 2003. on IEEE International Symposium. p. 159-164. 2003

CHUNG, J.; LEE, H.Web based Ecodesign supporting system for electronic products.IEEE.p. 246-250.2003.

CHUNG, C.; PENG, QUINQJIN.A hybrid approach to selective-disassembly sequence planning for de-manufacturing and its implementation on the internet. International Journal Adv Manuf Tecnhnol. V. 30, p. 521-529.2006

CIMDATA. Product Life Cycle Management(PLM) definition, Disponível em: http://www.cimdata.com/plm/definition.html Acesso em: 14 de dezembro de 2009.

CLARK, K. B.; FUJIMOTO, T. Product development performance: strategy, organization 
and management in the world auto industry. Boston-Mass.: Harvard Business School Press, 1991. 409 p.

COMISSÃO DAS COMUNIDADES EUROPÉIAS. O Livro verde sobre a Política Integrada Relativa aos Produtos, Bruxelas, 2001.

COMUNIDADE EUROPÉIA. Parlamento Europeu e do Conselho. Diretiva 2000/53/CE Relativa aos Veículos em Fim de Vida. 23 de Maio de 2000.

Parlamento Europeu e do Conselho. Diretiva 2002/96/CE Relativa à Restrição do uso de determinadas Substâncias Perigosas em Equipamentos Eletro- Eletrônicos. 8 de Novembro de 2002.

Parlamento Europeu e do Conselho. Diretiva 2002/95/CE Relativa aos Resíduos de Equipamentos Eletro- Eletrônicos 8 de Novembro de 2002.

COOPER, J.; LEE, S.J.; BOUSSU, J.; BOMAN, S. Life cycle design metrics for energy generation technologies: Method, data, and case study. Journal Powers Sources. V. 186., p. 138-157. 2009.

CRUZ-RIVERA, R; ERTEL, J. Acumulación de Productos al Final de su Vida Útil en México, El Caso de los Vehículos Automotores. Revista Internacional de. Contaminación Ambiental [online]. v.24, n.3, p. 117-130. 2008.

DESAI, A.; MITAL, A. Incorporating work factors in design for disassembly in product design. Journal of Manufacturing Technology Management, Bradford, v.16, n.7, p.712732, 2005.

DE JESUS, J.B.M. Tesauro: Um Instrumento de representação do conhecimento em sistemas de recuperação da infromação. XII Seminário Nacional de Bibliotecas Universitárias, Recife 2002.

DOS SANTOS, A.; SAMPAIO, C.P.; VEZZOLI, C. Cascade Approach On Recycling For Marble And Granite Product Design. Material and Design.v.30, p. 287291.2009.

ELKINGTON, J. Canibais com Garfo e Faca. Tradução. Patricia Martins Ramalho. São Paulo. Editora Makron Books. 2001. 444p. 
FELDMANN, K.; TRAUTHER, S.; MEEDT, O. Innovative Disassembly Strategies Based on Flexible Partial Destructive Tools. Annual Reviews in Control. v. 23, p.159-164. 1999.

FISKEL, J.; MCDANIEL, J.; SPITZLEY, D. Measuring Product Sustainability. The Journal of Sustainable Product Design. P. 7-16, 1998.

GARETTI M.; TERZI, S. Organisational change and knowledge management in PLM implementation. V. 1., n. 1., p. 43-51.2005.

GEHIN, A.; ZWOLINSKI, P.; BRISSAUD, D. A tool to implement sustainable end-of-life strategies in the product development phase. Journal of Cleaner Production Vol. 16, p. 566576, 2008.

GIL, A.C. Métodos e Técnicas de Pesquisa Social. 5 ed. São Paulo. Editora Atlas. 1999. 206p.

. Como Elaborar Projetos de Pesquisa. 4 ED. São Paulo: Editora Atlas, 2007. 175p.

GIUNTINI, R.; GAUDETTE, K. Remanufacturing: The next great opportunity for boosting US productivity. Business Horizons, v.46, n.6, p.41-48, 2003.

GOEDKOOP, M.J. et al. Product Service Systems: Ecological and Economic Basics. 1999. Disponível em: <http://www.pre.nl/pss/download_PSSreport.htm>. Acesso em: 21 mar. 2009

GONZÁLEZ, B.; ADENSO-DÍAZ, B.A bill of materials-based approach for end-of-life decision making in design for the environment. International Journal of Production Research. V. 43, n. 10,15 p. 2071-2099.2005.

GRAY, C.; CHARTER, M. Remanufacturing and product design: designing for the $7^{\text {th }}$ generation. The Centre for Sustainable Design.University College for the Creative Arts, Farnham, Reino Unido. 2006.

GUANGFU, L.; SHICHUN, B.; ZHIFENG, L.; PENG, C.; QINGDI, K. Product End-of-Life Strategies Based on Neural Network Model. Proceedings of the 15th CIRP Conference on life Cycle Engineering. 2008, Austrália. Annals, 2008. p. 1-5.

GUELERE FILHO, A.; ROZENFELD, H. Integrating Ecodesign Methods and Tools into a Reference Model for Product Development. IV Global Conference on Sustainable 
Manufacturing. 2006.

GUNGOR, A.; Evaluation of connection types in design for disassembly (DFD) using analytic network process. Computers \& industrial engineering.v.50.,p.35-54.2006.

HARJULA, T.; RAPOZA, B; KNIGHT, W.A. BOOTHROYD, G. Design for Dissassembly and the Environment. Annals of the CIRP. v. 45., p. 109-114.1996.

HAUSCHILD, M.; JESWIET, J.; ALTING, L. From Life Cycle to Sustainable Production: Status and Perspectives. Annals of the CIRP 54/2. p.70-87. 2005.

HAUSER, W.; LUND, R.T. Remanufacturing An American Resource. Boston University. 2003. Disponível em: www.bu.edu/reman/RemanSlides.ppt. Acesso em: 30 mar. 2009.

HEISKANEN, E. The Institucional Logic of Life Cycle Thinking. Journal of Cleaner Production. V.10, p. 427-437. 2002.

HUISMAN, J.; BOKS, C.B.; STEVELS A.L.N. Quotes for environmentally weigthed recyclability (QWERTY): concept of describing product recyclability in terms of environmental value.Int. J. Production Research.v. 41., n. 16., p. 3649-3665. 2003.

IJOMAH, W.L. et al. Development of robust design-for-remanufacturing guidelines to further the aims of sustainable development. International Journal of Production Research, v.45, n.18-19, p.4513-4536, 2007.

Development of Design for Remanufacturing Guidelines to Support Sustainable

Manufacturing. Robotics and Computer-Integrates manufacturing. v.23, p.712719.2007.

IJOMAH, W.L.; BENNETT, J.P.; PEARCE, J. Remanufacturing: Evidence of Environmentally Coscious Business Practice in the UK. Ecodesign. First International Symposium on Environmentally Conscious Design and Inverse Manufacturing, pp.192, 1999.

INTERNATIONAL CENTRE FOR TRADE AND SUSTAINABLE DEVELOPMENT (ICTSD). Bens Usados x Remanufaturados: as provavéis mudanças nos cenários comerciais, internacioanl e brasileiro. disponível em http://ictsd.org/i/news/12432/ Acesso em 03 de dezembro de 2009. 
ISHII, K. Incorporating End-of-Life Strategy in Product Definition, Invited paper, EcoDesign'99 First International Symposium on Environmentally Conscious Design and Inverse Manufacturing. Japão. p. 1-6 1999 .

ISO NBR 14.062. Gestão Ambiental- Integração de Aspectos Ambientais no Projeto e desenvolvimento de Produtos. 2004.

JACOBSSON, N. Emerging Product Strategies. Selling Services of Remanufactures Products. 193 f. Licentiate Dissertation-The International Institute for Industrial Environmental Economics.Lund University Sweden, 2000.

JARRAR, Y.F.; ZAIRI, M. Internal transfer of best practice for performance excellence: a global survey. Benchmarking An International Journal, v. 7. n. 4, p. 239-246. 2000.

JESWIET, J.; HAUSCHILD, M. Ecodesign and Future Environmental Impacts. Materials and Design. V. 26, p. 629-634. 2005.

JOHANSSON, G. Success factor for integration of Ecodesign in product development: A review of state of the art. In: Environmental Management and Health, v. 13, n. 1, p. 98-107.2002.

KAEBERNICK, H. Reuse, Recycling and Remanufacturing Impediments for Industrial Implementation. PROCEEDINGS OF THE 14TH CIRP CONFERENCE ON LIFE CYCLE ENGINEERING, 2008, Australia. Annals, 2008. P 5.

KABERNICK, H.; O'SHEA, B.; GREWAL, S.S. A method sequencing the Dissassembly of Products. Annals CIRP. v. 49.p. 13-16.2000.

KARA, S.; POMPRASITPOL, P.; KAEBERNICK, H. Selective Disassembly Sequencing: A Methodology for the Disassembly of End-of-Life Products. S of the Annals of the CIRP, v.55.2006.

KATES, R.W.; PARRIS, T.M.; LEISEROWITZ, A.A. What is sustainable development? Goals, indicators, values, and practice. Environment: Science and Policy for Sustainable Development, v.47, n.3, p.8-21, 2005.

KERNBAUM, S.; HEYER, S.; CHIOTELLIS, S.; SELIGER, G.Process planning for ITequipment remanufacturing. CIRP Journal of Manufacturing and Technology. Article in press.2009. 
KIM, K.; HWANG, Y.; PARK, K. An assessment of the recycling potential of materials based on environmental and economic factors; case study in South Korea. Journal of Cleaner Production. v.17, p. 1264-1271. 2009.

KING, A.M., et al. Reducing Waste: Repair, Recondition, Remanufacture or Recycle?. Sustainable Development. v.14, p. 257-267. 2006.

KRIWET, A.; ZUSSMAN, E.; SELIGER, G. Systematic Integration of Design-for-Recycling into Product Design. International Journal of Production Economics. v.38, p. 15-22.1995.

KUO, T.C. The construction of a collaborative-design platform to support waste electrical and electronic equipment recycling. Robotics and Computer-Integrated Manufacturing.v. 26., p. 100-108. 2009.

KURK, F.; EAGAN, P. The value of Adding Design-for-the-Environment to Pollution Prevention Assistance Options. Journal Cleaner Production. v. 16 p.722-726.2008.

LAKATOS, E.M.; MARCONI, M.A. Fundamentos de Metodologia Científica. 3 ed.São Paulo: Editora Atlas.1991. 249p.

LEE, H.M. et al. System Architecture for Design and EoL Information Integration Framework. International Conference on Product Lifecycle Management, p.1-10, 2008. 2008. A Framework for Design and End-of-Life Integration (DELII). LCE Annals. p.2-6.

LEE, S.G.; LYE, S.W.; KHOO, M.K. .A Multi-objective merhodology for evaluating product End-of life Options and Disassembly. Advanced Manufacturing Technology. V. 18, p. 148156. 2001.

LEUNG, R. Facilitating DfE in enterprises: the taiwan Green Design Network .International IEEE conference on Asian Green Electronics (AGEC). P. 164-166.2004.

LINDAHL, M.; SUNDIN, E.; OSTLIN, J. Environmental Issues within the Remanufacturing Industry. Proceedings of the 14th CIRP Conference on life Cycle Engineering. 2008, Suécia. Annals, 2006. P 447-452.

LINDHQVIST, T. Extended Producer Responsibility in Cleaner Production. Policy Principle to promote environmental. Tese de doutorado. University Lund. The International Institute for Industrial Environmental Economics. Suécia 2000. 
LUTTROPP, C.; LAGERSTEDT, J. Ecodesign and the Ten Golden Rules: generic advice for Merging Environmental Aspects into Product Development. Journal Cleaner Production. v. 14 p.1396-1408.2006.

MABEE, D.G.; BOMMER, M.; KEAT, W.D. Design charts for remanufacturing assessment. Journal of manufacturing systems. v.18.,n.5, p. 358-366.1999

MACHADO, M.C.; TOLEDO, N.N. Gestão do Processo de Desenvolvimento de Produtos: uma abordagem baseada na criação de valor. São Paulo. Editora Atlas, 2008. 147p.

MANGUN, D.; THURSTON, D.L. Incorporating Component Reuse, Remanufacture, and Recycle Into Product Portfolio Design. IEEE Transactions on Engineering Management. v. 49., n. 4. p. 479-490.2002.

MANZINI, E.; VEZZOLI, C. O Desenvolvimento de Produtos Sustentáveis: os requisitos ambientais dos produtos industriais. Tradução Astrid de Carvalho. São Paulo. Editora da Universidade de São Paulo, 2002. 367p.

MASANET, E.; TSUDA, R.A.D.; BAYNES T.B.A. An assessment and priorization of "Design for recycling Guidelines for plastics components. IEEE. P.5-10. 2002.

MATHIEUX, F.; FROELICH, D.; MOSZKOWICZ, P. ReSICLED: a new recoveryconscious design method for complex products based on a multicriteria assessment of the recoverability. Journal of Cleaner Production. v.16, p.277-298. 2008.

McKERLIE, K.; KNIGHT, N.; THORPE, B. Advancing Extended Producer Responsibility in Canada. Journal of Cleaner Production. v. 14, p.616-628.2006.

MEMEI, G. ZHOU, M.; CAUDILL, R.J. Developmentod Demanufacturing Module for Multi-lifecycle Assessment and Analysis of produtcs. Systems, Man, and Cybernetics, 2001 IEEE International Conference . IEEE. v. 3, P. 1856-1861.2001.

MILANEZ,B.; BÜHRS, T. Extended producer responsibility in Brazil: the case of tyre waste. Journal Cleaner Production, v.17, p.608-615, 2009 
MONT, O.K. Clarifying the concept of product-service system. Journal of Cleaner Production, v.10, n.3, p.237-245, 2002.

MURTAGH, N.; BAMBA, T.; IWAMA, K. An Evaluation Tool for Eco-Design of electrical Products.Environmentally Conscious Design and Inverse Manufacturing, 1999. Proceedings. EcoDesign '99: First International Symposium On Tokio. Japão. 1999.

NASR,N.; HILTON, B. Design for Remanufacturing. Proceedings of the 15th CIRP Conference on life Cycle Engineering. 2008, Austrália. Annals, 2008. P 19-22.

NIELSEN, P.H.; WENZEL, H. Integration of Environmental Aspects in Product Development: a Stepwise Procedure based on Quantitative Life Cycle Assessment. Journal of Cleaner Production. v. 10, p. 247-257. 2002.

OIKO, O.T., et al. Além do Projeto Conceitual: A Remanufatura No Processo de Desenvolvimento de Produtos. XXXIX Encontro Nacional de Engenharia de produção. ENEGEP 2009.

ONG, S.K.; T.H. KOH, NEE A.Y.C.Development of a Semi-quantitative pre-LCA tool .Journal of Materials Processing Technology. N. 89-90, p.574-582.1999.

PIGOSSO, D. A. Integração de métodos e ferramentas do eco-design ao Processo de Desenvolvimento de Produtos. (Relatório final de Iniciação Científica apresentado à FAPESP). São Carlos, 2008.

PIGOSSO, D.C.A, et al. Ecodesign Methods Focused on Remanufacturing. Journal of Cleaner Production. V. 18, p. 21-31. 2010.

POSSAMAI, O.; VALENTINA, L.V.O.D. A model of Evaluation of Design for Disassembly. Product Management \& Development, v. 5, n. 2, p. 133-137.2007

POSSAMAI, O.; VALENTINA, L.V.O.D. A model of Evaluation of Design for Disassembly. Product Management and Development, v. 5, n. 2, p. 133-137.2007.

RANKY,P.G.; CAUDILL, R.J.; DAS, S.K.A web-enabled Virtual Disassembly Manager (webVDM) for electronics Products.IEEE anais.2001. 
ROMANO, L.N. Modelo de referência para o processo de desenvolvimento de máquinas agrícolas. (tese de doutorado). Universidade Federal de Santa Catarina. Programa de Pósgraduação em Engenharia Mecânica. P.323.2003.

ROSE. C. Design for Environment: A Method for Formulating Product End-of-life Strategies.Ph D Dissertation. Stanford University. 2000.

ROSE, C.M.; BEITER, K.A.; ISHII, K. Determining End-of-life Strategies as Part of Product Definition. IEEE International Symposium on Electronics and the Environment Danyers. MA, USA. p. 219-224. 1999.

ROSE, C.M; ISHII, K.; STEVELS, A.. ELDA and EVCA: Tools for Building product Endof-Life Strategy. The Journal of Sustainable Product Design. v. 1, p.181-195.2001. Influencing Design to Improve Product End-of-life Stage. Research in Engineering Design. v. 13, p. 83-93. 2002.

ROSEMANN et al. Design for Recycling, recycling data management and optimal end-of-life plannign based on recycling-graphs. International Conference on Engineering Design ICED 99. Munich .1999.

ROSSI, R. M. Método para análise interna das organizações: uma abordagem a partir da Resource-Advantage Theory. Tese (Doutorado em Engenharia de Produção) - Programa de Pós-Graduação em Engenharia de Produção, UFSCar, São Carlos, 2009.

ROZENFELD, et al. Gestão do Desenvolvimento de Produtos. Uma referência para a melhoria do processo. São Paulo. Saraiva. 2006. 542 p.

SAAVEDRA, Y.M.B; SOUSA, S.R.; OMETTO, A.R. Sistema produto-serviço e Remanufatura Como Alternativas no Desenvolvimento de Ciclo de Vida Sustentáveis. Simpósio de Engenharia de Produção. XVI SIMPEP. 2009

SAND, J.C.; GU, P.; WATSON, G.HOME: House of Modular Enhacement a tools for modular product redesign. Concurrent engineering: Research and aplications. V.10, n. 2., 
p. 153-164. 2002.

SANTOCHI, M.; DINI, G.; FALILLI, F. Computer Aided Disassembly Planning: State of the Art and Perspectives. Annals CIRP.2002.

SANTOS, A.; SAMPAIO, C.P.; VEZZOLI, C. Cascade approach on recycling for marble and granite product design. Material and Design, v.30, p.287-291, 2009.

SCHARNHORST, W.; ALTHAUS, H-J.; CLASSEN, M.; JOLLIET, O.; HILTY, L.M.The end of life treatment of second generation mobile phone networks: Strategies to reduce the environmental impact. Environmental Impact assessment. V. 25., p. 540-566. 2005.

SEITZ, M.A.;WELLS, P.E. Challenging the Implementation of Corporate Sustainability. The case of automotive engine remanufacturing. Business Process Managament Journal, v. 12, n.6, p. 822-836,2006.

SELIGER, G.; BASDERE, B.; KEIL, T. e-Cycling Platform for Profitable Reuse. International Symposium on Assembly and Task Planning Soft Research Park. p. 453457.2001.

SELIGER G.; WEINERT, N.; ZETTL, M. Module Configurator for the Development of Products for Ease of Remanufacturing. In: TAKATA, S.; UMEDA, Y. (Ed.). Proceedings of the 14th CIRP Conference on Life Cycle Engineering, p.47-52, 2007.

SELIGER, G. et al. European Remanufacturing Market Analysis on example products Medical Treatment machines and Industrial Robots. Interim Report. Technishe Universitat Berlin. Department of Machine Tools and Factory Management, 2009.

SHU, L.H.; FLOWERS, W.C. Considering Remanufacture and other End-of-life-options in Selection of Fastening and Joining Methods. Procedings of IEEE International Symposium on Electronics \& the Environment, p. 75-80, 1995.

SILVA, E. L.; MENEZES, E. M. Metodologia da pesquisa e elaboração de dissertação. 4.ed. Florianópolis: UFSC, 2005. 138 p.

SPICER, A.; WANG, M.H. Environmental Design Industrial Template (EDIT): A Software tool for Analysis of Product Retirement. Journal Cleaner Production, v. 5, n. 3 p. 193-198, 1997.

STAIKOS, T.; RAHIMIFARD, S. An end-of-life decision support tool for product recovery 
considerations in the footwear industry. International Journal of computer integrated manufacturing. v.20, n.6, p. 602-615.2007.

STEINHILPER, R. Remanufacturing: the ultimate form of recycling. 1998. Disponível em http://www.reman.org/Publications_main.htm . Acesso em: 27 jun 2008.

STEVELS, A.; BOKS, C. Lessons Learned From 10 Years take-back and Recycling. Proceedings of the 7th CIRP International Seminar on Life Cycle Engineering, IEEE. p.30-37. 2000.

SUCH, G. et al, E. Process Oriented Framework to Support PLM Implementation. Computers in Industry. V. 59, p. 210-218. 2008.

SUN,J., et al. Design For Environment: Methodologies, Tools and Implementation. Society for Design and Process Science. v.7, n.1, p. 59-75. 2003.

SUNDIN, E. Product and Process Design for Successful Remanufacturing. $\mathrm{PhD}$

Dissertation, Linköping's Universitet. 2004.

SUNDIN, E. LINDAHL, M. Rethinking Product Design for Remanufacturing to facilite Integrated Porduct Service Offerings. International Symposium on Electronics and the Environment. Estados Unidos.p.1-6. 2008.

SUNDIN, E ;ÖSTLIN, J. Case Study Analysis of three toner cartridge remanufaturers. 4th International Symposium on Environmentally Conscious Design and Inverse Manufacturing p. 460-465. 2005.

THIERRY,M. et al. Strategies Issues in Product Recovery Management. California Management Review, v.37, n.2, p.114-135, 1995.

UMEDA, Y.; KONDOH, S.; SUGINO, T. Analysis of Reusability "Marginal Reuse Rate”. Annals of the CIRP. v. 55. p.1-4. 2006.

UNITED NATIONS ENVIRONMENT PROGRAMME (UNEP). The role of Product Service Systems in $a$ sustainable society. Disponível em: http://www.unep.fr/scp/design/pdf/pss-brochure-final.pdf . Acesso em: 20 set. 2008. 
. Life Cycle Management. A Business Guide to Sustainability 2007. Disponível em: http://www.uneptie.org/shared/publications/pdf/DTIx0889xPA-lifeCycleManagement.pdf . Acesso em: 14 de setembro de 2009.

UNITED NATIONS ENVIRONEMT PROGRAMME. Division of Technology Industry and Economics. Financing cleaner production - profiting from cleaner production. Resource Kit for Training Checklists for Action. Disponível em: $<$ www.financingcp.org/training/training.html $>$. Acesso em: 30 June 2008.

WANYAMA, W et al. Life-cycle engineering: issues, tools and research. Journal of Computer Integrated Manufacturing, v. 16, n.4-5, p. 307-316, 2003.

WEENEN, J. C. Towards sustainable product development. Journal of Cleaner Production, v. 3, n. 1-2, p. 95-100, 1995.

WILLEMS,B. et al, Contribution to Design for Adaptation: Method to asses the adaptability of products (MAAP).Proceedings of EcoDesign 2003: Third International Symposium on Environmentally Conscious Design and inverse Manufacturing; Tokyo, Japan, December 8-11,p. 589-596. 2003.

WILLIEMS, B.; DEWULF, W.; DUFLOU, J. A Method to Assess the Lifetime Prolongation Capabilities of Products. International Journal Sustainable Manufacturing. v.1, n 1-2, p. 122-144. 2008.

WORLD COMMISSION ON ENVIRONMENT AND DEVELOPMENT - WCED. Our Common Future. New York, Oxford: University Press, 1987.

WORLD TRADE ORGANIZATION: Negotiating Group on Market Access. WTO TN/MA/18/ Addendum. Negotiatin Non-Tariff Barriers Related to Remanufacturing and Refurbishing: Communication from teh United States. Geneva, Suiça: 05 de dezeembro de 2005.

WRIGHT, et al. E..Improving recyclability by design: a case study of fibre optic cable. Resources conservation and recycling.v 44., p.37-50. 2005.

XING, K.; LUONG, L.; ABHARY, K. A methodical to enhance reutilisation potential in product design. Conference International on Asian Green Electrics, 2005

YIN, R.K. Estudo de Caso. Planejamento e Métodos. São Paulo. Editorial Bookman. 2005.

ZANCUL, E.S. Gestão do Ciclo de Vida de Produtos: Seleção de Sistemas PLM com base em Modelos de Referência. 2009.212p.Dissertação (Doutorado em Engenharia) Departamento de Engenharia de Produção. Universidade de São Paulo, São Carlos, 2009. 
ZANETTE, E.T. Levantamento dos Cenários Tecnológicos da Remanufatura de Bens de Capital no Brasil. (Relatório final de Iniciação Científica apresentado à CNPq). São Carlos, 2008.

ZHANG, H.C., YU, S.Y; ERTAS,A. Environmental Conscious Design: An Introduction to EDST.Society for Design and Process Science, v. 3, n.4 p. 27-38, 1999.

ZWOLINSKI, P.; LOPEZ-ONTIVEROS, M.A.; BRISSAUD, D. Integrated design of remanufacturable products based on product profiles. Journal of Cleaner Production, v.14 p. 1333-1345, 2006.

ZWOLINSKI, P.; SGHAIER, A.; BRISSAUD, D. Definition of a VR Tool for early design stage of the product structure under consideration of disassembly. 14th CIRP Conference on Life Cycle Engineering. P. 71-76. 2007 


\section{APÊNDICES}

\section{Apêndice A- Regulações e Políticas relacionadas à Recuperação de Produtos}

O Japão e a União Européia são considerados os países com maiores níveis de desenvolvimento relacionados aos marcos legais de regulamentação ambiental, responsabilizando cada vez mais os fabricantes pelo destino final dos produtos. Outros países menos desenvolvidos também vêm realizando esforços para regulamentar aspectos ambientais para os diferentes setores industriais das economias internas. No caso do Brasil, observa-se que a legislação ambiental ainda é limitada e pouco estruturada e regulamentada, situação que dificulta a integração e conscientização ambiental para o ciclo de vida dos produtos comercializados pelas empresas. O Quadro 22 resume as leis/políticas relacionadas à recuperação de produtos, vistas no contexto internacional e nacional, e descritas brevemente a seguir.

\begin{tabular}{|c|c|c|}
\hline Leis/Política & Objetivos & $\begin{array}{l}\text { País de } \\
\text { Origem }\end{array}$ \\
\hline $\begin{array}{c}\text { Política Integrada } \\
\text { Relativa aos } \\
\text { Produtos (IPP) } \\
\end{array}$ & $\begin{array}{l}\text { Produtos mais Ecológicos e consumo mais eficiente por parte dos } \\
\text { consumidores. }\end{array}$ & União Européia \\
\hline $\begin{array}{l}\text { Responsabilidade } \\
\text { Estendida do } \\
\text { Produtor (REP) }\end{array}$ & $\begin{array}{l}\text { Maior acompanhamento por parte das empresas dos seus produtos ao } \\
\text { longo do ciclo de vida, incluindo a etapa de pós-consumo, buscando } \\
\text { mudanças e melhorias ambientais ao longo do ciclo. }\end{array}$ & União Européia \\
\hline $\begin{array}{l}\text { Fim de Vida de } \\
\text { Veículos (ELV) }\end{array}$ & $\begin{array}{l}\text { Melhorar, recuperar e reduzir os resíduos provenientes dos veículos. } \\
\text { Projetar veículos integrando as questões ambientais e recuperção de } \\
\text { produtos com seus componentes e materiais. }\end{array}$ & União Européia \\
\hline $\begin{array}{c}\text { Restrição de } \\
\text { Substâncias } \\
\text { Perigosas (RoHS) }\end{array}$ & Restringir o uso de susbtâncias perigosas ao meio ambiente & União Européia \\
\hline $\begin{array}{l}\text { Resíduos de } \\
\text { Equipamentos } \\
\text { Eletro-Eletrônicos } \\
\text { (WEEE) }\end{array}$ & Incentivar a reciclagem de equipamentos eletro-eletrônicos & União Européia \\
\hline $\begin{array}{l}\text { Lei } N^{\circ} 12.305 \text {, de } 2 \\
\text { de Agosto de } 2010 .\end{array}$ & Política Nacional de Resíduos Sólidos & Brasil \\
\hline
\end{tabular}




\begin{tabular}{|c|l|c|}
\hline Lei no 9.974/00 & $\begin{array}{l}\text { Recolhimento e destinação final das embalagens dos produtos } \\
\text { fitosanitários (agrotóxicos) }\end{array}$ & Brasil \\
\hline $\begin{array}{c}\text { Nota Técnica (n } \\
\text { 67/2006) }\end{array}$ & $\begin{array}{l}\text { Define a remanufatura, estabelece diferenças entre as outras } \\
\text { estratégias de fim de vida e destaca alguns aspectos econômicos e } \\
\text { positivos da remanufatura. }\end{array}$ & Brasil \\
\hline $\begin{array}{c}\text { DECEX n⿳8 e } \\
\text { DECEX n }{ }^{\circ} \text { 235 }\end{array}$ & $\begin{array}{l}\text { Restrição da importação de bens usados, aplicado também para } \\
\text { produtos remanufaturados. }\end{array}$ & Brasil \\
\hline
\end{tabular}

Quadro 22-Leis/Políticas Relacionadass à Recuperação de Produtos

\section{- Política integrada relativa aos produtos (IPP)}

A Política Integrada Relativa aos Produtos (IPP) é uma abordagem criada pela União Européia e traça como desafio tornar os produtos mais ecológicos, onde as ações devem ser adotadas, principalmente, por empresas e consumidores (HAUSCHILD; JESWIET, ALTING, 2005).

A abordagem de IPP visa promover o desenvolvimento de produtos mais ecológicos e tornar mais eficiente o consumo desses bens por parte dos consumidores, reduzindo os impactos ambientais ao longo do ciclo de vida dos produtos, desde sua extração até as fases de produção, distribuição, utilização, tratamento e gestão de resíduos.

As empresas são motivadas a tomar decisões para incorporar soluções relacionadas aos impactos ambientais dos produtos. Uma vez o produto lançado no mercado, é pouco o que pode ser realizado para melhorar as suas características ambientais (COMISSÃO DAS COMUNIDADES EUROPÉIAS, 2001). Por sua vez, os esforços realizados na fase de design para conseguir produtos mais ecológicos serão inúteis se os consumidores não adquirirem uma consciência ambiental pelo consumo destes bens.

\section{- Responsabilidade estendida do produtor (REP)}

O conceito de Responsabilidade Estendida do Produtor (REP) derivada do termo em inglês Extender Producer Responsability (EPR), apareceu nos inícios dos anos 90’, na Suécia, em um relatório para o Ministério do Meio Ambiente, elaborado por Lindhqvist ${ }^{17}$ (1990 apud Lindhqvist, 2000). Neste trabalho, foram analisados os esquemas de gestão de resíduos e

17 Lindhqvist, T, e Lidgren, K. (1990). Modeller för förlängt producentansvar [Models for Extended Producer Responsibility]. In Ministry of the Environment, Frånvaggan till graven - sex studier av varors miljöpåverkan [From the Cradle to the Grave - six studies of the environmental impact of products]. (Ds 1991:9). 
reciclagem, assim como o uso de vários instrumentos políticos para promover a produção mais limpa. Em 2000, o próprio autor apresentou a definição de REP como sendo: “a iniciativa de promover a redução de impactos ambientais e aumentar o comprometimento dos fabricantes por seus produtos ao longo do ciclo de vida, especialmente na fase de pósconsumo, integrando estratégias de fim de vida (EoL) e de disposição final adequada”. Ainda, destaca que sua implementação é conduzida por meio de instrumentos informativos, administrativos e econômicos. Menciona que é uma abordagem consistente com o princípio poluidor-pagador ${ }^{18}$.

Já a Organization for Economic Cooperation and Development (OECD) define a responsabilidade estendida do produtor como uma política ambiental em que a responsabilidade seja física e/ou financeira do produtor se estende até a fase de pós-consumo do produto. Ou seja, os fabricantes têm a responsabilidade de buscar, nas diferentes fases de vida de um produto, mudanças e melhorias ambientais.

Por sua vez, Manzini e Vezzoli (2002) ressaltam como a REP aciona a capacidade dos produtores na solução de problemas (neste caso de resíduos). As empresas que se responsabilizam por seus produtos na etapa de pós-consumo estimulam a criatividade e conhecimento, especialmente no projeto do produto, sobre medidas que possibilitem fechar o ciclo de vida desses de uma forma mais eficiente. McKerlie, Knight e Thorpe (2006) apresentam como a REP pode estimular a inovação de produtos e a prevenção da poluição por meio de atividades como:

- $\quad$ Redução de materiais, insumos e energia;

- $\quad$ Eliminar o uso de substancias tóxicas no produto;

- $\quad$ Incrementar o uso de materiais recicláveis e reciclados;

- $\quad$ Melhorar a eficiência de sistemas de transporte e processos de produção;

- $\quad$ Estender o uso de vida útil dos produtos;

- $\quad$ Incrementar a oportunidade de recuperação e reuso do produto na sua fase de fim de vida e

18 Conforme Barbieri (2006), o princípio do Poluidor-pagador impõe ao estado o dever de estabelecer um tributo ao agente poluidor, usuário ou não do serviço público destinado a tratar a poluição. Dos seus objetivos, o primeiro é de natureza fiscal, relacionado a arrecadar receita para custear os serviços públicos ambientais evitando que os prejuízos dos poluidores recaiam sobre a sociedade. O segundo, de natureza extrafiscal, o qual induz a um comportamento ambiental preventivo por parte dos agentes privados. 
- $\quad$ Criar novas formas de entregas do produto como, por exemplo, o Sistema ProdutoServiço (SPS).

Milanez e Buhrs (2009) também acrescentam que a REP é uma das alternativas que permitem integrar práticas sustentáveis e estratégias de fim de vida. Na União Européia e no Japão, por exemplo, já estão em vigor legislações a respeito da REP.

\section{- Fim de vida de veículos (ELV)}

As diretrizes para a destinação do fim de vida de veículos, derivada do inglês End of life Vehicles (ELV), foram indicadas pela União Européia, no ano de 2000, pela diretiva 2000/53/CE, com a intenção de recuperá-los, reduzir os resíduos e obter uma melhoria da qualidade ambiental do produto. As principais ações estão centradas na coleta, reuso e reciclagem destes veículos (CRUZ-RIVERA; ERTEL, 2008; GEHIN et al., 2008). Entre os objetivos traçados estão:

i. Esforço por reduzir o uso de substâncias perigosas no desenvolvimento dos veículos;

ii. Desenho e produção de veículos que facilitem a desmontagem reuso, recuperação e reciclagem no fim de vida dos veículos;

iii. Incrementar o uso de materiais reciclados na manufatura de veículos; e

iv. Assegurar que os componentes dos veículos liberados no mercado a partir do dia 03 de julho de 2003 não contenham substâncias como mercúrio, cromo hexavalente, cádmio ou chumbo.

A estratégia de fim de vida dos veículos visa diminuir os prejuízos que podem ser causados pelos seus materiais e componentes para o meio ambiente e para a sociedade. $\mathrm{O}$ propósito é incentivar as empresas a projetar os veículos integrando as questões ambientais e a recuperação de produtos com seus componentes e materiais na etapa de pós-consumo.

\section{- Restrição de substâncias perigosas (RoHS) e resíduos de equipamentos eletro-eletrônicos (REEE)}

A iniciativa da restrição de substâncias perigosas derivada do inglês Restriction of the Use of certain Hazardous Substances in Electrical and Electronic Equipment (RoHS), diretiva 2002/95/CE e de Resíduos de Equipamentos Eletro-Eletrônicos derivada do inglês 
Waste Electrical and Electronic Equipment (WEEE), diretiva 2002/96/CE da união Européia, começaram oficialmente, no dia 01 de julho de 2006. A RoHS restringiu o uso de substâncias perigosas no meio ambiente e a WEEE iniciou a reciclagem de equipamentos eletroeletrônicos.

A WEEE é uma abordagem que estimula os designers a desenvolver produtos com foco na reciclagem. Gehin et al. (2008) destacam o Japão como o país que mais alcançou pressionar as empresas para que busquem eliminar o chumbo nos equipamentos eletrônicos, assim como, também inseriu uma lei aplicada ao consumidor, a qual demanda a reciclagem de um número de itens eletrônicos domésticos por cada um.

Gehin et al. (2008) mencionam que nos próximos anos as regulações exigirão, das empresas, o desenvolvimento de produtos com menores danos ambientais e que incrementem o uso de recuperação de produtos e materiais. Essas tarefas são consideradas como fundamentais e críticas, pelos desenvolvedores e designer, para o sucesso do produto no mercado.

\section{- Legislação brasileira e acordos internacionais}

Atualmente, no Brasil existem algumas leis, decretos e políticas que apresentam uma relação na parte de responsabilidade estendida do produtor, recuperação de produtos, e disposição adequada dos resíduos gerados para alguns produtos específicos. Entretanto, a falta de estrutura das empresas e do governo limita o acompanhamento dos produtos ao longo do ciclo de vida.

Em um contexto mais amplo pode ser descrita a lei $\mathrm{n}^{\circ} 12.305$, de 02 de agosto de 2010, que institui a Política Nacional de Resíduos Sólidos. Esta lei define diretrizes relativas à gestão integrada e ao gerenciamento de resíduos sólidos, incluindo os perigosos, às responsabilidades pelos geradores e do poder público e aos instrumentos econômicos aplicáveis.

O Capítulo II, artigo 6, destaca os princípios e os objetivos. Dentre os princípios destaca-se: a prevenção e a precaução, o poluidor-pagador e o protetor-recebedor, o desenvolvimento sustentável, a ecoeficiência, a cooperação entre as diferentes esferas do poder público, o setor empresarial e demais segmentos da sociedade, a responsabilidade compartilhada pelo ciclo de vida dos produtos, o reconhecimento do resíduo sólido reutilizável e reciclável como um bem econômico e de valor social, gerador de trabalho e 
renda e promotor de cidadania. Já o artigo 7, correspondente aos objetivos, menciona: a não geração, redução, reutilização, reciclagem e tratamento dos resíduos sólidos, bem como disposição final ambientalmente adequada dos rejeitos; estímulo à adoção de padrões sustentáveis de produção e consumo de bens e serviços; adoção, desenvolvimento e aprimoramento de tecnologias limpas como forma de minimizar impactos ambientais, incentivo à indústria da reciclagem, tendo em vista fomentar o uso de matérias-primas e insumos derivados de materiais recicláveis e reciclados, produtos reciclados e recicláveis. Integração dos catadores de materiais reutilizáveis e recicláveis nas ações que envolvam a responsabilidade compartilhada pelo ciclo de vida dos produtos, estímulo à implementação da avaliação do ciclo de vida do produto, incentivo ao desenvolvimento de sistemas de gestão ambiental e empresarial para a melhoria dos processos produtivos e ao reaproveitamento dos resíduos sólidos, incluídos a recuperação e o aproveitamento energético e, finalmente, o estímulo à rotulagem ambiental e ao consumo sustentável.

Como instrumentos desta política são destacados: a coleta seletiva, os sistemas de logística reversa e outras ferramentas relacionadas à implementação da responsabilidade compartilhada pelo ciclo de vida dos produtos, a cooperação técnica e financeira entre os setores público e privado para o desenvolvimento de pesquisas de novos produtos, métodos, processos e tecnologias de gestão, reciclagem, reutilização, tratamento e disposição final ambientalmente adequada de rejeitos.

De outro lado, casos específicos foram regulamentados, como a responsabilidade estendida do produtor-REP com relação a embalagens de agrotóxicos, a qual pode ser verificada na Lei $\mathrm{n}^{\circ}$ 9.974/00, que determina o recolhimento e destinação final das embalagens dos produtos fitossanitários (agrotóxicos), estabelecendo responsabilidades entre agricultores, canais de distribuição, indústria e poder público.

No que se refere às estratégias de fim de vida (EoL), aparece o caso dos produtos remanufaturados. A nota técnica ( $\mathrm{n}^{\circ}$ 67/2006) do Departamento de Negociações Internacionais do Ministério do Desenvolvimento, Indústria e Comércio Exterior do Brasil define a remanufatura "como o processo de desmontagem de produtos onde as partes são limpas, reparadas ou trocadas, sendo montadas de forma que apresentem perfeitas condições de funcionamento". Além disso, o documento enfatiza aspectos ambientais e econômicos positivos da remanufatura, estabelecendo diferenças com as outras estratégias de fim de vida (reuso, reparo, recondicionamento e reciclagem).

Conforme a legislação brasileira, os produtos remanufaturados têm a mesma condição de produtos usados e sua comercialização e importação, tem que seguir a portaria DECEX 
n8, de 13 de maio de 1991, dentro dos artigos 22 a 27, Titulo XI e a portaria DECEX n 235, de 07 de dezembro de 2006 do Ministério de Estado do Desenvolvimento, Indústria e Comercio Exterior (MDIC). Por meio destas Portarias, é restringida a importação de bens usados, aplicado neste caso também para produtos remanufaturados. Contudo, o documento menciona que existem algumas exceções para aqueles sem cobertura cambial e para doação.

Devido a estas restrições, os Estados Unidos entraram com uma representação contra o Brasil na Organização Mundial de Comercio (OMC), mencionando que o país impõe barreiras não-tarifárias sobre tais produtos (WTO TN/MA/W/18/Add.11, de dezembro de 2005). No documento aparecem algumas menções aos produtos remanufaturados, exigindo a destinação que deve ser realizada frente aos bens usados e como esses produtos devem passar por um processo industrial que permita obter a funcionalidade, garantia e qualidade equivalente a um produto novo. O documento também destaca os benefícios desses produtos para a economia e para o meio ambiente, visto seus potenciais fundamentados nos princípios dos 3Rs (Reduzir, Reutilizar e Reciclar ).

Como resposta às alegações apresentadas pelos Estados Unidos, o Brasil apresentou argumentos como: a proposta não garante a inspeção e os testes dos bens, além de não prever ao fabricante a garantia sobre os bens comercializados como se novos fossem: a capacidade do consumidor para conferir a qualidade de um bem remanufaturado, especificamente, quando apenas partes de um bem são remanufaturadas. A principal preocupação é a de transformar o país em um grande lixeiro por causa da importação desses bens usados ou remanufaturados (INTERNATIONAL CENTRE FOR TRADE AND SUSTAINABLE DEVELOPMENT, 2009).

Zanette (2008) menciona que diversos órgãos do governo brasileiro se manifestaram diante do documento dos Estados Unidos, como a câmara de comércio exterior, Departamento das Indústrias de Equipamentos de Transporte, a Secretaria de Assuntos Internacionais do Ministério de Fazenda. Como essa discussão não evoluiu internamente no país e, ainda, não há marco legal sobre o assunto, as discussões sobre a importação de produto remanufaturados pelo Brasil estão estagnadas.

As diferentes legislações/políticas visam recuperar os produtos na fase de pósconsumo, onde se apresentam a maioria dos impactos causados pela inadequada disposição final. No entanto, a importância de integrar EoL são necessárias para alcançar uma adequada recuperação desses produtos e uma integração desses materiais à cadeia produtiva. 


\section{Apêndice B - Protocolo Carta de Apresentação}

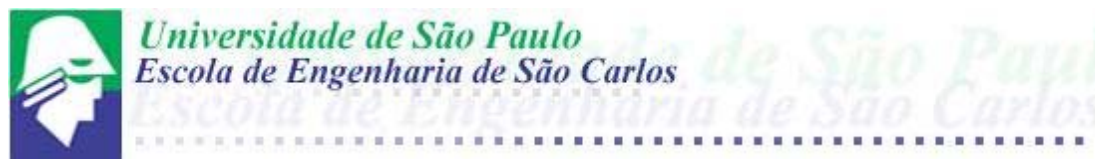

\section{Prezado Senhor,}

Meu nome é Yovana M.B. Saavedra, sou formada em Engenharia Ambiental e coordeno um Projeto de Pesquisa no Programa de Pós-Graduação do Departamento de Engenharia de Produção da Universidade de São Paulo / Escola de Engenharia de São Carlos, sob a orientação do Professor Eng,-Dr. Aldo Roberto Ometto, coordenador do Grupo de Pesquisa de Engenharia do Ciclo de Vida < http://www.prod.eesc.usp.br/sep $>$.

O objetivo do projeto é pesquisar e apresentar para os fabricantes de produtos um conjunto de práticas operacionais que devem ser seguidas para implantar com mais eficiência as diferentes estratégias de fim de vida (reuso, recondicionamento, remanufatura e reciclagem) de produtos como, por exemplo, toners, amortecedores, embreagens, alternadores, motores, entre outros. Um dos principais resultados esperados é descrever como os desenvolvedores ou designers podem projetar um produto que integre essas estratégias e que as empresas tenham melhores resultados do ponto de vista econômico, ambiental e social.

Um levantamento inicial realizados com empresas de recuperação no Brasil apontou a sua empresa XXXX como um case de sucesso no processo de remanufatura de XXXX. Com o objetivo de realizar uma visita técnica as suas instalações, viemos por meio deste documento solicitar a sua colaboração na execução da pesquisa. Os principais tópicos que gostaríamos de tratar com vocês são:

1. Motivos para a integração das estratégias de fim de vida dentro do modelo de negócios da empresa;

2. Benefícios Ambientais, econômicos e sociais;

3. Processo e etapas da estratégia de fim de vida adotada pela empresa;

4. Maiores dificuldades com o produto e processo;

5. Logística reversa para retorno dos produtos;

6. Verificação das práticas operacionais identificadas

Destacamos que esta pesquisa é de tipo acadêmico, onde os resultados e os dados da empresa com seus respondentes serão de uso restrito e confidencial.

Agradecemos pela sua colaboração e contamos com a sua participação na pesquisa. Para maiores esclarecimentos sobre o trabalho entrar em contato por meio dos Telefones: (16) 3373-8287 / 8175-1985 ou mensagem eletrônica no endereço < ybarrera@sc.usp.br >.

Atenciosamente,

Eng $^{\text {a }}$ Yovana M.B. Saavedra

Universidade de São Paulo / Escola de Engenharia de São Carlos

Departamento de Produção / Grupo Engenharia do Ciclo de Vida
Prof. Eng.-Dr. Aldo Roberto Ometto

Universidade de São Paulo / Escola de Engenharia de São Carlos Departamento de Produção / Grupo Engenharia do Ciclo de Vida 


\section{Apêndice C - Roteio de entrevista}

\section{ROTEIRO DE ENTREVISTA}

Nome da Empresa:

Respondente:

Cargo:

Data:

Questionário No.

\section{CARACTERIZAÇÃO DA EMPRESA}

Objetivo: Caracterizar a empresa quanto ao número de funcionários, existência da área de desenvolvimento de produtos dentro da empresa, formação dos funcionários e motivações principais para integrar as estratégias de fim de vida (Reuso, Reparo, Recondicionamento, Canibalização, Remanufatura e Reciclagem) na empresa.

1. Quantos funcionários na recuperação de produtos, a empresa possui?

2. A empresa possui a área de desenvolvimento de Produtos?

$\begin{array}{ll}\text { Sim } & \text { ( ) } \\ \text { Não } & \text { ( ) }\end{array}$

3. Qual é a formação dos funcionários que desenvolvem produtos?

4. Quais são as principais motivações da empresa para integrar as Estratégias de Fim de Vida (Reuso Reparo, Recondicionamento, Canibalização, Remanufatura e Reciclagem)? Marque com uma X

\section{Ambiental}

Diminuir o uso dos recursos 
Diminuir os impactos Ambientais

Reaproveitamento de materiais e produtos

Normas o Leis sobre responsabilidade estendida do produtor

Outros

\section{Econômica}

Reduzir Consumo de materiais

Reduzir os Custos de Produção

Demanda de produtos com melhor desempenho ambiental

Novas oportunidades de mercado

Outros

\section{Social}

Aumento de Empregos

Outros

\section{CARACTERIZAÇÃO DOS PRODUTOS E DOS PROCESSOS QUE INTEGRAM AS ESTRATÉGIAS DE FIM DE VIDA}

Objetivo: caracterizar os produtos e processos em relação a produtos oferecidos ao mercado, origem e produtos que integram as estratégias de fim de vida, destino e quantidade de matéria prima descartada.

5. Quais são os produtos que a empresa oferece ao mercado?

6. Os produtos são: 
Próprios

Multimarcas

Ambos

\section{( )}

7. Quais produtos integram Estratégias de Fim de Vida: (Reuso Reparo, Recondicionamento, Canibalização, Remanufatura e Reciclagem)?

8. Como é obtida a matéria-prima para os produtos que integram as estratégias de fim de vida? Marque com uma X.

Compra e Sucata

Parceria com o Fornecedor

Outros

9. Existem parcerias com os fornecedores? Se sim, de que tipo?

10. Como esta organizada a logística reversa para o retorno da matéria-prima (carcaça)?

11. Quais são os principais problemas de qualidade dessa matéria-prima (carcaça)?

12. Da matéria prima obtida qual é a porcentagem de recuperação?

13. Qual é a destinação das partes da matéria prima (carcaça) que não são recuperadas? Explique brevemente.

14. Quais são as etapas usadas para realizar os produtos que integram as estratégias de fim de vida? Enumere a seqüência.

Estratégia adotada: 


$\begin{array}{lc}\text { Coleta } & \text { ( ) } \\ \text { Inspeção } & \text { ( ) } \\ \text { Desmontagem } & \text { ( ) } \\ \text { Armazenamento } & \text { ( ) } \\ \text { Limpeza } & \text { ( ) } \\ \text { Remontagem } & \text { ( ) } \\ \text { Teste } & \text { ( ) }\end{array}$

15. Das etapas anteriores, qual (s) considera que é a mais complexa e por quê?

16. Dentro do processo que integra as estratégias de fim de vida, existe alguma etapa (s) que é terceirizada? Se sim explique qual e porque desta decisão? 


\section{VERIFICAÇÃO DAS PRÁTICAS OPERACIONAIS}

O objetivo deste projeto é analisar a aplicação das práticas operacionais dentro de empresas que adotam esta visão, e assim subsidiar a desenvolver produtos que no seu final de vida possam ser recuperados e integrados novamente na cadeia. Para isso, o presente documento apresenta as práticas extraídas dos métodos, técnicas e ferramentas de EoL, a fim de avaliar a sua aplicação dentro da empresa. Para facilitar sua compreensão, foi elaborada uma planinha formato Excel, onde a sua avaliação e observações relacionadas às práticas podem ser indicadas.

\begin{tabular}{|c|c|c|c|c|c|}
\hline \multirow[t]{2}{*}{ Atividade } & \multirow[t]{2}{*}{ Práticas Operacionais } & \multicolumn{2}{|c|}{$\begin{array}{lll}\text { A prática } & \text { operacional é } \\
\text { aplicada } & \text { dentro } & \text { do } \\
\text { produto recuperado da } & \\
\text { empresa? } & & \end{array}$} & \multirow[t]{2}{*}{$\begin{array}{l}\text { Como esta sendo aplicada a prática } \\
\text { operacional }\end{array}$} & \multirow[t]{2}{*}{ Observações } \\
\hline & & Sim & Não & & \\
\hline \multirow[t]{6}{*}{$\begin{array}{c}\text { Desmontagem e } \\
\text { remontagem }\end{array}$} & \begin{tabular}{lr}
\multicolumn{1}{c}{ Projetar } & a \\
desmontagem & de \\
produtos
\end{tabular} & & & & \\
\hline & $\begin{array}{l}1.1 \text { Analisar as restrições } \\
\text { dos componentes }\end{array}$ & & & & \\
\hline & $\begin{array}{l}\text { 1.2 Desenvolver guias para } \\
\text { desmontagem do produto }\end{array}$ & & & & \\
\hline & $\begin{array}{l}\text { 1.3 Desenvolver produtos } \\
\text { que facilitem a retirada de } \\
\text { componentes de difícil } \\
\text { acesso }\end{array}$ & & & & \\
\hline & $\begin{array}{lr}\text { 1.4 Diminuir as mudanças } \\
\text { de direções e de sentidos } \\
\text { dos movimentos de } \\
\text { desmontagem rem } \\
\text { remontagem } \\
\text { componentes }\end{array}$ & & & & \\
\hline & $\begin{array}{lllll}1.5 & \text { Evitar } & \text { a } & \text { quebra } & \mathrm{e}\end{array}$ & & & & \\
\hline
\end{tabular}




\begin{tabular}{|c|c|c|c|c|c|}
\hline \multirow[t]{12}{*}{ Atividade } & \multirow[t]{2}{*}{ Práticas Operacionais } & \multicolumn{2}{|c|}{$\begin{array}{lll}\text { A prática } & \text { operacional é } \\
\text { aplicada } & \text { dentro } & \text { do } \\
\text { produto recuperado da } & \\
\text { empresa? } & & \end{array}$} & \multirow[t]{2}{*}{$\begin{array}{c}\text { Como esta sendo aplicada a prática } \\
\text { operacional }\end{array}$} & \multirow[t]{2}{*}{ Observações } \\
\hline & & Sim & Não & & \\
\hline & $\begin{array}{llll}\begin{array}{l}\text { possibilitar o } \\
\text { componentes }\end{array} & \text { reuso de } \\
\end{array}$ & & & & \\
\hline & $\begin{array}{l}\text { 1.6 Evitar o uso de metais } \\
\text { dentro das partes plásticas } \\
\text { para diminuir a quebra dos } \\
\text { componentes }\end{array}$ & & & & \\
\hline & $\begin{array}{l}1.7 \quad \text { Identificar } \\
\text { componentes de difícil } \\
\text { remoção dentro do produto }\end{array}$ & & & & \\
\hline & $\begin{array}{l}\text { 1.8 Maximizar a integração } \\
\text { de funções entre os } \\
\text { componentes }\end{array}$ & & & & \\
\hline & $\begin{array}{l}1.9 \text { Melhorar o acesso e } \\
\text { identificação dos pontos de } \\
\text { separação do produto }\end{array}$ & & & & \\
\hline & $\begin{array}{l}\text { 1.10 Minimizar o tempo de } \\
\text { desmontagem } \\
\text { remontagem do produto }\end{array}$ & & & & \\
\hline & $\begin{array}{l}1.11 \text { Minimizar } \\
\text { elementos de junção } \\
\text { fixação usadas no produto }\end{array}$ & & & & \\
\hline & $\begin{array}{l}\text { 1.12 Minimizar o número } \\
\text { de componentes no produto }\end{array}$ & & & & \\
\hline & $\begin{array}{l}1.13 \text { Minimizar o uso de } \\
\text { soldas no produto }\end{array}$ & & & & \\
\hline & $\begin{array}{l}1.14 \text { Padronizar os } \\
\text { elementos de Fixação } \\
\text { conforme ISO 8992:2005 } \\
\text { (Fasteners -General } \\
\text { requirements for bolts, } \\
\text { screws, studs and nuts) }\end{array}$ & & & & \\
\hline
\end{tabular}




\begin{tabular}{|c|c|c|c|c|c|}
\hline \multirow[t]{9}{*}{ Atividade } & \multirow[t]{2}{*}{ Práticas Operacionais } & \multicolumn{2}{|c|}{ 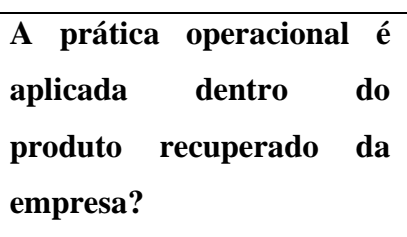 } & \multirow[t]{2}{*}{$\begin{array}{l}\text { Como esta sendo aplicada a prática } \\
\text { operacional }\end{array}$} & \multirow[t]{2}{*}{ Observações } \\
\hline & & Sim & Não & & \\
\hline & $\begin{array}{l}\text { 1.15 Projetar marcação em } \\
\text { cores }\end{array}$ & & & & \\
\hline & $\begin{array}{l}\text { 1.16 Projetar produtos de } \\
\text { fácil desmontagem para } \\
\text { evitar a destruição de } \\
\text { componentes }\end{array}$ & & & & \\
\hline & $\begin{array}{l}1.17 \text { Projetar para que as } \\
\text { partes isoladas sejam de } \\
\text { baixo valor para diminuir } \\
\text { os custos por quebra }\end{array}$ & & & & \\
\hline & $\begin{array}{l}1.18 \text { Promover o uso de } \\
\text { Snap fits (métodos } \\
\text { definidos por pressão ou } \\
\text { encaixes multiplos) }\end{array}$ & & & & \\
\hline & $\begin{array}{l}1.19 \text { Usar ferramentas } \\
\text { comuns } \quad \text { para a a } \\
\text { desmontagem de produtos }\end{array}$ & & & & \\
\hline & $\begin{array}{l}\text { 2. Desenvolver produtos } \\
\text { modulares }\end{array}$ & & & & \\
\hline & $\begin{array}{l}\text { 2.1 Minimizar as interações } \\
\text { entre os módulos existentes } \\
\text { do produto }\end{array}$ & & & & \\
\hline \multirow[t]{3}{*}{ Limpeza } & $\begin{array}{l}\text { 1. Projetar produtos que } \\
\text { sejam de fácil limpeza }\end{array}$ & & & & \\
\hline & 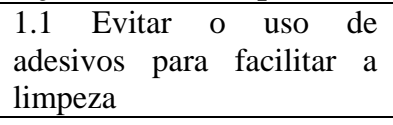 & & & & \\
\hline & 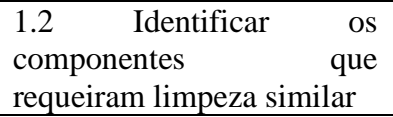 & & & & \\
\hline
\end{tabular}




\begin{tabular}{|c|c|c|c|c|}
\hline \multirow[t]{5}{*}{ Atividade } & \multirow[t]{2}{*}{ Práticas Operacionais } & $\begin{array}{lll}\text { A prática } & \text { operacional é } \\
\text { aplicada } & \text { dentro do } \\
\text { produto recuperado da } & \text { da } \\
\text { empresa? } & & \\
\end{array}$ & \multirow[t]{2}{*}{$\begin{array}{l}\text { Como esta sendo aplicada a prática } \\
\text { operacional }\end{array}$} & \multirow[t]{2}{*}{ Observações } \\
\hline & & Sim & & \\
\hline & $\begin{array}{l}1.3 \text { Projetar superfícies } \\
\text { lisas no produto para } \\
\text { facilitar sua limpeza }\end{array}$ & & & \\
\hline & $\begin{array}{l}\text { 1.4 Projetar Produtos } \\
\text { minimizando a limpeza } \\
\text { durante o uso para evitar } \\
\text { desgaste dos componentes }\end{array}$ & & & \\
\hline & $\begin{array}{l}1.5 \text { Usar componentes } \\
\text { resistentes à deformação } \\
\text { pelo uso de produtos } \\
\text { químicos na limpeza }\end{array}$ & & & \\
\hline \multirow[t]{6}{*}{ Recuperação } & $\begin{array}{l}\text { 1. Projetar a recuperação } \\
\text { dos produtos }\end{array}$ & & & \\
\hline & $\begin{array}{l}\text { 1.1 Analisar a composição } \\
\text { dos materiais para sua } \\
\text { posterior recuperação }\end{array}$ & & & \\
\hline & $\begin{array}{lr}1.2 \quad \text { Codificar } & \text { os } \\
\text { componentes } & \text { para } \\
\text { rastreabilidade } & \text { e } \\
\text { recuperação } & \\
\end{array}$ & & & \\
\hline & $\begin{array}{l}1.3 \quad \text { Evitar o } \quad \text { uso de } \\
\text { materiais com } \\
\text { tempos de vida }\end{array}$ & & & \\
\hline & $\begin{array}{l}1.4 \text { Identificar os } \\
\text { componentes plásticos do } \\
\text { produto, conforme a ISO } \\
11469 \text { Plastics -Generic } \\
\text { identification and marking } \\
\text { of plastics products) }\end{array}$ & & & \\
\hline & $\begin{array}{l}1.5 \text { Identificar os } \\
\text { componentes e materiais }\end{array}$ & & & \\
\hline
\end{tabular}




\begin{tabular}{|c|c|c|c|c|c|}
\hline \multirow[t]{10}{*}{ Atividade } & \multirow[t]{2}{*}{ Práticas Operacionais } & \multicolumn{2}{|c|}{$\begin{array}{lll}\text { A prática } & \text { operacional é } \\
\text { aplicada } & \text { dentro } & \text { do } \\
\text { produto recuperado da } & \\
\text { empresa? } & & \end{array}$} & \multirow[t]{2}{*}{$\begin{array}{c}\text { Como esta sendo aplicada a prática } \\
\text { operacional }\end{array}$} & \multirow[t]{2}{*}{ Observações } \\
\hline & & Sim & Não & & \\
\hline & recuperáveis do produto & & & & \\
\hline & $\begin{array}{l}\text { 1.6 Identificar os diferentes } \\
\text { tipos de plásticos usados no } \\
\text { produto }\end{array}$ & & & & \\
\hline & $\begin{array}{l}\text { 1.7 Incentivar o reuso de } \\
\text { elementos de } \\
\text { consixaçarano, } \\
\text { funcionalidades originais } \\
\text { para não comprometer a } \\
\text { qualidade e funcionalidade } \\
\text { do produto } \\
\end{array}$ & & & & \\
\hline & $\begin{array}{l}1.8 \text { Incrementar a } \\
\text { quantidade de componentes } \\
\text { e materiais recuperáveis no } \\
\text { produto }\end{array}$ & & & & \\
\hline & $\begin{array}{l}\text { 1.9 Manter as } \\
\text { especificaç̃̃es originais } \\
\text { dos elementos de junção e } \\
\text { fixação usados em produtos } \\
\text { remanufaturados }\end{array}$ & & & & \\
\hline & $\begin{array}{l}1.10 \quad \text { Melhorar a } \\
\text { adaptabilidade dos } \\
\text { produtos para processos de } \\
\text { recuperação, manutenção e } \\
\text { atualização }\end{array}$ & & & & \\
\hline & $\begin{array}{l}\text { 1.11 Minimizar a mistura } \\
\text { de materiais do produto }\end{array}$ & & & & \\
\hline & $\begin{array}{l}1.12 \text { Minimizar o número } \\
\text { de diferentes materiais } \\
\text { usados no produto }\end{array}$ & & & & \\
\hline
\end{tabular}




\begin{tabular}{|c|c|c|c|c|c|}
\hline \multirow[t]{11}{*}{ Atividade } & \multirow[t]{2}{*}{ Práticas Operacionais } & \multicolumn{2}{|c|}{$\begin{array}{lll}\text { A prática } & \text { operacional é } \\
\text { aplicada } & \text { dentro } & \text { do } \\
\text { produto recuperado da } & \\
\text { empresa? } & & \end{array}$} & \multirow[t]{2}{*}{$\begin{array}{c}\text { Como esta sendo aplicada a prática } \\
\text { operacional }\end{array}$} & \multirow[t]{2}{*}{ Observações } \\
\hline & & Sim & Não & & \\
\hline & $\begin{array}{l}1.13 \text { Projetar o reuso de } \\
\text { componentes do produto }\end{array}$ & & & & \\
\hline & $\begin{array}{l}1.14 \text { Projetar o uso de } \\
\text { componentes que facilitem } \\
\text { a atualização e adaptação } \\
\text { de mudanças tecnológicas }\end{array}$ & & & & \\
\hline & $\begin{array}{l}1.15 \text { Projetar o uso de } \\
\text { elementos de fixação que } \\
\text { permitam fácil separação } \\
\text { de componentes }\end{array}$ & & & & \\
\hline & $\begin{array}{l}\text { 1.16 Projetar os produtos } \\
\text { para fácil manutenção }\end{array}$ & & & & \\
\hline & $\begin{array}{l}\text { 1.17 Projetar produtos com } \\
\text { materiais que sejam de } \\
\text { fácil separação para } \\
\text { facilitar processos } \\
\text { recuperação e triagem }\end{array}$ & & & & \\
\hline & $\begin{array}{l}\text { 1.18 Proteger os grupos de } \\
\text { montagem da poluição e } \\
\text { corrosão para evitar a } \\
\text { deteriorização }\end{array}$ & & & & \\
\hline & $\begin{array}{l}1.19 \text { Reusar produtos com } \\
\text { longos ciclos de vida }\end{array}$ & & & & \\
\hline & $\begin{array}{l}\text { 1.20 Reduzir as dimensões } \\
\text { do produto, tornando-o } \\
\text { mais leve e mais fino }\end{array}$ & & & & \\
\hline & $\begin{array}{l}1.21 \text { Usar componentes } \\
\text { duráveis com um ciclo de } \\
\text { vida maior que das partes } \\
\text { auxiliares }\end{array}$ & & & & \\
\hline
\end{tabular}




\begin{tabular}{|c|c|c|c|c|c|}
\hline \multirow[t]{6}{*}{ Atividade } & \multirow[t]{2}{*}{ Práticas Operacionais } & \multicolumn{2}{|c|}{\begin{tabular}{llr} 
A prática & \multicolumn{2}{c}{ operacional é } \\
aplicada & dentro & do \\
produto recuperado da & da \\
empresa? & &
\end{tabular}} & \multirow[t]{2}{*}{$\begin{array}{l}\text { Como esta sendo aplicada a prática } \\
\text { operacional }\end{array}$} & \multirow[t]{2}{*}{ Observações } \\
\hline & & Sim & \begin{tabular}{|l|} 
Não \\
\end{tabular} & & \\
\hline & 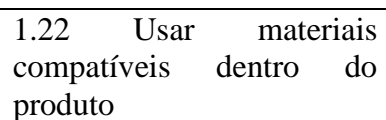 & & & & \\
\hline & $\begin{array}{l}1.23 \text { Usar materiais } \\
\text { duráveis no produto }\end{array}$ & & & & \\
\hline & $\begin{array}{l}\text { 1.24 Usar quando possível } \\
\text { material reciclado }\end{array}$ & & & & \\
\hline & $\begin{array}{l}1.25 \text { Usar material } \\
\text { reciclável no produto }\end{array}$ & & & & \\
\hline $\begin{array}{c}\text { Impactos } \\
\text { ambientais }\end{array}$ & $\begin{array}{l}\text { 1. Determinar } \\
\text { impactos ambientais } \\
\text { produto }\end{array}$ & & & & \\
\hline & $\begin{array}{l}\text { 1.1 Determinar os impactos } \\
\text { ambientais relacionado aos } \\
\text { recursos consumidos }\end{array}$ & & & & \\
\hline & $\begin{array}{l}\text { 1.2 Determinar os impactos } \\
\text { ambientais relacionado às } \\
\text { emissões dos produtos }\end{array}$ & & & & \\
\hline & $\begin{array}{lr}\text { 1.3 Determinar } & \text { os } \\
\text { impactos } & \text { ambientais } \\
\text { relacionados } & \text { a } \\
\text { ecotoxicidade e toxicidade } \\
\text { humana }\end{array}$ & & & & \\
\hline & $\begin{array}{l}\text { 1.3.1 Analisar a toxicidade } \\
\text { dos materiais usados no } \\
\text { produto }\end{array}$ & & & & \\
\hline & \begin{tabular}{llll}
1.3 .2 & \multicolumn{3}{c}{ Eliminar } \\
combinação de & materiais \\
corrosivos com & os & não \\
corrosivos & & &
\end{tabular} & & & & \\
\hline
\end{tabular}




\begin{tabular}{|c|c|c|c|c|}
\hline \multirow[t]{6}{*}{ Atividade } & \multirow[t]{2}{*}{ Práticas Operacionais } & $\begin{array}{lll}\text { A prática } & \text { operacional é } \\
\text { aplicada } & \text { dentro } & \text { do } \\
\text { produto recuperado da } & \\
\text { empresa? } & & \end{array}$ & \multirow[t]{2}{*}{$\begin{array}{c}\text { Como esta sendo aplicada a prática } \\
\text { operacional }\end{array}$} & \multirow[t]{2}{*}{ Observações } \\
\hline & & Sim & & \\
\hline & $\begin{array}{l}\text { 1.3.3 Usar produtos } \\
\text { químicos amigavéis ao } \\
\text { meio ambiente ( ex. } \\
\text { adesivos solúveis em água) }\end{array}$ & & & \\
\hline & $\begin{array}{l}\text { 1.3.4 Minimizar o uso de } \\
\text { materiais tóxicos no } \\
\text { produto }\end{array}$ & & & \\
\hline & $\begin{array}{l}\text { 1.3.5 Projetar a remoção e } \\
\text { separação de } \\
\text { contenham quates que } \\
\text { tóxicas }\end{array}$ & & & \\
\hline & $\begin{array}{l}\text { 1.3.6 Projetar unidades } \\
\text { fechadas para substâncias } \\
\text { tóxicas }\end{array}$ & & & \\
\hline
\end{tabular}




\section{Apêndice D Base de Dados da Revisão Sistemática}

A seguir, são apresentadas as bases de dados pesquisadas durante a revisão sistemática. O levantamento bibliográfico ajudou a identificar os trabalhos que mencionavam métodos, ferramentas, e técnicas referentes à remanufatura e outras estratégias de fim de vida de produtos.

- Compendex (http://www.engineeringvillage2.org/): é o banco de dados bibliográfico mais exclusivo de pesquisa de engenharia cientifica e técnica disponível, inclui milhões de citações bibliográficas.

- Emerald (http://hermia.emeraldinsight.com): proporciona acessos a mais de 200 revistas, inumeráveis livros de diversas áreas de conhecimento da mais alta qualidade. Apresenta interligação entre o mundo real e a área de pesquisa.

- IEEE Explore (http://ieeexplore.ieee.org): proporciona acesso a publicações de periódicos, livros, em diversas áreas de conhecimento com a mais alta qualidade técnica.

- Find articles (http://www.findarticles.com): acesso a milhões de artigos de publicações de alto nível.

- Science Direct (http://www.sciencedirect.com): proporciona acesso a mais de 2500 periódicos e a mais de 6000 livros e trabalhos de referência.

- Scholar Google (http://scholar.google.com): proporciona publicações revisadas por especialistas como teses, livros, resumos e artigos de editoras acadêmicas, organizações profissionais, universidades e outras entidades acadêmicas.

- Scopus (http://www.scopus.com): proporciona acesso a milhões de publicações de pesquisa bibliográfica da mais alta qualidade técnica com grande reconhecimento mundial.

- Springer Link (http://www.springerlink.com/home/main.mpx): base de dados com reconhecimento mundial que apresenta uma grande variedade de publicações de diversos periódicos da mais alta qualidade técnica.

- Web of Science

o (http://apps.isiknowledge.com/UA_GeneralSearch_input.do?product=UA\&sea 
rch_mode=GeneralSearch\&SID=V1bPeJPmeEP9leAKb2F\&preferencesSaved =): é uma das bases mais reconhecidas a nível científico, tem milhões de publicações de diferentes revistas da mais alta qualidade, sendo um lugar de interação entre pesquisadores e científicos

- Wiley Interscence

- http://www3.interscience.wiley.com/cgi-bin/home?CRETRY=1\&SRETRY=0: é uma base de dados que proporciona um acesso a mais de três milhões de artigos provenientes de periódicos internacionais consolidados nas diferentes áreas, sendo uns dos recursos mais utilizados por pesquisadores e científicos. 


\section{Apêndice E Padronização dos Estudos Obtidos com a Revisão Sistemática}

\begin{tabular}{|c|c|c|c|c|c|c|c|}
\hline No. & Titulo & Autor (es) & Palavras chave & $\begin{array}{l}\text { País de } \\
\text { origem }\end{array}$ & $\begin{array}{c}\text { Ano } \\
\text { Publicação }\end{array}$ & Tipo & Fonte \\
\hline 1 & $\begin{array}{l}\text { A strategic framework for the } \\
\text { design and implementation of } \\
\text { remanufacturing operations in } \\
\text { reverse logistics }\end{array}$ & DOWLASTSHAHI, S. & $\begin{array}{c}\text { Reverse logistics; Strategic } \\
\text { factors; RL } \\
\text { Framework;Remanufacturing }\end{array}$ & $\begin{array}{l}\text { Estados } \\
\text { Unidos }\end{array}$ & 2005 & Artigo & $\begin{array}{l}\text { International } \\
\text { Journal of } \\
\text { Production } \\
\text { Research }\end{array}$ \\
\hline 2 & $\begin{array}{c}\text { A balancing method and genetic } \\
\text { algorithm } \\
\text { for disassembly line balancing }\end{array}$ & $\begin{array}{c}\text { McGOVEN,S.M.;GUPTA,S } \\
\text {.M. }\end{array}$ & $\begin{array}{c}\text { Genetic algorithm; Disassembly; } \\
\text { Disassembly line balancing; } \\
\text { Combinatorial optimization; } \\
\text { Product recovery }\end{array}$ & $\begin{array}{l}\text { Estados } \\
\text { Unidos }\end{array}$ & 2007 & Artigo & $\begin{array}{l}\text { European Journal } \\
\text { of Operational } \\
\text { Research }\end{array}$ \\
\hline 3 & $\begin{array}{c}\text { A Behavior-based Classification } \\
\text { and retrieval Technique for } \\
\text { object-oriented Specification } \\
\text { reuse }\end{array}$ & $\begin{array}{l}\text { CHOU, S.C.; CHEN, J.Y.; } \\
\text { CHUNG, C.G. }\end{array}$ & $\begin{array}{l}\text { specification reuse, specification } \\
\text { classification, sprecification } \\
\text { retrieval, similarity behavioral }\end{array}$ & China & 1996 & Artigo & $\begin{array}{l}\text { Software-Practice } \\
\text { and experience }\end{array}$ \\
\hline 4 & \begin{tabular}{|c|} 
A bill of m \\
aterials-based approach for end- \\
of-life decision making in \\
design for the environment
\end{tabular} & $\begin{array}{l}\text { GONZÁLEZ, B.; } \\
\text { ADENSO-DÍAZ, B. }\end{array}$ & \begin{tabular}{|c|} 
Design for the environment \\
(DfE), End-of-life (EOL), \\
decision making, Dissassembly, \\
Heuristics, Computer-aided \\
design (CAD) systems, Scatter \\
search (SS)
\end{tabular} & Espanha & 2005 & Artigo & $\begin{array}{l}\text { International } \\
\text { Journal of } \\
\text { Production } \\
\text { Research }\end{array}$ \\
\hline 5 & $\begin{array}{l}\text { A Case Study of Serial-Flow } \\
\text { Car Disassembly Ergonomics, } \\
\text { Productivity and Potential } \\
\text { System performance }\end{array}$ & $\begin{array}{l}\text { KAZMIERCZAK, K.; } \\
\text { NEUMANN. W.P.; } \\
\text { WINKEL, J. }\end{array}$ & Sem palavras chave & Suécia & 2007 & Artigo & $\begin{array}{l}\text { Human factors and } \\
\text { ergnomics in } \\
\text { manufacturing }\end{array}$ \\
\hline 6 & $\begin{array}{l}\text { A concave-cost production } \\
\text { planning problem with }\end{array}$ & $\begin{array}{c}\text { YANG, J.; GOLANY, B.; } \\
\text { YU, G. }\end{array}$ & $\begin{array}{l}\text { production planning; } \\
\text { remanufacturing; heuristics }\end{array}$ & $\begin{array}{l}\text { Estados } \\
\text { Unidos }\end{array}$ & 2005 & Artigo & $\begin{array}{l}\text { Naval Research } \\
\text { Logistics }\end{array}$ \\
\hline
\end{tabular}




\begin{tabular}{|c|c|c|c|c|c|c|c|}
\hline & remanufacturing options & & & & & & \\
\hline 7 & $\begin{array}{l}\text { A continuous time inventory } \\
\text { model for a product recovery } \\
\text { system with multiple options }\end{array}$ & $\begin{array}{l}\text { KLEBER, R.; MINNER, S.; } \\
\text { KIESMULLER, G }\end{array}$ & $\begin{array}{l}\text { Reverse logistics; Optimal } \\
\text { control; Deterministic dynamic } \\
\text { inventory model; Recovery } \\
\text { options }\end{array}$ & Alemanha & 2002 & Artigo & $\begin{array}{l}\text { International } \\
\text { Journal of } \\
\text { Production } \\
\text { Economics }\end{array}$ \\
\hline 8 & $\begin{array}{l}\text { A critical assessment of motives } \\
\text { for product recovery : the case } \\
\text { of engine remanufacturing }\end{array}$ & $\begin{array}{l}\text { SEITZ } \\
\text {, M.A. }\end{array}$ & $\begin{array}{l}\text { Remanufacturing;Closed-loop } \\
\text { supply chain } \\
\text { management;Profitability;Envir } \\
\text { onmental legisltation }\end{array}$ & Alemanha & 2007 & Artigo & $\begin{array}{l}\text { Journal of Cleaner } \\
\text { Production }\end{array}$ \\
\hline 9 & $\begin{array}{l}\text { A demanufacturing projector- } \\
\text { vision system } \\
\text { for combined manual and } \\
\text { automated } \\
\text { processing of used electronics }\end{array}$ & BAILEY,M.;KUREN, V. & $\begin{array}{c}\text { Projector-vision; } \\
\text { Demanufacturing; Machine } \\
\text { vision; Manifolds }\end{array}$ & $\begin{array}{l}\text { Estados } \\
\text { Unidos }\end{array}$ & 2005 & Artigo & $\begin{array}{l}\text { Computers in } \\
\text { Industry }\end{array}$ \\
\hline 10 & $\begin{array}{l}\text { A Desicion-Support tool for the } \\
\text { take-back of plastics from End- } \\
\text { of-life electronics }\end{array}$ & $\begin{array}{l}\text { MASSANET, E.R.; } \\
\text { HORVATH, A. }\end{array}$ & Sem palavras chave & $\begin{array}{l}\text { Estados } \\
\text { Unidos }\end{array}$ & 2004 & Artigo & IEEE \\
\hline 11 & $\begin{array}{l}\text { A Framework for Design and } \\
\text { End-of-Life Integration (DELII) }\end{array}$ & $\begin{array}{l}\text { LEE, H. M.; FENG LU, } \\
\text { W.; SONG, B.; GAY, R. }\end{array}$ & $\begin{array}{l}\text { Design for EoL; Ontology; EoL } \\
\text { Information Management }\end{array}$ & Cingapura & 2008 & Artigo & LCE Annals \\
\hline 12 & $\begin{array}{c}\text { A genetic algorithm approach } \\
\text { for solving a closed loop supply } \\
\text { chain } \\
\text { model: A case of battery } \\
\text { recycling }\end{array}$ & $\begin{array}{l}\text { KANNAN, G.; } \\
\text { SASIKUMAR, P.; } \\
\text { DEVIKA, K. }\end{array}$ & $\begin{array}{c}\text { Reverse logistics } \\
\text { Recycling } \\
\text { SLI batteries } \\
\text { Closed loop supply chain }\end{array}$ & Dinamarca & 2009 & Artigo & $\begin{array}{l}\text { Applied } \\
\text { Mathematical } \\
\text { Modelling }\end{array}$ \\
\hline 13 & $\begin{array}{l}\text { A geometric algorithm for } \\
\text { single } \\
\text { selective disassembly using the } \\
\text { wave propagation abstraction }\end{array}$ & $\begin{array}{c}\text { SRINIVASAN,H.;GADH, } \\
\text { R. }\end{array}$ & $\begin{array}{c}\text { selective disassembly, } \\
\text { disassembly wave propagation, } \\
\text { design for disassembly and } \\
\text { product design }\end{array}$ & $\begin{array}{l}\text { Estados } \\
\text { Unidos }\end{array}$ & 1998 & Artigo & $\begin{array}{l}\text { Computer Aided } \\
\text { Design }\end{array}$ \\
\hline 14 & $\begin{array}{c}\text { A Holistic approach to reverse } \\
\text { supply chain planning for }\end{array}$ & AHMED,A. & Sem palavras chave & Japão & 2003 & Artigo & Proceedings of \\
\hline
\end{tabular}




\begin{tabular}{|c|c|c|c|c|c|c|c|}
\hline & remanufacturing & & & & & & Ecodesign 2003. \\
\hline 15 & $\begin{array}{l}\text { A hybrid approach to selective- } \\
\text { disassembly sequence planning } \\
\text { for de-manufacturing and its } \\
\text { implementation on the internet }\end{array}$ & CHUNG, C.; PENG, Q. & $\begin{array}{c}\text { De-manufacturing, global } \\
\text { concurrent de-manufacturability } \\
\text { analysis, hybrid sequence } \\
\text { planning, selective-disassembly, } \\
\text { tool accessibility }\end{array}$ & Canada & 2006 & Artigo & $\begin{array}{l}\text { International } \\
\text { Journal Manuf } \\
\text { Tecnhnol }\end{array}$ \\
\hline 16 & $\begin{array}{l}\text { A hybrid simulation } \\
\text { optimization method for } \\
\text { production planning of } \\
\text { dedicated remanufacturing }\end{array}$ & $\begin{array}{c}\text { LI, JIANZHI.; } \\
\text { GONZÁLEZ, M.; ZHU, Y. }\end{array}$ & $\begin{array}{l}\text { remanufacturing, optimization } \\
\text { with simulation, genetic } \\
\text { algorithm, fractional factorial } \\
\text { design }\end{array}$ & $\begin{array}{l}\text { Estados } \\
\text { Unidos }\end{array}$ & 2009 & Artigo & $\begin{array}{l}\text { International } \\
\text { Journal of } \\
\text { Production } \\
\text { Economics }\end{array}$ \\
\hline 17 & $\begin{array}{l}\text { A Key Issue in Product Life } \\
\text { Cycle: Disassembly }\end{array}$ & JOVANE F. et al. & $\begin{array}{l}\text { Assembly, Disassembly, } \\
\text { Recycling }\end{array}$ & Italia & 1993 & Artigo & CIRP Annals \\
\hline 18 & $\begin{array}{c}\text { A management system for end- } \\
\text { of-life tyres: A portuguese case } \\
\text { study }\end{array}$ & $\begin{array}{l}\text { FERRÃO, P.; RIBEIRO, P.; } \\
\text { SILVA, P. }\end{array}$ & Sem palavras chave & Portugal & 2008 & Artigo & $\begin{array}{l}\text { Waste } \\
\text { Management }\end{array}$ \\
\hline 19 & $\begin{array}{l}\text { A Method for Sequencing the } \\
\text { Disassembly of Products }\end{array}$ & $\begin{array}{c}\text { KAEBERNICK,H.; } \\
\text { O'SHEA, B.; GREWAL, S. }\end{array}$ & $\begin{array}{c}\text { Disassembly, Sequencing, Task } \\
\text { allocation. }\end{array}$ & Austrália & 2000 & Artigo & CIRP Annals \\
\hline 20 & $\begin{array}{c}\text { A method to assess the lifetime } \\
\text { prolongation capabilities of } \\
\text { products }\end{array}$ & $\begin{array}{l}\text { WILLEMS, B.; DEWULF, } \\
\text { W.; DUFLOU, F.R. }\end{array}$ & $\begin{array}{l}\text { design for adaptation; prduct life } \\
\text { cycle; PLC; product design } \\
\text { improvements }\end{array}$ & Bélgica & 2008 & Artigo & $\begin{array}{l}\text { Int. J. Sustainable } \\
\text { Manufacturing }\end{array}$ \\
\hline 21 & $\begin{array}{l}\text { A method, a tool (CORA) and } \\
\text { apllication examples for } \\
\text { analysing disassembly user } \\
\text { interfase design criteria }\end{array}$ & $\begin{array}{c}\text { RANKY,P.G.; } \\
\text { CHAMYVELUMANI, S. }\end{array}$ & Sem palavras chave & $\begin{array}{l}\text { Estados } \\
\text { Unidos }\end{array}$ & 2003 & Artigo & $\begin{array}{l}\text { Int. J. Computer } \\
\text { integrated } \\
\text { manufactruing }\end{array}$ \\
\hline 22 & $\begin{array}{l}\text { A methodical to enhance } \\
\text { reutilisation potential in product } \\
\text { design }\end{array}$ & $\begin{array}{l}\text { XING, K.; LOUNG, L.; } \\
\text { ABHARY, K. }\end{array}$ & Sem palavras chave & Austrália & 2005 & Artigo & $\begin{array}{l}\text { International } \\
\text { Conference on } \\
\text { Asian Green } \\
\text { Electronics }\end{array}$ \\
\hline 23 & A methodological framework & IAKOVOUA,E.;; & Electronic products & Greça & 2009 & Artigo & Resources \\
\hline
\end{tabular}




\begin{tabular}{|c|c|c|c|c|c|c|c|}
\hline & $\begin{array}{l}\text { for end-of-life management of } \\
\text { electronic products }\end{array}$ & \begin{tabular}{|l} 
MOUSSIOPOULOS ,N.; \\
XANTHOPOULOS ,A.; \\
ACHILLAS, CH.; \\
MICHAILIDIS, N.; \\
CHATZIPANAGIOTI, M.; \\
KORONEOS,C.; \\
BOUZAKIS, K.-D.; \\
KIKIS,V.
\end{tabular} & $\begin{array}{c}\text { End-of-life management } \\
\text { Multicriteria analysis } \\
\text { Extended producer } \\
\text { responsibility } \\
\text { Life cycle analysis } \\
\text { Effective disassembly process }\end{array}$ & & & & $\begin{array}{l}\text { conservation and } \\
\text { recycling }\end{array}$ \\
\hline 24 & $\begin{array}{l}\text { A methodology for Modeling } \\
\text { and Adaptive Planning of } \\
\text { Disassembly Porcess }\end{array}$ & ZUSSMAN E.; ZHOU M. & $\begin{array}{c}\text { Adaptive planning, disassembly } \\
\text { process, Petri net, process } \\
\text { planning system modeling }\end{array}$ & Israel & 1999 & Artigo & $\begin{array}{l}\text { IEEE transations } \\
\text { on Robotics and } \\
\text { Automotaion }\end{array}$ \\
\hline 25 & $\begin{array}{c}\text { A methodology for the } \\
\text { development of cleaner products }\end{array}$ & NISSEN,U. & $\begin{array}{l}\text { Ideal-eco product Approach; } \\
\text { Manufacture; design }\end{array}$ & Alemanha & 1995 & Artigo & $\begin{array}{l}\text { Journal of Cleaner } \\
\text { Production }\end{array}$ \\
\hline 26 & $\begin{array}{l}\text { A mixed integer programming } \\
\text { model for remanufacturing in } \\
\text { reverse logistics environment }\end{array}$ & $\begin{array}{c}\text { DEMIREL,N.Ö.;GÖKÇEN, } \\
\text { H. }\end{array}$ & $\begin{array}{c}\text { Integer programming; Product } \\
\text { recovery; } \\
\text { Remanufacturing; Reverse } \\
\text { logistics. }\end{array}$ & Turquia & 2007 & Artigo & $\begin{array}{l}\text { The International } \\
\text { Journal of } \\
\text { Advanced } \\
\text { Manufacturing } \\
\text { Technology }\end{array}$ \\
\hline 28 & $\begin{array}{c}\text { A model of evaluation of design } \\
\text { for disasssembly }\end{array}$ & $\begin{array}{l}\text { POSSAMAI,O.; DALLA } \\
\text { VALENTINA,L. V. O. }\end{array}$ & $\begin{array}{l}\text { Concurrent engineering; Design } \\
\text { for disassembly;Product } \\
\text { development process. }\end{array}$ & Brasil & 2007 & Artigo & $\begin{array}{l}\text { Product: } \\
\text { Management \& } \\
\text { Development }\end{array}$ \\
\hline 29 & $\begin{array}{l}\text { A model of the operations } \\
\text { concerned in remanufature }\end{array}$ & $\begin{array}{l}\text { IJOMAH, W.L.; CHILDE, } \\
\text { S.J. }\end{array}$ & $\begin{array}{c}\text { remanufacture, business process, } \\
\text { IDEF0, electromechanical } \\
\text { indsutry }\end{array}$ & Inglaterra & 2007 & Artigo & $\begin{array}{l}\text { International } \\
\text { Journal of } \\
\text { Production } \\
\text { Research }\end{array}$ \\
\hline
\end{tabular}




\begin{tabular}{|c|c|c|c|c|c|c|c|}
\hline 30 & $\begin{array}{l}\text { A model to evaluate inventory } \\
\text { costs in a remanufacturing } \\
\text { environment }\end{array}$ & $\begin{array}{l}\text { BAYINDIR, Z.P.; ERKIP, } \\
\text { N. GÜLLÜ,REFIK }\end{array}$ & $\begin{array}{l}\text { remanufacturing, inventory, } \\
\text { queuing network }\end{array}$ & Turquia & 2003 & Artigo & $\begin{array}{l}\text { International } \\
\text { Journal of } \\
\text { Production } \\
\text { Economics }\end{array}$ \\
\hline 33 & $\begin{array}{l}\text { A normative strategy for } \\
\text { sustainable resource } \\
\text { choice and recycling }\end{array}$ & REIJNDERS, L. & $\begin{array}{l}\text { Resource choice; Recycling; } \\
\text { Sustainability; Cascading; } \\
\text { Contaminant removal }\end{array}$ & Holanda & 2000 & Artigo & $\begin{array}{l}\text { Resources } \\
\text { conservation and } \\
\text { recycling }\end{array}$ \\
\hline 34 & $\begin{array}{c}\text { A PC-BASED } \\
\text { RETROFITTING TOWARD } \\
\text { CAD/CAM/CNC } \\
\text { INTEGRATION }\end{array}$ & $\begin{array}{c}\text { SUH,S.H.;NOH,S.K.;CHOI, } \\
\text { Y.J. }\end{array}$ & Sem palavras chave & Korea & 1995 & Artigo & $\begin{array}{l}\text { computer \& } \\
\text { industrial } \\
\text { engineering }\end{array}$ \\
\hline 36 & $\begin{array}{l}\text { A production/remanufacturing } \\
\text { inventory model with price and } \\
\text { quality dependant return rate }\end{array}$ & \begin{tabular}{|c|} 
EL \\
SAADANY,A.M.A.;JABE \\
R, M.Y.
\end{tabular} & $\begin{array}{c}\text { EPQ model } \\
\text { Production } \\
\text { Remanufacturing/repair } \\
\text { Waste disposal } \\
\text { Price/quality dependent return } \\
\text { rate } \\
\text { Reverse logistics }\end{array}$ & Canada & 2009 & Artigo & $\begin{array}{l}\text { Computers \& } \\
\text { industrial } \\
\text { engineering }\end{array}$ \\
\hline 37 & A quantitative approach to & LEBRETON, B.; TUMA, & remanufacturing, reverse & Alemanha & 2006 & Artigo & International \\
\hline
\end{tabular}




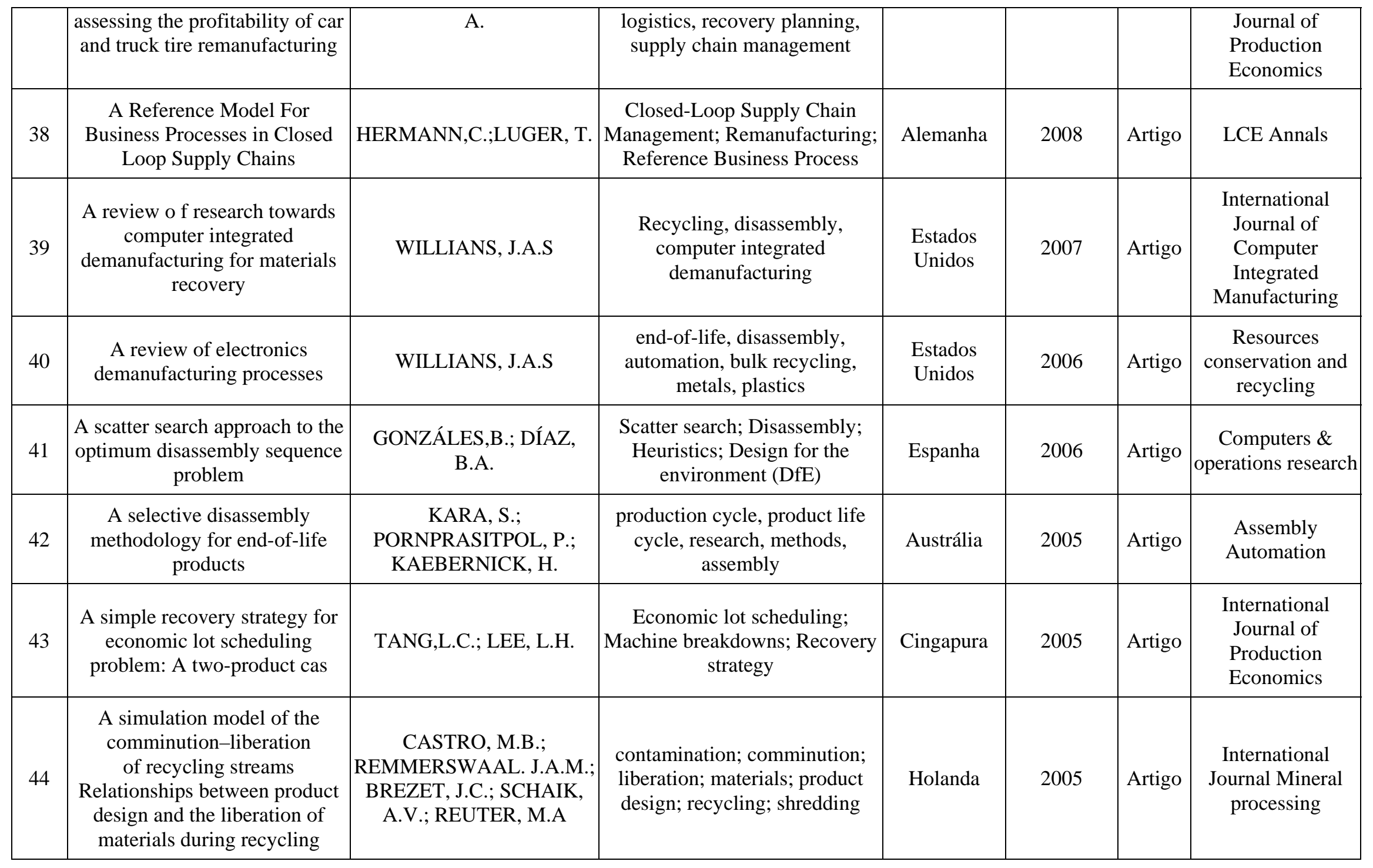




\begin{tabular}{|c|c|c|c|c|c|c|c|}
\hline 45 & $\begin{array}{c}\text { A software tool for end-of-life- } \\
\text { cycle consideration within a } \\
\text { DSS approach to enviromentally } \\
\text { conscious design and } \\
\text { manufacturing }\end{array}$ & SPICER,A.; WANG,M.H. & Sem palavras chave & Canada & 1995 & Artigo & $\begin{array}{l}\text { Computers ind. } \\
\text { Engng }\end{array}$ \\
\hline 46 & \begin{tabular}{|c|} 
A synopsis of industrial \\
engineering methods utilized in \\
desisgning for the environment
\end{tabular} & $\begin{array}{l}\text { CAPORELLO, T.J.; } \\
\text { WOLFE, P.M. }\end{array}$ & Sem palavras chave & $\begin{array}{l}\text { Estados } \\
\text { Unidos }\end{array}$ & 1995 & Artigo & $\begin{array}{l}\text { Computers ind. } \\
\text { Engng }\end{array}$ \\
\hline 48 & $\begin{array}{l}\text { A tool to implement sustainable } \\
\text { end-of-life strategies in the } \\
\text { product development phase }\end{array}$ & $\begin{array}{l}\text { GEHIN, A.; ZWOLINSKI } \\
\text { P.; BRISSAUD, D. }\end{array}$ & $\begin{array}{c}\text { Sustainable development; } \\
\text { Product development; } \\
\text { Optimisation of Eol; Strategies }\end{array}$ & França & 2008 & Artigo & $\begin{array}{l}\text { Journal of Cleaner } \\
\text { Production }\end{array}$ \\
\hline 51 & $\begin{array}{c}\text { A waste input-output life-cycle } \\
\text { cost analysis of the recycling } \\
\text { of end-of-life electrical home } \\
\text { appliances }\end{array}$ & $\begin{array}{c}\text { NAKAMURA,S.;KONDO, } \\
\text { Y. }\end{array}$ & $\begin{array}{l}\text { LCC; LCA; Electric appliances; } \\
\text { Recycling; Design for } \\
\text { Disassembly }\end{array}$ & Japão & 2006 & Artigo & $\begin{array}{l}\text { Ecological } \\
\text { Economics }\end{array}$ \\
\hline 52 & $\begin{array}{c}\text { A web-based system for reverse } \\
\text { manufactruing and product } \\
\text { environmental impact } \\
\text { assessment considering end-of- }\end{array}$ & $\begin{array}{l}\text { ZHANG,H.C.; LI,J.; } \\
\text { SHIRIVASTAVA, P.; } \\
\text { WHITLEY, A. }\end{array}$ & $\begin{array}{c}\text { Life Cycle, Reverse } \\
\text { Manufacturing, Desicion- } \\
\text { making }\end{array}$ & $\begin{array}{l}\text { Estados } \\
\text { Unidos }\end{array}$ & 2004 & Artigo & CIRP Annals \\
\hline
\end{tabular}




\begin{tabular}{|c|c|c|c|c|c|c|c|}
\hline & life dispositions & & & & & & \\
\hline 53 & $\begin{array}{c}\text { A web-enabled Virtual } \\
\text { Disassembly Manager } \\
\text { (webVDM) for electronics } \\
\text { Products }\end{array}$ & $\begin{array}{l}\text { RANKY,P.G.; CAUDILL, } \\
\text { R.J.; DAS, S.K. }\end{array}$ & Sem palavras chave & $\begin{array}{l}\text { Estados } \\
\text { Unidos }\end{array}$ & 2001 & Artigo & IEEE anais \\
\hline 54 & $\begin{array}{l}\text { An (s, Q) inventory model with } \\
\text { remanufacturing and disposal }\end{array}$ & $\begin{array}{c}\text { VAN DER LAAN,E.; } \\
\text { DEKKER,R.;SALOMON, } \\
\text { M.RIDDER,A }\end{array}$ & $\begin{array}{l}\text { Inventory; Manufacturing; } \\
\text { Optimisation }\end{array}$ & Holanda & 1996 & Artigo & $\begin{array}{l}\text { International } \\
\text { journal of } \\
\text { productions } \\
\text { economics }\end{array}$ \\
\hline 55 & $\begin{array}{l}\text { An analysis of decentralized } \\
\text { collection and processing of } \\
\text { end-of-life products }\end{array}$ & $\begin{array}{l}\text { KARAKAYALI, I.; EMIR } \\
\text { FARINAS, H.; AKCALI, E. }\end{array}$ & $\begin{array}{l}\text { Operations strategy; } \\
\text { Environmental issues; Product } \\
\text { recovery }\end{array}$ & $\begin{array}{l}\text { Estados } \\
\text { Unidos }\end{array}$ & 2007 & Artigo & $\begin{array}{l}\text { Journal of } \\
\text { operations } \\
\text { management }\end{array}$ \\
\hline 56 & $\begin{array}{l}\text { an architecture design with data } \\
\text { model for product recovery } \\
\text { management systems }\end{array}$ & $\begin{array}{l}\text { UM, J.; SUNG YOON, J.; } \\
\text { SUH, S.H. }\end{array}$ & $\begin{array}{l}\text { Product recovery management, } \\
\text { IbiDM, ubiquitous information, } \\
\text { infrastructure, ISSO product } \\
\text { infromations standars }\end{array}$ & Korea & 2008 & Artigo & $\begin{array}{l}\text { Resources } \\
\text { conservation and } \\
\text { recycling }\end{array}$ \\
\hline 57 & $\begin{array}{l}\text { An assessment and priorization } \\
\text { of "Design for recycling } \\
\text { Guidelines for plastics } \\
\text { components }\end{array}$ & $\begin{array}{l}\text { MASANET, E.; TSUDA, } \\
\text { R.A.D.; BAYNES T.B.A. }\end{array}$ & Sem palavras chave & $\begin{array}{l}\text { Estados } \\
\text { Unidos }\end{array}$ & 2002 & Artigo & IEEE \\
\hline 58 & $\begin{array}{l}\text { An assessment of household } \\
\text { willingness to pay for curbside } \\
\text { recycling:A comparison of } \\
\text { payment card and referendum } \\
\text { approaches }\end{array}$ & $\begin{array}{l}\text { BLAINE, T.W.; } \\
\text { LICHTKOPPLER,F.R. } \\
\text { JONES, K.R.; ZONDAG, } \\
\text { R.H. }\end{array}$ & $\begin{array}{c}\text { Curbside recycling; Willingness } \\
\text { to pay (WTP); Contingent } \\
\text { valuation method (CVM); } \\
\text { Single bounded referendum; } \\
\text { Payment card }\end{array}$ & $\begin{array}{l}\text { Estados } \\
\text { Unidos }\end{array}$ & 2005 & Artigo & $\begin{array}{l}\text { Journal of } \\
\text { Environmental } \\
\text { management }\end{array}$ \\
\hline 59 & $\begin{array}{l}\text { An assessment of the recycling } \\
\text { potential of materials based } \\
\text { on environmental and economic } \\
\text { factors; case study in South } \\
\text { Korea }\end{array}$ & $\begin{array}{l}\text { KIM, K.; HWANG, Y.; } \\
\text { PARK, K. }\end{array}$ & $\begin{array}{l}\text { Recycling potential } \\
\text { Life cycle assessment (LCA) } \\
\text { Analytical hierarchy process } \\
\text { (AHP) } \\
\text { Environmental and economic }\end{array}$ & $\begin{array}{l}\text { Estados } \\
\text { Unidos }\end{array}$ & 2009 & Artigo & $\begin{array}{l}\text { Journal of Cleaner } \\
\text { Production }\end{array}$ \\
\hline
\end{tabular}




\begin{tabular}{|c|c|c|c|c|c|c|c|}
\hline & & & $\begin{array}{c}\text { assessment } \\
\text { Waste home appliance }\end{array}$ & & & & \\
\hline 60 & $\begin{array}{l}\text { An Economical and Technical } \\
\text { Analysis of Household } \\
\text { Appliance Remanufacturing } \\
\text { Process }\end{array}$ & SUNDIN, E & Sem palavras chave & Suécia & 2001 & Artigo & IEEE \\
\hline 61 & $\begin{array}{c}\text { An end-of-life decision support } \\
\text { tool for product recovery } \\
\text { considerations in the footwear } \\
\text { industry }\end{array}$ & $\begin{array}{l}\text { STAIKOS, T.; } \\
\text { RAHIMIFARD, S. }\end{array}$ & $\begin{array}{c}\text { Shoe recycling, foorwear } \\
\text { industry, End-of-life } \\
\text { management, Desisicon Support }\end{array}$ & Inglaterra & 2007 & Artigo & $\begin{array}{l}\text { Internaitonal } \\
\text { Journal of } \\
\text { Computer } \\
\text { Integrated } \\
\text { Manufacturing }\end{array}$ \\
\hline 62 & $\begin{array}{c}\text { An environmental analysis of } \\
\text { the reverse supply chain of SLI } \\
\text { batteries }\end{array}$ & $\begin{array}{c}\text { TSOULFAS,G.T.; } \\
\text { PAPPIS,C.P.; MINNER,S. }\end{array}$ & $\begin{array}{c}\text { SLI Batteries; Material } \\
\text { Recovery; Recycling; Reverse } \\
\text { Logistics }\end{array}$ & Greça & 2002 & Artigo & $\begin{array}{l}\text { Resources } \\
\text { conservation and } \\
\text { recycling }\end{array}$ \\
\hline 63 & $\begin{array}{c}\text { An Evaluation Methodology For } \\
\text { Disassembly Processes }\end{array}$ & $\begin{array}{l}\text { GUNGOR, A.; GUPTA, } \\
\text { S.M. }\end{array}$ & $\begin{array}{l}\text { Disassembly, disassembly } \\
\text { evaluation, disassembly } \\
\text { sequencing, motion study of } \\
\text { disassembly, tool change in } \\
\text { disassembly }\end{array}$ & $\begin{array}{l}\text { Estados } \\
\text { Unidos }\end{array}$ & 1997 & Artigo & $\begin{array}{l}\text { Computers ind. } \\
\text { Engng }\end{array}$ \\
\hline 64 & $\begin{array}{c}\text { An evaluation model of product } \\
\text { upgradeability for } \\
\text { remanufacture }\end{array}$ & $\begin{array}{l}\text { XING, K.; BELUSKO, M.; } \\
\text { LUONG, L.; ABHARY, K. }\end{array}$ & $\begin{array}{l}\text { End-of-life, remanufature, } \\
\text { Upgradeability, reusability, } \\
\text { modularity, evaluation model, } \\
\text { fuzzy set theory }\end{array}$ & Austrália & 2007 & Artigo & $\begin{array}{l}\text { Int J Adv. Manuf } \\
\text { technol }\end{array}$ \\
\hline 65 & $\begin{array}{l}\text { An evaluation of order release } \\
\text { strategies in a remanufactruing } \\
\text { environment }\end{array}$ & $\begin{array}{l}\text { GUIDE Jr, V.D.R.; } \\
\text { SRIVASTAVA, R. }\end{array}$ & Sem palavras chave & $\begin{array}{l}\text { Estados } \\
\text { Unidos }\end{array}$ & 1997 & Artigo & $\begin{array}{l}\text { Computers Ops } \\
\text { Res. }\end{array}$ \\
\hline 66 & $\begin{array}{l}\text { An Evaluation tool for Eco- } \\
\text { Design of Electrical Products }\end{array}$ & $\begin{array}{c}\text { MURTAGH, N.; } \\
\text { BAMBA,T.;IWAMA, K. }\end{array}$ & Sem palavras chave & Japão & 1999 & Artigo & $\begin{array}{l}\text { Mitsubishi Eletric } \\
\text { Corporation }\end{array}$ \\
\hline 67 & $\begin{array}{l}\text { An explorationof institucional } \\
\text { constrainsts on developing end- }\end{array}$ & MIEMCZYK, J. & $\begin{array}{c}\text { Product recovery, } \\
\text { Institutionalism,constraints, }\end{array}$ & França & 2008 & Artigo & $\begin{array}{l}\text { Int. J. Productions } \\
\text { Economics }\end{array}$ \\
\hline
\end{tabular}




\begin{tabular}{|c|c|c|c|c|c|c|c|}
\hline & $\begin{array}{l}\text { of-life prduct recovery } \\
\text { capabilities }\end{array}$ & & End-of-life, capabilities & & & & \\
\hline 68 & $\begin{array}{l}\text { An integrated approach to } \\
\text { disassembly planning and } \\
\text { demanufacturing operation }\end{array}$ & $\begin{array}{l}\text { TANG, Y.; ZHOU, M.; } \\
\text { CAUDILL, R.J. }\end{array}$ & $\begin{array}{c}\text { demamufacturing systems, } \\
\text { disassembly planning. Petri nets }\end{array}$ & $\begin{array}{l}\text { Estados } \\
\text { Unidos }\end{array}$ & 2001 & Artigo & $\begin{array}{l}\text { IEEE transactions } \\
\text { on robotics and } \\
\text { automation }\end{array}$ \\
\hline 69 & $\begin{array}{c}\text { An Investigation of lead-time } \\
\text { effects in } \\
\text { manufacturing/remanufacturing } \\
\text { systems under simple PUSH and } \\
\text { PULL control strategies }\end{array}$ & $\begin{array}{c}\text { VAN DER LAAN, E.; } \\
\text { SALOMON, M.; DEKKER, } \\
\text { R. }\end{array}$ & Sem palavras chave & Holanda & 1999 & Artigo & $\begin{array}{l}\text { European Journal } \\
\text { of Operational } \\
\text { Research }\end{array}$ \\
\hline 70 & $\begin{array}{l}\text { An object-oriented intelligent } \\
\text { disassembly sequence } \\
\text { planner for maintenance }\end{array}$ & $\begin{array}{l}\text { LI, J.R.; KHOO, } \\
\text { L.P.;BENG TOUR, S. }\end{array}$ & $\begin{array}{c}\text { Disassembly sequence planning; } \\
\text { Maintenance; Object-oriented } \\
\text { software design }\end{array}$ & Cingapura & 2005 & Artigo & $\begin{array}{l}\text { Computers in } \\
\text { Industry }\end{array}$ \\
\hline 71 & $\begin{array}{c}\text { Analysis of remanufacturing } \\
\text { waste streams for electronic } \\
\text { products }\end{array}$ & WILLIAM, J.; SHU, L.H. & Sem palavras chave & Canada & 2001 & Artigo & IEEE \\
\hline 72 & $\begin{array}{l}\text { Analysis of Reusability using } \\
\text { 'Marginal Reuse Rate }\end{array}$ & $\begin{array}{c}\text { UMEDA,Y.; } \\
\text { KONDOH,S.;SUGINO, T. }\end{array}$ & $\begin{array}{l}\text { Lifecycle; Product Design; } \\
\text { Reuse Rate }\end{array}$ & Japão & 2006 & Artigo & CIRP Annals \\
\hline 73 & $\begin{array}{l}\text { Analysis of Toner-Cartridge } \\
\text { Remanufacturer Waste Stream }\end{array}$ & WILLIAM, J.; SHU, L.H. & Sem palavras chave & Canada & 2000 & Artigo & IEEE \\
\hline 74 & $\begin{array}{c}\text { Analysys of Remanufacturer } \\
\text { waste streams across product } \\
\text { sectors }\end{array}$ & $\begin{array}{l}\text { WILLIANS, J.A.S.; SHU, } \\
\text { L.H. }\end{array}$ & $\begin{array}{l}\text { Design, environment, } \\
\text { remanufacturing }\end{array}$ & Canada & 2001 & Artigo & CIRP Annals \\
\hline 75 & $\begin{array}{l}\text { Application of a design-for- } \\
\text { remanufacture framework to the } \\
\text { selection of product life-cycle } \\
\text { fastening and joining methods }\end{array}$ & $\begin{array}{l}\text { SHU, L.H.; FLOWERS, } \\
\text { W.C. }\end{array}$ & $\begin{array}{l}\text { Design for remanufacture; Life- } \\
\text { cycle design; Environmentally } \\
\text { conscious product design; } \\
\text { Design for end-of-life; Scrap- } \\
\text { material recycling; } \\
\text { Repair; Maintenance; Assembly, } \\
\text { Disassembly; Fastening and } \\
\end{array}$ & $\begin{array}{l}\text { Estados } \\
\text { Unidos }\end{array}$ & 1999 & Artigo & $\begin{array}{l}\text { Robotics and } \\
\text { Computer- } \\
\text { Integrated } \\
\text { Manufacturing }\end{array}$ \\
\hline
\end{tabular}




\begin{tabular}{|c|c|c|c|c|c|c|c|}
\hline & & & joining & & & & \\
\hline 76 & $\begin{array}{l}\text { Applying the minimum relative } \\
\text { entropy method for bimodal } \\
\text { distribution in a } \\
\text { remanufacturing system }\end{array}$ & BAO, X.; TANG, O.; JI, J & $\begin{array}{l}\text { remanufacturing, bimodal } \\
\text { distribution, minimum relative } \\
\text { entropy method }\end{array}$ & China & 2008 & Artigo & $\begin{array}{l}\text { International } \\
\text { Journal of } \\
\text { Production } \\
\text { Economics }\end{array}$ \\
\hline 77 & $\begin{array}{c}\text { Assembly and Disassembly } \\
\text { Processes in Product Life Cycle } \\
\text { Perspectives }\end{array}$ & WESTKAMPER, E & $\begin{array}{l}\text { Assembly, Disassembly, Life } \\
\text { Cycle Management }\end{array}$ & Alemanha & 2003 & Artigo & CIRP Annals \\
\hline 79 & $\begin{array}{l}\text { Assessing the benefits of } \\
\text { remanufacturing option under } \\
\text { one-way substitution and } \\
\text { capacity constraint }\end{array}$ & $\begin{array}{l}\text { BAYINDIR, Z.P.; ERKIP, } \\
\text { N. GÜLLÜ,REFIK }\end{array}$ & $\begin{array}{l}\text { remanufacturing, inventory, } \\
\text { one-way substitution, capacity } \\
\text { constraint }\end{array}$ & Holanda & 2007 & Artigo & $\begin{array}{c}\text { computer \& } \\
\text { operations research }\end{array}$ \\
\hline 81 & $\begin{array}{c}\text { Assessing the recycling } \\
\text { efficiency of copper from } \\
\text { end-of-life products in Western } \\
\text { Europe }\end{array}$ & RUHRBERG, M. & $\begin{array}{l}\text { Collection; Copper; End-of-life } \\
\text { management; Flow model; } \\
\text { Metal; Recovery; Recycling; } \\
\text { Recycling } \\
\text { input rate; Recycling efficiency } \\
\text { rate; Scrap }\end{array}$ & Portugal & 2006 & Artigo & $\begin{array}{l}\text { Resources } \\
\text { conservation and } \\
\text { recycling }\end{array}$ \\
\hline 82 & $\begin{array}{l}\text { Assessment of factors } \\
\text { influencing the performance of } \\
\text { solid waste recycling programs }\end{array}$ & $\begin{array}{c}\text { SUTTIBAK,S.; } \\
\text { NITIVATTANANON,V. }\end{array}$ & $\begin{array}{l}\text { Capacity enhancement } \\
\text { Local government authorities } \\
\text { Performance indicators }\end{array}$ & Tailandia & 2008 & Artigo & $\begin{array}{c}\text { Resources } \\
\text { conservation and } \\
\text { recycling }\end{array}$ \\
\hline
\end{tabular}




\begin{tabular}{|c|c|c|c|c|c|c|c|}
\hline & & & $\begin{array}{l}\text { Solid waste recycling } \\
\text { Statistical analysis }\end{array}$ & & & & \\
\hline 83 & $\begin{array}{l}\text { Assessment of products for } \\
\text { optimal lifetime }\end{array}$ & $\begin{array}{c}\text { KARA, S.; KAEBERNICK, } \\
\text { H.; IBBOTSON }\end{array}$ & $\begin{array}{l}\text { Sustainable manufacturing } \\
\text { Environmental impact } \\
\text { Product development }\end{array}$ & Austrália & 2008 & Artigo & CIRP Annals \\
\hline 84 & $\begin{array}{c}\text { Asymmetric negotiation based } \\
\text { collaborative product design for } \\
\text { component reuse } \\
\text { in disparate products }\end{array}$ & $\begin{array}{l}\text { LI, J.; CHAO ZHANG, } \\
\text { H.;LIN, Z. }\end{array}$ & $\begin{array}{l}\text { Design for the environment } \\
\text { Negotiation } \\
\text { Collaborative product design } \\
\text { Negotiation support system }\end{array}$ & $\begin{array}{l}\text { Estados } \\
\text { Unidos }\end{array}$ & 2009 & Artigo & $\begin{array}{l}\text { Computers \& } \\
\text { industrial } \\
\text { engineering }\end{array}$ \\
\hline 85 & $\begin{array}{l}\text { Automatic disassembly plans: } \\
\text { application to the continuous } \\
\text { process industries }\end{array}$ & $\begin{array}{l}\text { DIAZ, B.A.; MOURE, F.; } \\
\text { RENDUELES, M. }\end{array}$ & $\begin{array}{l}\text { process optimization, heuristics, } \\
\text { Disassembly, planning, } \\
\text { continuous process, and/or trees }\end{array}$ & Espanha & 2002 & Artigo & $\begin{array}{l}\text { Journal of } \\
\text { manufacturing } \\
\text { systems }\end{array}$ \\
\hline 86 & $\begin{array}{c}\text { Automatic Generation of } \\
\text { Product Disassembly Sequences }\end{array}$ & $\begin{array}{c}\text { SUBRAMANI,A.K.;DEWH } \\
\text { URST,P. }\end{array}$ & $\begin{array}{l}\text { design, service, assemoly } \\
\text { disassembly }\end{array}$ & NA & 1991 & Artigo & CIRP Annals \\
\hline 87 & $\begin{array}{c}\text { Automobile life cycle } \\
\text { assessment issues at end-of-life } \\
\text { and recycling }\end{array}$ & $\begin{array}{c}\text { FUNAZAKI, A.; TANEDA, } \\
\text { K.; TAHARA, K.; INABA, } \\
\text { A. }\end{array}$ & Sem palavras chave & Japão & 2003 & Artigo & JSA \\
\hline 89 & $\begin{array}{c}\text { Biomimetic concept generation } \\
\text { applied to design for } \\
\text { remanufacture }\end{array}$ & HACCO,E.; SHU,L.H. & $\begin{array}{l}\text { Biomimicry; Analogy;Function; } \\
\text { Remanufacture }\end{array}$ & Canada & 2002 & Artigo & $\begin{array}{c}\text { ASME } 2002 \\
\text { Design } \\
\text { Engineering } \\
\text { Technical } \\
\text { Conferences and } \\
\text { Computers and } \\
\text { Information in } \\
\text { Engineering } \\
\text { Conference }\end{array}$ \\
\hline 90 & $\begin{array}{l}\text { Buffer allocation plan for a } \\
\text { remanufacturing cell }\end{array}$ & $\begin{array}{l}\text { AKSOY, H.K.; GUPTA, } \\
\text { S.M. }\end{array}$ & $\begin{array}{l}\text { Remanufacturing, Buffer } \\
\text { allocarion, Disassembly, open }\end{array}$ & Turquia & 2005 & Artigo & $\begin{array}{l}\text { Computers \& } \\
\text { industrial }\end{array}$ \\
\hline
\end{tabular}




\begin{tabular}{|c|c|c|c|c|c|c|c|}
\hline & & & queueing networks, throughput & & & & engineering \\
\hline 91 & $\begin{array}{l}\text { Building contingency planning } \\
\text { for closed-loop supply } \\
\text { chains with product recovery }\end{array}$ & $\begin{array}{l}\text { GUIDE Jr,V.D.R.; } \\
\text { JAYARAMAN,V.; } \\
\text { LINTON,J. D. }\end{array}$ & $\begin{array}{l}\text { Case study; Production } \\
\text { planning; Closed-loop supply } \\
\text { chain management }\end{array}$ & $\begin{array}{l}\text { Estados } \\
\text { Unidos }\end{array}$ & 2003 & Artigo & $\begin{array}{l}\text { Journal of } \\
\text { operations } \\
\text { management }\end{array}$ \\
\hline 92 & $\begin{array}{l}\text { Business case Roteb: recovery } \\
\text { strategies for monitors }\end{array}$ & $\begin{array}{c}\text { KRIKKE, H.R.; VAN } \\
\text { HARTER, A.; SCHUUR, } \\
\text { P.C. }\end{array}$ & $\begin{array}{c}\text { Reverse logistics; Recovery } \\
\text { strategies; Electronics recycling; } \\
\text { Case study }\end{array}$ & Holanda & 1999 & Artigo & $\begin{array}{l}\text { Computers \& } \\
\text { industrial } \\
\text { engineering }\end{array}$ \\
\hline 94 & $\begin{array}{c}\text { Cascade approach on recycling } \\
\text { form marble and granite product } \\
\text { design }\end{array}$ & $\begin{array}{l}\text { DOS SANTOS, A.; } \\
\text { SAMPAIO, C.P.; } \\
\text { VEZZOLI, C. }\end{array}$ & $\begin{array}{c}\text { Natural materials, reutilization, } \\
\text { cascade approach }\end{array}$ & Brasil & 2009 & Artigo & $\begin{array}{l}\text { Materials \& } \\
\text { Design }\end{array}$ \\
\hline 96 & $\begin{array}{c}\text { Challenging the implementation } \\
\text { of corporate sustainability }\end{array}$ & SEITZ, M.A.; WELLS, P.E. & $\begin{array}{l}\text { Automotive components } \\
\text { industry, Supply chain } \\
\text { management, Product } \\
\text { management, Reverse } \\
\text { scheduling }\end{array}$ & Inglaterra & 2006 & Artigo & $\begin{array}{l}\text { Business Process } \\
\text { Management } \\
\text { Journal }\end{array}$ \\
\hline 97 & $\begin{array}{l}\text { Characterizing the } \\
\text { remanufacturability of } \\
\text { engineering systems }\end{array}$ & $\begin{array}{c}\text { AMEZQUITA, } \\
\text { T.;HAMMOND,R.;SALAZ } \\
\text { AR.M.;BRAS,B. }\end{array}$ & Sem palavras chave & $\begin{array}{l}\text { Estados } \\
\text { Unidos }\end{array}$ & 1995 & Artigo & $\begin{array}{l}\text { ASME Design } \\
\text { Technical } \\
\text { Engineering } \\
\text { Conferences }\end{array}$ \\
\hline
\end{tabular}




\begin{tabular}{|c|c|c|c|c|c|c|c|}
\hline 98 & $\begin{array}{c}\text { Close to } 100 \% \text { recirculation of } \\
\text { electronic waste }\end{array}$ & LIEN,T.K. & $\begin{array}{l}\text { Recycling; Electronics; } \\
\text { Organization }\end{array}$ & Noruega & 2008 & Artigo & LCE Annals \\
\hline 99 & $\begin{array}{c}\text { Closed-loop supply chain } \\
\text { network equilibrium under } \\
\text { legislation }\end{array}$ & $\begin{array}{l}\text { HAMMOND, D.; } \\
\text { BEULLENS, P. }\end{array}$ & $\begin{array}{c}\text { Supply chain management; OR } \\
\text { in strategic planning; Logistics; } \\
\text { Nonlinear programming }\end{array}$ & Inglaterra & 2007 & Artigo & $\begin{array}{l}\text { European Journal } \\
\text { of Operational } \\
\text { Research }\end{array}$ \\
\hline 100 & Competition in remanufacturing & $\begin{array}{l}\text { MAJUMDER, P.; } \\
\text { GROENEVELT,H. }\end{array}$ & $\begin{array}{l}\text { remanufacturing, compettiton, } \\
\text { reverse logistics }\end{array}$ & $\begin{array}{l}\text { Estados } \\
\text { Unidos }\end{array}$ & 2001 & Artigo & $\begin{array}{l}\text { Production and } \\
\text { operations } \\
\text { managment }\end{array}$ \\
\hline 101 & $\begin{array}{c}\text { Competition in remanufacturing } \\
\text { and the effects of goverment } \\
\text { subsidies }\end{array}$ & SUPRIYA, M.; SCOTT, W. & $\begin{array}{l}\text { remanufactruing, pricing, } \\
\text { competive strategy, reverse } \\
\text { logistics, closed-loop supply } \\
\text { chains }\end{array}$ & India & 2008 & Artigo & $\begin{array}{l}\text { International } \\
\text { Journal of } \\
\text { Production } \\
\text { Economics }\end{array}$ \\
\hline 102 & $\begin{array}{l}\text { Competitive strategy in } \\
\text { remanufacturing and the impact } \\
\text { of take-back laws }\end{array}$ & WEBSTER, S.; MITRA, S. & $\begin{array}{l}\text { remanufacturing,environmental } \\
\text { laws, pricing, competitive } \\
\text { strategy, reverse logistics, } \\
\text { closed loop supply chains }\end{array}$ & $\begin{array}{l}\text { Estados } \\
\text { Unidos }\end{array}$ & 2007 & Artigo & $\begin{array}{l}\text { Journal of } \\
\text { operations } \\
\text { management }\end{array}$ \\
\hline 103 & $\begin{array}{l}\text { Computational issues in a } \\
\text { stochastic finite horizon one } \\
\text { product recovery inventory } \\
\text { model }\end{array}$ & $\begin{array}{l}\text { KIESMULLER, G.P.; } \\
\text { SCHERER, C.W. }\end{array}$ & $\begin{array}{c}\text { Inventory; Optimal control; } \\
\text { Dynamic programming; Reverse } \\
\text { logistics }\end{array}$ & Holanda & 2003 & Artigo & $\begin{array}{l}\text { European Journal } \\
\text { of Operational } \\
\text { Research }\end{array}$ \\
\hline 104 & $\begin{array}{l}\text { Computer Aided Design for } \\
\text { Demanufacturing and } \\
\text { Remanufacturing }\end{array}$ & BRAS, B.; ROSEN, D. & Sem palavras chave & $\begin{array}{l}\text { Estados } \\
\text { Unidos }\end{array}$ & 1998 & Artigo & $\begin{array}{c}\text { Georgia Institute } \\
\text { of } \\
\text { Technology }\end{array}$ \\
\hline 105 & $\begin{array}{c}\text { Computer Aided Disassembly } \\
\text { Planning: State of the Art and } \\
\text { Perspectives }\end{array}$ & $\begin{array}{c}\text { SANTOCHI,M.;DINI,G.;F } \\
\text { AILLI,F }\end{array}$ & $\begin{array}{c}\text { Disassembly, recycling, } \\
\text { planning }\end{array}$ & Italia & 2002 & Artigo & CIRP Annals \\
\hline 106 & $\begin{array}{l}\text { Conceptual Design of product } \\
\text { Structure for Parts Reuse }\end{array}$ & WU,Y.;KIMURA,F. & $\begin{array}{l}\text { Parts reuse; Conceptual design; } \\
\text { End-of-life product }\end{array}$ & Japão & 2007 & Artigo & CIRP Annals \\
\hline 107 & Considering Remanufature and & SHU, L.H.; FLOWERS, & Sem palavras chave & Estados & 1995 & Artigo & IEEE \\
\hline
\end{tabular}




\begin{tabular}{|c|c|c|c|c|c|c|c|}
\hline & $\begin{array}{l}\text { other End-of-life Options ins } \\
\text { selection of Fastening and } \\
\text { Joining Methods }\end{array}$ & W.C. & & Unidos & & & \\
\hline 108 & $\begin{array}{c}\text { Constraint-based schedule repair } \\
\text { for product development } \\
\text { projects with time-limited } \\
\text { constraints }\end{array}$ & WANG,J & $\begin{array}{c}\text { Product development; Project } \\
\text { scheduling; Resource allocation; } \\
\text { Simulated annealing; Genetic } \\
\text { algorithms }\end{array}$ & China & 2005 & Artigo & $\begin{array}{l}\text { International } \\
\text { Journal of } \\
\text { Production } \\
\text { Economics }\end{array}$ \\
\hline 109 & $\begin{array}{c}\text { Continuing support for aging ate } \\
\text { through remanufacturing } \\
\text { engineering }\end{array}$ & $\begin{array}{l}\text { HULETT, J.N.; MOST, } \\
\text { G.F. }\end{array}$ & Sem palavras chave & $\begin{array}{l}\text { Estados } \\
\text { Unidos }\end{array}$ & 2005 & Artigo & IEEE \\
\hline 110 & $\begin{array}{c}\text { Contribution to Design for } \\
\text { Adaptation: Method to asses the } \\
\text { adaptability of products } \\
\text { (MAAP) }\end{array}$ & $\begin{array}{c}\text { WILLEMS,B.; } \\
\text { SELIGER,G.; DUFLOU,J.; } \\
\text { BASDERE,B. }\end{array}$ & Sem palavras chave & Alemanha & 2003 & Artigo & IEEE \\
\hline 111 & $\begin{array}{l}\text { Cradle to cradle: Reverse } \\
\text { Logistics strategies and } \\
\text { opprotunities across three } \\
\text { industry sectors }\end{array}$ & KUMAR,S.; PUTNAM,V. & $\begin{array}{c}\text { Closer-lopp supply chain; } \\
\text { SWOT; Remanufacturing; } \\
\text { Reuse;Recylcing; End-of-life } \\
\text { product management }\end{array}$ & $\begin{array}{l}\text { Estados } \\
\text { Unidos }\end{array}$ & 2008 & Artigo & $\begin{array}{l}\text { International } \\
\text { Journal of } \\
\text { Production } \\
\text { Economics }\end{array}$ \\
\hline 113 & $\begin{array}{c}\text { Cycling Platform for profitable } \\
\text { reuse }\end{array}$ & $\begin{array}{c}\text { SELIGER, G., BASDERE, } \\
\text { B.; KEIL, T. }\end{array}$ & Sem palavras chave & Alemanha & 2001 & Artigo & IEEE \\
\hline 114 & $\begin{array}{l}\text { Definition of a VR Tool for the } \\
\text { Early Design Stage of the } \\
\text { Product strutucture under } \\
\text { Consideration of Dissasembly }\end{array}$ & $\begin{array}{l}\text { ZWOLINSKY,P.; } \\
\text { SGHAIER, A.; } \\
\text { BRISSAUD,D. }\end{array}$ & $\begin{array}{l}\text { DFD; End of life; Virtual } \\
\text { reality; Product design }\end{array}$ & França & 2007 & Artigo & CIRP Annals \\
\hline 115 & $\begin{array}{l}\text { Design and Innovation for } \\
\text { Sustainable Manufacturing -A }\end{array}$ & $\begin{array}{c}\text { SELIGER,G.; FRANKE,C.; } \\
\text { KERNBAUM,S. }\end{array}$ & $\begin{array}{c}\text { Sustainability; } \\
\text { Remanufacturing; IT equipment }\end{array}$ & Alemanha & 2006 & Artigo & $\begin{array}{l}\text { The 16th CIRP } \\
\text { International }\end{array}$ \\
\hline
\end{tabular}




\begin{tabular}{|c|c|c|c|c|c|c|c|}
\hline & European Perspective & & & & & & $\begin{array}{c}\text { Design Seminar } \\
2006\end{array}$ \\
\hline 116 & $\begin{array}{l}\text { Design charts for } \\
\text { remanufacturing assessment }\end{array}$ & $\begin{array}{c}\text { MABEE, D.G.; BOMMER, } \\
\text { M.; KEAT, W.D. }\end{array}$ & $\begin{array}{l}\text { remanufacturing, product life } \\
\text { cycle, design methodology }\end{array}$ & $\begin{array}{l}\text { Estados } \\
\text { Unidos }\end{array}$ & 1999 & Artigo & $\begin{array}{l}\text { Journal of } \\
\text { manufacturing } \\
\text { systems }\end{array}$ \\
\hline 117 & $\begin{array}{l}\text { Design for adaptability } \\
\text { (DFAD)—a new concept for } \\
\text { achieving sustainable design }\end{array}$ & $\begin{array}{l}\text { KASARDA,M.E.; } \\
\text { TERPENNY,J.P.; } \\
\text { INMAN,D.; } \\
\text { PRECODA,K.R.; } \\
\text { JELESKO,J.; SAHIN,A. } \\
\text {;PARK, J. }\end{array}$ & $\begin{array}{l}\text { Sustainable design; Design for } \\
\text { adaptability; Engineering } \\
\text { design; Dynamic systems }\end{array}$ & $\begin{array}{l}\text { Estados } \\
\text { Unidos }\end{array}$ & 2007 & Artigo & $\begin{array}{l}\text { Robotics and } \\
\text { Computer- } \\
\text { Integrated } \\
\text { Manufacturing }\end{array}$ \\
\hline 118 & $\begin{array}{l}\text { Design for Assembly and } \\
\text { Disassembly }\end{array}$ & $\begin{array}{l}\text { BOOTHROYD, G.; } \\
\text { ALTING, L. }\end{array}$ & Design, Asessmby, Disassembly & $\begin{array}{l}\text { Estados } \\
\text { Unidos }\end{array}$ & 1992 & Artigo & CIRP Annals \\
\hline 119 & $\begin{array}{c}\text { Design for Bulk Recycling: } \\
\text { Analysis of Materials Separation }\end{array}$ & $\begin{array}{c}\text { KNIGTH, W.A.; SODHI, } \\
\text { M. }\end{array}$ & $\begin{array}{l}\text { Life Cycle Design, Product } \\
\text { Analysis, Material Selection. }\end{array}$ & $\begin{array}{l}\text { Estados } \\
\text { Unidos }\end{array}$ & 2000 & Artigo & CIRP Annals \\
\hline 120 & $\begin{array}{c}\text { Design for Disassembly and the } \\
\text { environment }\end{array}$ & $\begin{array}{c}\text { HARJULA,T.; } \\
\text { RAPOZA,B.; } \\
\text { KNIGHT,W.A.; } \\
\text { BOOTHROYD,G. }\end{array}$ & $\begin{array}{c}\text { Design; } \\
\text { Disassembly;Environmental }\end{array}$ & $\begin{array}{l}\text { Estados } \\
\text { Unidos }\end{array}$ & 1996 & Artigo & CIRP Annals \\
\hline 121 & $\begin{array}{c}\text { Design for Environment: A } \\
\text { method for formulating product } \\
\text { end-of-life strategies }\end{array}$ & ROSE,C.M. & Sem palavras chave & $\begin{array}{l}\text { Estados } \\
\text { Unidos }\end{array}$ & 2000 & Tese & Stanford university \\
\hline 122 & $\begin{array}{l}\text { Design for environment: } \\
\text { Methodologies, tools, and } \\
\text { implementation }\end{array}$ & $\begin{array}{c}\text { SUN,J.; HAN,B.; } \\
\text { OSIRE,S.E.; ZHNAG,H.C. }\end{array}$ & $\begin{array}{l}\text { Design for environment; DfE; } \\
\text { tools;implementation }\end{array}$ & $\begin{array}{l}\text { Estados } \\
\text { Unidos }\end{array}$ & 2003 & Artigo & $\begin{array}{l}\text { Society for Design } \\
\text { and Process } \\
\text { Science }\end{array}$ \\
\hline 123 & $\begin{array}{l}\text { Design for manufacture and } \\
\text { design for ' } \mathrm{X} \text { ': concepts, } \\
\text { applications adn perpectives }\end{array}$ & $\begin{array}{c}\text { KUO,T-C.; } \\
\text { HUANG,S.H.;ZHANG, H- } \\
\text { C. }\end{array}$ & $\begin{array}{l}\text { Design for manufacture; Design } \\
\text { for life-cycle; Design for } \\
\text { Disassembly; Design for X. }\end{array}$ & $\begin{array}{l}\text { Estados } \\
\text { Unidos }\end{array}$ & 2001 & Artigo & $\begin{array}{l}\text { Computers \& } \\
\text { industrial } \\
\text { engineering }\end{array}$ \\
\hline 124 & Design for product retirement & ISHII, K.; EUBANKS, C.F.; & design for product retirement; & Estados & 1994 & Artigo & Materials \& \\
\hline
\end{tabular}




\begin{tabular}{|c|c|c|c|c|c|c|c|}
\hline & $\begin{array}{l}\text { and material } \\
\text { life-cycle }\end{array}$ & DI MARCO, P. & $\begin{array}{l}\text { clumping; material life-cycle } \\
\text { analysis }\end{array}$ & Unidos & & & Design \\
\hline 125 & $\begin{array}{c}\text { Design for Recycling and Rema } \\
\text { Fuel Cells }\end{array}$ & FREIBERGER,S. & $\begin{array}{c}\text { Eco design; Recycling; } \\
\text { Remanufacturing; Fuel cell }\end{array}$ & Alemanha & 2005 & Artigo & IEEE \\
\hline 126 & $\begin{array}{c}\text { Design for Recycling, recycling } \\
\text { data magement and optimal end- } \\
\text { of-life plannign based on } \\
\text { recycling-graphs }\end{array}$ & $\begin{array}{l}\text { ROSEMANN,B.; } \\
\text { MEERKAMM,H.; } \\
\text { TRAUTNER, St.; } \\
\text { FELDMANN, K. }\end{array}$ & $\begin{array}{c}\text { Recycling-Graph-editos } \\
\text { (reGrEd); Disassembly- } \\
\text { planning- system } \\
\text { (DisPlay);Design for recycling } \\
\text { (RecyKon), Recycling-Data- } \\
\text { Management-System (ReDaMa) }\end{array}$ & Alemanha & 1999 & Artigo & ICED 99 \\
\hline 127 & Design for Remanufacturing & NASR, N.; HILTON,B. & $\begin{array}{l}\text { Remanufacturing; Design for } \\
\text { remanufacturing; Technology } \\
\text { Obsolescence; Life cycle } \\
\text { Engineering }\end{array}$ & $\begin{array}{l}\text { Estados } \\
\text { Unidos }\end{array}$ & 2008 & Artigo & LCE Annals \\
\hline 128 & Design for the next generation & $\begin{array}{l}\text { ROSSI, M.; CHARON, } \\
\text { S.;WING, G. EWELL, J. }\end{array}$ & $\begin{array}{l}\text { chemical hazards and toxicity, } \\
\text { design for environment (DfE), } \\
\text { disassembly, industrial ecology, } \\
\text { office contract furniture industry }\end{array}$ & $\begin{array}{l}\text { Estados } \\
\text { Unidos }\end{array}$ & 2006 & Artigo & $\begin{array}{c}\text { Journal of } \\
\text { Industrial Ecology }\end{array}$ \\
\hline 129 & $\begin{array}{l}\text { Design Knowledge recycling } \\
\text { using precedent-based analysis } \\
\text { and systhesis models }\end{array}$ & EILOUTI, B.H. & $\begin{array}{c}\text { architectural design, case-based } \\
\text { reasoning, design knowledge, } \\
\text { design precedents, knowledge } \\
\text { recycling }\end{array}$ & Arábia & 2005 & Artigo & Design Studies \\
\hline 130 & $\begin{array}{l}\text { Design of a flexible assembly } \\
\text { and remanufacturing cell for } \\
\text { advanced SM components: } \\
\text { selection of cell design concept } \\
\text { based on reflow tools }\end{array}$ & $\begin{array}{l}\text { GEREN, N.; ÇAKIRCA, } \\
\text { M.;BAYRAMOGLU }\end{array}$ & $\begin{array}{l}\text { Component manufacturing, } \\
\text { printed circuits, System } \\
\text { monitoring, Design of work. }\end{array}$ & Turquia & 2006 & Artigo & $\begin{array}{l}\text { Soldering \& } \\
\text { Surface Mount } \\
\text { Technology }\end{array}$ \\
\hline 131 & $\begin{array}{l}\text { Design optimisation of } \\
\text { aluminium recycling }\end{array}$ & $\begin{array}{l}\text { KHOEI, A.R.; MASTERS, } \\
\text { I.; GETHIN, D.T. }\end{array}$ & $\begin{array}{l}\text { Process optimisation; Taguchi } \\
\text { method; Aluminium recycling; }\end{array}$ & Iran & 2002 & Artigo & $\begin{array}{l}\text { Journal of } \\
\text { Materials }\end{array}$ \\
\hline
\end{tabular}




\begin{tabular}{|c|c|c|c|c|c|c|c|}
\hline & $\begin{array}{l}\text { processes using Taguchi } \\
\text { technique }\end{array}$ & & $\begin{array}{l}\text { Signal-to-noise ratio; ANOVA } \\
\text { analysis; Response surface } \\
\text { method }\end{array}$ & & & & $\begin{array}{l}\text { Processing } \\
\text { Technology }\end{array}$ \\
\hline 132 & $\begin{array}{c}\text { Designing sustainable recovery } \\
\text { network of end-of-life products } \\
\text { using genetic algorithm }\end{array}$ & $\begin{array}{l}\text { DEHGHANIAN, F.; } \\
\text { MANSOUR, S. }\end{array}$ & $\begin{array}{l}\text { Sustainable development, } \\
\text { recovery networks, life cycle } \\
\text { assessment (LCA). Anaçytical } \\
\text { hierarchy process (AHP), } \\
\text { genetic algorithm, scrap tires }\end{array}$ & India & 2009 & Artigo & $\begin{array}{l}\text { Resources } \\
\text { conservation and } \\
\text { recycling }\end{array}$ \\
\hline 133 & $\begin{array}{c}\text { Destructive Disassembly of } \\
\text { Bolts and Screws } \\
\text { by Impact Fracture }\end{array}$ & PAK, K.G.; SODHI, R. & $\begin{array}{c}\text { Destructive Disassembly, } \\
\text { Impact Fracture, } \\
\text { Stress Wave, Demanufacturing }\end{array}$ & $\begin{array}{l}\text { Estados } \\
\text { Unidos }\end{array}$ & 2002 & Artigo & $\begin{array}{l}\text { Journal of } \\
\text { manufacturing } \\
\text { systems }\end{array}$ \\
\hline 134 & $\begin{array}{l}\text { Determing end-of-life strategies } \\
\text { as a part of production definition }\end{array}$ & $\begin{array}{l}\text { ROSE,C.M.; BEITER,K.A.; } \\
\text { ISHII, K. }\end{array}$ & Sem palavras chave & $\begin{array}{l}\text { Estados } \\
\text { Unidos }\end{array}$ & 1999 & Artigo & IEEE \\
\hline 135 & $\begin{array}{c}\text { Determining optimal } \\
\text { disassembly and recovery } \\
\text { strategies }\end{array}$ & TEUNTER, R.H & $\begin{array}{l}\text { Disassembly; Recovery; Profit } \\
\text { maximization; Dynamic } \\
\text { programming }\end{array}$ & Inglaterra & 2006 & Artigo & $\begin{array}{l}\text { The International } \\
\text { Journal of } \\
\text { Management } \\
\text { Science }\end{array}$ \\
\hline 136 & $\begin{array}{l}\text { Determining optimum } \\
\text { disassembly sequences in } \\
\text { electronic } \\
\text { equipment }\end{array}$ & LAMBERT, A.J.D & $\begin{array}{c}\text { Disassembly; Mathematical } \\
\text { programming; Optimization; } \\
\text { Recycling; Electronic equipment }\end{array}$ & Holanda & 2002 & Artigo & $\begin{array}{l}\text { Computers \& } \\
\text { industrial } \\
\text { engineering }\end{array}$ \\
\hline 137 & $\begin{array}{c}\text { Development of a life cycle } \\
\text { assessment tool for construction } \\
\text { and maintenance of asphalt } \\
\text { pavements }\end{array}$ & $\begin{array}{l}\text { HUANG, Y.; BIRD, R.; } \\
\text { HEIDRICH, O. }\end{array}$ & $\begin{array}{l}\text { Asphalt pavements, life cycle } \\
\text { assessment, recycling, } \\
\text { sustainable construction }\end{array}$ & Inglaterra & 2009 & Artigo & $\begin{array}{c}\text { Journal of Cleaner } \\
\text { Production }\end{array}$ \\
\hline 138 & $\begin{array}{l}\text { Development of a Semi- } \\
\text { quantitative pre-LCA tool }\end{array}$ & $\begin{array}{l}\text { ONG, S.K.; T.H. KOH, } \\
\text { NEE A.Y.C. }\end{array}$ & $\begin{array}{c}\text { life-cycle assessment, } \\
\text { Envioronmental impacts, Pre- } \\
\text { LCA }\end{array}$ & Cingapura & 1999 & Artigo & $\begin{array}{l}\text { Journal of } \\
\text { Materials } \\
\text { Processing } \\
\text { Technology }\end{array}$ \\
\hline 139 & Development of an integrated & CHOW, J.; LEE, S.-M.; & CAD-CAM integration, & Estados & 2002 & Artigo & the international \\
\hline
\end{tabular}




\begin{tabular}{|c|c|c|c|c|c|c|c|}
\hline & $\begin{array}{c}\text { laser-based reverse engineering } \\
\text { and machine system }\end{array}$ & KENGSKOOL, K. & $\begin{array}{l}\text { concurrent engineering, laser } \\
\text { scanning, reverse engineering }\end{array}$ & Unidos & & & $\begin{array}{l}\text { journal advanced } \\
\text { manufactruing } \\
\text { technology }\end{array}$ \\
\hline 140 & $\begin{array}{l}\text { Development of } \\
\text { demanufacturing module for } \\
\text { multi-lifecycle assessment and } \\
\text { analysis of products }\end{array}$ & $\begin{array}{c}\text { GAO,M.; ZHOU, } \\
\text { M.C.;CAUDILL, R.J. }\end{array}$ & $\begin{array}{l}\text { Multi-lifecycle, MLCA, } \\
\text { demanufacturing }\end{array}$ & $\begin{array}{l}\text { Estados } \\
\text { Unidos }\end{array}$ & 2001 & Artigo & IEEE anais \\
\hline 141 & $\begin{array}{l}\text { Development of design for } \\
\text { remanufacturing guidelines to } \\
\text { support sustainble } \\
\text { manufacturing }\end{array}$ & $\begin{array}{l}\text { IJOMAH, W.L.; } \\
\text { McMAHON,C.A.; } \\
\text { HAMMOND,G.P.; } \\
\text { NEWMAN, S.T. }\end{array}$ & $\begin{array}{l}\text { Remanufacture; Design for } \\
\text { environment; Sustainable } \\
\text { manufacture. }\end{array}$ & Inglaterra & 2007 & Artigo & $\begin{array}{l}\text { Robotics and } \\
\text { Computer- } \\
\text { Integrated } \\
\text { Manufacturing }\end{array}$ \\
\hline 142 & $\begin{array}{l}\text { Development of integrated } \\
\text { design for disassembly and } \\
\text { recycling in concurrent } \\
\text { engineering }\end{array}$ & CHEN,K.Z. & $\begin{array}{c}\text { Concurrent engineering; Product } \\
\text { development; Design; } \\
\text { Environment;Recycling. }\end{array}$ & China & 2001 & Artigo & $\begin{array}{l}\text { Integrated } \\
\text { Manufacturing } \\
\text { systems }\end{array}$ \\
\hline 143 & $\begin{array}{c}\text { Development of robust design } \\
\text { for-remanufactruing guidelines } \\
\text { to further the aims of sustainable } \\
\text { development }\end{array}$ & $\begin{array}{l}\text { IJOMAH,W.L.; } \\
\text { McMAHON,C.A.; } \\
\text { HAMMOND,G.P.; } \\
\text { NEWMAN,S.T. }\end{array}$ & $\begin{array}{l}\text { Remanufacture; Design-for- } \\
\text { remanufacturing (DFRem); } \\
\text { Environmentally conscious } \\
\text { manufature. }\end{array}$ & Inglaterra & 2008 & Artigo & $\begin{array}{l}\text { International } \\
\text { Journal of } \\
\text { Production } \\
\text { Research }\end{array}$ \\
\hline 144 & $\begin{array}{l}\text { Development of separation } \\
\text { methods and system design } \\
\text { of recycling of solid wastes }\end{array}$ & $\begin{array}{c}\text { HIRAOKA, M.; TAKEDA, } \\
\text { N.; FUJITA, K. }\end{array}$ & Sem palavras chave & Japão & 1980 & Artigo & $\begin{array}{l}\text { Conservation \& } \\
\text { recycling }\end{array}$ \\
\hline 145 & $\begin{array}{c}\text { Different kinds of consumer } \\
\text { response to the reward recycling } \\
\text { technique: similarities at the } \\
\text { desired routine level }\end{array}$ & $\begin{array}{l}\text { MENESES, G.D.; } \\
\text { PALACIO, A.B. }\end{array}$ & $\begin{array}{l}\text { Social marketing, Recycling, } \\
\text { Promotion }\end{array}$ & Espanha & 2006 & Artigo & $\begin{array}{l}\text { Asia Pacific } \\
\text { Journal of } \\
\text { Marketing }\end{array}$ \\
\hline 146 & $\begin{array}{l}\text { Disassembly and recycling of } \\
\text { electronic consumer products: } \\
\text { an overview }\end{array}$ & RON, A.; PENEV, K. & Sem palavras chave & Holanda & 1995 & Artigo & Technovation \\
\hline 147 & Disassembly Complexity and & MANI, V.; DAS, S.; & Sem palavras chave & Estados & 2001 & Artigo & IEEE \\
\hline
\end{tabular}




\begin{tabular}{|c|c|c|c|c|c|c|c|}
\hline & $\begin{array}{l}\text { recyclability analysis of news } \\
\text { designs from cad file data }\end{array}$ & CAUDILL, R. & & Unidos & & & \\
\hline 148 & $\begin{array}{l}\text { Disassembly of a Modular } \\
\text { Humeral Prosthesis }\end{array}$ & $\begin{array}{c}\text { SISTO, D.J.;MATTEW, } \\
\text { P.F.BLAZINA, } \\
\text { M.E.;HIRSH L.C. }\end{array}$ & $\begin{array}{c}\text { prosthesis } \\
\text { disassembly, shoulder } \\
\text { hemiarthroplasty, modular } \\
\text { humerus. }\end{array}$ & $\begin{array}{l}\text { Estados } \\
\text { Unidos }\end{array}$ & 1993 & Reporte & $\begin{array}{l}\text { The Journal of } \\
\text { Arthoplasty }\end{array}$ \\
\hline 149 & Disassembly of products & $\begin{array}{l}\text { GUPTA, S.M.; McLEAN, } \\
\text { C.R. }\end{array}$ & Sem palavras chave & $\begin{array}{l}\text { Estados } \\
\text { Unidos }\end{array}$ & 1996 & Artigo & $\begin{array}{l}\text { Computers ind. } \\
\text { Engng }\end{array}$ \\
\hline 150 & $\begin{array}{l}\text { Disassembly Scheduling with } \\
\text { Multiple Product Types }\end{array}$ & $\begin{array}{c}\text { KIM, H.J.; LEE, D.H.; } \\
\text { XIROUCHAKIS, P.; ZUST, } \\
\text { R. }\end{array}$ & $\begin{array}{c}\text { Disassembly. Produdion } \\
\text { Planning and Scheduling. } \\
\text { Optimization }\end{array}$ & Suiza & 2003 & Artigo & CIRP Annals \\
\hline 151 & $\begin{array}{c}\text { Disassembly Sequence } \\
\text { Generation Using a } \\
\text { Neural Network Approach }\end{array}$ & $\begin{array}{l}\text { HUANG,H,H.; WANG, } \\
\text { M.H.; JOHNSON, M.R. }\end{array}$ & $\begin{array}{c}\text { Disassembly Sequence, Neural } \\
\text { Network }\end{array}$ & China & 2000 & Artigo & $\begin{array}{l}\text { Journal of } \\
\text { manufacturing } \\
\text { systems }\end{array}$ \\
\hline 152 & $\begin{array}{c}\text { Disassembly Sequence Planning } \\
\text { for Products with Defective } \\
\text { Parts } \\
\text { in Product Recovery }\end{array}$ & $\begin{array}{l}\text { GUNGOR, A.; GUPTA, } \\
\text { S.M. }\end{array}$ & Sem palavras chave & $\begin{array}{l}\text { Estados } \\
\text { Unidos }\end{array}$ & 1998 & Artigo & $\begin{array}{l}\text { Computers ind. } \\
\text { Engng }\end{array}$ \\
\hline 153 & $\begin{array}{l}\text { Disassembly-oriented } \\
\text { assessment methodology to } \\
\text { support design for recycling }\end{array}$ & $\begin{array}{l}\text { ZUSSMAN, E.; KRIWET, } \\
\text { A.; SELIGER, G. }\end{array}$ & $\begin{array}{l}\text { disassembly, assessment, } \\
\text { environment }\end{array}$ & Alemanha & 1997 & Artigo & CIRP Annals \\
\hline 154 & $\begin{array}{l}\text { Discarded tire recycling } \\
\text { practices in the United } \\
\text { States, Japan and Korea }\end{array}$ & $\begin{array}{c}\text { WON JANG, J.; YOO, T.S.; } \\
\text { O. J.H.; IWASAKI, I. }\end{array}$ & Sem palavras chave & Korea & 1998 & Artigo & $\begin{array}{l}\text { Resources } \\
\text { conservation and } \\
\text { recycling }\end{array}$ \\
\hline 155 & $\begin{array}{l}\text { Dynamic lot sizing with product } \\
\text { returns and remanufacturing }\end{array}$ & $\begin{array}{l}\text { TEUNTER,R.H.; } \\
\text { BAYINDIR,Z.P.; } \\
\text { HEUVEL,W.V.D. }\end{array}$ & $\begin{array}{l}\text { Inventory;Batch sizing; Reverse } \\
\text { logistics;Remanufacturing }\end{array}$ & Turquia & 2006 & Artigo & $\begin{array}{l}\text { International } \\
\text { Journal of } \\
\text { Production } \\
\text { Research }\end{array}$ \\
\hline 156 & Dynamic performance of a & ZHOU, L.; NAIM, M.M.; & hybrid system, combined & Inglaterra & 2006 & Artigo & The International \\
\hline
\end{tabular}




\begin{tabular}{|c|c|c|c|c|c|c|c|}
\hline & $\begin{array}{l}\text { hybrid inventory system with a } \\
\text { Kanban policy in } \\
\text { remanufacturing process }\end{array}$ & TANG, O.; TOWILL, D.R & $\begin{array}{c}\text { manufacturing and } \\
\text { remanufacturing, Dynamic } \\
\text { performance }\end{array}$ & & & & $\begin{array}{l}\text { Journal of } \\
\text { Management } \\
\text { Science }\end{array}$ \\
\hline 157 & $\begin{array}{c}\text { Ecodesign methods focused on } \\
\text { remanufacturing }\end{array}$ & $\begin{array}{l}\text { PIGOSSO, D.C.A.; } \\
\text { ZANETTE, E.T.; } \\
\text { GUELERE FILHO, A.; } \\
\text { OMETTO, A.R. }\end{array}$ & \begin{tabular}{|} 
Eco-design, remanufacturing, \\
life cycle, methods, \\
environmental impact, 'end-of- \\
life' approaches
\end{tabular} & Brasil & 2010 & Artigo & $\begin{array}{l}\text { Journal of Cleaner } \\
\text { Production }\end{array}$ \\
\hline 158 & $\begin{array}{l}\text { ECO-design of reuse and } \\
\text { recycling networks by multi- } \\
\text { objective optimization }\end{array}$ & EROL, P.; THOMING, J. & $\begin{array}{c}\text { LCIA, environmental impacts } \\
\text { sensitivity, Nickel plating. Zero- } \\
\text { water discharge, Multi-objective } \\
\text { optimization, MINLP }\end{array}$ & Alemanha & 2004 & Artigo & $\begin{array}{l}\text { Journal of Cleaner } \\
\text { Production }\end{array}$ \\
\hline 159 & $\begin{array}{c}\text { Eco-efficiency gains from } \\
\text { remanufacturing: A case study } \\
\text { of photocopier remanufacturing } \\
\text { at Fuji Xerox Australia }\end{array}$ & KERR, W.; RYAN, C; & $\begin{array}{c}\text { remanufacturing, eco-efficiency, } \\
\text { life cycle assesment, xerox } \\
\text { photocopiers }\end{array}$ & Suécia & 2001 & Artigo & $\begin{array}{l}\text { Journal of Cleaner } \\
\text { Production }\end{array}$ \\
\hline 161 & $\begin{array}{l}\text { Eco-efficiency, asset recovery } \\
\text { and Remanufacturing }\end{array}$ & $\begin{array}{l}\text { AYRES,R.;FERRER,G.; } \\
\text { LEYNSEELE, T.V. }\end{array}$ & Sem palavras chave & França & 1997 & Artigo & $\begin{array}{l}\text { European } \\
\text { Management } \\
\text { journal }\end{array}$ \\
\hline 162 & $\begin{array}{l}\text { Economic comparison of } \\
\text { recycling over-ordered } \\
\text { fresh concrete: A case study } \\
\text { approach }\end{array}$ & TAM, V.W.Y.; TAM C.M. & $\begin{array}{c}\text { Benefit; Cost; Recycling; } \\
\text { Concrete; Concrete reclaimer; } \\
\text { Construction }\end{array}$ & Austrália & 2007 & Artigo & $\begin{array}{l}\text { Resources } \\
\text { conservation and } \\
\text { recycling }\end{array}$ \\
\hline 163 & $\begin{array}{c}\text { Economic Impact of Aluminun- } \\
\text { intensive vehicles on the U.S. } \\
\text { automotive recycling } \\
\text { infrastructure }\end{array}$ & $\begin{array}{l}\text { BOON, J.E.; ISAACS, } \\
\text { J.A.;GUPTA, S.R. }\end{array}$ & $\begin{array}{c}\text { aluminium, automobile, } \\
\text { disassembly, goal programming, } \\
\text { recycling, scrap, }\end{array}$ & $\begin{array}{l}\text { Estados } \\
\text { Unidos }\end{array}$ & 2001 & Artigo & $\begin{array}{c}\text { Journal of } \\
\text { Industrial Ecology }\end{array}$ \\
\hline
\end{tabular}




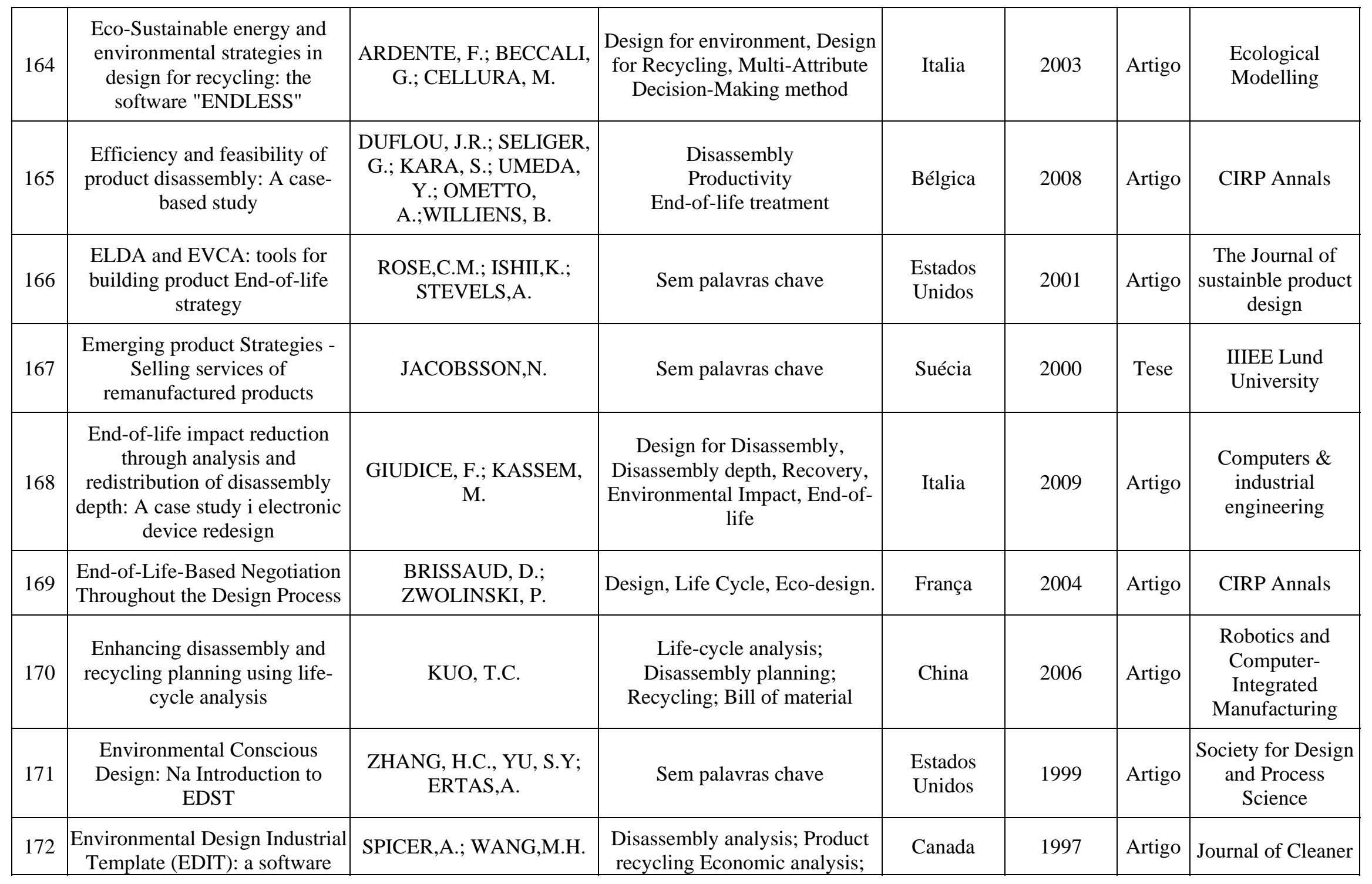




\begin{tabular}{|c|c|c|c|c|c|c|c|}
\hline & $\begin{array}{l}\text { tool for analysis of product } \\
\text { retirement }\end{array}$ & & Disassembly software & & & & Production \\
\hline 173 & $\begin{array}{c}\text { Environmental Issues within the } \\
\text { Remanufacturing Industry }\end{array}$ & $\begin{array}{l}\text { LINDAHL, M.; SUNDIN, } \\
\text { E.; OSTLIN, J. }\end{array}$ & $\begin{array}{c}\text { Remanufacturing, Life Cycle } \\
\text { Assessment, Design for } \\
\text { Environment }\end{array}$ & Suécia & 2006 & Artigo & CIRP Annals \\
\hline 174 & $\begin{array}{l}\text { Environmental-Economic } \\
\text { Supply Chain Management } \\
\text { from a Original equipment } \\
\text { Manufacturer's perspective: } \\
\text { How can we make it happen }\end{array}$ & $\begin{array}{l}\text { NAGEL, M.H.; } \\
\text { STEVELS,A.LN. }\end{array}$ & Sem palavras chave & Holanda & 2002 & Artigo & IEEE \\
\hline 175 & $\begin{array}{c}\text { Evaluation of connection types } \\
\text { in design for disassembly } \\
\text { (DFD)using analytic network } \\
\text { process }\end{array}$ & GUNGOR, A.; & $\begin{array}{c}\text { Design for disassembly; } \\
\text { Disassembly; Connectors; ANP; } \\
\text { Environment }\end{array}$ & Turquia & 2006 & Artigo & $\begin{array}{l}\text { Computers \& } \\
\text { industrial } \\
\text { engineering }\end{array}$ \\
\hline 176 & $\begin{array}{l}\text { Evaluation of disassemblability } \\
\text { to enable design for } \\
\text { disassembly in mass production }\end{array}$ & DESAI, A,.; MITAL, A. & $\begin{array}{c}\text { Disassemblability; End-of-life } \\
\text { products; Design for X (DfX); } \\
\text { Design for disassembly; } \\
\text { Disassembly evaluation metrics }\end{array}$ & $\begin{array}{l}\text { Estados } \\
\text { Unidos }\end{array}$ & 2003 & Artigo & $\begin{array}{l}\text { Internatrional } \\
\text { Journal industrial } \\
\text { ergonomics }\end{array}$ \\
\hline 177 & $\begin{array}{c}\text { Exact methods in optimum } \\
\text { disassembly sequence search for } \\
\text { problems subject to sequence } \\
\text { dependent costs }\end{array}$ & LAMBERT, A.J.D & $\begin{array}{c}\text { Assembly planning; } \\
\text { Disassembly planning; } \\
\text { Mathematical programming; } \\
\text { Network; Traveling salesperson } \\
\text { problem; Optimization }\end{array}$ & Holanda & 2006 & Artigo & $\begin{array}{l}\text { The International } \\
\text { Journal of } \\
\text { Management } \\
\text { Science }\end{array}$ \\
\hline 178 & $\begin{array}{l}\text { Explicit accounting methods for } \\
\text { recycling in LCI }\end{array}$ & $\begin{array}{l}\text { NEWELL, S.A.; FIELD, } \\
\text { F.R. }\end{array}$ & $\begin{array}{l}\text { Life cycle analysis, inventory } \\
\text { analysis, recycling }\end{array}$ & $\begin{array}{l}\text { Estados } \\
\text { Unidos }\end{array}$ & 1998 & Artigo & $\begin{array}{l}\text { Resources } \\
\text { conservation and } \\
\text { recycling }\end{array}$ \\
\hline 179 & $\begin{array}{c}\text { Facilitating DfE in enterprises: } \\
\text { the taiwan Green Design } \\
\text { Network }\end{array}$ & LEUNG, R. & $\begin{array}{l}\text { Design for environment (DfE), } \\
\text { Green Design, Networking, } \\
\text { Recycling, Green Electronics }\end{array}$ & China & 2004 & Artigo & $\begin{array}{l}\text { International IEEE } \\
\text { conference on } \\
\text { Asian Green } \\
\text { Electronics }\end{array}$ \\
\hline
\end{tabular}




\begin{tabular}{|c|c|c|c|c|c|c|c|}
\hline & & & & & & & (AGEC) \\
\hline 180 & $\begin{array}{c}\text { Flexibility robotic } \\
\text { demanufacturing using real time } \\
\text { tool path generation }\end{array}$ & VAN KUREN, M.B. & $\begin{array}{l}\text { demnaufacturing, robotics, } \\
\text { vision }\end{array}$ & $\begin{array}{l}\text { Estados } \\
\text { Unidos }\end{array}$ & 2006 & Artigo & $\begin{array}{l}\text { Robotics and } \\
\text { Computer- } \\
\text { Integrated } \\
\text { Manufacturing }\end{array}$ \\
\hline 181 & $\begin{array}{c}\text { Flexibility specialization, } \\
\text { uncertainty, and the firm } \\
\text { enterprise strategies in the wood } \\
\text { remanufacturing industry of the } \\
\text { Vancouver metropolitan area, } \\
\text { Britihs Columbia }\end{array}$ & REES, K.;HAYTER, R. & $\begin{array}{l}\text { flexible specialization, } \\
\text { uncertainty, wood } \\
\text { remanufacturing, enterprise } \\
\text { strategy, Vancouver }\end{array}$ & Canada & 2008 & Artigo & $\begin{array}{l}\text { Canadian } \\
\text { Geographer }\end{array}$ \\
\hline 182 & $\begin{array}{c}\text { Flexible robotic } \\
\text { demanufacturing using real time } \\
\text { tool path generation }\end{array}$ & KUREN, M.B.V & $\begin{array}{l}\text { Demanufacturing; Robotics; } \\
\text { Vision }\end{array}$ & $\begin{array}{l}\text { Estados } \\
\text { Unidos }\end{array}$ & 2006 & Artigo & $\begin{array}{l}\text { Robotics and } \\
\text { Computer- } \\
\text { Integrated } \\
\text { Manufacturing }\end{array}$ \\
\hline 183 & $\begin{array}{c}\text { Fundamental limits for the } \\
\text { recycling of end-of-life vehicles }\end{array}$ & $\begin{array}{c}\text { REUTER, M.;A.VAN } \\
\text { SHAIK,IGNATENKO,O.; } \\
\text { HAAN, G.J. }\end{array}$ & $\begin{array}{c}\text { Modelling; Process } \\
\text { optimisation/synthesis; } \\
\text { Environmental; Recycling }\end{array}$ & Austrália & 2006 & Artigo & $\begin{array}{c}\text { Mineral } \\
\text { engineering }\end{array}$ \\
\hline 184 & $\begin{array}{c}\text { Getting value from wastewater: } \\
\text { by-products recovery in a potato } \\
\text { chips industry }\end{array}$ & $\begin{array}{c}\text { CATARINO, J.; } \\
\text { MENDOÇA, E.; PICADO, } \\
\text { A.; ANSELMO, A.; DA } \\
\text { COSTA, J.N.; } \\
\text { PARTIDÁRIO, P. }\end{array}$ & $\begin{array}{l}\text { Eco-efficiency; Starch recovery; } \\
\text { Ecotoxicity; Wastewater } \\
\text { valorisation; Agro-food industry }\end{array}$ & Portugal & 2007 & Artigo & $\begin{array}{l}\text { Journal of Cleaner } \\
\text { Production }\end{array}$ \\
\hline 185 & $\begin{array}{c}\text { Green remanufacturing } \\
\text { engineering in structural } \\
\text { machinery based on reverse } \\
\text { engineering }\end{array}$ & $\begin{array}{l}\text { ZHOU, G.; DUAN, G.; } \\
\text { WU, H.; YAO.T }\end{array}$ & $\begin{array}{c}\text { Green remanufacturing, strutural } \\
\text { machinery }\end{array}$ & China & 2008 & Artigo & $\begin{array}{l}\text { Internationa } \\
\text { coneference on } \\
\text { security } \\
\text { technology }\end{array}$ \\
\hline 186 & $\begin{array}{l}\text { Heavy metal partitioning from } \\
\text { electronic scrap during thermal } \\
\text { End-of-Life treatment }\end{array}$ & $\begin{array}{c}\text { SCHARHORST, W.; } \\
\text { LUDWIG,C.; } \\
\text { WOCHELE,J.;JOLLIET,O. }\end{array}$ & $\begin{array}{l}\text { Heavy metals; Printed wiring } \\
\text { board assembly; Electronic } \\
\text { scrap; Waste management; }\end{array}$ & Suiza & 2007 & Artigo & $\begin{array}{l}\text { Sience of the total } \\
\text { environment }\end{array}$ \\
\hline
\end{tabular}




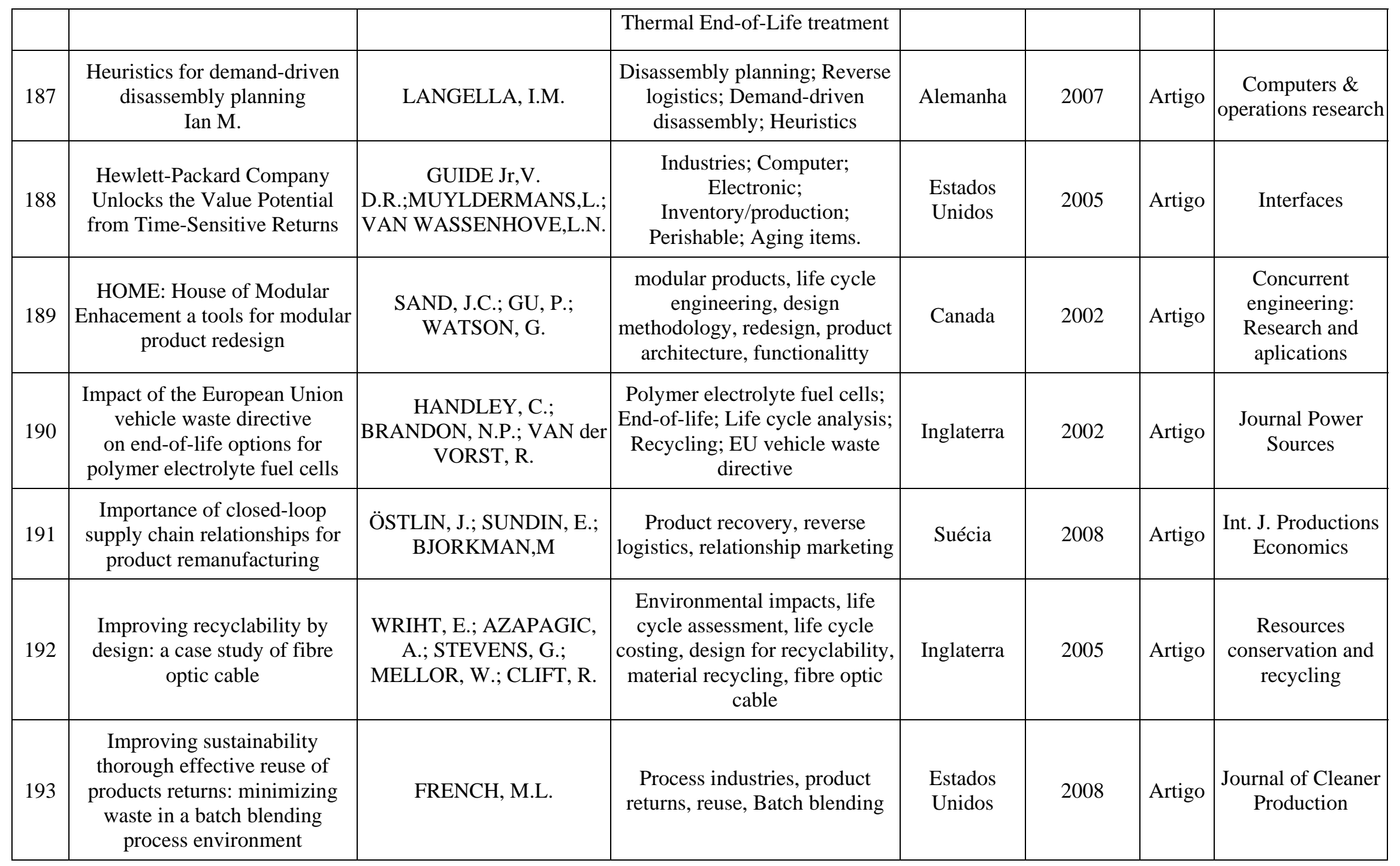




\begin{tabular}{|c|c|c|c|c|c|c|c|}
\hline 194 & $\begin{array}{l}\text { Incentive and production } \\
\text { decisions for remanufacturing } \\
\text { operations }\end{array}$ & KAYA, O. & $\begin{array}{l}\text { Supply chain management } \\
\text { Remanufacturing } \\
\text { Demand substitution }\end{array}$ & Turquia & 2009 & Artigo & $\begin{array}{c}\text { European Journal } \\
\text { of Operational } \\
\text { Research }\end{array}$ \\
\hline 195 & $\begin{array}{c}\text { Incorporating component reuse, } \\
\text { remanufature, and recycle into } \\
\text { product portfolio design }\end{array}$ & $\begin{array}{l}\text { MANGUN, D.; } \\
\text { THURSTON, D.L. }\end{array}$ & $\begin{array}{l}\text { cost of recycling, design for } \\
\text { reuse, personal computer } \\
\text { recycling, products portfolios, } \\
\text { remaunfacturing, reuse }\end{array}$ & $\begin{array}{l}\text { Estados } \\
\text { Unidos }\end{array}$ & 2002 & Artigo & IEEE \\
\hline 196 & $\begin{array}{l}\text { Incorporating End-on-life } \\
\text { strategy in product definition }\end{array}$ & ISHII,K. & Sem palavras chave & $\begin{array}{l}\text { Estados } \\
\text { Unidos }\end{array}$ & 1999 & Artigo & IEEE \\
\hline 197 & $\begin{array}{l}\text { Incorporating work factors in } \\
\text { design for disassembly in } \\
\text { product design }\end{array}$ & DESAI, A,.; MITAL, A. & $\begin{array}{l}\text { Task analysis, Time } \\
\text { measurement, Work design }\end{array}$ & $\begin{array}{l}\text { Estados } \\
\text { Unidos }\end{array}$ & 2005 & Artigo & $\begin{array}{l}\text { Journal of } \\
\text { manufacturing } \\
\text { technology } \\
\text { Management }\end{array}$ \\
\hline 198 & $\begin{array}{l}\text { industrial recycling and the } \\
\text { basel convention }\end{array}$ & ALTER, H. & $\begin{array}{c}\text { Recycling, industrial wastes, } \\
\text { basel convention, hazardous } \\
\text { wastes }\end{array}$ & $\begin{array}{l}\text { Estados } \\
\text { Unidos }\end{array}$ & 1997 & Artigo & $\begin{array}{l}\text { Resources } \\
\text { conservation and } \\
\text { recycling }\end{array}$ \\
\hline 200 & $\begin{array}{c}\text { Informing packaging Design } \\
\text { Decisions at Toyota Motor Sales } \\
\text { using life assessment and } \\
\text { costing }\end{array}$ & $\begin{array}{c}\text { EARLY, C.; KIDMAN, T.; } \\
\text { MENVIELLE.M.; GEYER, } \\
\text { R.; McMULLAN, R. }\end{array}$ & $\begin{array}{c}\text { automobile industry, industrial } \\
\text { ecology, logisitics, supply chain } \\
\text { management, secondary } \\
\text { packaging, software }\end{array}$ & $\begin{array}{l}\text { Estados } \\
\text { Unidos }\end{array}$ & 2009 & Artigo & $\begin{array}{c}\text { Journal of } \\
\text { Industrial Ecology }\end{array}$ \\
\hline 201 & $\begin{array}{l}\text { Initiating automoitve component } \\
\text { reuse in Malaysia }\end{array}$ & $\begin{array}{c}\text { AMELIA, L.; WAHAB, } \\
\text { D.A.; CHE HARON, C.H.; } \\
\text { MUHAMAD, N.; AZHARI, } \\
\text { C.H. }\end{array}$ & $\begin{array}{l}\text { reuse, deisgn for reuse (DFR), } \\
\text { end-of-life directive, automotive }\end{array}$ & Ásia & 2009 & Artigo & $\begin{array}{c}\text { Journal of Cleaner } \\
\text { Production }\end{array}$ \\
\hline 202 & $\begin{array}{l}\text { Innovative disassembly } \\
\text { strategies based on felxible }\end{array}$ & \begin{tabular}{|c|} 
FELDMANN, K.; \\
TRAUTNER, S.; MEEDT,
\end{tabular} & $\begin{array}{l}\text { Disassembly, disassembly tools, } \\
\text { recycling, waste management }\end{array}$ & Alemanha & 1999 & Artigo & $\begin{array}{c}\text { Annual Reviews in } \\
\text { Control }\end{array}$ \\
\hline
\end{tabular}




\begin{tabular}{|c|c|c|c|c|c|c|c|}
\hline & partial destructive tools & O. & legislation & & & & \\
\hline 203 & $\begin{array}{l}\text { Innovative process and tools for } \\
\text { disassembly }\end{array}$ & $\begin{array}{c}\text { SELIGER, G.; BASDERE, } \\
\text { B.; KEIL, T.; REBAFKA, } \\
\text { U. }\end{array}$ & $\begin{array}{c}\text { Disassembly process, } \\
\text { disassembly tools, product } \\
\text { accompanying information } \\
\text { systems }\end{array}$ & Alemanha & 2002 & Artigo & CIRP Annals \\
\hline 204 & $\begin{array}{l}\text { Integrated design of } \\
\text { remanufacturable products } \\
\text { based on product profiles }\end{array}$ & \begin{tabular}{|c|} 
ZWOLINSKY,P.; LOPEZ- \\
ONTIVEROS,M.A.; \\
BRISSAUD,D.
\end{tabular} & Eco-design; Remanufacturing & França & 2006 & Artigo & $\begin{array}{l}\text { Journal of Cleaner } \\
\text { Production }\end{array}$ \\
\hline 205 & $\begin{array}{l}\text { Inventory buffers in recoverable } \\
\text { manufacturing }\end{array}$ & $\begin{array}{l}\text { GUIDE, Jr, D.V.; } \\
\text { SRIVASTAVA, R. }\end{array}$ & $\begin{array}{c}\text { Environmental issues; } \\
\text { Manufacturing control systems }\end{array}$ & $\begin{array}{l}\text { Estados } \\
\text { Unidos }\end{array}$ & 1998 & Artigo & $\begin{array}{l}\text { Journal of } \\
\text { operations } \\
\text { management }\end{array}$ \\
\hline 206 & \begin{tabular}{|c|} 
Inventory control for a \\
MARKOVIAN remanufacturing \\
system with stochastic \\
decomposition process
\end{tabular} & $\begin{array}{c}\text { TAKAHASHI, K.; } \\
\text { MORIKAWA, K. } \\
\text { TAKEDA, M.D.;MIZUNO, } \\
\text { A. }\end{array}$ & $\begin{array}{l}\text { remanufacturing system, } \\
\text { stochastic decomposition, } \\
\text { inventory controls, markov } \\
\text { analysis }\end{array}$ & Japão & 2007 & Artigo & $\begin{array}{l}\text { Internaitonal } \\
\text { journal of } \\
\text { production } \\
\text { economics }\end{array}$ \\
\hline 207 & $\begin{array}{l}\text { Inventory control with product } \\
\text { returns: The impact of } \\
\text { imperfect information }\end{array}$ & $\begin{array}{l}\text { BRITO, M.P.; VAN DER } \\
\text { LAAN, E.A. }\end{array}$ & $\begin{array}{c}\text { Reverse logistics; Inventory; } \\
\text { Product returns; Value of } \\
\text { information }\end{array}$ & Holanda & 2009 & Artigo & $\begin{array}{c}\text { European Journal } \\
\text { of Operational } \\
\text { Research }\end{array}$ \\
\hline 208 & $\begin{array}{l}\text { Inventory control; Product } \\
\text { substitution; Remanufacturing }\end{array}$ & $\begin{array}{l}\text { INDERFURTH, K; KOK, } \\
\text { A.G.; FLAPPER, S.D.P; }\end{array}$ & $\begin{array}{c}\text { Product recovery mannagement, } \\
\text { remanufacturing, Multiple reuse } \\
\text { options, optimal policies }\end{array}$ & Alemanha & 2001 & Artigo & $\begin{array}{c}\text { European Journal } \\
\text { of Operational } \\
\text { Research }\end{array}$ \\
\hline 209 & $\begin{array}{l}\text { Issues in end-of-life product } \\
\text { recovery and reverse logistics }\end{array}$ & $\begin{array}{l}\text { FERGUSON,N.; } \\
\text { BROWNE,J. }\end{array}$ & \begin{tabular}{|c|} 
Reverse logistics; Extended \\
enterprise; End-of-life products; \\
Automotive; Recycling; \\
Information systems
\end{tabular} & Irlanda & 2001 & Artigo & $\begin{array}{c}\text { Production } \\
\text { planning \& control }\end{array}$ \\
\hline 210 & $\begin{array}{l}\text { Issues in environmentally } \\
\text { conscious manufacturing and } \\
\text { product recovery: a survey }\end{array}$ & $\begin{array}{l}\text { GUNGOR, A.; GUPTA, } \\
\text { S.M. }\end{array}$ & $\begin{array}{l}\text { Disassembly; Environmentally } \\
\text { conscious manufacturing; } \\
\text { Product recovery; Recycling; } \\
\text { Remanufacturing; }\end{array}$ & $\begin{array}{l}\text { Estados } \\
\text { Unidos }\end{array}$ & 1999 & Artigo & $\begin{array}{l}\text { Computers \& } \\
\text { industrial } \\
\text { engineering }\end{array}$ \\
\hline
\end{tabular}




\begin{tabular}{|c|c|c|c|c|c|c|c|}
\hline & & & Reuse; Survey & & & & \\
\hline 211 & $\begin{array}{c}\text { Joint Life-Cycle Dynamics of } \\
\text { New and Remanufactured } \\
\text { Products }\end{array}$ & $\begin{array}{l}\text { DEBO, L.G.; TOKTAY, } \\
\text { L.B.; WASSENHOVE, } \\
\text { L.N.V }\end{array}$ & $\begin{array}{c}\text { remanufacturing; product } \\
\text { diffusion; closed-loop supply } \\
\text { chains }\end{array}$ & $\begin{array}{l}\text { Estados } \\
\text { Unidos }\end{array}$ & 2006 & Artigo & $\begin{array}{l}\text { Production and } \\
\text { operations } \\
\text { managment }\end{array}$ \\
\hline 212 & $\begin{array}{l}\text { Joint procurement and } \\
\text { production decisions in } \\
\text { remanufacturing under quality } \\
\text { and demand uncertainty }\end{array}$ & $\begin{array}{l}\text { MUKHOPADHYAY, } \\
\text { S.K.;MA, H. }\end{array}$ & $\begin{array}{l}\text { Remanufacturing, Randon yield, } \\
\text { Procurement, Production }\end{array}$ & Korea & 2008 & Artigo & $\begin{array}{l}\text { International } \\
\text { Journal of } \\
\text { Production } \\
\text { Economics }\end{array}$ \\
\hline 213 & $\begin{array}{l}\text { Leadtime effects and policy } \\
\text { improvement for stochastic } \\
\text { inventory control with } \\
\text { remanufacturing }\end{array}$ & $\begin{array}{l}\text { INDERFUTH, K.; VAN } \\
\text { DER LAAN, E. }\end{array}$ & $\begin{array}{l}\text { remanufacturing, inventory } \\
\text { control, optimization }\end{array}$ & Alemanha & 2001 & Artigo & $\begin{array}{l}\text { International } \\
\text { Journal of } \\
\text { Production } \\
\text { Economics }\end{array}$ \\
\hline 214 & $\begin{array}{c}\text { Lean Production Principles in } \\
\text { Remanufacturing }\end{array}$ & ÖSTLIN, J.; EKHOLM, H. & $\begin{array}{c}\text { lean production, value steam } \\
\text { mapping, rapid plant assesment, } \\
\text { remanufactuering }\end{array}$ & Suécia & 2007 & Artigo & IEEE \\
\hline 215 & $\begin{array}{l}\text { Lessons learned from } 10 \text { years } \\
\text { take-back and recycling }\end{array}$ & STEVELS, A.; BOKS, C. & $\begin{array}{l}\text { Recycling, electronics, take- } \\
\text { back }\end{array}$ & Holanda & 2001 & Artigo & CIRP Annals \\
\hline 216 & $\begin{array}{l}\text { Life cycle assessment of EPS } \\
\text { and CPB inserts: design } \\
\text { considerations and end of life } \\
\text { scenarios }\end{array}$ & TAN, R.B.H.; KHOO, H.H. & \begin{tabular}{|} 
life cycle assessment, expanded \\
polystyrene, corrugates \\
paperboard, impact assessment, \\
design and end-of=life \\
comparisons.
\end{tabular} & Cingapura & 2005 & Artigo & $\begin{array}{l}\text { Journal of } \\
\text { Environmental } \\
\text { management }\end{array}$ \\
\hline 217 & \begin{tabular}{|} 
Life cycle design metrics for \\
energy generation technologies: \\
Method, data, and \\
case study
\end{tabular} & $\begin{array}{c}\text { COOPER, J.; LEE, S.J.; } \\
\text { BOUSSU, J.; BOMAN, S. }\end{array}$ & $\begin{array}{c}\text { Life Cycle Assessment } \\
\text { Energy generation } \\
\text { Design } \\
\text { PEMFC }\end{array}$ & $\begin{array}{l}\text { Estados } \\
\text { Unidos }\end{array}$ & 2009 & Artigo & $\begin{array}{c}\text { Journal of power } \\
\text { sources }\end{array}$ \\
\hline 218 & $\begin{array}{l}\text { Life cycle engineering and } \\
\text { Design }\end{array}$ & $\begin{array}{c}\text { ALTING,L.; LEGARTH,J. } \\
\text { B. }\end{array}$ & $\begin{array}{l}\text { Environment; Product design; } \\
\text { Disassembling. }\end{array}$ & Dinamarca & 1995 & Artigo & CIRP Annals \\
\hline 219 & Life Cycle Tools tools for future & PRZEKOP, L.A.;KERR, S. & Sem palavras chave & Estados & 2004 & Artigo & IEEE \\
\hline
\end{tabular}




\begin{tabular}{|c|c|c|c|c|c|c|c|}
\hline & product sustainability & & & Unidos & & & \\
\hline 220 & $\begin{array}{c}\text { Life design for remanufacturing } \\
\text { durable products }\end{array}$ & $\begin{array}{c}\text { OKUMURA,S.; } \\
\text { MORIKUNI,T.; OKINO,N. }\end{array}$ & Sem palavras chave & Japão & 2001 & Artigo & IEEE \\
\hline 221 & $\begin{array}{c}\text { Linear programming in } \\
\text { disassembly/clustering sequence } \\
\text { generation }\end{array}$ & LAMBERT, A.J.D & $\begin{array}{l}\text { Disassembly sequence; } \\
\text { Recycling; Mathematical } \\
\text { programming; Design for } \\
\text { disassembly; Design for en- } \\
\text { vironment }\end{array}$ & Holanda & 1999 & Artigo & $\begin{array}{l}\text { Computers \& } \\
\text { industrial } \\
\text { engineering }\end{array}$ \\
\hline 222 & $\begin{array}{l}\text { Logistics network design for } \\
\text { product recovery in fuzzy } \\
\text { environment }\end{array}$ & QIN,Z.;JI,X. & $\begin{array}{l}\text { Credibility measure } \\
\text { Product recovery } \\
\text { Reverse logistics } \\
\text { Fuzzy programming } \\
\text { Genetic algorithm } \\
\text { Fuzzy simulation }\end{array}$ & China & 2009 & Artigo & $\begin{array}{l}\text { European Journal } \\
\text { of Operational } \\
\text { Research }\end{array}$ \\
\hline 223 & $\begin{array}{l}\text { Lot sizing in reverse MRP for } \\
\text { scheduling disassembly }\end{array}$ & $\begin{array}{l}\text { GUTIÉRREZ, Y.B.; DÍAZ, } \\
\text { B.A.; GUPTA, S.M. }\end{array}$ & $\begin{array}{l}\text { Reverse logistics; MRP; Lot } \\
\text { sizing }\end{array}$ & Espanha & 2008 & Artigo & $\begin{array}{l}\text { International } \\
\text { Journal of } \\
\text { Production } \\
\text { Economics }\end{array}$ \\
\hline 224 & \begin{tabular}{|c|} 
Making functional sales \\
environmentally and \\
economically beneficial through \\
product remanufacturing
\end{tabular} & SUNDIN, E.; BRAS, B. & $\begin{array}{l}\text { functional sales, service selling, } \\
\text { remanufacturing, design for } \\
\text { environment, Ecodesing, Design } \\
\text { for Remanufactruing, Activity } \\
\text { bases costing (ABC) }\end{array}$ & Suécia & 2005 & Artigo & $\begin{array}{l}\text { Journal of Cleaner } \\
\text { Production }\end{array}$ \\
\hline 225 & $\begin{array}{l}\text { Managing New and } \\
\text { remanufactured Products }\end{array}$ & $\begin{array}{l}\text { FERRER,G.; } \\
\text { SWAMINATHAN, J.M. }\end{array}$ & $\begin{array}{l}\text { remanufacturing, duopoly, self- } \\
\text { selection,product-line pricing }\end{array}$ & $\begin{array}{l}\text { Estados } \\
\text { Unidos }\end{array}$ & 2006 & Artigo & $\begin{array}{l}\text { Management } \\
\text { Science }\end{array}$ \\
\hline 226 & $\begin{array}{l}\text { Managing product returns for } \\
\text { remanufacturing }\end{array}$ & $\begin{array}{c}\text { GUIDE Jr, D.V.; } \\
\text { WASSENHOVE, L.N.V. }\end{array}$ & $\begin{array}{l}\text { REMANUFACTURING, } \\
\text { ECONOMIC VALUE- } \\
\text { ANALYSIS , PRODUCT } \\
\text { ACQUISITION } \\
\text { MANAGEMENT }\end{array}$ & França & 2009 & Artigo & $\begin{array}{l}\text { Production and } \\
\text { operations } \\
\text { managment }\end{array}$ \\
\hline
\end{tabular}




\begin{tabular}{|c|c|c|c|c|c|c|c|}
\hline 227 & $\begin{array}{c}\text { Managing reuse in } \\
\text { manufacturing system } \\
\text { modelling and design a value } \\
\text { net approach }\end{array}$ & $\begin{array}{l}\text { DANI,S.H./ HARDING } \\
\text { J.A. }\end{array}$ & Sem palavras chave & Inglaterra & 2004 & Artigo & $\begin{array}{l}\text { int J. Computer } \\
\text { Integrated } \\
\text { manufacturing }\end{array}$ \\
\hline 230 & $\begin{array}{l}\text { Matching Demand and Supply } \\
\text { to Maximize } \\
\text { Profits from Remanufacturing }\end{array}$ & $\begin{array}{l}\text { GUIDE Jr, V.D.R.; } \\
\text { TEUNTER, R.H.; VAN } \\
\text { WASSENHOVE, L.N. }\end{array}$ & $\begin{array}{l}\text { Remanufacturing; Product } \\
\text { Acquisition; Econometric } \\
\text { Models }\end{array}$ & $\begin{array}{l}\text { Estados } \\
\text { Unidos }\end{array}$ & 2003 & Artigo & $\begin{array}{c}\text { Manufactruring \& } \\
\text { service operations } \\
\text { management }\end{array}$ \\
\hline 232 & $\begin{array}{c}\text { Material flows of mobile phones } \\
\text { and accessories in Nigeria: } \\
\text { Environmental implications and } \\
\text { sound end-of-life management } \\
\text { options }\end{array}$ & $\begin{array}{l}\text { OSIBANJO, O.; } \\
\text { NNOROM, I.C. }\end{array}$ & $\begin{array}{c}\text { Mobile phone, Nigeria, E-waste, } \\
\text { End-of-life management, } \\
\text { material recovery }\end{array}$ & Nigeria & 2008 & Artigo & $\begin{array}{c}\text { Environmental } \\
\text { Impact Assessment } \\
\text { review }\end{array}$ \\
\hline 233 & $\begin{array}{l}\text { Material Planning for a } \\
\text { remanufacturing facility }\end{array}$ & $\begin{array}{l}\text { FERRER, G.; WHYBARK, } \\
\text { C. }\end{array}$ & $\begin{array}{c}\text { Material requirements planning, } \\
\text { product recovery, } \\
\text { remanufacturing, recycling }\end{array}$ & $\begin{array}{l}\text { Estados } \\
\text { Unidos }\end{array}$ & 2001 & Artigo & $\begin{array}{l}\text { Production and } \\
\text { operations } \\
\text { managment }\end{array}$ \\
\hline 234 & $\begin{array}{l}\text { Materials selection and design } \\
\text { for development of sustainable }\end{array}$ & LJUNGBERG, L.Y. & $\begin{array}{l}\text { Sustainable product } \\
\text { development; Design; }\end{array}$ & Suécia & 2007 & Artigo & $\begin{array}{l}\text { Materials \& } \\
\text { Design }\end{array}$ \\
\hline
\end{tabular}




\begin{tabular}{|c|c|c|c|c|c|c|c|}
\hline & products & & $\begin{array}{l}\text { Recycling; Materials selection; } \\
\text { Environmental impact; Ecology }\end{array}$ & & & & \\
\hline 235 & $\begin{array}{c}\text { Mechanical Bus for Modular } \\
\text { Product Design }\end{array}$ & GU, P.; SLEVINSKY, M. & $\begin{array}{c}\text { Design, Module, Mechanical } \\
\text { Bus }\end{array}$ & Canada & 2003 & Artigo & CIRP Annals \\
\hline 236 & $\begin{array}{l}\text { Method for assessment of reuse } \\
\text { suitability witihin modular } \\
\text { assembly systems }\end{array}$ & $\begin{array}{c}\text { WEULE, H.; BUCHHOLZ. } \\
\text { C. }\end{array}$ & $\begin{array}{l}\text { assembly, reliability, } \\
\text { assessment, maintenance }\end{array}$ & Alemanha & 2001 & Artigo & $\begin{array}{l}\text { Assembly } \\
\text { Automation }\end{array}$ \\
\hline 237 & $\begin{array}{l}\text { Metrics for End-of-life } \\
\text { Strategies (ELSEIM) }\end{array}$ & ROSE, C.M.; STEVELS, A. & Sem palavras chave & Holanda & 2001 & Artigo & IEEE \\
\hline 238 & $\begin{array}{l}\text { Mixed assembly and } \\
\text { disassembly operations for } \\
\text { remanufacturing }\end{array}$ & $\begin{array}{l}\text { KETZENBERG, M.E.; } \\
\text { SOUZA, G.C.; GUIDE Jr, } \\
\text { V.D.R. }\end{array}$ & $\begin{array}{l}\text { remanufacturing, assembly } \\
\text { lines, queuing, simulation }\end{array}$ & $\begin{array}{l}\text { Estados } \\
\text { Unidos }\end{array}$ & 2003 & Artigo & $\begin{array}{l}\text { Production and } \\
\text { operations } \\
\text { managment }\end{array}$ \\
\hline 239 & $\begin{array}{l}\text { Modelling of the cycle of } \\
\text { products with data acquisition } \\
\text { features }\end{array}$ & $\begin{array}{c}\text { SIMON,M.;BEE, } \\
\text { G.;MOORE,P.;PU,J.S.;XIE, } \\
\text { C. }\end{array}$ & $\begin{array}{l}\text { Appliances, reuse, data } \\
\text { acquisiton, Information system, } \\
\text { life cycle modelling }\end{array}$ & Inglaterra & 2001 & Artigo & $\begin{array}{l}\text { Computers in } \\
\text { Industry }\end{array}$ \\
\hline 240 & $\begin{array}{c}\text { Modular design to support green } \\
\text { life-cycle engineering }\end{array}$ & $\begin{array}{l}\text { TSENG, H-E.; CHEN } \\
\text { CHANG, C.; LI,J.D. }\end{array}$ & $\begin{array}{l}\text { Modular design; Green life- } \\
\text { cycle engineering; Grouping } \\
\text { genetic algorithm; Liaison } \\
\text { intensity; Green analysis }\end{array}$ & China & 2008 & Artigo & $\begin{array}{l}\text { Expert Systems } \\
\text { with Applications }\end{array}$ \\
\hline 241 & $\begin{array}{l}\text { Module Configurator for the } \\
\text { Development of Products for } \\
\text { ease of remanufacturing }\end{array}$ & $\begin{array}{l}\text { SELIGER,G.; WEINERT, } \\
\text { N.;ZETTL M. }\end{array}$ & $\begin{array}{l}\text { Modularity, Remanufacturing, } \\
\text { Module Configurator }\end{array}$ & Alemanha & 2007 & Artigo & CIRP Annals \\
\hline 242 & $\begin{array}{c}\text { Multi-criteria material selections } \\
\text { and end-of-life product strategy: } \\
\text { Grey relational analysis } \\
\text { approach }\end{array}$ & $\begin{array}{c}\text { CHAN, J.W.K.; TONG, } \\
\text { T.K.L; }\end{array}$ & $\begin{array}{l}\text { Selection of materials; Product } \\
\text { end-of-life strategy; Multi- } \\
\text { criteria decisions; Grey } \\
\text { relational analysis }\end{array}$ & China & 2007 & Artigo & $\begin{array}{l}\text { Materials \& } \\
\text { Design }\end{array}$ \\
\hline 243 & $\begin{array}{l}\text { Negotiation-based coordination } \\
\text { in product recovery networks }\end{array}$ & $\begin{array}{c}\text { WALTHER, G.; SCHMID, } \\
\text { E.; SPENGLER, T.S. }\end{array}$ & $\begin{array}{l}\text { Product recovery; Distributed } \\
\text { decision making; Multiagent } \\
\text { systems; Linear programming }\end{array}$ & Alemanha & 2008 & Artigo & $\begin{array}{l}\text { International } \\
\text { Journal of } \\
\text { Production }\end{array}$ \\
\hline
\end{tabular}




\begin{tabular}{|c|c|c|c|c|c|c|c|}
\hline & & & & & & & Economics \\
\hline 244 & $\begin{array}{c}\text { Network management and } \\
\text { environmental effectiveness: the } \\
\text { management } \\
\text { of end-of-life vehicles in the } \\
\text { United Kingdom and in Sweden }\end{array}$ & MANOMAIVIBOOL,P. & \begin{tabular}{|c|} 
Extended producer \\
responsibility; ELV Directive; \\
Network management; Theory- \\
based evaluation; Policy \\
paradigm
\end{tabular} & Suécia & 2008 & Artigo & $\begin{array}{l}\text { Journal of Cleaner } \\
\text { Production }\end{array}$ \\
\hline 245 & $\begin{array}{l}\text { Neural Network Model for } \\
\text { Product End-of-Life Strategies }\end{array}$ & CHEN,J.L.;WU,J.N. & $\begin{array}{l}\text { End-of-life; Neural networks; } \\
\text { Design for environment; } \\
\text { Remanufacture; Recycling. }\end{array}$ & Japão & 2003 & Artigo & IEEE \\
\hline 246 & $\begin{array}{l}\text { Neuro-Fuzzy approach to } \\
\text { forescast returns of scrapped } \\
\text { products to recycling and } \\
\text { remanufacturing }\end{array}$ & $\begin{array}{c}\text { GÓMEZ,J.M.;RAUTENST } \\
\text { RAUCH, } \\
\text { C.;NURNBERGER,A.;KR } \\
\text { USE,R. }\end{array}$ & $\begin{array}{l}\text { Recylcing,simulation,Fuzzy,Neu } \\
\text { ro-fuzzy,function approximation }\end{array}$ & Alemanha & 2002 & Artigo & $\begin{array}{l}\text { Knowledge based } \\
\text { systems }\end{array}$ \\
\hline 247 & $\begin{array}{c}\text { New methods of aluminium and } \\
\text { aluminium-alloy chips } \\
\text { recyclings }\end{array}$ & $\begin{array}{l}\text { GRONOSTAJSKI, J.; } \\
\text { MARCINIAK, H.; } \\
\text { MATUSZAK, A. }\end{array}$ & $\begin{array}{l}\text { Aluminium, aluminium alloys, } \\
\text { recycling, composities }\end{array}$ & Polónia & 2000 & Artigo & $\begin{array}{l}\text { Journal of } \\
\text { Materials } \\
\text { Processing } \\
\text { Technology }\end{array}$ \\
\hline 249 & $\begin{array}{l}\text { On remanufacturing systems } \\
\text { Analysing and managing } \\
\text { material flows and } \\
\text { remanufacturing processes }\end{array}$ & ÖSTLIN, J. & Sem palavras chave & Suécia & 2008 & Tese & $\begin{array}{l}\text { Institute of } \\
\text { technology, } \\
\text { Linköpings } \\
\text { universitet }\end{array}$ \\
\hline 250 & $\begin{array}{l}\text { On the necessity ofa disposal } \\
\text { option for returned items that } \\
\text { can } \\
\text { be remanufactured }\end{array}$ & $\begin{array}{l}\text { TEUNTER,R.H.;VLACHO } \\
\text { S,D. }\end{array}$ & $\begin{array}{l}\text { Inventory control; } \\
\text { Remanufacturing; Disposal }\end{array}$ & Holanda & 2002 & Artigo & $\begin{array}{l}\text { International } \\
\text { Journal of } \\
\text { Production } \\
\text { Economics }\end{array}$ \\
\hline 251 & $\begin{array}{l}\text { On the optimal design of the } \\
\text { disassembly and recovery }\end{array}$ & XANTHOPOULOS, A.; & Sem palavras chave & Greça & 2009 & Artigo & Waste \\
\hline
\end{tabular}




\begin{tabular}{|c|c|c|c|c|c|c|c|}
\hline & processes & IAKOVOU,E. & & & & & Management \\
\hline 252 & $\begin{array}{c}\text { Online design reuse tool for the } \\
\text { support of the generation, } \\
\text { embodiment and detailes design } \\
\text { of products. }\end{array}$ & ONG, S.K.; GUO, D.O & Sem palavras chave & Inglaterra & 2004 & Artigo & $\begin{array}{l}\text { International } \\
\text { Journal of } \\
\text { Production } \\
\text { Research }\end{array}$ \\
\hline 253 & $\begin{array}{c}\text { Operations Planning Issues in na } \\
\text { Assembly-Disassembly } \\
\text { Environment }\end{array}$ & $\begin{array}{l}\text { BRENNAN, L.; GUPTA, } \\
\text { S.M.;TALEB,K.N. }\end{array}$ & Sem palavras chave & $\begin{array}{l}\text { Estados } \\
\text { Unidos }\end{array}$ & 1994 & Artigo & $\begin{array}{l}\text { International } \\
\text { Journal of } \\
\text { Operations \& } \\
\text { Production } \\
\text { Management }\end{array}$ \\
\hline 254 & \begin{tabular}{|c|} 
Opportunities for \\
remanufactured electronic \\
products from developing \\
countries: hypotheses to \\
characterise the perspectives of \\
a global remanufacturing \\
industry
\end{tabular} & STEINHILPER, R. & $\begin{array}{c}\text { life cycle management. Product } \\
\text { stewarsship, remanufacturing, } \\
\text { repair }\end{array}$ & Alemanha & 2004 & Artigo & IEEE AFRICON \\
\hline 256 & $\begin{array}{c}\text { Optimal biocompatible solvent } \\
\text { design for a two-stage extractive } \\
\text { fermentation process with cell } \\
\text { recycling }\end{array}$ & $\begin{array}{c}\text { CHENG, H.C.; WANG, } \\
\text { F.S. }\end{array}$ & $\begin{array}{c}\text { Solvent design; Extractive } \\
\text { fermentation; MINLP; CAMD; } \\
\text { Fuzzy optimization; } \\
\text { Evolutionary computation }\end{array}$ & China & 2008 & Artigo & $\begin{array}{l}\text { Computers \& } \\
\text { Chemical } \\
\text { Engineering }\end{array}$ \\
\hline 257 & $\begin{array}{l}\text { Optimal control of a one product } \\
\text { recovery }\end{array}$ & KIESMULLER, G.P. & $\begin{array}{c}\text { Recovery system; Deterministic } \\
\text { inventory model; Dynamic } \\
\text { demands; Pontryagin’s } \\
\text { maximum principle; Optimal } \\
\text { control }\end{array}$ & Holanda & 2003 & Artigo & $\begin{array}{l}\text { International } \\
\text { Journal of } \\
\text { Production } \\
\text { Economics }\end{array}$ \\
\hline 258 & Optimal design of municipal & DIAMADOPOULOS,E.; & Municipal solid waste, & Greça & 1995 & Artigo & Resources \\
\hline
\end{tabular}




\begin{tabular}{|c|c|c|c|c|c|c|c|}
\hline & solid waste recycling systems & $\begin{array}{c}\text { KOUTSANTONAKIS,Y.; } \\
\text { ZAGLARA, V. }\end{array}$ & $\begin{array}{c}\text { economic benefit, Recycling, } \\
\text { optimization }\end{array}$ & & & & $\begin{array}{l}\text { conservation and } \\
\text { recycling }\end{array}$ \\
\hline 259 & $\begin{array}{l}\text { Optimal Disassembly } \\
\text { Configurations for } \\
\text { Single and Multiple Products }\end{array}$ & $\begin{array}{l}\text { MEACHAM,A.;UZSOY,R.; } \\
\text { VENKATADRI,U. }\end{array}$ & $\begin{array}{c}\text { Disassembly Planning, Column } \\
\text { Generation, } \\
\text { Environmentally Conscious } \\
\text { Manufacturing }\end{array}$ & India & 1999 & Artigo & $\begin{array}{l}\text { Journal of } \\
\text { manufacturing } \\
\text { systems }\end{array}$ \\
\hline 260 & \begin{tabular}{|} 
Optimal policies in hybrid \\
manufacturing/remanufacturing \\
systems with product \\
substitution
\end{tabular} & INDERFURTH, K & $\begin{array}{l}\text { Inventory control; Product } \\
\text { substitution; Remanufacturing }\end{array}$ & Alemanha & 2004 & Artigo & $\begin{array}{l}\text { International } \\
\text { Journal of } \\
\text { Production } \\
\text { Economics }\end{array}$ \\
\hline 261 & $\begin{array}{c}\text { Optimal policy for a closed-loop } \\
\text { supply chain inventory system } \\
\text { with remanufacturing }\end{array}$ & $\begin{array}{c}\text { CHUNG, S.L.; WEE, H.M.; } \\
\text { YANG, P.C. }\end{array}$ & $\begin{array}{l}\text { Supply chain management; } \\
\text { Closed-loop supply chain; } \\
\text { Multi-echelon inventory; } \\
\text { Reverse logistics }\end{array}$ & China & 2008 & Artigo & $\begin{array}{l}\text { Mathematical and } \\
\text { Computer } \\
\text { Modelling }\end{array}$ \\
\hline 262 & $\begin{array}{l}\text { Optimal pricing, EOL (end of } \\
\text { life) warranty, and spare } \\
\text { parts manufacturing strategy } \\
\text { amid product transition }\end{array}$ & KIM, B.; PARK, S. & $\begin{array}{c}\text { EOL (end of life) services; } \\
\text { Warranty; Manufacturing } \\
\text { strategy }\end{array}$ & Korea & 2008 & Artigo & $\begin{array}{l}\text { European Journal } \\
\text { of Operational } \\
\text { Research }\end{array}$ \\
\hline 264 & $\begin{array}{c}\text { Optimal replace-repair strategy } \\
\text { for servicing } \\
\text { products sold with warranty } \\
\text { D. }\end{array}$ & $\begin{array}{c}\text { NGUYEN, } \\
\text { D.G.;MURTHY,D.N.P; }\end{array}$ & $\begin{array}{l}\text { Warranty, servicing, repair, } \\
\text { optimization }\end{array}$ & Austrália & 1989 & Artigo & $\begin{array}{l}\text { European Journal } \\
\text { of Operational } \\
\text { Research }\end{array}$ \\
\hline 265 & $\begin{array}{c}\text { Optimizing disassembly } \\
\text { processes subjected to sequence- } \\
\text { dependent cost }\end{array}$ & LAMBERT, A.J.D & $\begin{array}{c}\text { Disassembly planning; } \\
\text { Assembly; Network; } \\
\text { Mathematical programming; } \\
\text { Optimization; Traveling } \\
\text { salesperson } \\
\end{array}$ & Holanda & 2007 & Artigo & $\begin{array}{c}\text { Computers \& } \\
\text { operations research }\end{array}$ \\
\hline
\end{tabular}




\begin{tabular}{|c|c|c|c|c|c|c|c|}
\hline & & & problem & & & & \\
\hline 266 & $\begin{array}{l}\text { Parts remanufacturing in the } \\
\text { oilfield industry }\end{array}$ & $\begin{array}{l}\text { MAPLES, G.E.; HEADY, } \\
\text { R.B.; ZHU, Z }\end{array}$ & $\begin{array}{l}\text { Demand forecastign, } \\
\text { manufacturing industries, } \\
\text { inventory control }\end{array}$ & $\begin{array}{l}\text { Estados } \\
\text { Unidos }\end{array}$ & 2005 & Artigo & $\begin{array}{c}\text { Industrial } \\
\text { Management \& } \\
\text { Data Systems }\end{array}$ \\
\hline 267 & $\begin{array}{l}\text { Periodic review, push inventory } \\
\text { policies for remanufacturing }\end{array}$ & $\begin{array}{l}\text { MAHADEVAN,B.;PYKE, } \\
\text { D.F.;FLEISCHMANN,M. }\end{array}$ & $\begin{array}{l}\text { Inventory; Remanufacturing; } \\
\text { Environment; Heuristics; } \\
\text { Reverse logistics }\end{array}$ & India & 2003 & Artigo & $\begin{array}{l}\text { European Journal } \\
\text { of Operational } \\
\text { Research }\end{array}$ \\
\hline 269 & $\begin{array}{c}\text { Planned lead time determination } \\
\text { in a make-to-order } \\
\text { remanufacturing system }\end{array}$ & $\begin{array}{l}\text { TANG, O.; } \\
\text { GRUBBSTRÖM, R.W.; } \\
\text { ZANONI, S. }\end{array}$ & $\begin{array}{c}\text { Disassembly, Remanufacturing, } \\
\text { Reverse logistics systems }\end{array}$ & Suécia & 2007 & Artigo & $\begin{array}{l}\text { International } \\
\text { Journal of } \\
\text { Production } \\
\text { Economics }\end{array}$ \\
\hline 271 & $\begin{array}{l}\text { Plastics recycling and waste } \\
\text { management in the } \\
\text { US }\end{array}$ & SUBRAMANIAN,P.M. & $\begin{array}{c}\text { Environment; Plastics recycling; } \\
\text { Waste management; Municipal } \\
\text { waste; Integrated waste } \\
\text { management; Waste-to-energy; } \\
\text { Incineration; Landfill; Life cycle } \\
\text { analysis }\end{array}$ & $\begin{array}{l}\text { Estados } \\
\text { Unidos }\end{array}$ & 2000 & Artigo & $\begin{array}{l}\text { Resources } \\
\text { conservation and } \\
\text { recycling }\end{array}$ \\
\hline 272 & $\begin{array}{l}\text { Positive trends and } \\
\text { opportunities for sustainable } \\
\text { design in opertaions } \\
\text { management textbooks }\end{array}$ & WILLIAM, J.A. & $\begin{array}{l}\text { operations management, } \\
\text { education, sustainable design, } \\
\text { electronics }\end{array}$ & $\begin{array}{l}\text { Estados } \\
\text { Unidos }\end{array}$ & 2007 & Artigo & IEEE \\
\hline
\end{tabular}




\begin{tabular}{|c|c|c|c|c|c|c|c|}
\hline 273 & $\begin{array}{l}\text { Pricing used products for } \\
\text { remanufacturing }\end{array}$ & $\begin{array}{c}\text { LIANG,Y.; } \\
\text { POKHAREL,S.; LIM,G.H. }\end{array}$ & $\begin{array}{l}\text { Remanufacturing; Pricing } \\
\text { policy; Brownian motion; Core } \\
\text { price; Reverse logistics }\end{array}$ & Cingapura & 2009 & Artigo & $\begin{array}{l}\text { European Journal } \\
\text { of Operational } \\
\text { Research }\end{array}$ \\
\hline 274 & $\begin{array}{l}\text { Pricing used products for } \\
\text { remanufacturing }\end{array}$ & $\begin{array}{c}\text { LIANG,Y.; } \\
\text { POKHAREL,S.; LIM,G.H. }\end{array}$ & $\begin{array}{l}\text { Remanufacturing, Pricing } \\
\text { policy, Brownian motion, core } \\
\text { price, reverse logistics }\end{array}$ & Cingapura & 2009 & Artigo & $\begin{array}{l}\text { European Journal } \\
\text { of Operational } \\
\text { Research }\end{array}$ \\
\hline 275 & $\begin{array}{l}\text { Process and Facility Planning } \\
\text { for Mobile Phone } \\
\text { Remanufacturing }\end{array}$ & $\begin{array}{l}\text { SELIGER, G.; FRANKE, } \\
\text { C.; CIUPEK, M.; } \\
\text { BASDERE, B. }\end{array}$ & $\begin{array}{c}\text { Mobile phone remanufacturing; } \\
\text { linear optimization, discrete- } \\
\text { event simulation }\end{array}$ & Alemanha & 2004 & Artigo & CIRP Annals \\
\hline 276 & $\begin{array}{l}\text { Process planning for IT- } \\
\text { equipment remanufacturing }\end{array}$ & $\begin{array}{c}\text { HEYER, } \\
\text { S.C.S.;CHIOTELLIS, S.; } \\
\text { SELIGER, G. }\end{array}$ & $\begin{array}{l}\text { Remanufacturing, process } \\
\text { planning, mathematical } \\
\text { programming }\end{array}$ & Alemanha & 2009 & Artigo & $\begin{array}{l}\text { CIRP Journal of } \\
\text { manufacturing } \\
\text { Science and } \\
\text { Technology }\end{array}$ \\
\hline 277 & $\begin{array}{l}\text { Product and Process Design for } \\
\text { Successful Remanufacturing }\end{array}$ & SUNDIN,E. & Sem palavras chave & Suécia & 2004 & Tese & $\begin{array}{l}\text { Linköpings } \\
\text { Universitet }\end{array}$ \\
\hline 279 & $\begin{array}{c}\text { Product Design for disassembly } \\
\text { and bulk recycling }\end{array}$ & SODHI, M.; KNIGHT,W.A. & $\begin{array}{c}\text { Design;Disassembly;Environme } \\
\text { ntal }\end{array}$ & $\begin{array}{l}\text { Estados } \\
\text { Unidos }\end{array}$ & 1998 & Artigo & CIRP Annals \\
\hline 280 & $\begin{array}{c}\text { Product End-of life Strategies } \\
\text { Based on Neural Network } \\
\text { Model }\end{array}$ & $\begin{array}{l}\text { GUANGFU,L.; SHICHUN, } \\
\text { B.;ZHIFENG,L.; PENG,C.; } \\
\text { QINGDI,K. }\end{array}$ & $\begin{array}{c}\text { End-of-Life; Neural networks; } \\
\text { Reuse }\end{array}$ & China & 2008 & Artigo & LCE Annals \\
\hline 281 & $\begin{array}{l}\text { Product life-cycle implications } \\
\text { for remanufacturing strategies }\end{array}$ & $\begin{array}{l}\text { OSTLIN, J.; SUNDIN, E.; } \\
\text { BJORKMAN,M }\end{array}$ & $\begin{array}{l}\text { Remanufacturing, component } \\
\text { cannibalization, product life- } \\
\text { cycle, remanufacturing } \\
\text { strategies }\end{array}$ & Suécia & 2009 & Artigo & $\begin{array}{l}\text { Journal of Cleaner } \\
\text { Production }\end{array}$ \\
\hline 282 & Product lifecycle management & LEE,S.G.;MA, Y. -S.; & Product lifecycle management; & Cingapura & 2008 & Artigo & Computers in \\
\hline
\end{tabular}




\begin{tabular}{|c|c|c|c|c|c|c|c|}
\hline & $\begin{array}{l}\text { in aviation maintenance, } \\
\text { repair and overhaul }\end{array}$ & $\begin{array}{c}\text { THIMM, G.L.; } \\
\text { VERSTRAETEN, J. }\end{array}$ & $\begin{array}{c}\text { Maintenance, repair and } \\
\text { overhaul; Enterprise } \\
\text { management; PDM; CAD/CAM }\end{array}$ & & & & Industry \\
\hline 283 & $\begin{array}{l}\text { Product Modularization for } \\
\text { Parts Reuse in inverse } \\
\text { Manufacturing }\end{array}$ & $\begin{array}{l}\text { KIMURA,F.; KATO,S.; } \\
\text { HATA,T.;MASUDA,T. }\end{array}$ & $\begin{array}{l}\text { Product design;Module } \\
\text { structure; Product life cycle }\end{array}$ & Japão & 2001 & Artigo & CIRP Annals \\
\hline 284 & $\begin{array}{c}\text { Product recovery with some } \\
\text { byte: an overview of } \\
\text { management } \\
\text { challenges and environmental } \\
\text { consequences in reverse } \\
\text { manufacturing for the computer } \\
\text { industry }\end{array}$ & $\begin{array}{c}\text { WHITE,C.D.; } \\
\text { MASANET,E.;ROSEN,C. } \\
\text { M.; BECKMAN,S.L. }\end{array}$ & $\begin{array}{l}\text { Product recovery; Computer; } \\
\text { Reverse manufacturing; } \\
\text { Demanufacturing; } \\
\text { Remanufacturing; Design for } \\
\text { environment; Environmental } \\
\text { management }\end{array}$ & $\begin{array}{l}\text { Estados } \\
\text { Unidos }\end{array}$ & 2003 & Artigo & $\begin{array}{l}\text { Journal of Cleaner } \\
\text { Production }\end{array}$ \\
\hline 285 & \begin{tabular}{|} 
Product, process, and \\
organizational design for \\
remanufacture -an overview of \\
research
\end{tabular} & $\begin{array}{c}\text { BRAS,B.; } \\
\text { MCINTOSH,M.W. }\end{array}$ & Sem palavras chave & $\begin{array}{l}\text { Estados } \\
\text { Unidos }\end{array}$ & 1999 & Artigo & $\begin{array}{l}\text { Robotics and } \\
\text { Computer- } \\
\text { Integrated } \\
\text { Manufacturing }\end{array}$ \\
\hline 287 & $\begin{array}{c}\text { Production planning and control } \\
\text { for remanufacturing: } \\
\text { a state-of-the-art survey }\end{array}$ & $\begin{array}{l}\text { GUIDE Jr, V. D.R.; } \\
\text { JAYARAMAN, } \\
\text { V.;SRIVASTAVA, R. }\end{array}$ & $\begin{array}{l}\text { Remanufacturing; Production } \\
\text { planning and control; Ecom }\end{array}$ & $\begin{array}{l}\text { Estados } \\
\text { Unidos }\end{array}$ & 1999 & Artigo & $\begin{array}{l}\text { Robotics and } \\
\text { Computer- } \\
\text { Integrated } \\
\text { Manufacturing }\end{array}$ \\
\hline 288 & $\begin{array}{l}\text { Production planning and } \\
\text { inventory control with } \\
\text { remanufacturing and disposal }\end{array}$ & $\begin{array}{l}\text { VAN DEL LAAN, E.; } \\
\text { SALOMON, M. }\end{array}$ & \begin{tabular}{|} 
Production planning, inventory \\
control, manufacturing, \\
remanufacturingm disposal, \\
product life-cycle, statistical \\
reorder point strategies, \\
computational experiments
\end{tabular} & Holanda & 1997 & Artigo & $\begin{array}{l}\text { European Journal } \\
\text { of Operational } \\
\text { Research }\end{array}$ \\
\hline
\end{tabular}




\begin{tabular}{|c|c|c|c|c|c|c|c|}
\hline 289 & $\begin{array}{l}\text { Production Planning for } \\
\text { Companies with } \\
\text { Remanufacturing Capability }\end{array}$ & $\begin{array}{c}\text { CLEGG, A.J.; WILLIAMS, } \\
\text { D.J. }\end{array}$ & Sem palavras chave & Inglaterra & 1995 & Artigo & IEEE \\
\hline 290 & $\begin{array}{l}\text { Production planning for } \\
\text { remanufactured products }\end{array}$ & $\begin{array}{l}\text { DEPUY, G.W.; USHER, } \\
\text { J.S.; WALKER, R.L.; } \\
\text { TAYLOR, G.D. }\end{array}$ & $\begin{array}{l}\text { Production planning, variable } \\
\text { processing time, variable yield } \\
\text { rate, MRP }\end{array}$ & $\begin{array}{l}\text { Estados } \\
\text { Unidos }\end{array}$ & 2007 & Artigo & $\begin{array}{c}\text { Production } \\
\text { planning \& control }\end{array}$ \\
\hline 291 & $\begin{array}{c}\text { Production planning in } \\
\text { remanufacturing-manufacturing } \\
\text { production system. }\end{array}$ & $\begin{array}{c}\text { KASMARA, } \\
\text { A.;MURAKI,M.;MATSUO } \\
\text { KA,S.;SUKOYO.;SURYA } \\
\text { DR.K. }\end{array}$ & \begin{tabular}{|c|} 
Remanufacturing, \\
Remanufacturing-manufacturing \\
production system, Production \\
planning, Cyclical process
\end{tabular} & Ásia & 2001 & Artigo & IEEE \\
\hline 292 & $\begin{array}{l}\text { Production rate control for } \\
\text { stochastic remanufacturing } \\
\text { systems }\end{array}$ & $\begin{array}{c}\text { GHARBI, A.; PELLERIN, } \\
\text { R.; SADR. J. }\end{array}$ & $\begin{array}{c}\text { Remanufacturing, Maintenance, } \\
\text { Control Policy, simulation, } \\
\text { Experimental design }\end{array}$ & Canada & 2008 & Artigo & $\begin{array}{l}\text { International } \\
\text { Journal of } \\
\text { Production } \\
\text { Economics }\end{array}$ \\
\hline 293 & $\begin{array}{l}\text { Proposal for new quantitative } \\
\text { eco-design indicators: a first } \\
\text { case study }\end{array}$ & $\begin{array}{c}\text { CERDAN, C.; GAZULLA, } \\
\text { C.;RAUGEI, M.; } \\
\text { MARTINEZ, E.; } \\
\text { FULLANA-IPALMER, P. }\end{array}$ & $\begin{array}{l}\text { lca, Eco-design, inidcators, } \\
\text { desig for recycling, design for } \\
\text { disassembly }\end{array}$ & Espanha & 2005 & Artigo & $\begin{array}{l}\text { Journal of Cleaner } \\
\text { Production }\end{array}$ \\
\hline 294 & $\begin{array}{l}\text { Quantitative Evaluation of } \\
\text { Product Disassembly for } \\
\text { Recycling }\end{array}$ & KROLL, E.; HANFT, T.A. & $\begin{array}{l}\text { Design for Disassembly, } \\
\text { Disassembly depth, Recovery, } \\
\text { concurrent engineering }\end{array}$ & $\begin{array}{l}\text { Estados } \\
\text { Unidos }\end{array}$ & 1998 & Artigo & $\begin{array}{l}\text { Research in } \\
\text { Engineering } \\
\text { Design }\end{array}$ \\
\hline 295 & \begin{tabular}{|} 
Quotes for environmentally \\
weigthed recyclability \\
(QWERTY): concept of \\
describing product recyclability \\
in terms of environmental value
\end{tabular} & $\begin{array}{l}\text { HUISMAN, J.; BOKS, } \\
\text { C.B.; STEVELS A.L.N }\end{array}$ & Sem palavras chave & Holanda & 2003 & Artigo & $\begin{array}{l}\text { Int. J. Production } \\
\text { Research. }\end{array}$ \\
\hline 296 & $\begin{array}{c}\text { Real world disassembly } \\
\text { modeling and sequencing } \\
\text { problem: } \\
\text { OptimizationbyAlgorithmofSelf }\end{array}$ & $\begin{array}{c}\text { TRIPATHI,M.; } \\
\text { AGRAWAL, S.; PANDEY, } \\
\text { M.K.; SHANKAR, R.; } \\
\text { TIWARI, M.K. }\end{array}$ & $\begin{array}{l}\text { Disassembly; Ant colony } \\
\text { optimization;Fuzzy } \\
\text { logic;Product recovery }\end{array}$ & India & 2009 & Artigo & $\begin{array}{l}\text { Robotics and } \\
\text { Computer- } \\
\text { Integrated } \\
\text { Manufacturing }\end{array}$ \\
\hline
\end{tabular}




\begin{tabular}{|c|c|c|c|c|c|c|c|}
\hline & -GuidedAnts(ASGA) & & & & & & \\
\hline 297 & $\begin{array}{l}\text { Recent trends and benefits of } \\
\text { remanufacturing: from closed } \\
\text { loop business to synergetic } \\
\text { networks }\end{array}$ & STEINHILPER, R. & Sem palavras chave & Alemanha & 2001 & Artigo & IEEE \\
\hline 298 & $\begin{array}{l}\text { Recyclin process planning for } \\
\text { the end-of-life management of } \\
\text { waste from electrical and } \\
\text { electronic equipment. }\end{array}$ & $\begin{array}{l}\text { RAHIMIFARD, S.; ABU } \\
\text { BAKAR, M.S.; } \\
\text { WILLIAMS, D.J. }\end{array}$ & $\begin{array}{c}\text { Planning } \\
\text { Recycling } \\
\text { Process planning }\end{array}$ & Inglaterra & 2009 & Artigo & CIRP Annals \\
\hline 299 & Recycling and raw materials & FLEISCHERM G. & $\begin{array}{l}\text { Ram materials, manufacturing } \\
\text { residues, waste products and } \\
\text { materialsm ecological limits of } \\
\text { recycling, product design and } \\
\text { recycling needs }\end{array}$ & Alemanha & 1997 & Artigo & $\begin{array}{l}\text { The science of the } \\
\text { total environment }\end{array}$ \\
\hline 300 & $\begin{array}{c}\text { Recycling strategy and a } \\
\text { recyclability assessment model } \\
\text { based on an artificial neural } \\
\text { network }\end{array}$ & $\begin{array}{c}\text { LIU, Z.F.; LIU, X.P.; } \\
\text { WANG, S.W.; LIU, G.F. }\end{array}$ & $\begin{array}{l}\text { Recycling strategy; Product } \\
\text { recycling; Artificial neural } \\
\text { network; Assessment model; } \\
\text { Design for recycling }\end{array}$ & China & 2002 & Artigo & $\begin{array}{l}\text { Journal of } \\
\text { Materials } \\
\text { Processing } \\
\text { Technology }\end{array}$ \\
\hline 302 & $\begin{array}{l}\text { Regional Porcess Modeling for } \\
\text { Desing for Environment }\end{array}$ & $\begin{array}{l}\text { DOGRU, A.H.; } \\
\text { SEBASTIAN, D.H. }\end{array}$ & $\begin{array}{l}\text { Material -flow modeling, } \\
\text { process modeling, design for } \\
\text { environment, multi-lifecycle }\end{array}$ & $\begin{array}{l}\text { Estados } \\
\text { Unidos }\end{array}$ & 1998 & Artigo & $\begin{array}{l}\text { Journal of systems } \\
\text { integration }\end{array}$ \\
\hline 303 & $\begin{array}{c}\text { relationsships between set-out } \\
\text { rate, participation rate and set- } \\
\text { out quantity in recylcing } \\
\text { programs }\end{array}$ & $\begin{array}{l}\text { WANG, F.S.; } \\
\text { RICHARDSON, A.J.; } \\
\text { RODDICK,F.A. }\end{array}$ & $\begin{array}{l}\text { Participation rate. Set-out rate. } \\
\text { Quantity of recyclables, } \\
\text { participation behavior in } \\
\text { recycling programs, demand } \\
\text { modelling of solid waste } \\
\text { management. }\end{array}$ & Austrália & 1997 & Artigo & $\begin{array}{l}\text { Resources } \\
\text { conservation and } \\
\text { recycling }\end{array}$ \\
\hline
\end{tabular}




\begin{tabular}{|c|c|c|c|c|c|c|c|}
\hline 304 & $\begin{array}{l}\text { Reliability Analysis of Non- } \\
\text { Constant-Size Part Populations } \\
\text { in Design for Remanufacture }\end{array}$ & $\begin{array}{l}\text { JIANG,Z.H.; SHU,L.H.; } \\
\text { BENHABIB,B. }\end{array}$ & Sem palavras chave & Canada & 2000 & Artigo & $\begin{array}{c}\text { Journal of } \\
\text { Mechanical design }\end{array}$ \\
\hline 305 & $\begin{array}{c}\text { Remanufactruing as a marketing } \\
\text { strategy }\end{array}$ & $\begin{array}{l}\text { ATASU, A.; SARVARY, } \\
\text { M.; VAN WASSENHOVE, } \\
\text { L.N. }\end{array}$ & $\begin{array}{l}\text { remanufacturing, producs } \\
\text { returns, price }\end{array}$ & $\begin{array}{l}\text { Estados } \\
\text { Unidos }\end{array}$ & 2008 & Artigo & $\begin{array}{l}\text { Management } \\
\text { Science }\end{array}$ \\
\hline 306 & $\begin{array}{l}\text { Remanufactruing } \\
\text { processplanning for IT } \\
\text { equipment }\end{array}$ & $\begin{array}{l}\text { CHIOTELLIS, S.; } \\
\text { KERNBAUNM,S.; } \\
\text { SELIGER, G. }\end{array}$ & $\begin{array}{l}\text { remanufacturing, process } \\
\text { design, process planning, } \\
\text { mixed-ineger programming }\end{array}$ & Alemanha & 2008 & Artigo & IEEE \\
\hline 307 & $\begin{array}{l}\text { Remanufacturing and Product } \\
\text { Design: Designing for the 7th } \\
\text { Generation }\end{array}$ & GRAY, C.; CHARTER, M. & Sem palavras chave & Inglaterra & 2006 & $\begin{array}{c}\text { Publica } \\
\text { ção }\end{array}$ & $\begin{array}{c}\text { The Centre for } \\
\text { sustainable Design }\end{array}$ \\
\hline 308 & $\begin{array}{l}\text { Remanufacturing Approaches } \\
\text { contributing to sustainable } \\
\text { engineering }\end{array}$ & $\begin{array}{l}\text { SELIGER, G.; } \\
\text { KERNBAUM, S.; } \\
\text { ZETTL,M. }\end{array}$ & $\begin{array}{l}\text { sustainability, engineering, } \\
\text { remanufacturing, design for } \\
\text { remanufaturing, modularity }\end{array}$ & Alemanha & 2006 & Artigo & Gestão e produção \\
\hline 310 & $\begin{array}{l}\text { Remanufacturing of mobile } \\
\text { phones-capacity, program and } \\
\text { facility adaptation planning }\end{array}$ & $\begin{array}{c}\text { FRANKE,C.; } \\
\text { BASDERE,B.; } \\
\text { CIUPEK,M.; SELIGER,S. }\end{array}$ & $\begin{array}{l}\text { Mobile phone manufacturing; } \\
\text { Production program } \\
\text { planning;Linear optimization; } \\
\text { Discrete-event simulation }\end{array}$ & Alemanha & 2006 & Artigo & $\begin{array}{l}\text { The International } \\
\text { Journal of } \\
\text { Management } \\
\text { Science }\end{array}$ \\
\hline 311 & $\begin{array}{c}\text { Remanufacturing: A Key } \\
\text { Enabler to Sustainable Product } \\
\text { Systems }\end{array}$ & NASR, N.; THURSTON,M. & $\begin{array}{c}\text { Remanufacturing, Sustainable } \\
\text { product systems }\end{array}$ & $\begin{array}{l}\text { Estados } \\
\text { Unidos }\end{array}$ & 2006 & Artigo & LCE Annals \\
\hline 312 & $\begin{array}{l}\text { Remanufacturing: Evidence of } \\
\text { Environmental Conscious } \\
\text { Business Practice in the UK }\end{array}$ & $\begin{array}{l}\text { IJOMAH, W.L.;BENNETT, } \\
\text { J.P.; PEARCE, J. }\end{array}$ & Sem palavras chave & Inglaterra & 1999 & Artigo & IEEE \\
\hline
\end{tabular}




\begin{tabular}{|c|c|c|c|c|c|c|c|}
\hline 313 & $\begin{array}{l}\text { Remanufacturing: The next } \\
\text { great opportunity for } \\
\text { boosting US productivity }\end{array}$ & $\begin{array}{l}\text { GIUNTINI, R.; } \\
\text { GAUDETTE, K. }\end{array}$ & Sem palavras chave & $\begin{array}{l}\text { Estados } \\
\text { Unidos }\end{array}$ & 2003 & Artigo & Business Horizons \\
\hline 314 & \begin{tabular}{|c|} 
Remanufacturing-the Key \\
solution for transforming \\
Downcycling into upcycling of \\
electronics
\end{tabular} & $\begin{array}{l}\text { STEINHILPER, R.; } \\
\text { HIEBER, M; }\end{array}$ & Sem palavras chave & Alemanha & 2001 & Artigo & IEEE \\
\hline 315 & $\begin{array}{c}\text { Research issues on closed-loop } \\
\text { PLM }\end{array}$ & $\begin{array}{l}\text { JUN, H.B.; KIRITSIS, D.; } \\
\text { XIROUCHAKIS }\end{array}$ & $\begin{array}{c}\text { PLM; Product lifecycle; Product } \\
\text { identification technologies; } \\
\text { Research issues }\end{array}$ & Suiza & 2007 & Artigo & $\begin{array}{l}\text { Computers in } \\
\text { Industry }\end{array}$ \\
\hline 316 & $\begin{array}{c}\text { ReSICLED: a new recovery- } \\
\text { conscious design method for } \\
\text { complex } \\
\text { products based on a multicriteria } \\
\text { assessment of the recoverability }\end{array}$ & $\begin{array}{l}\text { MATHIEUX, F.; } \\
\text { FROELICH, D.; } \\
\text { MOSZKOWICZ, P. }\end{array}$ & \begin{tabular}{|c|} 
Product \\
recoverability/recyclability; \\
Recovery route complexity and \\
variability; Waste; Electric and \\
electronic equipment; \\
Multicriteria; Design for \\
environment; Ecodesign
\end{tabular} & França & 2008 & Artigo & $\begin{array}{l}\text { Journal of Cleaner } \\
\text { Production }\end{array}$ \\
\hline 318 & $\begin{array}{l}\text { Reuse, Recycling and } \\
\text { Remanufacturin Impediments } \\
\text { for industrial Implementation }\end{array}$ & KAEBERNICK,H. & $\begin{array}{l}\text { Reuse; Recycling; } \\
\text { Remanufacturing }\end{array}$ & Austrália & 2008 & Artigo & LCE Annals \\
\hline 319 & $\begin{array}{l}\text { Revenue management for } \\
\text { remanufactured products }\end{array}$ & MITRA,S. & $\begin{array}{l}\text { Reverse logistics; } \\
\text { Remanufacturing; Revenue } \\
\text { management; Pricing model }\end{array}$ & India & 2007 & Artigo & $\begin{array}{l}\text { The International } \\
\text { Journal of } \\
\text { Management } \\
\text { Science }\end{array}$ \\
\hline 320 & $\begin{array}{l}\text { Review of Current End-of-life } \\
\text { Options for Electronics and }\end{array}$ & $\begin{array}{c}\text { CARRELL,J.; ZHANG, } \\
\text { H.C.;LI,H. }\end{array}$ & $\begin{array}{c}\text { End-of-Life;Active Disassembly } \\
\text { using Smart Materials;Shape }\end{array}$ & $\begin{array}{l}\text { Estados } \\
\text { Unidos }\end{array}$ & 2008 & Artigo & LCE Annals \\
\hline
\end{tabular}




\begin{tabular}{|c|c|c|c|c|c|c|c|}
\hline & $\begin{array}{l}\text { Future automatic Disassembly } \\
\text { options with Shape Memory } \\
\text { Materials with Carbon } \\
\text { Annotubes for Electronics }\end{array}$ & & Memory Materials & & & & \\
\hline 323 & $\begin{array}{l}\text { Scheduling Policies for } \\
\text { Remanufacturing }\end{array}$ & $\begin{array}{c}\text { GUIDE Jr, V. D.R.; } \\
\text { KRAUS, } \\
\text { M.E.;SRIVASTAVA, R. }\end{array}$ & $\begin{array}{c}\text { Recoverable } \\
\text { manufacturing;Priority } \\
\text { despatching; Disassembly } \\
\text { sheduling }\end{array}$ & $\begin{array}{l}\text { Estados } \\
\text { Unidos }\end{array}$ & 1997 & Artigo & $\begin{array}{l}\text { International } \\
\text { Journal of } \\
\text { Production } \\
\text { Economics }\end{array}$ \\
\hline 325 & \begin{tabular}{|c|} 
Selective Disassembly \\
Sequencing: A Methodology for \\
the \\
Disassembly of End-of-Life \\
Products
\end{tabular} & $\begin{array}{l}\text { KARA, S.; } \\
\text { POMPRASITPOL, P.; } \\
\text { KAEBERNICK, H. }\end{array}$ & $\begin{array}{l}\text { Disassembly, Reuse, } \\
\text { Environmental Impact }\end{array}$ & Austrália & 2006 & Artigo & CIRP Annals \\
\hline 326 & $\begin{array}{c}\text { Setting the holding cost rates in } \\
\text { a two-product system with } \\
\text { remanufacturing }\end{array}$ & $\begin{array}{c}\text { ÇORBACIOGLU,U.; VAN } \\
\text { DER LAAN,E.A. }\end{array}$ & $\begin{array}{l}\text { Reverse logistics; } \\
\text { Remanufacturing; Net present } \\
\text { value; Holding cost; Inventory } \\
\text { management }\end{array}$ & Holanda & 2007 & Artigo & $\begin{array}{l}\text { International } \\
\text { Journal of } \\
\text { Production } \\
\text { Economics }\end{array}$ \\
\hline
\end{tabular}




\begin{tabular}{|c|c|c|c|c|c|c|c|}
\hline 327 & $\begin{array}{l}\text { Simple heuristics for push and } \\
\text { pull remanufacturing policies }\end{array}$ & $\begin{array}{l}\text { VAN DER LAAN, E.A.; } \\
\text { TEUNTER, R.H. }\end{array}$ & $\begin{array}{c}\text { Inventorycontrol;Remanufacturi } \\
\text { ng;Heuristics }\end{array}$ & Holanda & 2006 & Artigo & $\begin{array}{l}\text { European Journal } \\
\text { of Operational } \\
\text { Research }\end{array}$ \\
\hline 328 & $\begin{array}{c}\text { Simulation for product life cycle } \\
\text { managment }\end{array}$ & XIE, X.; SIMON, M. & $\begin{array}{c}\text { product life cycle, simulation, } \\
\text { failure (mechanical), } \\
\text { maintenance }\end{array}$ & Inglaterra & 2006 & Artigo & $\begin{array}{l}\text { Journal of } \\
\text { manufacturing } \\
\text { technology } \\
\text { Management }\end{array}$ \\
\hline 329 & $\begin{array}{c}\text { State of the art of plastic sorting } \\
\text { and recycling: Feedback to } \\
\text { vehicle design }\end{array}$ & \begin{tabular}{|c|} 
FROELICH, D.; MARIS, \\
E.; HAOUES, N.; \\
CHEMINEAU, L.; \\
RENARD, H.; ABRAHAM, \\
F.; LASSARTESSES, R.
\end{tabular} & $\begin{array}{l}\text { Recycling, mining, sortign } \\
\text { method, liberation, modelling, } \\
\text { environmental }\end{array}$ & França & 2007 & Artigo & $\begin{array}{l}\text { Mineral } \\
\text { engineering }\end{array}$ \\
\hline 330 & $\begin{array}{l}\text { Strategic evolution of eco- } \\
\text { products: a product life cycle } \\
\text { planning methodology }\end{array}$ & KOBAYASHI, HIDEKI & \begin{tabular}{|c|} 
Enviromentally conscious \\
design (ecodesign),Design for \\
environment (DfE), life cycle \\
planning (LCP), Quality \\
Function Development (QFD), \\
Life Cycle Assessment (LCA), \\
Environmentally conscious \\
product (eco-product)
\end{tabular} & Japão & 2005 & Artigo & $\begin{array}{l}\text { Research in } \\
\text { Engineering } \\
\text { Design }\end{array}$ \\
\hline 331 & $\begin{array}{l}\text { Strategic Issues in product } \\
\text { Recovery Management }\end{array}$ & \begin{tabular}{|c|} 
THIERRY, M.; \\
SALOMON, M.; NUMEN, \\
J.V.; WASSENHOVE, L.V.
\end{tabular} & Sem palavras chave & $\begin{array}{l}\text { Estados } \\
\text { Unidos }\end{array}$ & 1995 & Artigo & $\begin{array}{l}\text { California } \\
\text { Management } \\
\text { Review }\end{array}$ \\
\hline 332 & $\begin{array}{l}\text { Strategic Management of } \\
\text { Product Recovery }\end{array}$ & TOFFEL, M.W. & Sem palavras chave & $\begin{array}{l}\text { Estados } \\
\text { Unidos }\end{array}$ & 2004 & Artigo & $\begin{array}{l}\text { California } \\
\text { Management } \\
\text { Review }\end{array}$ \\
\hline 333 & $\begin{array}{c}\text { Strategic network design for } \\
\text { reverse logistics and } \\
\text { remanufacturing using new and } \\
\text { old product modules }\end{array}$ & $\begin{array}{c}\text { MUTHA, A.; POKHAREL, } \\
\text { S; }\end{array}$ & $\begin{array}{c}\text { Reverse logistics, Network } \\
\text { design, Product moularity, Cost, } \\
\text { Remanufacturing. }\end{array}$ & Cingapura & 2009 & Artigo & $\begin{array}{l}\text { Computers \& } \\
\text { industrial } \\
\text { engineering }\end{array}$ \\
\hline
\end{tabular}




\begin{tabular}{|c|c|c|c|c|c|c|c|}
\hline 334 & $\begin{array}{l}\text { Strategic response to EEE } \\
\text { returns Product eco-design or } \\
\text { new recovery processes }\end{array}$ & $\begin{array}{c}\text { ZUIDWIJK, R.; KRIKKE, } \\
\text { H. }\end{array}$ & $\begin{array}{l}\text { Eco-design, Closed loop chain, } \\
\text { WEEE-directive, Product data } \\
\text { management, Integer Program }\end{array}$ & Holanda & 2008 & Artigo & $\begin{array}{l}\text { European Journal } \\
\text { of Operational } \\
\text { Research }\end{array}$ \\
\hline 335 & $\begin{array}{l}\text { Supply planning model for } \\
\text { remanufacturing system in } \\
\text { reverse logistics environment }\end{array}$ & $\begin{array}{l}\text { KIM, K.; SONG, I.; KIM, } \\
\text { J.; JEONG, B. }\end{array}$ & $\begin{array}{c}\text { Supply plannig } \\
\text { remanufacturing, reverse } \\
\text { logisitics }\end{array}$ & Korea & 2006 & Artigo & $\begin{array}{l}\text { Computers \& } \\
\text { industrial } \\
\text { engineering }\end{array}$ \\
\hline 336 & $\begin{array}{l}\text { Supporting Design for } \\
\text { remanufacture through waste } \\
\text { stream analysis of automotive } \\
\text { remanufactures }\end{array}$ & $\begin{array}{l}\text { SHERWOOD,M.; } \\
\text { SHU,L.H. }\end{array}$ & $\begin{array}{c}\text { Design; Remanufacture; Waste } \\
\text { Stream }\end{array}$ & Canada & 2000 & Artigo & CIRP Annals \\
\hline 337 & $\begin{array}{l}\text { Sustainable Management of } \\
\text { Electronic Waste }\end{array}$ & HERAT, S. & $\begin{array}{l}\text { Electronic waste (e-waste); } \\
\text { Environmental Safety; Producer } \\
\text { responsibility; Sustainability; }\end{array}$ & Austrália & 2007 & Artigo & $\begin{array}{l}\text { CLEAN-Soil, Air, } \\
\text { Water }\end{array}$ \\
\hline 338 & $\begin{array}{l}\text { Synthesis and optimization of } \\
\text { the recovery route for residual } \\
\text { products under uncertain } \\
\text { product demand }\end{array}$ & $\begin{array}{l}\text { DUQUE, J.; PÓVOA, } \\
\text { A.P.F.D.B.; NOVAIS, A.Q. }\end{array}$ & $\begin{array}{l}\text { Residual products recovery; } \\
\text { Optimization; Network } \\
\text { synthesis; Environmental } \\
\text { impact; Stochastic flexibility } \\
\text { index }\end{array}$ & Portugal & 2007 & Artigo & $\begin{array}{c}\text { Computers \& } \\
\text { operations research }\end{array}$ \\
\hline 339 & $\begin{array}{c}\text { System architecture for design } \\
\text { and EoL information integration } \\
\text { framework }\end{array}$ & $\begin{array}{l}\text { LEE, H.M.; LU, W.F.; } \\
\text { SONG, B.; GAY, R. }\end{array}$ & $\begin{array}{c}\text { End of life, system architecture, } \\
\text { web services, ontology }\end{array}$ & Cingapura & 2008 & Artigo & $\begin{array}{c}\text { International } \\
\text { Conference on } \\
\text { Product lifecycle } \\
\text { management }\end{array}$ \\
\hline 340 & $\begin{array}{l}\text { SYSTEM ARCHITECTURE } \\
\text { FOR CLOSED-LOOP PLM }\end{array}$ & $\begin{array}{l}\text { JUN, H.B.; KIRITSIS, D.; } \\
\text { XIROUCHAKIS }\end{array}$ & $\begin{array}{c}\text { system architectures, enterprise } \\
\text { integration, enterprise modeling, } \\
\text { system } \\
\text { design, system concepts. }\end{array}$ & Suiza & 2006 & $\begin{array}{l}\text { Publica } \\
\text { ção }\end{array}$ & $\begin{array}{l}\text { Elsevir IFAC } \\
\text { publications }\end{array}$ \\
\hline 341 & $\begin{array}{l}\text { Systematic Integration of } \\
\text { Design for Recycling into } \\
\text { Product Design }\end{array}$ & $\begin{array}{l}\text { KRIWET, A.; ZUSSMAN, } \\
\text { E.; SELIGER, G. }\end{array}$ & Sem palavras chave & Alemanha & 1995 & Artigo & $\begin{array}{l}\text { International } \\
\text { Journal of } \\
\text { Production } \\
\text { Economics }\end{array}$ \\
\hline
\end{tabular}




\begin{tabular}{|c|c|c|c|c|c|c|c|}
\hline 342 & $\begin{array}{l}\text { Technological Forecasting for } \\
\text { Component Reuse }\end{array}$ & $\begin{array}{c}\text { RUGRUNGRUANG, F.; } \\
\text { KARA, S.; KAEBERNICK, } \\
\text { H. }\end{array}$ & $\begin{array}{l}\text { Reuse; Lifetime prediction, } \\
\text { Technological forecasting }\end{array}$ & Austrália & 2008 & Artigo & LCE Annals \\
\hline 343 & $\begin{array}{c}\text { The } \\
\text { constructionofacollaborative- } \\
\text { designplatformtosupportwaste } \\
\text { electrical } \\
\text { andelectronicequipmentrecyclin } \\
\mathrm{g}\end{array}$ & KUO, T.C. & $\begin{array}{c}\text { Wasteelectricalandelectronicequ } \\
\text { ipment } \\
\text { Recycling } \\
\text { Collaborativedesign } \\
\text { Life-cyclemanagement } \\
\text { Green supplychainmanagement }\end{array}$ & China & 2009 & Artigo & $\begin{array}{l}\text { Robotics and } \\
\text { Computer- } \\
\text { Integrated } \\
\text { Manufacturing }\end{array}$ \\
\hline 344 & $\begin{array}{l}\text { The development of a } \\
\text { remanufacturing design } \\
\text { platform model (RDPM) } \\
\text { applying design platfrom } \\
\text { principles }\end{array}$ & BARKER, S.; KING, A. & $\begin{array}{c}\text { Remanufacturing, Delphi } \\
\text { Technique }\end{array}$ & Inglaterra & 2006 & Artigo & Annais LCE \\
\hline 345 & $\begin{array}{l}\text { The economics of } \\
\text { remanufacturing under limited } \\
\text { component durability and finite } \\
\text { product life cycles }\end{array}$ & $\begin{array}{c}\text { GEYER, R.; VAN } \\
\text { WASSENHOVE, L.N.; } \\
\text { ATASU, A. }\end{array}$ & $\begin{array}{l}\text { remanufacturing, life cycle, } \\
\text { durability, economic model }\end{array}$ & $\begin{array}{l}\text { Estados } \\
\text { Unidos }\end{array}$ & 2007 & Artigo & $\begin{array}{l}\text { Management } \\
\text { Science }\end{array}$ \\
\hline 346 & $\begin{array}{l}\text { The economics of tire } \\
\text { remanufacturing }\end{array}$ & FERRER, G. & $\begin{array}{l}\text { remanufacturing, recycling, } \\
\text { retreading, incineration, material } \\
\text { recovery, product recovery, tire } \\
\text { industry, wastre reduction, } \\
\text { resource conservation, pollution } \\
\text { prevention, environmental } \\
\text { economics }\end{array}$ & França & 1997 & Artigo & $\begin{array}{l}\text { Resources } \\
\text { conservation and } \\
\text { recycling }\end{array}$ \\
\hline 347 & $\begin{array}{l}\text { The effect of categorizing } \\
\text { returned products in } \\
\text { remanufacturing }\end{array}$ & $\begin{array}{l}\text { ARAS,N.; BOYACI, } \\
\text { T.;VERTER, V. }\end{array}$ & Sem palavras chave & Turquia & 2003 & Artigo & IIE Transactions \\
\hline 348 & $\begin{array}{c}\text { The Effect of Competition on } \\
\text { Recovery Strategies }\end{array}$ & $\begin{array}{l}\text { FERGUSON, M.E.; } \\
\text { TOKTAY, B. }\end{array}$ & $\begin{array}{l}\text { remanufacturing, competition, } \\
\text { pricing, entry-deterrent } \\
\text { strategies }\end{array}$ & $\begin{array}{l}\text { Estados } \\
\text { Unidos }\end{array}$ & 2006 & Artigo & $\begin{array}{l}\text { Production and } \\
\text { operations } \\
\text { managment }\end{array}$ \\
\hline
\end{tabular}




\begin{tabular}{|c|c|c|c|c|c|c|c|}
\hline 349 & $\begin{array}{l}\text { The effect of remanufacturing } \\
\text { on procurement decisions for } \\
\text { resellers in secondary markets }\end{array}$ & $\begin{array}{l}\text { ROBOTIS,ANDREAS, } \\
\text { BHATTACHARYA, S.; } \\
\text { WASSENHOVE, L.N.V. }\end{array}$ & $\begin{array}{c}\text { Inventory/production; } \\
\text { Stochastic; Multiproduct; } \\
\text { Substitution; Newsvendor } \\
\text { problem; Product acquisition } \\
\text { management; Remanufacturing }\end{array}$ & França & 2005 & Artigo & $\begin{array}{l}\text { European Journal } \\
\text { of Operational } \\
\text { Research }\end{array}$ \\
\hline 350 & $\begin{array}{l}\text { The effect of remanufacturing } \\
\text { on procurement decisions } \\
\text { for resellers in secondary } \\
\text { markets }\end{array}$ & $\begin{array}{c}\text { ROBOTIS, A.; } \\
\text { BHATTACHARYA, } \\
\text { S.;VAN WASSENHOVE, } \\
\text { L.N. }\end{array}$ & $\begin{array}{c}\text { Inventory/production; } \\
\text { Stochastic; Multiproduct; } \\
\text { Substitution; Newsvendor } \\
\text { problem; Product acquisition } \\
\text { management; } \\
\text { Remanufacturing }\end{array}$ & França & 2005 & Artigo & $\begin{array}{l}\text { European Journal } \\
\text { of Operational } \\
\text { Research }\end{array}$ \\
\hline 351 & \begin{tabular}{|} 
The effects of environmental \\
parameters on product recovery
\end{tabular} & $\begin{array}{l}\text { GEORGIADIS,P.; } \\
\text { VLACHOS, D.; } \\
\text { TAGARAS, G. }\end{array}$ & $\begin{array}{l}\text { Reverse logistics, supply chain } \\
\text { management, system dynamics }\end{array}$ & Greça & 2004 & Artigo & $\begin{array}{l}\text { European Journal } \\
\text { of Operational } \\
\text { Research }\end{array}$ \\
\hline 352 & $\begin{array}{c}\text { The end of life treatment of } \\
\text { second generation } \\
\text { mobile phone networks: } \\
\text { Strategies to } \\
\text { reduce the environmental impact }\end{array}$ & $\begin{array}{l}\text { SCHARNHORST, W.; } \\
\text { ALTHAUS, H-J.; } \\
\text { CLASSEN, M.; JOLLIET, } \\
\text { O.; HILTY, L.M. }\end{array}$ & Sem palavras chave & Suécia & 2005 & Artigo & $\begin{array}{l}\text { Environmental } \\
\text { Impact Assessment } \\
\text { review }\end{array}$ \\
\hline 354 & $\begin{array}{c}\text { The Impact of Product Lifecycle } \\
\text { on Capacity Planning of Closed- } \\
\text { Loop Supply Chains with } \\
\text { Remanufacturing }\end{array}$ & $\begin{array}{l}\text { GEORGIADIS,P.; } \\
\text { VLACHOS, D.; } \\
\text { TAGARAS, G. }\end{array}$ & $\begin{array}{c}\text { closed-loop supply chains } \bullet \\
\text { remanufacturing } \bullet \text { capacity } \\
\text { planning } \bullet \text { system dynamics } \bullet \\
\text { lifecycle }\end{array}$ & Greça & 2006 & Artigo & $\begin{array}{l}\text { Production and } \\
\text { operations } \\
\text { managment }\end{array}$ \\
\hline 355 & $\begin{array}{l}\text { The impact of remanufacturing } \\
\text { in the economy }\end{array}$ & FERRER, G.; AYRES, R.U. & $\begin{array}{l}\text { Remanufacturing, product } \\
\text { recovery, inter-industry flows, } \\
\text { Input-Output model, France }\end{array}$ & $\begin{array}{l}\text { Estados } \\
\text { Unidos }\end{array}$ & 2000 & Artigo & $\begin{array}{l}\text { Ecological } \\
\text { Economics }\end{array}$ \\
\hline
\end{tabular}




\begin{tabular}{|c|c|c|c|c|c|c|c|}
\hline 356 & $\begin{array}{l}\text { The impact of two-product joint } \\
\text { lifecycles on capacity planning } \\
\text { of remanufacturing networks }\end{array}$ & $\begin{array}{l}\text { GEORGIADIS,P.; } \\
\text { ATHANASIOU, E. }\end{array}$ & $\begin{array}{l}\text { System dynamics, capacity } \\
\text { planning, closed-loop supply } \\
\text { chain, robutness and sesnsivity } \\
\text { analysis, decision support } \\
\text { system }\end{array}$ & Greça & 2009 & Artigo & $\begin{array}{l}\text { European Journal } \\
\text { of Operational } \\
\text { Research }\end{array}$ \\
\hline 357 & $\begin{array}{l}\text { The influence of modularity and } \\
\text { industry clockspeed on reverse } \\
\text { logistics strategy:Implications } \\
\text { for the purchasing function }\end{array}$ & $\begin{array}{l}\text { FERNÁNDEZ, I.; } \\
\text { KEKALE,T. }\end{array}$ & $\begin{array}{l}\text { Purchasing patterns, product } \\
\text { recovery, contingency theory, } \\
\text { configurational theory, industry } \\
\text { clockspeed, Product architecture }\end{array}$ & Espanha & 2005 & Artigo & $\begin{array}{l}\text { Journal of } \\
\text { Purchasing and } \\
\text { supply } \\
\text { management }\end{array}$ \\
\hline 358 & $\begin{array}{l}\text { The market-oriented dynamic } \\
\text { product recovery model in the } \\
\text { just-in-time framework }\end{array}$ & RITCHER,K.;GOBSCH & $\begin{array}{c}\text { Product recovery; Just-in-time; } \\
\text { Lot sizing; Inventory } \\
\text { management }\end{array}$ & Alemanha & 2003 & Artigo & $\begin{array}{l}\text { International } \\
\text { Journal of } \\
\text { Production } \\
\text { Economics }\end{array}$ \\
\hline 359 & $\begin{array}{l}\text { The profit-making allure of } \\
\text { product reconstruction }\end{array}$ & PEARCE II, J.A. & Sem palavras chave & $\begin{array}{l}\text { Estados } \\
\text { Unidos }\end{array}$ & 2009 & Artigo & $\begin{array}{l}\text { MITSloan } \\
\text { management } \\
\text { review }\end{array}$ \\
\hline 360 & $\begin{array}{l}\text { The recycling business for } \\
\text { sustainability in Taiwan }\end{array}$ & $\begin{array}{l}\text { CHEN, Y.J.; WU, T.H..; } \\
\text { CHEN, Y.L. }\end{array}$ & Recycling, Waste, Taiwan & Japão & 2009 & Artigo & $\begin{array}{c}\text { European } \\
\text { bussiness review }\end{array}$ \\
\hline 361 & $\begin{array}{l}\text { The reverse Wagner/Whitin } \\
\text { model with variable } \\
\text { manufacturing and } \\
\text { remanufacturing cost }\end{array}$ & RICHTER, K.; WEBER, J. & $\begin{array}{c}\text { Product recovery, } \\
\text { remanufacturing, lot sizing, } \\
\text { inventory management }\end{array}$ & Alemanha & 2001 & Artigo & $\begin{array}{l}\text { International } \\
\text { Journal of } \\
\text { Production } \\
\text { Economics }\end{array}$ \\
\hline 362 & $\begin{array}{l}\text { The time-varying factors } \\
\text { influencing } \\
\text { the recycling rate of products }\end{array}$ & $\begin{array}{l}\text { VAN SCHAIK,A.; } \\
\text { REUTER, M.A. }\end{array}$ & $\begin{array}{c}\text { Recycling (Dynamic), } \\
\text { modelling, simulation, Eu } \\
\text { legislation, Passenger vehicles }\end{array}$ & Holanda & 2004 & Artigo & $\begin{array}{l}\text { Resources } \\
\text { conservation and } \\
\text { recycling }\end{array}$ \\
\hline 363 & $\begin{array}{l}\text { The use of fuzzy rule models to } \\
\text { link automotive design } \\
\text { to recycling rate calculation }\end{array}$ & $\begin{array}{l}\text { VAN SHAIK, } \\
\text { A.;REUTER,M.A. }\end{array}$ & $\begin{array}{l}\text { Liberation; Recycling; } \\
\text { Modelling; Optimisation; } \\
\text { Environmental }\end{array}$ & Holanda & 2007 & Artigo & $\begin{array}{c}\text { Mineral } \\
\text { engineering }\end{array}$ \\
\hline 364 & $\begin{array}{l}\text { The use of virtual reality } \\
\text { techniques during the design }\end{array}$ & $\begin{array}{l}\text { ZWOLINSKI, P.; } \\
\text { TICHKIEWITCH, S.; }\end{array}$ & Conceptual design, product & França & 2007 & Artigo & LCE Annals \\
\hline
\end{tabular}




\begin{tabular}{|c|c|c|c|c|c|c|c|}
\hline & $\begin{array}{l}\text { process: from the functional } \\
\text { definition of the product to the } \\
\text { design of its structure }\end{array}$ & SGHAIER, A. & lifecycle, virtual reality & & & & \\
\hline 365 & $\begin{array}{c}\text { The Value of Quality Grading in } \\
\text { Remanufacturing }\end{array}$ & $\begin{array}{c}\text { FERGUSON, M.; GUIDE } \\
\text { Jr, V.; KOCA, E.; SOUZA, } \\
\text { G.C. }\end{array}$ & $\begin{array}{l}\text { remanufacturing } \bullet \text { production } \\
\text { planning • quality grading }\end{array}$ & $\begin{array}{l}\text { Estados } \\
\text { Unidos }\end{array}$ & 2009 & Artigo & $\begin{array}{l}\text { Production and } \\
\text { operations } \\
\text { managment }\end{array}$ \\
\hline 366 & $\begin{array}{c}\text { The value of remanufactured } \\
\text { Engines }\end{array}$ & $\begin{array}{l}\text { SMITH, V.M.; } \\
\text { KEOLEIAN, G.A. }\end{array}$ & \begin{tabular}{|c} 
Automobiles,end-of-life \\
vehicles (ELVs), life cycle \\
inventory (LCI), \\
rebuilding,reconditioning, reuse
\end{tabular} & $\begin{array}{l}\text { Estados } \\
\text { Unidos }\end{array}$ & 2004 & Artigo & $\begin{array}{c}\text { Journal of } \\
\text { Industrial Ecology }\end{array}$ \\
\hline 367 & $\begin{array}{c}\text { Thermodynamic Metrics for } \\
\text { measuring the "sustainability" of } \\
\text { Design for recycling }\end{array}$ & $\begin{array}{l}\text { REUTER,M.; VAN } \\
\text { SCHAIK, A. }\end{array}$ & Sem palavras chave & Austrália & 2008 & Artigo & JOM \\
\hline 368 & $\begin{array}{c}\text { Third-party demanufacturing as } \\
\text { a solution for extended producer } \\
\text { responsibility }\end{array}$ & $\begin{array}{l}\text { SPICER,A.J.;JOHNSON, } \\
\text { M.R. }\end{array}$ & \begin{tabular}{|} 
Extended producer \\
responsibility; Reverse logistics; \\
Recycling; Demanufacturing; \\
Internet
\end{tabular} & Canada & 2004 & Artigo & $\begin{array}{l}\text { Journal of Cleaner } \\
\text { Production }\end{array}$ \\
\hline 369 & $\begin{array}{l}\text { Three shops, three strategies } \\
\text { using mrp-ii, jit, and toc in }\end{array}$ & FARGHER Jr. J.S.W. & Sem palavras chave & $\begin{array}{l}\text { Estados } \\
\text { Unidos }\end{array}$ & 1997 & Artigo & $\begin{array}{l}\text { National } \\
\text { productivity } \\
\text { review }\end{array}$ \\
\hline 370 & $\begin{array}{l}\text { Towards Design for } \\
\text { remanufacturing Metrics for } \\
\text { Assessing Remanufacturability }\end{array}$ & BRAS,B.; HAMMOND,R. & Sem palavras chave & $\begin{array}{l}\text { Estados } \\
\text { Unidos }\end{array}$ & 1996 & Artigo & $\begin{array}{l}\text { Proceedings of the } \\
\text { 1st International } \\
\text { Workshop on } \\
\text { Reuse }\end{array}$ \\
\hline 371 & $\begin{array}{c}\text { Towards the use of LCA During } \\
\text { Early design Phase to Define } \\
\text { EoL Scenarios }\end{array}$ & $\begin{array}{c}\text { GEHIN,A.; } \\
\text { ZWOLINSKI,P.;BRISSAU } \\
\text { D, D. }\end{array}$ & $\begin{array}{l}\text { Life Cycle Assessment; End of } \\
\text { life strategies;Product and } \\
\text { lifecycle model building; } \\
\text { Product Design }\end{array}$ & França & 2007 & Artigo & CIRP Annals \\
\hline 372 & $\begin{array}{l}\text { TWO-DIMENSIONAL } \\
\text { ANALYTICAL }\end{array}$ & $\begin{array}{c}\text { LINGAM, R.; } \\
\text { CARAPCIOGLU, M.Y. }\end{array}$ & Sem palavras chave & $\begin{array}{l}\text { Estados } \\
\text { Unidos }\end{array}$ & 1995 & Artigo & $\begin{array}{c}\text { Waste } \\
\text { Management }\end{array}$ \\
\hline
\end{tabular}




\begin{tabular}{|c|c|c|c|c|c|c|c|}
\hline & $\begin{array}{l}\text { SOLUTIONS FOR A TWO- } \\
\text { PUMP FREE PRODUCT } \\
\text { RECOVERY SYSTEM }\end{array}$ & & & & & & \\
\hline 373 & $\begin{array}{l}\text { Using the Delphi technique to } \\
\text { establish a robust research } \\
\text { agenda for remanufacturing }\end{array}$ & KING,A.; BARKER, S. & $\begin{array}{l}\text { Remanufacturing; Delphi } \\
\text { Technique }\end{array}$ & Inglaterra & 2007 & Artigo & CIRP Annals \\
\hline 374 & $\begin{array}{l}\text { using remanufactured switching } \\
\text { equipment to reduce restoration } \\
\text { tine in case of a disaster }\end{array}$ & $\begin{array}{l}\text { CHARLES, L.;GOLDEY, } \\
\text { L.M.E.; OLSON, D.; } \\
\text { TROTTIER, S.L. }\end{array}$ & Sem palavras chave & $\begin{array}{l}\text { Estados } \\
\text { Unidos }\end{array}$ & 2004 & Artigo & $\begin{array}{c}\text { Bell Labs } \\
\text { Technical Journal }\end{array}$ \\
\hline 375 & $\begin{array}{c}\text { Using the recyclability index of } \\
\text { materials as a tool } \\
\text { for design for disassembly }\end{array}$ & $\begin{array}{c}\text { VILLALBA,G.; } \\
\text { SEGARRA,M.;CHIMENO } \\
\text { S J.M.; ESPIELL,F. }\end{array}$ & $\begin{array}{c}\text { Recyclability index; } \\
\text { Disassembly; Recycling }\end{array}$ & Espanha & 2004 & Artigo & $\begin{array}{l}\text { Ecological } \\
\text { Economics }\end{array}$ \\
\hline 376 & $\begin{array}{l}\text { Using the recycling theme to } \\
\text { motivate product design } \\
\text { students: } \\
\text { a teaching methodology based } \\
\text { on domestic can crushers }\end{array}$ & PACE,S. & $\begin{array}{c}\text { Metals (A); Recycling (B); } \\
\text { Mechanical }\end{array}$ & Inglaterra & 2005 & Artigo & $\begin{array}{l}\text { Materials \& } \\
\text { Design }\end{array}$ \\
\hline 378 & $\begin{array}{l}\text { Virtual reality as a support tool } \\
\text { in the shoe life cycle }\end{array}$ & $\begin{array}{c}\text { VIGANÒ, G.; } \\
\text { MONTURA,S.; GRECI,L.; } \\
\text { SACCO, M.; BOER, C.R. }\end{array}$ & Sem palavras chave & Italia & 2004 & Artigo & $\begin{array}{l}\text { International } \\
\text { Journal of } \\
\text { Computer } \\
\text { Integrated } \\
\text { Manufacturing }\end{array}$ \\
\hline 379 & $\begin{array}{l}\text { Waste, recycling, and "'Design } \\
\text { for Environment"': } \\
\text { Roles for markets and policy }\end{array}$ & $\begin{array}{c}\text { CALCOTT, P.; WALLS, } \\
\text { M. }\end{array}$ & $\begin{array}{l}\text { Recycling; Design for } \\
\text { environment; Solid waste }\end{array}$ & $\begin{array}{l}\text { Estados } \\
\text { Unidos }\end{array}$ & 2005 & Artigo & $\begin{array}{l}\text { Resource and } \\
\text { energy economics }\end{array}$ \\
\hline
\end{tabular}




\begin{tabular}{|c|c|c|c|c|c|c|c|}
\hline & instruments & & & & & & \\
\hline 380 & $\begin{array}{c}\text { Web based Ecodesign } \\
\text { supporting system for electronic } \\
\text { products }\end{array}$ & CHUNG, J.; LEE, H. & $\begin{array}{l}\text { Eco-design; Recyclability, } \\
\text { ecolist, Simplified LCA, LCC }\end{array}$ & Korea & 2003 & Artigo & IEEE \\
\hline 381 & $\begin{array}{c}\text { WEEE recovery strategies and } \\
\text { the WEEE treatment status in } \\
\text { China }\end{array}$ & $\begin{array}{l}\text { HE, W.; LI, G.; MA, X.; } \\
\text { WANG H.; HUANG, J.; } \\
\text { XU, M.; HUANGM C. }\end{array}$ & $\begin{array}{c}\text { Waste electric and electronic } \\
\text { equipment; Management; } \\
\text { Recovery; Resource; Legislation }\end{array}$ & China & 2006 & Artigo & $\begin{array}{l}\text { Journal of } \\
\text { Hazardous } \\
\text { Materials }\end{array}$ \\
\hline 382 & $\begin{array}{l}\text { Yield information and supplier } \\
\text { responsiveness in } \\
\text { remanufacturing operations }\end{array}$ & FERRER,G. & $\begin{array}{c}\text { Remanufacturing;Stochasticproc } \\
\text { essyield;Laborskills;Supplierres } \\
\text { ponsiveness }\end{array}$ & $\begin{array}{l}\text { Estados } \\
\text { Unidos }\end{array}$ & 2003 & Artigo & $\begin{array}{l}\text { European Journal } \\
\text { of Operational } \\
\text { Research }\end{array}$ \\
\hline
\end{tabular}

Quadro 23 - Padronização dos Estudos Obtidos com a Revisão Sistemática 


\section{Apêndice F Resumos das Práticas das Estratégias de Fim de Vida}

\begin{tabular}{|c|c|c|}
\hline Nome & Resumo & Referência \\
\hline $\begin{array}{c}\text { Method to Asses the } \\
\text { Adaptability of } \\
\text { Products (MAAP) }\end{array}$ & $\begin{array}{l}\text { O Method of Asses the Adptability of Products (MAAP) ajuda a determinar e adequar um produto aos processos de } \\
\text { remanufatura, manutenção, reparo e atualização. Fornece informações (matriz de priorização) para localizar os } \\
\text { pontos de melhoria do design do produto, componentes e conexões. A proposta é utilizar métricas para avaliar a } \\
\text { adequação do produto aos processos, denominadas de métricas de adaptação - terceiro nível. Os valores que mais } \\
\text { se aproximam de } 1 \text { (um) representam a melhor adaptabilidade do design e valores próximos de } 0 \text { (zero) indicam } \\
\text { uma menor adaptabilidade do design do produto aos processos. A métrica de adaptabilidade é determinada a partir } \\
\text { da soma de todas as médias das sub-métricas determinadas para cada um dos critérios considerados nos quatro } \\
\text { processos. } \\
\text { O método propõe avaliar e agrupar os requisitos dos processos em critérios / direcionadores e sub-métricas, } \\
\text { denominados de métricas de segundo e primeiro nível respectivamente: partes - avaliam o número de partes } \\
\text { (componentes) e os componentes removíveis (parafusos, rebites etc.); conectores - avaliam os diferentes grupos de } \\
\text { conectores, os tipos de conexões e o grupo de ferramentas usadas para montagem e desmontagem dos conectores; } \\
\text { espacial - avalia a visibilidade, o acesso, a identificação dos conectores e as direções de desmontagem; } \\
\text { remanufatura - é a avaliação das partes e dos danos, garantindo a qualidade, reparo, recondicionamento e as } \\
\text { métricas de troca e limpeza; manutenção e reparos de montagem, desmontagem e de estrutura da arquitetura do } \\
\text { produto; e a atualização foca a parte de modularidade do produto com requisitos de separação das funções e } \\
\text { relações das partes. Genericamente o desempenho do parâmetro do produto é determinado a partir da razão entre o } \\
\text { valor ideal para um parâmetro específico e o desempenho real deste parâmetro. } \\
\text { Os resultados são apresentados por meio de uma matriz de priorização e baseados nesses resultados é possível } \\
\text { determinar as orientações ou recomendações para melhorar a adaptabilidade do produto a processo de } \\
\text { remanufatura, manutenção, reparo e atualização. }\end{array}$ & $\begin{array}{l}\text { WILLENS et al. } \\
\text { (2003); } \\
\text { WILLIENS; } \\
\text { DEWULF; } \\
\text { DUFLUO, (2008) }\end{array}$ \\
\hline ABC Method & $\begin{array}{l}\text { O ABC Method é um método utilizada basicamente para dar suporte ao processo de tomada de decisão em uma } \\
\text { estratégia de reciclagem e simplificar a avaliação das estruturas do produto. A proposta dos autores é utilizar uma } \\
\text { classificação de três categorias (ABC) de sub-montagem: Categoria A - reuso dos produtos com altos custos de } \\
\text { manufatura, longos ciclos de vida e longos ciclos de inovação; Categoria B - processamento especial que envolve } \\
\text { misturas complexas, ciclos de vida e ciclos de inovação pequenos; e a Categoria C que é a sub-montagem de } \\
\text { material reciclado com tecnologia existente, caracterizada pelos baixos custos de produção, grandes volumes e }\end{array}$ & $\begin{array}{l}\text { ALTING; } \\
\text { LEGARTH, } \\
\text { (1995) }\end{array}$ \\
\hline
\end{tabular}




\begin{tabular}{|c|c|c|}
\hline Nome & Resumo & Referência \\
\hline & baixos custos de materiais. & \\
\hline $\begin{array}{l}\text { Computer Tool for } \\
\text { Selection of Fastening } \\
\text { and Joining Methods }\end{array}$ & $\begin{array}{l}\text { O Computer Tool for Selection of Fastening and Joining Methods é uma ferramenta utilizada para estimar os } \\
\text { custos de produção, montagem, manutenção, remanufatura e reciclagem de acordo com os métodos de junção ou } \\
\text { fixação selecionados. Ajuda a determinar os requisitos funcionais e calcular as forças e condições de operação das } \\
\text { aplicações específicas. Inicialmente utiliza informações relacionadas ao produto, componentes das junções e } \\
\text { fixações (baseados na geometria de junção) e a aplicação de forças. É usada para calcular os custos de conexão dos } \\
\text { materiais, desmontagem e montagem, e estimar a probabilidade e as conseqüências de falhas das partes } \\
\text { substituídas com os métodos de junção ou fixação. } \\
\text { Para estimar os custos de vida é considerado uma parcela do custo de produção e o primeiro custo de montagem, } \\
\text { que é determinado pelo tipo e a quantidade de componentes de junção e fixação necessários para alcançar os } \\
\text { requisitos específicos do produto. Também é considerado o custo de reciclagem que inclui os custos de extração } \\
\text { do material introduzido pelo método de fixação que não é compatível para ser reciclado com a peça do material ou } \\
\text { a separação de partes construídas com diferentes materiais. Neste caso, o custo de reprocesso deve ser incluído. O } \\
\text { custo de manutenção é relacionado com as despesas de desmontagem e remontagem dos componentes. Valores } \\
\text { monetários que representam o tempo requerido (mão-de-obra) de cada atividade realizada para substituir as peças } \\
\text { defeituosas. O custo de remanufatura do método de fixação é calculado a partir das despesas relacionadas à } \\
\text { desmontagem, remontagem e à probabilidade de falhas das partes fixadas. }\end{array}$ & $\begin{array}{l}\text { SHU; } \\
\text { FLOWERS, } \\
\text { (1995) }\end{array}$ \\
\hline $\begin{array}{c}\text { Conceptual } \\
\text { Disassembly Model } \\
\text { (CDM) }\end{array}$ & $\begin{array}{l}\text { O Conceptual Disassembly Model (CDM) pode ser usado nas primeiras fases de construção do design do produto. } \\
\text { É uma ferramenta que considera os requisitos ambientais, objetivos de desmontagem, os principais componentes } \\
\text { do produto e a integração das funções. Permite estimar o peso global e os materiais dos principais componentes, } \\
\text { definir as estratégias de fim de vida e uma visão futura da solução adotada para a desmontagem do produto. A } \\
\text { principal proposta da ferramenta é melhorar a desmontagem de componentes por seqüências identificadas. Os } \\
\text { autores sugerem usar o Simplified Functional Block Diagram (SFBD) para construir o primeiro diagrama da } \\
\text { estrutura funcional do produto, representação gráfica que dá suporte a análise da transição da estrutura funcional } \\
\text { para a estrutura técnica do produto. }\end{array}$ & $\begin{array}{l}\text { ZWOLINSKI; } \\
\text { SGHAIER; } \\
\text { BRISSAUD; } \\
\text { (2007) }\end{array}$ \\
\hline $\begin{array}{c}\text { Design-for- } \\
\text { Environment } \\
\text { Evaluation Tool } \\
\text { (D4N) }\end{array}$ & $\begin{array}{l}\text { O Design-for-Environment Evaluation Tool (D4N) é uma ferramenta de ecodesign que além da análise do ciclo de } \\
\text { vida inclui a avaliação econômica e ambiental do design do produto. Além disso, permite construir um guideline } \\
\text { para o re-design, algumas das orientações são incorporadas pela ferramenta com o objetivo de semi-automatizar o } \\
\text { processo de re-design. Os dados são armazenados no sistema CAD e extraídos automaticamente em gráficos } \\
\text { (desenhos) que proporcionam a seqüência de desmontagem, indicando a seqüência para remover as partes e quais } \\
\text { são as partes mais importantes ambiental e economicamente. O objetivo é evitar desmontagens desnecessárias no }\end{array}$ & $\begin{array}{c}\text { MURTAGH; } \\
\text { BAMBA; } \\
\text { IWAMA (1999); } \\
\text { PIGOSSO et al. }\end{array}$ \\
\hline
\end{tabular}




\begin{tabular}{|c|c|c|}
\hline Nome & Resumo & Referência \\
\hline
\end{tabular}




\begin{tabular}{|c|c|c|}
\hline Nome & Resumo & Referência \\
\hline Disassembly Index & $\begin{array}{l}\text { O método Dissassembly Index descreve uma série de regras para construir um plano de desmontagem e propõe um } \\
\text { modelo para a avaliação da desmontagem do produto na fase final de vida. Os principais pontos destacados pelos } \\
\text { autores para o processo de implantação são: determinar o índice de desmontagem (Disassembly Index - ID), que é } \\
\text { dado pelo índice que contabiliza (IC) a soma do número de partes, uniões, tipos de materiais e níveis (hierarquia) } \\
\text { de desmontagem; a soma das unidades que serão desmontadas (disassembly difficulty - DDU) e a soma de todas as } \\
\text { mudanças de direções (possibilidades) para a desmontagem (change of direction of dismount - DDH) do produto. } \\
\text { A lógica de análise é que quanto maior o resultado da solução será pior a avaliação da desmontagem do produto. É } \\
\text { proposto também que sejam avaliadas outras relações / índices como, por exemplo: a relação entre o número de } \\
\text { uniões e componentes; o número de materiais e o número de componentes; o número máximo de níveis } \\
\text { hierárquicos e o número de componentes; as dificuldades de desmontagem e o número de uniões; e as mudanças } \\
\text { nas direções de desmontagem e o número de uniões. Neste caso, quanto menor sejam os valores das relaçôes } \\
\text { melhor será a solução do projeto de desmontagem. Outra proposta dos autores é incorporar dados novos na base de } \\
\text { dados do sistema, tais como: tipos de uniões, materiais e projetos (soluções). A idéia é que na fase de seleção das } \\
\text { soluções essa base de dados seja usada para consultar e construir os principais projetos de desmontagem. } \\
\text { Especificamente, são necessários os seguintes elementos: componentes do produto (processo de manufatura, } \\
\text { material, peso e direções de desmontagem: direita, esquerda, acima, embaixo, horizontal ou vertical), } \\
\text { características das uniões ( tipo de material, dificuldade e tempo de desmontagem) e tipo de material (custo, } \\
\text { possibilidade de reciclagem, hierarquia e dificuldade para desmontagem do produto). O relatório final apresentará } \\
\text { informações de cada projeto avaliado: número de componentes, elementos de união, materiais usados no projeto e } \\
\text { o número de níveis hierárquicos. }\end{array}$ & $\begin{array}{c}\text { POSSAMAI; } \\
\text { VALENTINA, } \\
\text { (2007) }\end{array}$ \\
\hline $\begin{array}{l}\text { Dissassembly- } \\
\text { Planning-System } \\
\text { (DisPlay) }\end{array}$ & $\begin{array}{l}\text { A proposta do Dissassembly-Planning-System (DisPlay) é determinar a melhor opção de desmontagem dos } \\
\text { produtos em termos econômicos. A avaliação é baseada inicialmente no Modelo de Produto criado no sistema } \\
\text { Recycling-Graph-Editor (ReGred), que fornece uma análise de todas as possibilidades para realizar conexões. Na } \\
\text { avaliação das opções de desmontagem é definida principalmente a composição dos materiais, que pode ser } \\
\text { avaliada a partir de cenários virtuais ou reais de reciclagem de materiais. As combinações de materiais são } \\
\text { avaliadas e ordenadas conforme o número total de potenciais benefícios (lucratividade e elevado nível de } \\
\text { desmontagem). Em seguida, são apresentas as possíveis opç̃̃es de reciclagem e os custos de desmantelamento. O } \\
\text { ganho total (lucratividade) é a diferença entre o lucro derivado da reciclagem menos o custo de desmantelamento. }\end{array}$ & $\begin{array}{l}\text { ROSEMANN, et } \\
\text { al (1999); } \\
\text { FELDMANN; } \\
\text { TRAUTNER; } \\
\text { MEEDT, (1999). }\end{array}$ \\
\hline
\end{tabular}




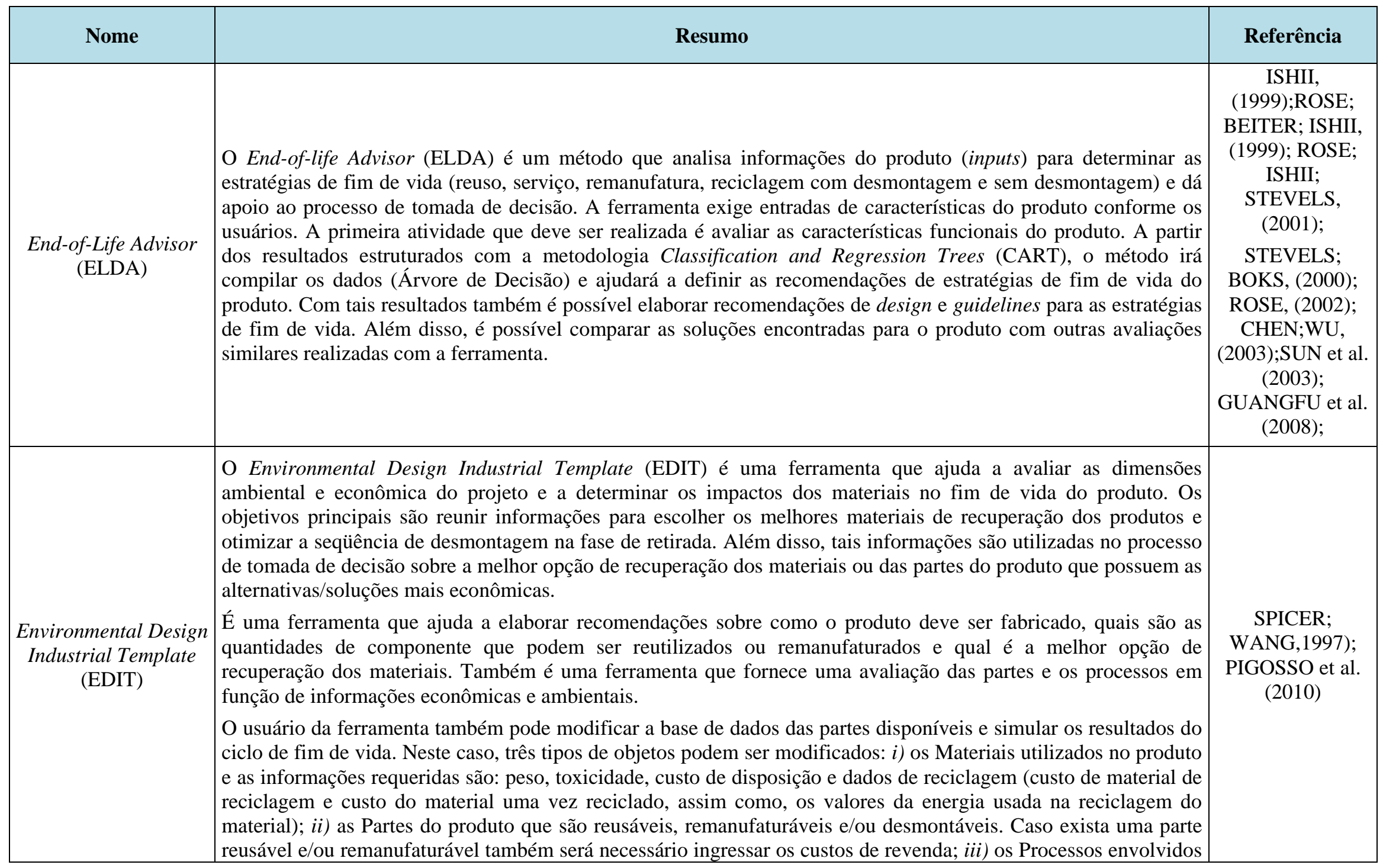




\begin{tabular}{|c|c|c|}
\hline Nome & Resumo & Referência \\
\hline $\begin{array}{c}\text { Environmental Design } \\
\text { Support Tool (EDST) }\end{array}$ & $\begin{array}{l}\text { O Environmental Design Support Tool (EDST) é uma ferramenta utilizada para construir um modelo de } \\
\text { desmontagem e visa auxiliar o desenvolvimento de produtos nas fases iniciais, principalmente, nas questões } \\
\text { relacionadas com sustentabilidade ambiental. } \\
\text { Os autores apresentam quatro (4) fases para realizar o projeto de avaliação do produto. A primeira é designada } \\
\text { como construção do modelo de desmontagem e será considerada como base para as outras três avaliações. Nesta } \\
\text { fase são apresentados dados relacionados com o produto e o inventário ambiental dos materiais (Environmental } \\
\text { Material Inventory - EMI). Tais dados são usados nas análises de desmontagem, materiais e reciclabilidade dos } \\
\text { materiais utilizados no produto. A segunda fase é designada de análise de desmontagem e refere-se à facilidade de } \\
\text { desmontar um produto no fim de vida com um baixo custo (nem sempre a desmontagem é a opção mais viável). } \\
\text { São reunidos dados relacionados com o número de componentes, o tempo de desmontagem e definido um índice } \\
\text { para avaliar o grau de dificuldade da desmontagem. A terceira fase consiste na avaliação de materiais e elaboração } \\
\text { de sugestões para melhoria. É elaborado um questionário geral com o formato de guideline e são incluídos o } \\
\text { checklist e as diversas alternativas para a seleção de materiais. Os principais índices utilizados são: peso total do } \\
\text { produto, o peso total com distintos tipos de materiais, o número total de materiais perigosos e materiais recicláveis. } \\
\text { Na última fase é realizada a avaliação da Reciclabilidade, cuja atividade é realizada para determinar os esforços } \\
\text { necessários para a gestão dos resíduos e o controle da poluição dos materiais. } \\
\text { A partir dessas análises são apresentadas / selecionadas as diversas alternativas de fim de vida do produto como, } \\
\text { por exemplo: reuso, remanufatura, reciclagem para material de alto grau de impacto ambiental, reciclagem para } \\
\text { material de baixo grau de impacto ambiental, incineração para gerar energia e disposição final. }\end{array}$ & $\begin{array}{c}\text { ZHANG; } \\
\text { ERTAS, (1999); } \\
\text { PIGOSSO et al. } \\
\text { (2010) }\end{array}$ \\
\hline $\begin{array}{c}\text { Environmental Value } \\
\text { Chain Analysis } \\
\text { (EVCA) }\end{array}$ & $\begin{array}{l}\text { A Environmental Value Chain Analysis (EVCA) é construída com base nos conceitos propostos pela ferramenta } \\
\text { Customer Value Chain Analysis (CVCA) - cujo objetivo é identificar os interesses pertinentes aos consumidores } \\
\text { finais e stakeholders. A proposta é integrar e fortalecer as relações entre os produtores, consumidores, governo e } \\
\text { recicladores, isto é, os stakeholders internos e externos que influenciam o processo de tomada de decisão } \\
\text { (implantação) da estratégia de fim de vida dos produtos. Além disso, é utilizada para avaliar as diferenças das } \\
\text { estratégias disponíveis para implantar um sistema de fim de vida dos produtos. A avaliação é realizada com base } \\
\text { na matriz de correlações. A principal função dessa matriz é descrever os diferentes fluxos de informação (valor } \\
\text { ambiental) relacionados com as perspectivas dos stakeholders sobre os novos produtos. }\end{array}$ & $\begin{array}{c}\text { ROSE (2000); } \\
\text { ROSE; ISHII; } \\
\text { STEVELS, } \\
\text { (2001) }\end{array}$ \\
\hline
\end{tabular}




\begin{tabular}{|c|c|c|}
\hline Nome & Resumo & Referência \\
\hline $\begin{array}{c}\text { Guidelines for } \\
\text { Designer avoid } \\
\text { Potential } \\
\text { Remanufacturing }\end{array}$ & $\begin{array}{l}\text { O Guidelines for Designer avoid Potential Remanufacturing é uma ferramenta que proporciona guidelines para } \\
\text { identificar e avaliar as denominadas causas-raízes ou obstáculos/aspectos que podem afetar o produto e } \\
\text { conseqüentemente o desempenho da estratégia de remanufatura do produto. As causas-raízes são agrupadas em } \\
\text { quatro categorias: i) aspectos que recebem múltiplas influências (falta de atendimento aos padrões de segurança do } \\
\text { uso do produto, abuso das funções do produto, contaminação, logística de remanufatura e manipulação imprópria); } \\
\text { ii) Etapas de remanufatura (problemas nas atividades de montagem, desmontagem e recondicionamento); iii) } \\
\text { Condições de Trabalho do Produto; e iv) Características Específicas do Projeto. } \\
\text { Além de identificar os obstáculos do processo de remanufatura também são reunidos os motivos que promovem a } \\
\text { ocorrência das causas-raízes. A análise dessas informações fornece soluções para melhorar e facilitar o projeto de } \\
\text { remanufatura do produto. }\end{array}$ & $\begin{array}{l}\text { WILLIAMS; } \\
\text { SHU,(2001). }\end{array}$ \\
\hline
\end{tabular}




\begin{tabular}{|c|c|c|}
\hline Nome & Resumo & Referência \\
\hline & $\begin{array}{l}\text { calcular os valores econômicos de desempenho da desmontagem e reciclagem (Integrated Disassembly and } \\
\text { Recycling Score - IDRS) para cada alternativa do projeto, incluindo o produto original; e iii) selecionar como } \\
\text { melhor solução econômica de redução de resíduos para o projeto do produto a alternativa com maior valor de } \\
\text { IDRS. }\end{array}$ & \\
\hline $\begin{array}{c}\text { Guidelines for } \\
\text { Remanufacturing }\end{array}$ & $\begin{array}{l}\text { O Guidelines for Remanufacturing é um método proposto para desenvolver projetos de produtos focados na } \\
\text { remanufatura. A proposta dos autores foi elaborada a partir de um workshop realizado para coletar e discutir } \\
\text { informações (brainstorming) relacionadas com a prática de desmontagem de produtos ou fatores chaves que } \\
\text { influenciam a remanufatura. A atividade foi dividida em três partes: introdução ou sessão de conhecimento, } \\
\text { atividades em grupo e apresentação e registros das idéias / soluções de cada grupo que participou do encontro. } \\
\text { As principais recomendações apontadas para a concepção de produtos remanufaturáveis são: evitar características } \\
\text { no projeto que impedem o retorno do produto ou componentes para as mesmas funcionalidades / condições de um } \\
\text { novo, isto incluí materiais não-duráveis, tecnológicas que impedem a separação dos componentes, características } \\
\text { que impedem a melhoria ou requerem substâncias proibidas ou métodos de processamento, e características } \\
\text { funcionais que tornam inviáveis economicamente a recuperação das funções dos produtos ou componentes. }\end{array}$ & $\begin{array}{l}\text { IJOMAH; et al. } \\
\text { (2007a); } \\
\text { IJOMAH; et al. } \\
\quad \text { (2007b). }\end{array}$ \\
\hline $\begin{array}{c}\text { Guidelines-rules for } \\
\text { design for } \\
\text { Disassembly }\end{array}$ & $\begin{array}{l}\text { O Guidelines-rules for design for Disassembly descreve um conjunto de regras que podem ser utilizadas como } \\
\text { referências para construir o projeto de desmontagem dos produtos. As principais recomendações são relacionadas } \\
\text { para atender os seguintes aspectos: Reduzir o número de atividades de desmontagem; Configuração do produto; } \\
\text { Fácil desmontagem; Fácil manipulação; Fácil separação de materiais; e Redução da variabilidade (Padronização). }\end{array}$ & $\begin{array}{l}\text { ALTING; } \\
\text { LEGARTH, } \\
\text { (1995). }\end{array}$ \\
\hline $\begin{array}{c}\text { Ideal-eco-product } \\
\text { Approach }\end{array}$ & $\begin{array}{l}\text { A metodologia Ideal-eco-product Approach é utilizada para desenvolver produtos com uma abordagem ambiental } \\
\text { denominada de eco-produto ideal (ideal-eco-product). A idéia é conceber um produto (versão extrema) e unificar } \\
\text { as características que atendem os critérios ou requisitos ambientais específicos. } \\
\text { Para introduzir o conceito é proposta uma metodologia de seis passos: i) Determinar as funções primárias e } \\
\text { secundárias do produto. Nesta etapa, serão analisadas as necessidades dos clientes e são contempladas as funções } \\
\text { primárias e secundárias do produto; ii) Identificar as possibilidades tecnológicas que podem atender a função } \\
\text { primária do produto. Tais soluções tecnológicas devem ser incorporadas / transferidas como características ou } \\
\text { idéias técnicas para o produto; iii) Investigar os impactos ambientais (a geração de resíduos, o elevado consumo de } \\
\text { água e energia etc.) que pode causar a transferência das tecnologias; iv) Desenvolver as versões extremas do } \\
\text { produto, cada uma será uma alternativa que pode ser adotada para minimizar os impactos ambientais causados em } \\
\text { uma área específica, i.e, para reduzir o uso de recursos materiais podem ser utilizadas técnicas de reciclagem ou } \\
\text { remanufatura, um dos principais resultados desta etapa é uma lista de soluções tecnológicas que minimizam os }\end{array}$ & NISSEN,(1995) \\
\hline
\end{tabular}




\begin{tabular}{|c|c|c|}
\hline Nome & Resumo & Referência \\
\hline $\begin{array}{l}\text { Metrics for Assessing } \\
\text { Remanufacturability }\end{array}$ & $\begin{array}{l}\text { O objetivo do modelo de Metrics for Assessing Remanufacturability é proporcionar (feedback) métricas eficientes } \\
\text { (rápidas) e efetivas (integradas e exatas) sobre a remanufaturabilidade de um produto. As métricas propostas pelos } \\
\text { autores são construídas utilizando como base as características propostas para construir projetos de montagem de } \\
\text { produtos (Design for Assembly - DFA). Especificamente, a estrutura das métricas é definida a partir de oito } \\
\text { processos genéricos de remanufatura: montagem, desmontagem, teste, reparação, limpeza, inspeção, } \\
\text { recondicionamento e substituição - que pode ser dividida em substituição básica e substituição chave (designada } \\
\text { para as principais partes de remanufatura e considerada como um processo crítico de avaliação - índice de nível } \\
\text { 1). Para os outros processos são propostas quatro categorias de métricas de avaliação interdependentes, com } \\
\text { diferentes pesos e classificadas de índices de nível 2: Partes de interfase (métricas de desmontagem e montagem) - } \\
\text { 30\%; Garantia da qualidade (métricas de teste e inspeção) - 5\%; Correção de danos (métricas de substituição } \\
\text { básica, reparo e recondicionamento) - } 40 \% \text { e Limpeza } 25 \% \text {. } \\
\text { As principais variáveis utilizadas no cálculo das métricas de desempenho podem ser destacadas: o numero de } \\
\text { partes do produto a ser avaliado, número de partes ideal para o produto, número de peças recondicionadas, número } \\
\text { de partes substituídas, número de partes chaves, número de partes chaves substituídas, números de testes, número } \\
\text { ideal de inspeções, score de limpeza, tempo de desmontagem, de montagem e tempo total. O índice de } \\
\text { remanufaturabilidade é obtido por meio do índice da métrica de substituição chave e o índice calculado a partir das } \\
\text { métricas de avaliação das categorias. }\end{array}$ & $\begin{array}{c}\text { BRAS; } \\
\text { HAMMOND, } \\
\text { (1996). }\end{array}$ \\
\hline Module Configurator & $\begin{array}{l}\text { O module configurator é uma ferramenta utilizada para desenvolver projetos de produtos modulares que facilitem } \\
\text { a remanufatura. A idéia básica é avaliar todas as configurações possíveis de módulos a partir de modules drives } \\
\text { (módulos de direção) e o target scheme que é caracterizado por uma variável de peso relacionada com os módulos } \\
\text { de direção que são atribuídos a cada uma das fases do ciclo de vida do produto. Conseqüentemente, as mudanças } \\
\text { que ocorrem no target scheme alteram a configuração do módulo. A idéia é alterar o target scheme focando o } \\
\text { reuso de materiais e facilitar a remanufatura. } \\
\text { Os módulos de direção são identificados a partir da análise e comparação de produtos modulares e não modulares } \\
\text { e integrados com as diferentes fases do ciclo de vida do produto: tempo de entrada do produto no mercado }\end{array}$ & $\begin{array}{c}\text { SELIGER; } \\
\text { WEINERT; } \\
\text { ZETTL,(2007) }\end{array}$ \\
\hline
\end{tabular}




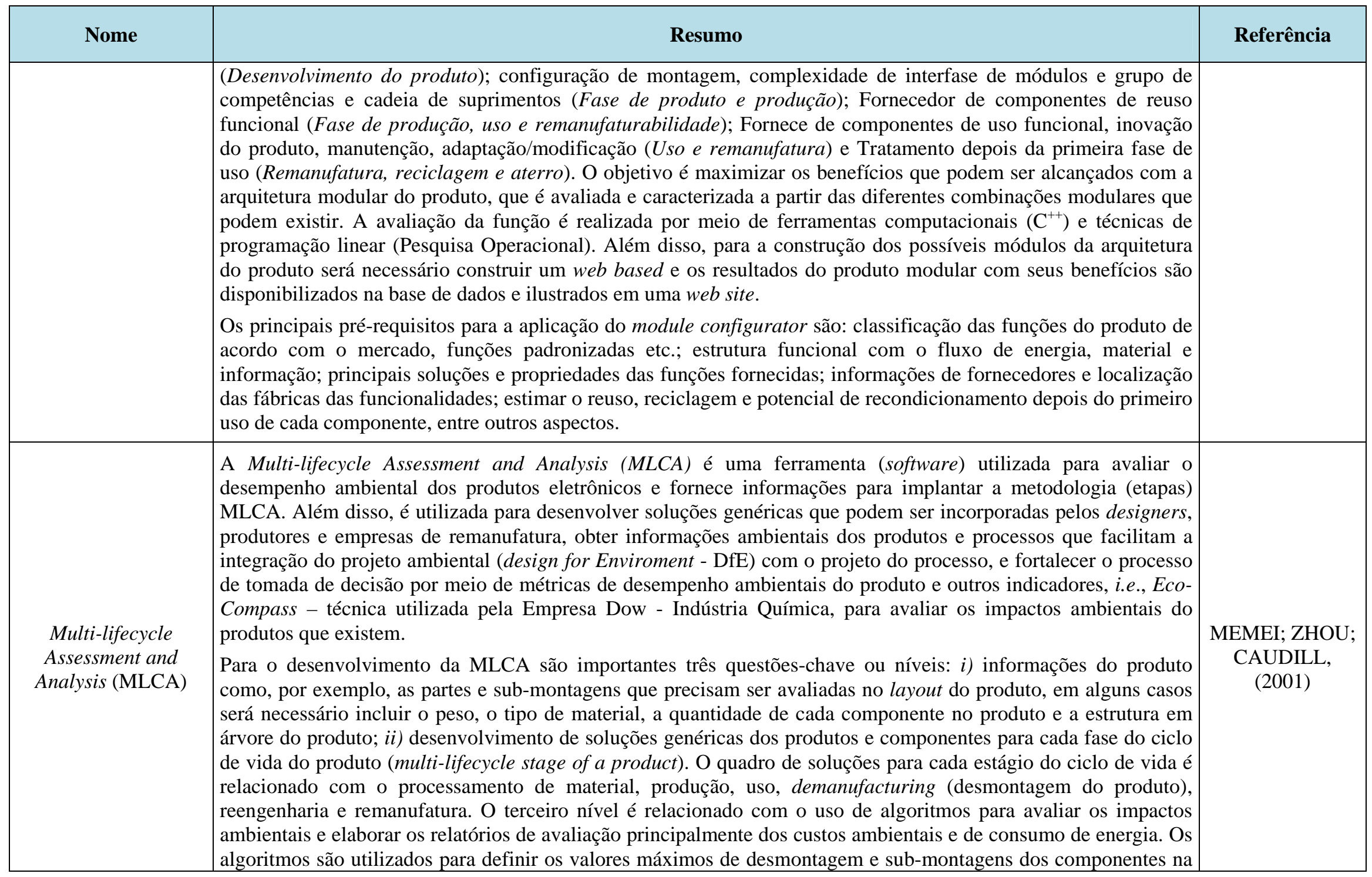




\begin{tabular}{|c|c|c|}
\hline Nome & Resumo & Referência \\
\hline ProdTect & $\begin{array}{l}\text { A proposta dos autores é introduzir um processo de remanufatura para produtos eletrônicos (monitor) e envolve } \\
\text { três passos: análise dos dados do produto (estrutura do produto) e instalações, elaboração do projeto das fases do } \\
\text { processo de remanufatura e a otimização das atividades relacionadas com o processo de remanufatura. } \\
\text { Especificamente, o ProdTect é uma ferramenta computacional (software comercial) que dá suporte a análise da } \\
\text { estrutura do produto. Fornece informações para o desenvolvimento ecológico de produtos e com isso poder } \\
\text { antecipar nas primeiras fases do desenvolvimento do produto a tomada de decisão relacionada com as estratégias } \\
\text { de reciclagem e tratamentos de materiais utilizados. As principais entradas do software são: informações das partes } \\
\text { (material, movimento de desmontagem, dimensões, acessibilidade, forma etc.), informações das conexões } \\
\text { utilizadas na montagem do produto e informações das partes prioritárias no desmantelamento do produto. } \\
\text { A ferramenta proporciona os cálculos dos parâmetros técnicos, econômicos e ambientais. São descritos os } \\
\text { resultados relacionados com os tempos de desmontagem, seqüência, custos de reciclagem e taxas de recuperação. } \\
\text { Tais informações podem ser utilizadas para o planejamento do processo de fim de vida de produtos, implantar o } \\
\text { processo de remanufatura e construir algoritmos de otimização. }\end{array}$ & $\begin{array}{l}\text { KERNBAUM et } \\
\text { al. (2009) }\end{array}$ \\
\hline
\end{tabular}




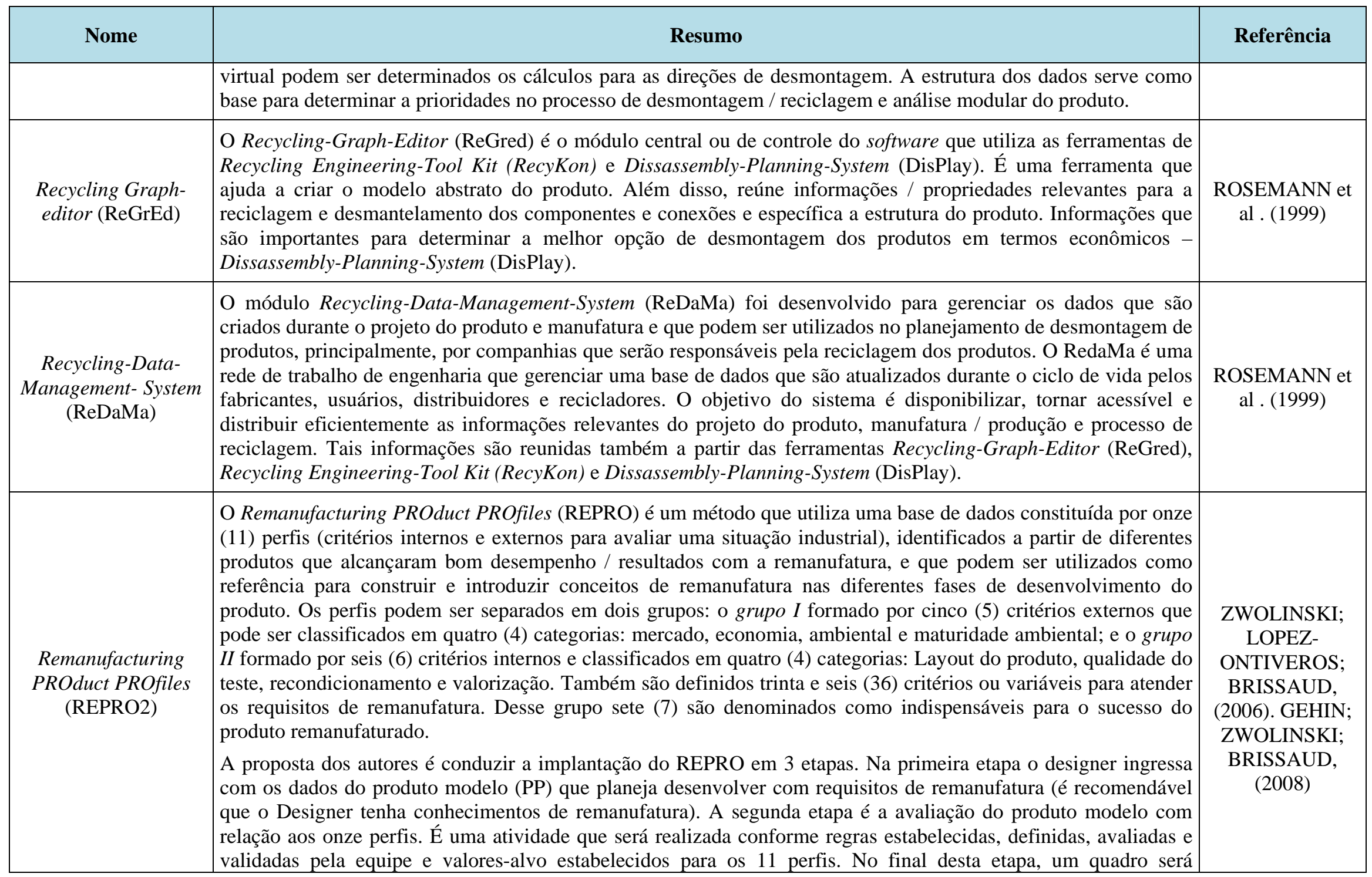




\begin{tabular}{|c|c|c|}
\hline Nome & Resumo & Referência \\
\hline RemPro Matrix & $\begin{array}{l}\text { A RemPro Matrix ilustra por meio de uma matriz as relação entre os passos do processo de remanufatura } \\
\text { (Inspeção, limpeza, desmontagem, armazenagem, reprocessamento, remontagem, teste) com as propriedades dos } \\
\text { produtos para que sejam remanufaturados (Facilidade de identificação, facilidade de verificação, facilidade de } \\
\text { acesso, facilidade de manuseio, facilidade de separação, facilidade de segurança, facilidade de alinhamento, } \\
\text { facilidade de estocagem, resistência ao desgaste). A RemPro Matrix também pode ser usada como ferramenta do } \\
\text { projeto do produto para introduzir as características ou propriedades necessárias que atendam as diferentes fases } \\
\text { do processo de remanufatura. }\end{array}$ & $\begin{array}{l}\text { SUNDIN, 2004; } \\
\text { SUNDIN, 2005; } \\
\text { SUNDIN, 2008; }\end{array}$ \\
\hline $\begin{array}{l}\text { Streamlined Life } \\
\text { Cycle Assessment } \\
\text { (SLCA) }\end{array}$ & $\begin{array}{l}\text { O Streamlined Life Cycle Assessment (SLCA) é uma ferramenta de avaliação do ciclo de vida do produto } \\
\text { (Extração de materiais, Manufatura e Montagem, Uso e fim-de-vida) construída a partir da técnica de Life Cycle } \\
\text { Assessment (LCA). A SLCA permite construir indicadores para avaliar o desempenho ambiental dos produtos ao } \\
\text { longo do seu ciclo de vida, mensurar os impactos ambientais nas diferentes fases do ciclo de vida, os impactos dos } \\
\text { diferentes componentes e os impactos dos componentes nas fases específicas do ciclo de vida. } \\
\text { A proposta dos autores é utilizar diferentes níveis de estratégias para o ciclo de vida dos produtos e componentes. } \\
\text { Para o nível de componentes e produtos, além das estratégias de fim de tubo (End-of-pipe): incineração e } \\
\text { disposição em aterros sanitários, também podem ser utilizadas estratégias de fim de vida de recuperação: reuso, } \\
\text { remanufatura e reciclagem. A avaliação das alternativas ou a identificação dos impactos dos componentes em cada } \\
\text { uma das fases do ciclo de vida do produto é realizada com o apoio do software Simapro 6. A avaliação dos } \\
\text { impactos fornece informações sobre os componentes que apresentam maior impacto e a ajudam a redefinir a } \\
\text { estratégia conforme os materiais, processos, transporte, distância, canais de distribuição, canais de coleta etc. } \\
\text { utilizados no produto. }\end{array}$ & $\begin{array}{c}\text { GEHIN; } \\
\text { ZWOLINSKI; } \\
\text { BRISSAUD, } \\
\text { (2007). }\end{array}$ \\
\hline Tool Decision & $\begin{array}{l}\text { A Tool Decision é uma ferramenta que auxilia no processo de tomada de decisão das estratégias de fim de vida de } \\
\text { um produto. Inicialmente, será criado um amplo portfólio de produto que inclui o reuso, a reciclagem e a } \\
\text { disposição dos componentes do produto. No modelo são considerados dos tipos básicos de componentes: com } \\
\text { multi-atributos e limitações nas funções. O objetivo do modelo de decisão é otimizar ou maximizar a utilidade do } \\
\text { conjunto inteiro do produto em linha. Cada componente é modelado para dois períodos relacionados com o ciclo } \\
\text { de vida. O primeiro período inclui a aquisição de materiais, manufatura e montagem do produto com novos }\end{array}$ & SUN et al. (2003) \\
\hline
\end{tabular}




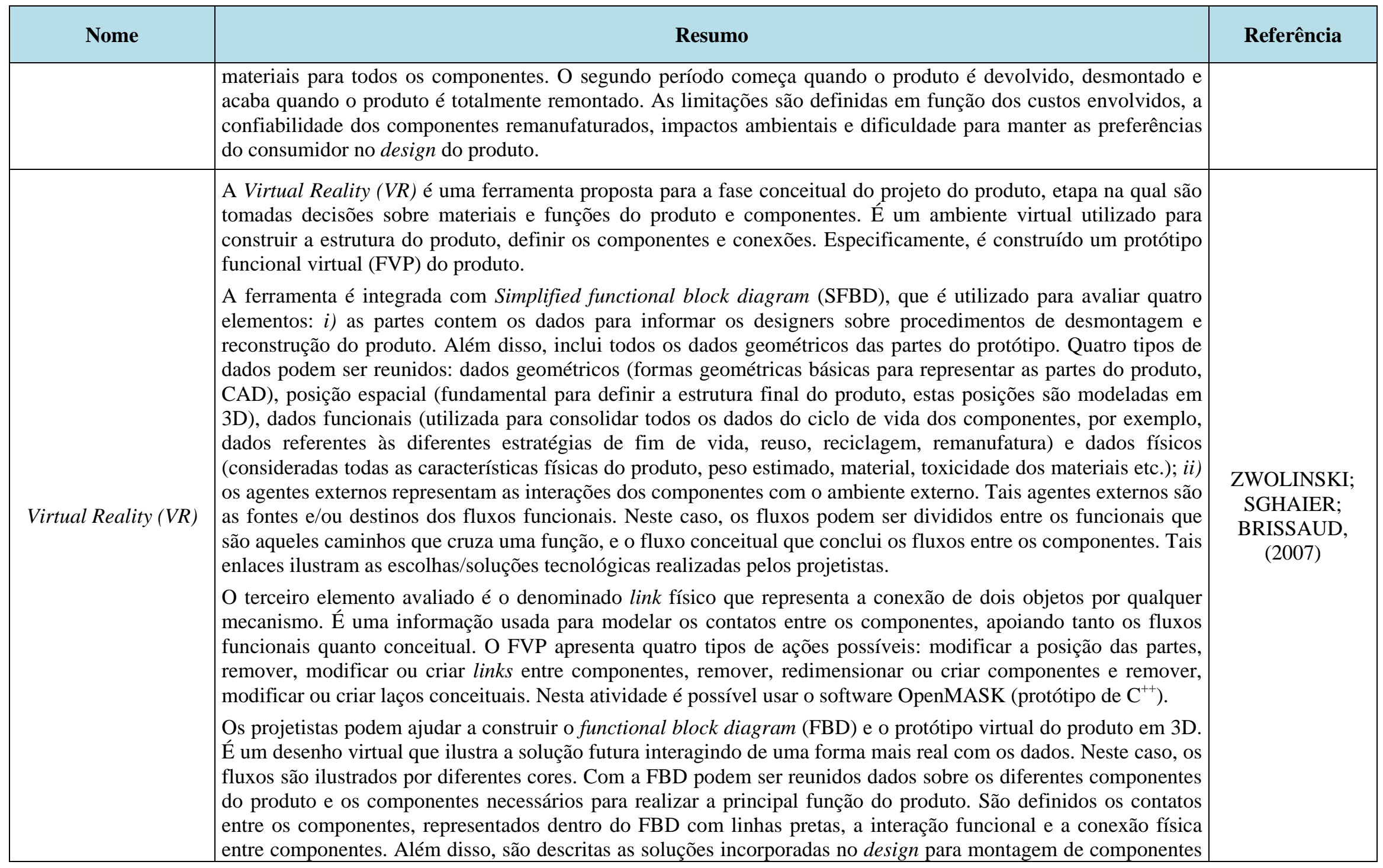




\begin{tabular}{|l|l|l|}
\hline Nome & Resumo & Referência \\
\hline & ou para posições e representadas dentro do diagrama com linha de cor verde. \\
\hline
\end{tabular}

Quadro 24 - Resumo das Práticas das Estratégias de Fim de Vida de Produtos 


\section{Apêndice G Classificação das Práticas Conforme o Procedimento Técnico Utilizado para a Avaliação do Produto}

\begin{tabular}{|c|c|c|c|c|c|}
\hline Nome & Checklist & Guideline & Matriz & Software & Outros Sistemas Associados \\
\hline $\begin{array}{l}\text { Method to asses the } \\
\text { adaptability of products } \\
\text { (MAAP) }\end{array}$ & & & & $\mathrm{X}$ & \\
\hline ABC Method & & & & $\mathrm{X}$ & \\
\hline AMETIDE & & & & $\mathrm{X}$ & \\
\hline $\begin{array}{l}\text { Analytic Network Process } \\
\text { (ANP) for Disassembly }\end{array}$ & & & & $\mathrm{X}$ & $\begin{array}{l}\text { Analytic network process } \\
\text { (ANP) }\end{array}$ \\
\hline $\begin{array}{l}\text { ATROiD (Assessment Tool } \\
\text { for Recycling Oriented } \\
\text { Design) }\end{array}$ & & & & $\mathrm{X}$ & \\
\hline $\begin{array}{l}\text { Cascade approach for } \\
\text { recycling }\end{array}$ & & $X$ & & & \\
\hline $\begin{array}{l}\text { Computer Tool for } \\
\text { selection of fastening and } \\
\text { joining methods }\end{array}$ & & & & $\mathrm{X}$ & \\
\hline $\begin{array}{l}\text { Conceptual Disassembly } \\
\text { Model (CDM) }\end{array}$ & & & & $\mathrm{X}$ & \\
\hline $\begin{array}{l}\text { CORA (object/ component } \\
\text { oriented requirements } \\
\text { analysis tool) }\end{array}$ & & & & $\mathrm{X}$ & $3 \mathrm{D}$ \\
\hline $\begin{array}{l}\text { CHAin management of } \\
\text { Materials and Products } \\
\text { (CHAMP) methodology }\end{array}$ & & & & $\mathrm{X}$ & LCA, DFE,LCC \\
\hline DAISY & & & & $\mathrm{X}$ & \\
\hline $\begin{array}{l}\text { DemAP (Dismantling } \\
\text { Analysis Program) }\end{array}$ & & & & $\mathrm{X}$ & \\
\hline DEMROP & & & & $\mathrm{X}$ & \\
\hline $\begin{array}{l}\text { Design and End-of-Life } \\
\text { Integration (DELII) }\end{array}$ & & & & $\mathrm{X}$ & \\
\hline Design Charts & & $\mathrm{X}$ & & & \\
\hline
\end{tabular}




\begin{tabular}{|c|c|c|c|c|c|}
\hline Nome & Checklist & Guideline & Matriz & Software & Outros Sistemas Associados \\
\hline $\begin{array}{l}\text { Design -for-environment } \\
\text { evaluation tool D4N }\end{array}$ & & $\mathrm{X}$ & & $\mathrm{X}$ & CAD, Eco-indicador \\
\hline DfD Compact & & & & $\mathrm{X}$ & \\
\hline DFE & & & & $\mathrm{X}$ & \\
\hline $\begin{array}{l}\text { Disassembly constract } \\
\text { graph (DCG) }\end{array}$ & & & & $\mathrm{X}$ & $3 \mathrm{D}$ \\
\hline Disassembly Index & & & & $\mathrm{X}$ & autoCAD \\
\hline $\begin{array}{l}\text { Dissassembly-Planning } \\
\text { system (DisPlay) }\end{array}$ & & & & $\mathrm{X}$ & \\
\hline DP3 & & & & $\mathrm{X}$ & \\
\hline Eco-Indicator & & & & $\mathrm{X}$ & \\
\hline Ecolist & $\mathrm{X}$ & & & & \\
\hline $\begin{array}{l}\text { ED (Environmental } \\
\text { Designer) }\end{array}$ & & & & $\mathrm{X}$ & \\
\hline ENDLESS & & & & & \\
\hline $\begin{array}{l}\text { End-of-life Advisor } \\
\text { (ELDA) }\end{array}$ & $\mathrm{X}$ & & & $\mathrm{X}$ & $\begin{array}{l}\text { CART (Classification and } \\
\text { Regression Trees) }\end{array}$ \\
\hline $\begin{array}{l}\text { Environmental Design } \\
\text { Industrial Template (EDIT) }\end{array}$ & & & & $\mathrm{X}$ & \\
\hline $\begin{array}{l}\text { Environmental Design } \\
\text { Support Tool (EDST) }\end{array}$ & $\mathrm{X}$ & $\mathrm{X}$ & & $\mathrm{X}$ & \\
\hline $\begin{array}{l}\text { Environmental Value Chain } \\
\text { Analysis (EVCA) }\end{array}$ & & & & & \\
\hline Green Design & & & & $\mathrm{X}$ & (CAD,PLM, ERP) \\
\hline Green Design Advisor & & & & $\mathrm{X}$ & \\
\hline Green Design Network & & $\mathrm{X}$ & & $\mathrm{X}$ & LCA, QFDE \\
\hline Grey Relational Analysis & & & & & \\
\hline $\begin{array}{l}\text { Guideline para Selection } \\
\text { Material }\end{array}$ & & $\mathrm{X}$ & & & \\
\hline $\begin{array}{l}\text { Guidelines for disassembly } \\
\text { EoL }\end{array}$ & & $\mathrm{X}$ & & & LCA \\
\hline $\begin{array}{l}\text { Guidelines for plastics } \\
\text { components }\end{array}$ & & $X$ & & & \\
\hline $\begin{array}{l}\text { Guidelines for design for } \\
\text { recycling }\end{array}$ & & $\mathrm{X}$ & & & \\
\hline
\end{tabular}




\begin{tabular}{|c|c|c|c|c|c|}
\hline Nome & Checklist & Guideline & Matriz & Software & Outros Sistemas Associados \\
\hline $\begin{array}{l}\text { Guidelines for Designer } \\
\text { avoid potential } \\
\text { remanufacturing }\end{array}$ & & $X$ & & & \\
\hline $\begin{array}{l}\text { Guidelines for Disassembly } \\
\text { and Recycling }\end{array}$ & & $\mathrm{X}$ & & & Design axiomático \\
\hline $\begin{array}{l}\text { Guidelines for } \\
\text { Remanufacturing }\end{array}$ & & $\mathrm{X}$ & & & \\
\hline $\begin{array}{l}\text { Guidelines-rules for design } \\
\text { for Disassembly }\end{array}$ & & $\mathrm{X}$ & & & \\
\hline $\begin{array}{l}\text { HOME (House of modular } \\
\text { enhancement-a toll for } \\
\text { modular product redesign) }\end{array}$ & & & & $\mathrm{X}$ & \\
\hline Ideal-eco-product approach & $\mathrm{X}$ & $\mathrm{X}$ & & & \\
\hline Impact 2002+ & $\mathrm{X}$ & & & & \\
\hline $\begin{array}{l}\text { LaySiD (Layout Simulation } \\
\text { for Disassembly) }\end{array}$ & & & & $\mathrm{X}$ & \\
\hline $\begin{array}{l}\text { Life Cycle Assesssment- } \\
\text { LCA }\end{array}$ & & & & $\mathrm{X}$ & \\
\hline $\begin{array}{l}\text { Life Cycle Custs Simplified } \\
\text { (LCC) }\end{array}$ & & & & $\mathrm{X}$ & \\
\hline Life cycle unit (LCU) & & & & $\mathrm{X}$ & \\
\hline LINKER & & & & $\mathrm{X}$ & \\
\hline $\begin{array}{l}\text { Matrix de conexão para } \\
\text { montagem e desmontagem } \\
\text { de produtos }\end{array}$ & & & & & \\
\hline $\begin{array}{l}\text { Método para avaliar a } \\
\text { Reciclagem de Materiais }\end{array}$ & & & & $\mathrm{X}$ & $\begin{array}{c}\text { LCA,analytical hierarchy } \\
\text { process (AHP), Excell }\end{array}$ \\
\hline $\begin{array}{l}\text { Metodologia de } \\
\text { desmontagem para fim de } \\
\text { vida dos produtos }\end{array}$ & & & & $\mathrm{X}$ & CAD, \\
\hline $\begin{array}{l}\text { Metodologia para } \\
\text { desmontagem de produtos }\end{array}$ & & $X$ & & & Algoritmo \\
\hline $\begin{array}{l}\text { Metodologia para } \\
\text { reciclagem e disposição de } \\
\text { produtos eletro-eletrônicos }\end{array}$ & & & & $\mathrm{X}$ & \\
\hline
\end{tabular}




\begin{tabular}{|c|c|c|c|c|c|}
\hline Nome & Checklist & Guideline & Matriz & Software & Outros Sistemas Associados \\
\hline $\begin{array}{l}\text { Metrics for Assessing } \\
\text { Remanufacturability }\end{array}$ & & & & & $\begin{array}{c}\text { Métricas para } \\
\text { remanufaturabilidade do } \\
\text { produto }\end{array}$ \\
\hline $\begin{array}{l}\text { Metrics for End-of-life } \\
\text { Strategies (ELSEIM) }\end{array}$ & & & & $\mathrm{X}$ & LCA, \\
\hline \multicolumn{6}{|l|}{$\begin{array}{l}\text { Modelo para o projeto de } \\
\text { desmontagem e reciclagem }\end{array}$} \\
\hline $\begin{array}{l}\text { Modelo para } \\
\text { reuso,remanufatura, } \\
\text { reciclagem e disposição de } \\
\text { componentes, }\end{array}$ & & & & $\mathrm{X}$ & $\begin{array}{c}\text { simaPro 4.0, modelos } \\
\text { matemáticos }\end{array}$ \\
\hline Module Configurator & & $X$ & & $\mathrm{X}$ & $\begin{array}{c}\text { CPLEX , MySQL,Webbased, } \\
\text { Web site }\end{array}$ \\
\hline $\begin{array}{l}\text { Multi-lifecycle Assessment } \\
\text { and Analysis (MLCA) }\end{array}$ & & & & $\mathrm{X}$ & $\begin{array}{c}\text { ProEngineer format, } \\
\text { Microsoft Access, Visual } \\
\text { Basic, CAD }\end{array}$ \\
\hline Planning Advisor & & & & $\mathrm{X}$ & \\
\hline $\begin{array}{l}\text { Processo de Planejamento } \\
\text { do Design }\end{array}$ & & $\mathrm{X}$ & & & \\
\hline ProdTect & & & & $\mathrm{X}$ & \\
\hline $\begin{array}{l}\text { Product life cycle planning } \\
(\mathrm{LCP})\end{array}$ & & & & $\mathrm{X}$ & LCPlanner \\
\hline $\begin{array}{l}\text { Product recovery } \\
\text { management system } \\
\text { (PRMS) }\end{array}$ & & & & $\mathrm{X}$ & IDEF0 \\
\hline $\begin{array}{l}\text { Product recovery } \\
\text { methodology }\end{array}$ & & & & $\mathrm{X}$ & \\
\hline ReAsCo & & & & $\mathrm{X}$ & \\
\hline Reciclability tool & & $\mathrm{X}$ & & $\mathrm{X}$ & indicadores \\
\hline $\begin{array}{l}\text { Recycling Engineering-Kit } \\
\text { (RecyKon) }\end{array}$ & & & & $\mathrm{X}$ & $\begin{array}{c}\text { ReGrEd (Recycling-Graph- } \\
\text { Editor) e CAD system, DIN } \\
8593\end{array}$ \\
\hline $\begin{array}{l}\text { Recycling Graph-editor } \\
\text { (ReGrEd) }\end{array}$ & & & & $\mathrm{X}$ & $\begin{array}{c}\text { DisPlay (Disassembly- } \\
\text { Planning-System) }\end{array}$ \\
\hline
\end{tabular}




\begin{tabular}{|c|c|c|c|c|c|}
\hline Nome & Checklist & Guideline & Matriz & Software & Outros Sistemas Associados \\
\hline $\begin{array}{l}\text { Recycling-Data- } \\
\text { Management- System } \\
\text { (ReDaMa) }\end{array}$ & & & & $\mathrm{X}$ & $\begin{array}{l}\text { DisPlay (Disassembly- } \\
\text { Planning System }\end{array}$ \\
\hline $\begin{array}{l}\text { REM (Recyclability } \\
\text { Evaluation Method) }\end{array}$ & & & & $\mathrm{X}$ & \\
\hline $\begin{array}{l}\text { Remanufacturing PROduct } \\
\text { PROfiles-REPRO2 }\end{array}$ & & & & $\mathrm{X}$ & \\
\hline RemPro Matrix & & & & & \\
\hline $\begin{array}{l}\text { ReSICLED Recovery } \\
\text { Systems modelling \& } \\
\text { Indicators calculation } \\
\text { Leading to End-of-life- } \\
\text { conscious Design }\end{array}$ & & & & $\mathrm{X}$ & \\
\hline Scatter search (SS) & & & & $\mathrm{X}$ & CAD \\
\hline Semi-quantitative pre-LCA & & & & $\mathrm{X}$ & \\
\hline $\begin{array}{l}\text { Streamlined Life Cycle } \\
\text { Assessment (SLCA) }\end{array}$ & & & & $\mathrm{X}$ & \\
\hline $\begin{array}{l}\text { The quotes for } \\
\text { environmentally weighted } \\
\text { recyclability (QWERTY) }\end{array}$ & $\mathrm{X}$ & & & $\mathrm{X}$ & $\begin{array}{l}\text { eco-indicator 95, LCA, Eco- } \\
\text { indicator 99, EPS } 2000 .\end{array}$ \\
\hline Tool Decision & & & & $\mathrm{X}$ & \\
\hline $\begin{array}{l}\text { Virtual Disassembly } \\
\text { Manager }\end{array}$ & & & & $\mathrm{X}$ & \\
\hline Virtual Reality (VR) & & & & $\mathrm{X}$ & CAD. \\
\hline Virtual reality technique & & & & $\mathrm{X}$ & $3 \mathrm{D}$ \\
\hline Web based system & & & & $\mathrm{X}$ & $\begin{array}{l}\text { JAVA, XML ( eXtensible } \\
\text { Markup Languaje), CAD, } \\
\text { Eco-indicator } 99\end{array}$ \\
\hline Web-based aplication & & & & $\mathrm{X}$ & $\begin{array}{c}\text { Java, HTML, VRML, Java } \\
\text { database connectivity } \\
\text { (JDBC),CAD }\end{array}$ \\
\hline $\begin{array}{l}\text { Web-enabled virtual } \\
\text { Disassembly Manager }\end{array}$ & & & & $\mathrm{X}$ & $3 \mathrm{D}$ \\
\hline
\end{tabular}

Quadro 25 - Classificação das práticas das Estratégias de Fim de Vida de Produtos conforme o Procedimento Técnico Utilizado para a Avaliação do Produto 


\section{Apêndice H Classificação das Práticas das Estratégias de Fim de Vida de Produtos Conforme a Nível Consolidação da Prática e o Setor de Aplicação}

\begin{tabular}{|c|c|c|c|c|}
\hline Nome & Alto & Medio & Baixo & Setor \\
\hline $\begin{array}{c}\text { Method to asses the } \\
\text { adaptability of products (MAAP) }\end{array}$ & & $\mathrm{X}$ & & eletro-eletrônicos \\
\hline ABC Method & & & X & Todos \\
\hline AMETIDE & & & X & \\
\hline $\begin{array}{l}\text { Analytic Network Process } \\
\text { (ANP) for Disassembly }\end{array}$ & & $X$ & & \\
\hline $\begin{array}{l}\text { ATROiD (Assessment Tool } \\
\text { for Recycling Oriented Design) }\end{array}$ & & $\mathrm{X}$ & & \\
\hline $\begin{array}{l}\text { Cascade approach for } \\
\text { recycling }\end{array}$ & & $\mathrm{X}$ & & construção-granito \\
\hline $\begin{array}{l}\text { Computer Tool for selection } \\
\text { of fastening and joining methods }\end{array}$ & & $\mathrm{X}$ & & $\begin{array}{l}\text { tonners de impressora, } \\
\text { fotocopiadoras }\end{array}$ \\
\hline $\begin{array}{l}\text { Conceptual Disassembly } \\
\text { Model (CDM) }\end{array}$ & & & $\mathrm{X}$ & \\
\hline $\begin{array}{l}\text { CORA (object/ component } \\
\text { oriented requirements analysis tool) }\end{array}$ & & & $\mathrm{X}$ & \\
\hline $\begin{array}{c}\text { CHAin management of } \\
\text { Materials and Products (CHAMP) } \\
\text { methodology }\end{array}$ & & $\mathrm{X}$ & & \\
\hline DAISY & & & $\mathrm{X}$ & \\
\hline $\begin{array}{l}\text { DemAP (Dismantling } \\
\text { Analysis Program) }\end{array}$ & & $\mathrm{X}$ & & Indústria Automótiva \\
\hline DEMROP & & & $\mathrm{X}$ & \\
\hline $\begin{array}{l}\text { Design and End-of-Life } \\
\text { Integration (DELII) }\end{array}$ & & $\mathrm{X}$ & & Não especificado \\
\hline Design Charts & & $\mathrm{X}$ & & eletro-eletrônicos \\
\hline
\end{tabular}




\begin{tabular}{|c|c|c|c|c|}
\hline Nome & Alto & Medio & Baixo & Setor \\
\hline $\begin{array}{l}\text { Design -for-environment } \\
\text { evaluation tool D4N }\end{array}$ & & $\mathrm{X}$ & & todos \\
\hline DfD Compact & & X & & \\
\hline DFE & & & X & \\
\hline $\begin{array}{l}\text { Disassembly constract } \\
\text { graph (DCG) }\end{array}$ & & $\mathrm{X}$ & & \\
\hline Disassembly Index & & & $X$ & \\
\hline $\begin{array}{l}\text { Dissassembly-Planning } \\
\text { system (DisPlay) }\end{array}$ & & & $X$ & \\
\hline DP3 & & & $X$ & \\
\hline Eco-Indicator & $\mathrm{X}$ & & & \\
\hline Ecolist & & & $\mathrm{X}$ & eletro-eletrônicos \\
\hline $\begin{array}{l}\text { ED (Environmental } \\
\text { Designer) }\end{array}$ & & & $\mathrm{X}$ & \\
\hline ENDLESS & & $\mathrm{X}$ & & \\
\hline $\begin{array}{l}\text { End-of-life Advisor } \\
\text { (ELDA) }\end{array}$ & & $\mathrm{X}$ & & eletro-eletrônicos \\
\hline $\begin{array}{l}\text { Environmental Design } \\
\text { Industrial Template (EDIT) }\end{array}$ & & & $\mathrm{X}$ & Não especificada \\
\hline $\begin{array}{l}\text { Environmental Design } \\
\text { Support Tool (EDST) }\end{array}$ & & $\mathrm{X}$ & & Não especificado \\
\hline $\begin{array}{l}\text { Environmental Value Chain } \\
\text { Analysis (EVCA) }\end{array}$ & & $\mathrm{X}$ & & eletro-eletrônicos \\
\hline Green Design & & $\mathrm{X}$ & & eletro-eletrônicos \\
\hline Green Design Advisor & & $\mathrm{X}$ & & \\
\hline
\end{tabular}




\begin{tabular}{|c|c|c|c|c|}
\hline Nome & Alto & Medio & Baixo & Setor \\
\hline Green Design Network & & $\mathrm{X}$ & & $\begin{array}{l}\text { eletro-eletrônicos, equipamentos } \\
\text { de oficina, móveis }\end{array}$ \\
\hline Grey Relational Analysis & & & X & \\
\hline $\begin{array}{l}\text { Guideline for Selection } \\
\text { Material }\end{array}$ & & $X$ & & \\
\hline $\begin{array}{l}\text { Guidelines for disassembly } \\
\text { EoL }\end{array}$ & & & $\mathrm{X}$ & \\
\hline $\begin{array}{l}\text { Guidelines for plastics } \\
\text { components }\end{array}$ & & $\mathrm{X}$ & & Plásticos \\
\hline $\begin{array}{l}\text { Guidelines for design for } \\
\text { recycling }\end{array}$ & & $\mathrm{X}$ & & máquina de lavar roupa \\
\hline $\begin{array}{r}\text { Guidelines for Designer } \\
\text { avoid potential remanufacturing }\end{array}$ & & $\mathrm{X}$ & & $\begin{array}{l}\text { motores elétricos, tonner de } \\
\text { impressora laser, válvulas e telefones }\end{array}$ \\
\hline $\begin{array}{l}\text { Guidelines for Disassembly } \\
\text { and Recycling }\end{array}$ & & & $\mathrm{X}$ & \\
\hline $\begin{array}{l}\text { Guidelines for } \\
\text { Remanufacturing }\end{array}$ & & $\mathrm{X}$ & & Não especificado \\
\hline $\begin{array}{l}\text { Guidelines-rules for design } \\
\text { for Disassembly }\end{array}$ & & & $\mathrm{X}$ & \\
\hline $\begin{array}{l}\text { HOME (House of modular } \\
\text { enhancement-a toll for modular } \\
\text { product redesign) }\end{array}$ & & & $\mathrm{X}$ & \\
\hline Ideal-eco-product approach & & $\mathrm{X}$ & & $\begin{array}{l}\text { Industria de linha Branca } \\
\text { (Máquinas de lavar roupa) }\end{array}$ \\
\hline Impact $2002+$ & & $\mathrm{X}$ & & \\
\hline $\begin{array}{l}\text { LaySiD (Layout Simulation } \\
\text { for Disassembly) }\end{array}$ & & & $\mathrm{X}$ & eletro-eletrônicos \\
\hline $\begin{array}{l}\text { Life Cycle Assesssment- } \\
\text { LCA }\end{array}$ & $\mathrm{X}$ & & & \\
\hline $\begin{array}{l}\text { Life Cycle Custs Simplified } \\
\text { (LCC) }\end{array}$ & & & $\mathrm{X}$ & \\
\hline Life cycle unit (LCU) & & $\mathrm{X}$ & & \\
\hline
\end{tabular}




\begin{tabular}{|c|c|c|c|c|}
\hline Nome & Alto & Medio & Baixo & Setor \\
\hline LINKER & & & X & \\
\hline $\begin{array}{l}\text { Matrix de conexão para } \\
\text { montagem e desmontagem de } \\
\text { produtos }\end{array}$ & & & $\mathrm{X}$ & Produtos Eletros-mecânico \\
\hline $\begin{array}{l}\text { Método para Avaliar a } \\
\text { Reciclagem de Materiais }\end{array}$ & $X$ & & & eletro-eletrônicos \\
\hline $\begin{array}{c}\text { Metodologia de } \\
\text { desmontagem para fim de vida dos } \\
\text { produtos }\end{array}$ & & $\mathrm{X}$ & & \\
\hline $\begin{array}{r}\text { Metodologia para } \\
\text { desmontagem de produtos }\end{array}$ & & & $X$ & eletro-eletrônicos \\
\hline $\begin{array}{l}\text { Metodologia para } \\
\text { reciclagem e disposição de produtos } \\
\text { eletro-eletrônicos }\end{array}$ & & & $\mathrm{X}$ & eletro-eletronicos \\
\hline $\begin{array}{l}\text { Metrics for Assessing } \\
\text { Remanufacturability }\end{array}$ & & X & & Automotivo e eletroeletrônico \\
\hline $\begin{array}{l}\text { Metrics for End-of-life } \\
\text { Strategies (ELSEIM) }\end{array}$ & & X & & eletro-eletrônicos \\
\hline $\begin{array}{l}\text { Modelo para o projeto de } \\
\text { desmontagem e reciclagem }\end{array}$ & & $\mathrm{X}$ & & \\
\hline $\begin{array}{c}\text { Modelo para } \\
\text { reuso,remanufatura, reciclagem e } \\
\text { disposição de componentes, }\end{array}$ & & $\mathrm{X}$ & & Eletro-eletrônicos \\
\hline Module Configurator & & $\mathrm{X}$ & & $\begin{array}{l}\text { não especificado (telefono } \\
\text { celular) }\end{array}$ \\
\hline $\begin{array}{l}\text { Multi-lifecycle Assessment } \\
\text { and Analysis (MLCA) }\end{array}$ & & X & & eletro-eletronicos \\
\hline Planning Advisor & & & X & eletro-eletrônicos \\
\hline $\begin{array}{l}\text { Processo de Planejamento } \\
\text { do Design }\end{array}$ & & $\mathrm{X}$ & & \\
\hline ProdTect & & & X & \\
\hline Product life cycle planning & & & & \\
\hline
\end{tabular}




\begin{tabular}{|c|c|c|c|c|}
\hline Nome & Alto & Medio & Baixo & Setor \\
\hline (LCP) & & & $\mathrm{X}$ & \\
\hline $\begin{array}{c}\text { Product recovery } \\
\text { management system (PRMS) }\end{array}$ & & $X$ & & \\
\hline $\begin{array}{l}\text { Product recovery } \\
\text { methodology }\end{array}$ & & $X$ & & \\
\hline ReAsCo & & & $X$ & \\
\hline Reciclability tool & & & X & \\
\hline $\begin{array}{l}\text { Recycling Engineering-Kit } \\
\text { (RecyKon) }\end{array}$ & & & X & Não especificado \\
\hline $\begin{array}{l}\text { Recycling Graph-editor } \\
\text { (ReGrEd) }\end{array}$ & & X & & Não especificado \\
\hline $\begin{array}{c}\text { Recycling-Data- } \\
\text { Management- System (ReDaMa) }\end{array}$ & & X & & Não especificado \\
\hline $\begin{array}{l}\text { REM (Recyclability } \\
\text { Evaluation Method) }\end{array}$ & & & $X$ & \\
\hline $\begin{array}{l}\text { Remanufacturing PROduct } \\
\text { PROfiles-REPRO2 }\end{array}$ & & $X$ & & $\begin{array}{l}\text { Industria de Cimento, Carro de } \\
\text { supermercado }\end{array}$ \\
\hline RemPro Matrix & & $X$ & & $\begin{array}{l}\text { Toner,máquina de gasolina, } \\
\text { máquina fotográfica de um } \\
\text { uso,desmontagem de caminhões pesados. }\end{array}$ \\
\hline $\begin{array}{l}\text { ReSICLED Recovery } \\
\text { Systems modelling \& Indicators } \\
\text { calculation Leading to End-of-life- } \\
\text { conscious Design }\end{array}$ & $\mathrm{X}$ & & & $\begin{array}{l}\text { eletro-eletrônicos, Industria } \\
\text { Automotiva }\end{array}$ \\
\hline Scatter search (SS) & & & X & eletro-eletrônicos \\
\hline Semi-quantitative pre-LCA & X & & & \\
\hline $\begin{array}{l}\text { Streamlined Life Cycle } \\
\text { Assessment (SLCA) }\end{array}$ & & X & & $\begin{array}{l}\text { Não especificado (tomada para } \\
\text { conexão elétrica) }\end{array}$ \\
\hline $\begin{array}{l}\text { The quotes for } \\
\text { environmentally weighted } \\
\text { recyclability (QWERTY) }\end{array}$ & $X$ & & & eletro-eletrônicos \\
\hline
\end{tabular}




\begin{tabular}{|c|c|c|c|c|}
\hline Nome & Alto & Medio & Baixo & Setor \\
\hline Tool Decision & & & X & \\
\hline $\begin{array}{l}\text { Virtual Disassembly } \\
\text { Manager }\end{array}$ & & & X & \\
\hline Virtual Reality (VR) & & & $X$ & Não especificado \\
\hline Virtual reality technique & & & X & \\
\hline web based system & & $X$ & & eletro-eletrônicos \\
\hline web-based aplication & & & X & \\
\hline $\begin{array}{l}\text { web-enabled virtual } \\
\text { Disassembly Manager }\end{array}$ & & & $\mathrm{X}$ & eletro-eletrônicos \\
\hline
\end{tabular}

Quadro 26 - Classificação das Práticas das Estratégias de Fim de Vida de Produtos Conforme o Nível de Consolidação da Prática e o Setor de Aplicação 


\section{Apêndice I Classificação das Práticas Conforme a Estratégia de Fim de Vida do Produto}

\begin{tabular}{|c|c|c|c|c|c|}
\hline Nome & Reparo & Remanufatura & Reciclagem & Todas & Outras Estratégias \\
\hline $\begin{array}{c}\text { Method to asses the } \\
\text { adaptability of products } \\
\text { (MAAP) }\end{array}$ & $\mathrm{X}$ & $\mathrm{X}$ & & & \\
\hline ABC Method & & & $\mathrm{X}$ & & Reuso \\
\hline $\begin{array}{l}\text { Computer Tool for } \\
\text { selection of fastening and } \\
\text { joining methods }\end{array}$ & & $\mathrm{X}$ & $\mathrm{X}$ & & \\
\hline $\begin{array}{c}\text { Conceptual Disassembly } \\
\text { Model (CDM) }\end{array}$ & & $\mathrm{X}$ & $\mathrm{X}$ & & \\
\hline $\begin{array}{l}\text { Design-for-environment } \\
\text { evaluation tool (D4N) }\end{array}$ & & & & $\mathrm{X}$ & Reuso \\
\hline $\begin{array}{l}\text { Design and End-of-Life } \\
\text { Integration (DELII) }\end{array}$ & & & & $\mathrm{X}$ & Disposição final \\
\hline Disassembly Index & & & $\mathrm{X}$ & & $\begin{array}{l}\text { Desmontagem de } \\
\text { produtos }\end{array}$ \\
\hline $\begin{array}{l}\text { Dissassembly-Planning } \\
\text { system (DisPlay) }\end{array}$ & & & $\mathrm{X}$ & & \\
\hline End-of-life Advisor ELDA & & $\mathrm{X}$ & $\mathrm{X}$ & & $\begin{array}{l}\text { Serviço, reciclagem } \\
\text { com desmontagem e } \\
\text { sem desmontagem }\end{array}$ \\
\hline $\begin{array}{c}\text { Environmental Design } \\
\text { Industrial Template } \\
\text { (EDIT) }\end{array}$ & & & & $\mathrm{X}$ & \\
\hline $\begin{array}{l}\text { Environmental Design } \\
\text { Support Tool (EDST) }\end{array}$ & & & & $\mathrm{X}$ & $\begin{array}{l}\text { Incineração para gerar } \\
\text { energia, disposição } \\
\text { em aterro sanitário, } \\
\text { reciclagem para } \\
\text { material de alto grau e } \\
\text { baixo grau. }\end{array}$ \\
\hline $\begin{array}{l}\text { Environmental Value } \\
\text { Chain Analysis (EVCA) }\end{array}$ & & & & $\mathrm{X}$ & $\begin{array}{l}\text { Serviço, reciclagem } \\
\text { com desmontagem e } \\
\text { sem desmontagem }\end{array}$ \\
\hline $\begin{array}{l}\text { Guidelines for design for } \\
\text { recycling }\end{array}$ & & & $\mathrm{X}$ & & \\
\hline $\begin{array}{l}\text { Guidelines for Designer } \\
\text { avoid potential } \\
\text { remanufacturing }\end{array}$ & & $\mathrm{X}$ & & & \\
\hline
\end{tabular}




\begin{tabular}{|c|c|c|c|c|c|}
\hline Nome & Reparo & Remanufatura & Reciclagem & Todas & Outras Estratégias \\
\hline $\begin{array}{l}\text { Guidelines for } \\
\text { Disassembly and } \\
\text { Recycling }\end{array}$ & & & $\mathrm{X}$ & & Desmontagem \\
\hline $\begin{array}{l}\text { Guidelines for } \\
\text { Remanufacturing }\end{array}$ & & $\mathrm{X}$ & & & \\
\hline $\begin{array}{l}\text { Guidelines-rules for design } \\
\text { for Disassembly }\end{array}$ & & & $\mathrm{X}$ & & Reuso \\
\hline $\begin{array}{c}\text { Ideal-eco-product } \\
\text { approach }\end{array}$ & & & & $\mathrm{X}$ & \\
\hline $\begin{array}{l}\text { Metrics for Assessing } \\
\text { Remanufacturability }\end{array}$ & $\mathrm{X}$ & $\mathrm{X}$ & & & Recondicionamento \\
\hline Module Configurator & & $\mathrm{X}$ & & & \\
\hline $\begin{array}{c}\text { Multi-lifecycle Assessment } \\
\text { and Analysis (MLCA) }\end{array}$ & & $\mathrm{X}$ & & & \\
\hline ProdTect & & $\mathrm{X}$ & $\mathrm{X}$ & & \\
\hline $\begin{array}{l}\text { Recycling Engineering- } \\
\text { Tool Kit (RecyKon) }\end{array}$ & & & $\mathrm{X}$ & & \\
\hline $\begin{array}{l}\text { Recycling Graph-editor } \\
\text { (ReGrEd) }\end{array}$ & & & $\mathrm{X}$ & & \\
\hline $\begin{array}{l}\text { Recycling-Data- } \\
\text { Management- System } \\
\text { (ReDaMa) }\end{array}$ & & & $\mathrm{X}$ & & \\
\hline \multicolumn{6}{|l|}{$\begin{array}{l}\text { Remanufacturing PROduct } \\
\text { PROfiles-REPRO }\end{array}$} \\
\hline RemPro Matrix & & $\mathrm{X}$ & & & \\
\hline $\begin{array}{l}\text { Streamlined Life Cycle } \\
\text { Assessment (SLCA) }\end{array}$ & & & & $\mathrm{X}$ & $\begin{array}{l}\text { Estratégias de fim de } \\
\text { tubo (incineração e } \\
\text { disposição em aterro } \\
\text { sanitário) }\end{array}$ \\
\hline Tool Decision & & & $\mathrm{X}$ & & Reuso \\
\hline Virtual Reality (VR) & & & & $\mathrm{X}$ & \\
\hline
\end{tabular}

Quadro 27 - Classificação das Práticas Conforme a Estratégia de Fim de Vida do Produto 


\section{Apêndice J Classificação das Práticas Conforme a Área de Sustentabilidade} Abordada na Estratégia de Fim de Vida do Produto

\begin{tabular}{|c|c|c|c|}
\hline Nome & Ambiental & Econômico & Social \\
\hline $\begin{array}{l}\text { Method to asses the adaptability of products } \\
\text { (MAAP) }\end{array}$ & $\mathrm{X}$ & $\mathrm{X}$ & \\
\hline ABC Method & $\mathrm{X}$ & $\mathrm{X}$ & \\
\hline AMETIDE & $\mathrm{X}$ & $\mathrm{X}$ & \\
\hline $\begin{array}{l}\text { Analytic Network Process (ANP) for } \\
\text { Disassembly }\end{array}$ & $\mathrm{X}$ & & \\
\hline $\begin{array}{l}\text { ATROiD (Assessment Tool for Recycling } \\
\text { Oriented Design) }\end{array}$ & $\mathrm{X}$ & $\mathrm{X}$ & \\
\hline Cascade approach for recycling & $\mathrm{X}$ & & \\
\hline $\begin{array}{l}\text { Computer Tool for selection of fastening and } \\
\text { joining methods }\end{array}$ & & $\mathrm{X}$ & \\
\hline Conceptual Disassembly Model (CDM) & $\mathrm{X}$ & & \\
\hline $\begin{array}{l}\text { CORA (object/ component oriented } \\
\text { requirements analysis tool) }\end{array}$ & & & \\
\hline $\begin{array}{l}\text { CHAin management of Materials and } \\
\text { Products (CHAMP) methodology }\end{array}$ & $\mathrm{X}$ & $\mathrm{X}$ & \\
\hline DAISY & & & \\
\hline DemAP (Dismantling Analysis Program) & $\mathrm{X}$ & & \\
\hline DEMROP & $\mathrm{X}$ & & \\
\hline Design and End-of-Life Integration (DELII) & $\mathrm{X}$ & $\mathrm{X}$ & \\
\hline Design Charts & $\mathrm{X}$ & $\mathrm{X}$ & \\
\hline Design -for-environment evaluation tool D4N & $\mathrm{X}$ & $\mathrm{X}$ & \\
\hline DfD Compact & & & \\
\hline DFE & $\mathrm{X}$ & $\mathrm{X}$ & \\
\hline Disassembly constract graph (DCG) & $\mathrm{X}$ & & \\
\hline
\end{tabular}




\begin{tabular}{|c|c|c|c|}
\hline Nome & Ambiental & Econômico & Social \\
\hline Disassembly Index & $\mathrm{X}$ & $\mathrm{X}$ & \\
\hline Dissassembly-Planning system (DisPlay) & & $\mathrm{X}$ & \\
\hline DP3 & $\mathrm{X}$ & & \\
\hline Eco-Indicator & $\mathrm{X}$ & $\mathrm{X}$ & \\
\hline Ecolist & $\mathrm{X}$ & & \\
\hline ED (Environmental Designer) & $\mathrm{X}$ & $\mathrm{X}$ & \\
\hline \multicolumn{4}{|l|}{ ENDLESS } \\
\hline End-of-life Advisor (ELDA) & $\mathrm{X}$ & $\mathrm{X}$ & \\
\hline $\begin{array}{l}\text { Environmental Design Industrial Template } \\
\text { (EDIT) }\end{array}$ & $\mathrm{X}$ & $\mathrm{X}$ & \\
\hline Environmental Design Support Tool (EDST) & $\mathrm{X}$ & & \\
\hline Environmental Value Chain Analysis (EVCA) & $\mathrm{X}$ & $\mathrm{X}$ & \\
\hline Green Design & $\mathrm{X}$ & $\mathrm{X}$ & \\
\hline Green Design Advisor & $\mathrm{X}$ & $\mathrm{X}$ & \\
\hline Green Design Network & $\mathrm{X}$ & & \\
\hline Grey Relational Analysis & $\mathrm{X}$ & $\mathrm{X}$ & \\
\hline \multicolumn{4}{|l|}{ Guideline para Selection Material } \\
\hline Guidelines for disassembly EoL & $\mathrm{X}$ & $\mathrm{X}$ & \\
\hline Guidelines for plastics components & $\mathrm{X}$ & & \\
\hline Guidelines for design for recycling & $\mathrm{X}$ & & \\
\hline $\begin{array}{l}\text { Guidelines for Designer avoid potential } \\
\text { remanufacturing }\end{array}$ & $\mathrm{X}$ & & \\
\hline Guidelines for Disassembly and Recycling & $\mathrm{X}$ & $\mathrm{X}$ & \\
\hline Guidelines for Remanufacturing & $\mathrm{X}$ & $\mathrm{X}$ & \\
\hline Guidelines-rules for design for Disassembly & $\mathrm{X}$ & $\mathrm{X}$ & \\
\hline
\end{tabular}




\begin{tabular}{|c|c|c|c|}
\hline Nome & Ambiental & Econômico & Social \\
\hline $\begin{array}{l}\text { HOME (House of modular enhancement-a toll } \\
\text { for modular product redesign) }\end{array}$ & $\mathrm{X}$ & $\mathrm{X}$ & \\
\hline Ideal-eco-product approach & & $\mathrm{X}$ & \\
\hline Impact $2002+$ & $\mathrm{X}$ & & \\
\hline LaySiD (Layout Simulation for Disassembly) & $\mathrm{X}$ & & \\
\hline Life Cycle Assesssment-LCA & $\mathrm{X}$ & & \\
\hline Life Cycle Custs Simplified (LCC) & & $\mathrm{X}$ & \\
\hline Life cycle unit (LCU) & $\mathrm{X}$ & $\mathrm{X}$ & \\
\hline LINKER & & $\mathrm{X}$ & \\
\hline $\begin{array}{l}\text { Matrix de conexão para montagem e } \\
\text { desmontagem de produtos }\end{array}$ & $\mathrm{X}$ & $\mathrm{X}$ & \\
\hline $\begin{array}{c}\text { Método para Avaliar a Reciclagem de } \\
\text { Materiais }\end{array}$ & $\mathrm{X}$ & $\mathrm{X}$ & \\
\hline $\begin{array}{l}\text { Metodologia de desmontagem para fim de } \\
\text { vida dos produtos }\end{array}$ & $\mathrm{X}$ & & \\
\hline Metodologia para desmontagem de produtos & & $\mathrm{X}$ & \\
\hline $\begin{array}{l}\text { Metodologia para reciclagem e disposição de } \\
\text { produtos eletro-eletrônicos }\end{array}$ & $\mathrm{X}$ & & \\
\hline Metrics for Assessing Remanufacturability & $\mathrm{X}$ & $\mathrm{X}$ & \\
\hline Metrics for End-of-life Strategies (ELSEIM) & $\mathrm{X}$ & & \\
\hline \multicolumn{4}{|l|}{$\begin{array}{l}\text { Modelo para o projeto de desmontagem e } \\
\text { reciclagem }\end{array}$} \\
\hline $\begin{array}{l}\text { Modelo para reuso,remanufatura, reciclagem e } \\
\text { disposição de componentes, }\end{array}$ & $\mathrm{X}$ & $\mathrm{X}$ & \\
\hline Module Configurator & $\mathrm{X}$ & & \\
\hline $\begin{array}{l}\text { Multi-lifecycle Assessment and Analysis } \\
\text { (MLCA) }\end{array}$ & $\mathrm{X}$ & $\mathrm{X}$ & \\
\hline Planning Advisor & $\mathrm{X}$ & $\mathrm{X}$ & \\
\hline
\end{tabular}




\begin{tabular}{|c|c|c|c|}
\hline Nome & Ambiental & Econômico & Social \\
\hline Processo de Planejamento do Design & $\mathrm{X}$ & & \\
\hline ProdTect & $\mathrm{X}$ & $\mathrm{X}$ & \\
\hline Product life cycle planning (LCP) & & $\mathrm{X}$ & \\
\hline $\begin{array}{l}\text { Product recovery management system } \\
\text { (PRMS) }\end{array}$ & $\mathrm{X}$ & & \\
\hline Product recovery methodology & $\mathrm{X}$ & $\mathrm{X}$ & $\mathrm{X}$ \\
\hline ReAsCo & & $\mathrm{X}$ & \\
\hline Reciclability tool & $\mathrm{X}$ & & \\
\hline Recycling Engineering-Kit (RecyKon) & & $\mathrm{X}$ & \\
\hline Recycling Graph-editor (ReGrEd) & $\mathrm{X}$ & $\mathrm{X}$ & \\
\hline $\begin{array}{l}\text { Recycling-Data-Management- System } \\
\text { (ReDaMa) }\end{array}$ & $\mathrm{X}$ & $\mathrm{X}$ & \\
\hline REM (Recyclability Evaluation Method) & $\mathrm{X}$ & & \\
\hline $\begin{array}{l}\text { Remanufacturing PROduct PROfiles- } \\
\text { REPRO2 }\end{array}$ & $\mathrm{X}$ & $\mathrm{X}$ & \\
\hline RemPro Matrix & $\mathrm{X}$ & $\mathrm{X}$ & \\
\hline $\begin{array}{l}\text { ReSICLED Recovery Systems modelling \& } \\
\text { Indicators calculation Leading to End-of-life- } \\
\text { conscious Design }\end{array}$ & X & X & \\
\hline Scatter search (SS) & $\mathrm{X}$ & $\mathrm{X}$ & \\
\hline Semi-quantitative pre-LCA & $\mathrm{X}$ & $\mathrm{X}$ & \\
\hline Streamlined Life Cycle Assessment (SLCA) & $\mathrm{X}$ & & \\
\hline $\begin{array}{l}\text { The quotes for environmentally weighted } \\
\text { recyclability (QWERTY) }\end{array}$ & $\mathrm{X}$ & & \\
\hline Tool Decision & $\mathrm{X}$ & $\mathrm{X}$ & \\
\hline Virtual Disassembly Manager & & $\mathrm{X}$ & \\
\hline Virtual Reality (VR) & $\mathrm{X}$ & & \\
\hline
\end{tabular}




\begin{tabular}{|c|r|r|r|}
\hline Nome & Ambiental & Econômico & Social \\
\hline Virtual reality technique & & $\mathrm{X}$ & \\
\hline web based system & $\mathrm{X}$ & $\mathrm{X}$ & \\
\hline web-based aplication & $\mathrm{X}$ & & \\
\hline web-enabled virtual Disassembly Manager & $\mathrm{X}$ & & \\
\hline
\end{tabular}

Quadro 28 - Classificação das práticas Conforme a Área de Sustentabilidade Abordada na Estratégia de Fim de Vida do Produto 